\title{
Novel Immunoregulatory Elements in a Murine Model of Epicutaneous Chemical Sensitization: A Role for Regulatory T Cells and microRNA 210
}

\author{
Carrie Mae Long
}

Follow this and additional works at: https://researchrepository.wvu.edu/etd

\section{Recommended Citation}

Long, Carrie Mae, "Novel Immunoregulatory Elements in a Murine Model of Epicutaneous Chemical Sensitization: A Role for Regulatory T Cells and microRNA 210" (2016). Graduate Theses, Dissertations, and Problem Reports. 6108.

https://researchrepository.wvu.edu/etd/6108

This Dissertation is protected by copyright and/or related rights. It has been brought to you by the The Research Repository @ WVU with permission from the rights-holder(s). You are free to use this Dissertation in any way that is permitted by the copyright and related rights legislation that applies to your use. For other uses you must obtain permission from the rights-holder(s) directly, unless additional rights are indicated by a Creative Commons license in the record and/ or on the work itself. This Dissertation has been accepted for inclusion in WVU Graduate Theses, Dissertations, and Problem Reports collection by an authorized administrator of The Research Repository @ WVU.

For more information, please contact researchrepository@mail.wvu.edu. 


\title{
Novel Immunoregulatory Elements in a Murine Model of Epicutaneous Chemical Sensitization: A Role for Regulatory T Cells and microRNA 210
}

\author{
Carrie Mae Long \\ Dissertation submitted to the School of Medicine \\ at West Virginia University \\ in partial fulfilment of the requirements \\ for the degree of \\ Doctor of Philosophy \\ In \\ Immunology and Microbial Pathogenesis \\ Stacey Anderson, Ph.D., Advisor \\ Rosana Schafer, Ph.D., Chair \\ John Barnett, Ph.D. \\ B.J. Meade, M.D., Ph.D., D.V.M. \\ Paul Siegel, Ph.D. \\ Department of Microbiology, Immunology, and Cell Biology \\ Morgantown, West Virginia \\ 2016
}

Keywords: Chemical sensitization, TDI, regulatory T cell, microRNA, isocyanate, allergy Copyright Carrie Mae Long 2016 


\section{ABSTRACT \\ Novel Immunoregulatory Elements in a Murine Model of Epicutaneous Chemical Sensitization}

\section{Carrie Mae Long}

Toluene diisocyanate (TDI) is a low molecular weight chemical sensitizer and a major cause of occupational allergic disease and asthma. The roles of immunomodulatory elements such as microRNAs, which alter gene expression, and regulatory $\mathrm{T}$ cells $\left(\mathrm{T}_{\text {regs }}\right)$, which suppress $\mathrm{T}$ cellmediated responses, in chemical sensitization are not fully elucidated. In order to further investigate the functional role of miR-210 and $\mathrm{T}_{\text {regs }}$ during TDI sensitization, BALB/c mice were dermally exposed to a single, sensitizing dose of TDI $(0.5-4 \% \mathrm{v} / \mathrm{v})$ and evaluated for immunologic endpoints. $\mathrm{dLN} \mathrm{T}_{\text {regs }}$ were phenotyped during TDI sensitization and a heterogeneous, expanded population was observed. To examine $T_{\text {reg }}$ functionality, a carboxyfluorescein succinimidyl ester-based $T_{\text {reg }}$ suppression assay was conducted. $\mathrm{T}_{\text {regs }}$ isolated from the $\mathrm{dLNs}$ of TDI sensitized mice were more suppressive than their control counterparts. The $\mathrm{T}_{\text {reg }}$ population was then depleted prior to TDI sensitization by in vivo administration of a CD25-targeting antibody. The sensitization response was intensified following $\mathrm{T}_{\text {reg }}$ depletion, as evidenced by amplified total dLN cellularity, Th2 expansion, and IL-4 mRNA production. This data suggests that $T_{\text {regs }}$ are important negative regulators of the TDI sensitization response.

We have previously shown that miR-210 expression in the draining lymph node (dLN) is augmented during TDI sensitization and several putative mRNA targets identified for this miRNA (foxp3 and runx3) were directly related to $\mathrm{T}_{\text {reg }}$ differentiation and function. Therefore, we hypothesized that miR-210 targets transcription factors central to $\mathrm{T}_{\text {reg }}$ development and function, antagonizing the development and functional role of this subset during TDI sensitization. In this work, we show that miR-210 expression is increased in the mouse $\mathrm{dLN}$ and $\mathrm{T}_{\text {reg }}$ subsets during TDI sensitization. Putative miR-210-target/key player interactions were examined using an ex vivo stimulation system in which miR-210 mimics were transfected into primary, stimulated dLN cells;

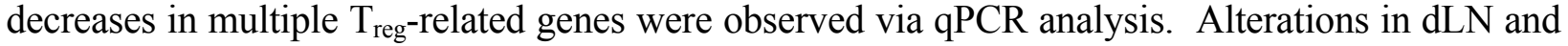
$\mathrm{T}_{\text {reg }}$ mRNA and protein expression of foxp3, runx3, ctla4, and cd 25 were observed at multiple time points following TDI exposure. These molecules are directly involved in $\mathrm{T}_{\text {reg }}$ expansion and function; therefore, miR-210 may potentially negatively target $\mathrm{T}_{\text {reg }}$ differentiation and function during TDI sensitization. In order to examine the effect of miR-210 modulation on $\mathrm{T}_{\text {reg }}$ functionality we performed a carboxyfluorescein succinimidyl ester-based $\mathrm{T}_{\text {reg }}$ suppression assay using $\mathrm{dLN} \mathrm{T}_{\text {regs }}$ from naïve mice transfected with miR-210 mimic. While the suppressive ability of TDI/mimic $\mathrm{T}_{\text {regs }}$ was increased compared to the acetone/mimic counterparts, the TDI/mimic samples had less expression of miR-210 compared to the acetone/mimic controls suggesting other factors, such as additional miRNAs, might be involved in the regulation of the functional capabilities of these cells. These novel findings indicate that $\mathrm{T}_{\text {regs }}$ likely play an important role in modulating allergic responses during TDI sensitization and that miR-210 may have an inhibitory role in this process. Because the functional roles of miRNAs and $\mathrm{T}_{\text {regs }}$ have not been previously elucidated in a model of chemical sensitization, these data contribute to the understanding of the immunologic mechanisms of chemical induced allergic disease and may aid in the development of preventative strategies. 


\section{DEDICATION}

I dedicate this work to my parents, Drs. Jim and Cathy Long. Their intelligence, success, humility, and character have been a source of inspiration throughout my life. Their unconditional love and unwavering support have enabled me to pursue my dreams.

I would also like to dedicate this work to my grandparents, Dr. and Mrs. Jim Long and Mr. and Mrs. Charles Romine. My life has been enriched because of your tremendous love.

I would like to thank my fiancé Evan Brusich for always making me laugh, reminding me to have perspective, and for helping me get through the ups and downs of graduate school.

Thank you to Katie Dunnick, Katie Roach, Breanne, Melissa, Donna, Colleen, my volleyball family, WVU track teammates, and everybody else that has helped make my time in Morgantown so special.

"For God hath not given us the spirit of fear; but of power, and of love, and of a sound mind."

-2 Timothy $1: 7$. 


\section{ACKNOWLEDGEMENTS}

My mentor, Dr. Stacey Anderson has enabled me to perform this research by being a supportive and caring advisor. I could not have asked for a better mentor. I am honored to be her first doctoral student and I know she will be an excellent mentor to the many students that come after me. Dr. Nikki Marshall has also been instrumental in my journey. I would like to thank Nikki for being a flow cytometry and immunology guru and one of my best friends. Dr Barbara Jean Meade has exhibited prolific kindness and intelligence in our interactions; I will use the lessons she has taught me throughout my entire life. I would also like to thank Ewa Lukomska for being an excellent lab manager and friend. The other members of our research team have also been a huge part of this project and my life for the past five years; thank you Hillary, Jodi, and Antonella.

I owe so much to the School of Medicine, the Graduate Office, and Dr. Fred Minnear for accepting me into the program and supporting me throughout my graduate career. I am also immensely thankful to the Immunology and Microbial Pathogenesis Program for allowing me to learn freely, develop as a researcher, and interact with brilliant scientists who care about my success and wellbeing. Specifically, I would like to thank Drs John Barnett and Rosana Schafer for agreeing to be on my committee and investing time and energy into my project and into my future. My time in the department has been a metamorphosis and a true blessing.

In the same regard, CDC-NIOSH has been a place that has fostered my learning and has supported me wholeheartedly. Drs Don Beezhold, Paul Siegel, and John Noti have been instrumental in my success. I would also like to acknowledge Drs Ava Dykes and Steve Martin for the maintenance of the LSRII flow cytometer and the real time PCR machine, respectively.

Lastly, it seems appropriate to include a poignant statement made by A. Munn (1965) regarding isocyanates as these chemicals have been a captivating and productive subject of research.

"The more one knows about these fascinating compounds the more fascinated one becomes. So diverse are their uses, it is obvious that they are here to stay, and that their use will increase. So numerous have been the accounts of their effects, it is obvious not merely they are hazardous but that the nature and extent of their hazard has not always been fully appreciated." 
TABLE OF CONTENTS

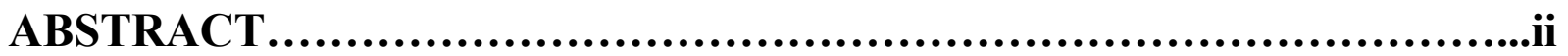

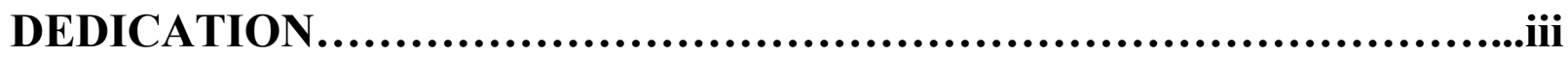

ACKNOWLEDGEMENTS......................................................iv

LIST OF FIGURES........................................................vii

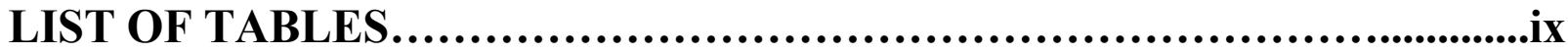

LIST OF SYMBOLS, ABBREVIATIONS, AND NOMENCLATURE........

1. CHAPTER 1- OCCUPATIONAL ALLERGIC DISEASE AND HYPERSENSITIVITY .......................................................1

1.1. INTRODUCTION .............................................

1.2. TYPES OF HYPERSENSITIVITY REACTIONS .....................

1.3. CHEMICAL-INDUCED SENSITIZATION..................................12

1.4. NOVEL MEDIATORS OF ALLERGIC DISEASE ..................29

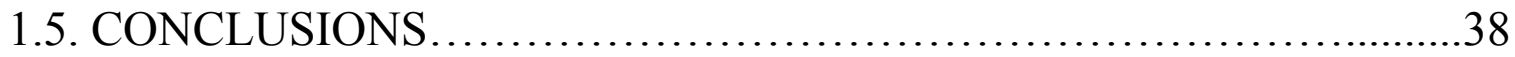

1.6. REFERENCES ................................................41

2. CHAPTER 2- TOLUENE DIISOCYANATE (TDI)..................50

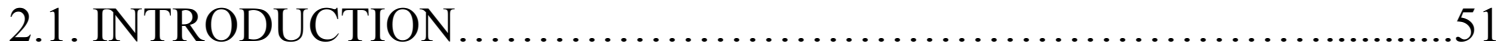

2.2. OCCUPATIONAL EXPOSURE TO TDI...........................52

2.3. TDI SENSITIZATION ...........................................54

2.4. DERMAL TDI SENSITIZATION ...................................57

2.5. IMMUNOLOGIC FACTORS INVOLVED IN TDI-INDUCED

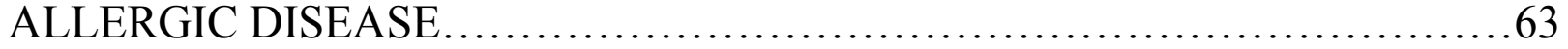

2.6. CONCLUSIONS ................................................... 76

2.7. REFERENCES ................................................... 79

3. CHAPTER 3- GENERAL EXPRESSION KINETICS, PHENOTYPE, AND FUNCTIONAL CHARACTERIZATION OF T $_{\text {REGS }}$ DURING TDI SENSITIZATION .........................................................85

3.1. INTRODUCTION ............................................ 88 


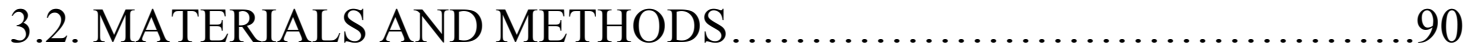

3.3. RESULTS .................................................. 97

3.4. DISCUSSION ................................................ 114

3.5. REFERENCES..............................................119

4. CHAPTER 4- INVESTIGATION OF THE EXPRESSION AND POTENTIAL TARGETS OF MICRORNA-210 DURING TDI SENSITIZATION.........................................................124

4.1. INTRODUCTION ................................................ 127

4.2. MATERIALS AND METHODS......................................129

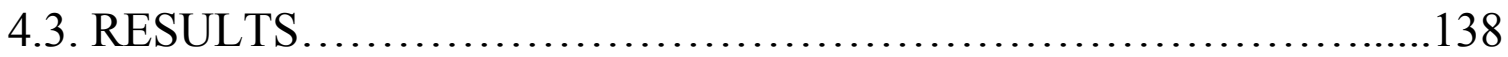

4.4. DISCUSSION ................................................. 148

4.5. REFERENCES..................................................... 155

5. CHAPTER 5- GENERAL DISCUSSION.............................158

5.1. INTRODUCTION .................................................

5.2. TDI SENSITIZATION ......................................... 166

5.3 THE ROLE OF T $T_{\text {REGS }}$ IN TDI SENSITIZATION .....................170

5.4 THE ROLE OF MIRNAS IN TDI SENSITIZATION .................189

5.5 OTHER CONCLUSIONS .......................................200

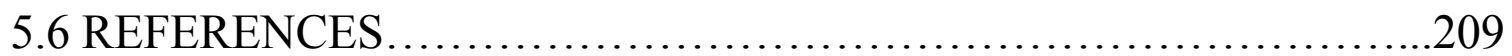

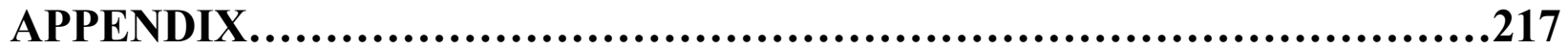

CURRICULUM VITAE..........................................................232 


\section{LIST OF FIGURES}

Figure

Page

Figure 1.1: Pictorial Overview of the LLNA

24

Figure 3.1: Confirmation of Sensitization and Evaluation of Skin Irritancy Following Dermal TDI

Exposure

98

Figure 3.2: $\mathrm{T}_{\text {reg }}$ Subset Expands During Dermal TDI Sensitization

102

Figure 3.2a: Expansion of CTLA4 ${ }^{+}$and $\mathrm{nT}_{\text {reg }}$ Populations During TDI Sensitization

104

Figure 3.2b: dLN Migratory Effector $\mathrm{T}_{\text {reg }}$ Population Expands During TDI Sensitization (Co-

Expression)

107

Figure 3.3: $\mathrm{T}_{\text {reg }}$ Suppression Assay Reveals Increased Suppressive Ability of $\mathrm{T}_{\text {regs }}$ During TDI

Sensitization

109

Figure 3.4: The Severity of the Sensitization Response is Intensified in the Absence of $\mathrm{T}_{\text {regs }}$ During TDI Sensitization

Figure 4.1: Mature miR-210 expression increases during TDI sensitization

136

Figure 4.2: Ex vivo Data Reveals Potential Inhibitory Effect of miR-31, -155, and -210 on $\mathrm{T}_{\text {reg- }}$ related Genes

Figure 4.3: In vivo Target mRNA Expression

Figure 4.4: Mature miRNA expression increases in $\mathrm{T}_{\text {regs }}$ during TDI sensitization

Figure 4.5: $\mathrm{T}_{\text {reg }}$ Suppression Assay Does Not Reveal Altered Suppression Following miR-210

Mimic Transfection

Figure 4.6: Ex vivo Data Reveals Potential Inhibitory Effect of miR-31, -155 on $\mathrm{T}_{\text {reg-related }}$

Genes

Figure 4.7: Mature miR-31 and -155 expression increases in $\mathrm{T}_{\text {regs }}$ during TDI sensitization 
Figure 5.1: Overview of the Immune Mechanisms of TDI Sensitization 168

Figure 5.2: Mechanisms of $T_{\text {reg }}$ Suppression 174

Figure 5.3: $\operatorname{ICOS}^{+} \mathrm{CD}_{103}{ }^{+} \mathrm{T}_{\text {reg }}$ Population in the $\mathrm{dLN}$ and Ear during TDI Sensitization 175

$\begin{array}{lr}\text { Figure 5.4: Ear } \mathrm{T}_{\text {reg }} \text { Phenotyping } & 180\end{array}$

Figure 5.5: HIF-1 $\alpha$ Protein Levels in Ear Lysates during TDI Sensitization 194

Figure 5.6: Potential Sites of miR-210 Action in T reg Biology 196

$\begin{array}{ll}\text { A 3.1: } \mathrm{dLN}_{\mathrm{reg}} \text { Phenotyping Strategy } & 218\end{array}$

A 3.2: $T_{\text {reg }}$ Depletion Study Model Confirmation 219

A 3.3: $\mathrm{T}_{\text {reg }}$ Depletion Study Supplemental Data 221

A 3.4: $T_{\text {reg }}$ Depletion Study General T Cell Endpoints 223

A 4.1: miR-210 Expression in a Variety of Tissues During 4\% TDI Sensitization 225

A 5.1: Ear $T_{\text {reg }}$ Phenotyping Gating Strategy 226 


\section{LIST OF TABLES}

Table

Page

Table 1.1: Gel and Coomb’s Hypersensitivity Reactions 4

Table 1.2: Secreted Mediators of Type I Hypersensitivity Reactions 7

Table 1.3: Summary of LMW Chemicals Causing Occupational Allergy 14

Table 1.4: T Cell Subsets 30

Table 3.1 - $\mathrm{T}_{\text {reg }}$ Flow Cytometry Phenotyping Marker Guide $\quad 100$

Table 3.2- dLN Migratory Effector $T_{\text {reg }}$ Population Expands During TDI Sensitization 105 


\section{LIST OF SYMBOLS, ABBREVIATIONS, AND NOMENCLATURE}

\begin{tabular}{|c|c|}
\hline${ }^{3} \mathrm{H}-\mathrm{dT}$ & Tritiated Thymidine \\
\hline AAALAC & $\begin{array}{l}\text { Association for Assessment and Accreditation of Laboratory Animal Care } \\
\text { International }\end{array}$ \\
\hline ACGIH & American Conference of Governmental Industrial Hygienists \\
\hline ADCC & Antibody-dependent cell-mediated cytotoxicity \\
\hline AHR & Aryl hydrocarbon receptor \\
\hline AICAR & 5-aminoimidazole-4-carboxamide-1- $\beta$-D-ribofunanoside \\
\hline AID & Activation-induced deaminase \\
\hline AMPK & adenosine $3^{\prime}, 5^{\prime}$-monophosphate -activated protein kinase \\
\hline $\mathrm{AO} / \mathrm{PI}$ & Acridine Orange/Propidium Iodide \\
\hline APC & Antigen presenting cell \\
\hline BAL & Bronchoalveolar lavage \\
\hline CTLA4 & Cytotoxic T lymphocyte-associated protein- 4 \\
\hline dLN & Draining lymph node \\
\hline $\mathrm{DNCB}$ & 2,4-dinitrochlorobenzene \\
\hline DNFB & Dinitrofluorobenzene \\
\hline DNTB & 2,4-dinitrothiocyanobenzene \\
\hline DPM & Disintegrations per minute \\
\hline DPRA & Direct Peptide Reactivity Assay \\
\hline ECM & Extracellular matrix \\
\hline ECVAM & European Center for the Validation of Alternative Methods \\
\hline FMO & Fluorescence Minus One \\
\hline Foxp3 & Forkhead box p3 \\
\hline
\end{tabular}




\begin{tabular}{|c|c|}
\hline GARD & Genomic Allergen Rapid Detection Assay \\
\hline GI & Gastrointestinal \\
\hline GPMT & Guinea Pig Maximization Test \\
\hline GRPS & GARD Respiratory Prediction Signature \\
\hline HDI & Hexamethylene Diisocyanate \\
\hline HIF-1 $1 \alpha$ & Hypoxia inducible factor $1 \alpha$ \\
\hline HLA & Human leukocyte antigen \\
\hline HMW & High molecular weight \\
\hline HRIPT & Human Repeated Insult Patch Test \\
\hline ICCVAM & $\begin{array}{l}\text { Interagency Coordinating Committee on the Validation of Alternative } \\
\text { Methods }\end{array}$ \\
\hline ICOS & Inducible T-cell costimulator \\
\hline IDLH & Immediately Dangerous to Life and Health \\
\hline IDO & Indolamine 2,3-dioxygenase \\
\hline IFN-y & Interferon gamma \\
\hline ILC & Innate lymphoid cell \\
\hline IPEX & $\begin{array}{l}\text { Immunodysregulation, polyendocrinopathy, enteropathy, X-linked } \\
\text { syndrome }\end{array}$ \\
\hline iTCR & Invariant TCR \\
\hline $\mathrm{kDa}$ & Kilodalton \\
\hline LCR & Locus control region \\
\hline LLNA & Local Lymph Node Assay \\
\hline LMW & Low molecular weight \\
\hline $\operatorname{lncRNA}$ & Long non-coding RNA \\
\hline LO & Lipofectamine only \\
\hline MAC & Membrane attack complex \\
\hline
\end{tabular}




\begin{tabular}{|c|c|}
\hline MBL & Mannose-binding lectin \\
\hline MDI & Diphenyl-methane diisocyanate \\
\hline MFI & Mean fluorescence intensity \\
\hline MHC & Major histocompatibility complex \\
\hline mRNA & Messenger RNA \\
\hline miRNA & MicroRNA \\
\hline MMP & Matrix Metalloproteinase \\
\hline NA & Nonanoic acid \\
\hline $\mathrm{Ni}^{2+}$ & Nickel \\
\hline NIOSH & National Institute for Occupational Safety and Health \\
\hline NK & Natural Killer Cells \\
\hline NKT & Natural Killer T Cells \\
\hline OECD & Organization for Economic Cooperation and Development \\
\hline OEL & Occupational Exposure Limit \\
\hline OPA & Ortho-phthalaldehyde \\
\hline OSHA & Occupational Safety and Health Administration \\
\hline OVA & Ovalbumin \\
\hline PBMC & Peripheral blood mononuclear cells \\
\hline $\mathrm{ppb}$ & Parts per billion \\
\hline PCR & Polymerase chain reaction \\
\hline PenH & Enhanced Pause \\
\hline PFOA & Perfluorooctanoic acid \\
\hline PPE & Personal Protective Equipment \\
\hline RAST & Radioallergosorbent tests \\
\hline RISC & RNA-induced Silencing Complex \\
\hline
\end{tabular}


ROS

RT

SCID

SI

TCR

TDA

TDI

$\mathrm{T}_{\mathrm{EM}}$

$\mathrm{Th}$

TMA

TNCB

TNF- $\alpha$

TNP

$\mathrm{T}_{\text {reg }}$

TSLP

U.S.

VEGFA
Reactive oxygen species

Reverse Transcription

Severe Combined Immunodeficiency

Stimulation Index

$\mathrm{T}$ cell receptor

Toluenediamine

Toluene diisocyanate

Effector memory $\mathrm{T}$ cell

T-helper

Trimellitic anydride

Trinitrochlorobenzene

Tumor necrosis factor alpha

Trinitrophenyl

Regulatory T Cell

Thymic stromal lymphopoetin

United States

Vascular endothelial growth factor A 


\section{CHAPTER 1}

\section{Occupational Allergic Disease and Hypersensitivity}




\subsection{INTRODUCTION}

Occupational allergic disease is a serious public health burden whose prevalence is growing worldwide. Workplace exposures can result in a number of allergic diseases and approximately 11 million American workers are potentially exposed to agents that can cause allergic disease (1). Asthma, allergic contact dermatitis, rhinitis, hypersensitivity pneumonitis, urticaria, eczema, and folliculitis can occur as a result of respiratory and dermal exposures in the workplace (1). Specifically, occupational exposures are responsible for approximately $9-25 \%$ of all adult onset asthma cases $(2,3)$ while occupational contact dermatitis represents $90 \%$ of all cases of work-related cutaneous disorders (4). These conditions may be detrimental to a worker's health and workplace performance, causing economic losses (5). Occupational asthma is sometimes more severe than general asthma as evidenced by persistence of symptoms despite treatment, reports of deaths following sensitization and repeated exposures, and the significantly increased use of medical resources by occupational asthmatics compared to those with non-occupationally related conditions (6).

A variety of agents can cause occupational allergic disease, including animal products (7), chemicals (1), drugs (8), foods (9), metals (4), molds (10), plant products (4), and venoms (11). Although both irritant and allergic conditions can be induced by occupational allergens, this work will focus on immune-mediated conditions such as allergic contact dermatitis and asthma caused by exposure to allergic sensitizers. Over 250 causative agents of occupational asthma have been reported (12), approximately 400 allergens are available for contact dermatitis patch testing in humans (4), and over 3000 contact allergens have been identified (13), demonstrating the breadth of potential allergens found in the workplace. Typically, these agents are classified as high or low molecular weight (HMW $>1 \mathrm{kDa}$; LMW $<1 \mathrm{kDa}$ ) and their size is thought to play a significant role 
in their allergenicity, dermal penetration, and allergic mechanism of action. Many workplace factors may influence allergic disease, including barrier dysregulation caused by repetitive movements and irritants such as hand washing and contact with disinfectants, and occupational-induced stress which may contribute to the development and/or persistence of immune responses (14).

\subsection{TYPES OF HYPERSENSITIVITY REACTIONS}

Many occupationally-relevant allergic agents are known as sensitizers, indicating that repeated exposures will result in immune sensitization followed by the elicitation of allergic disease. This biphasic allergic process is characterized by two distinct phases: sensitization and elicitation. Sensitization is thought to occur because of numerous complex host and allergen-associated factors. The interplay of mucosal surfaces and allergens is an important concept directly related to the

development of sensitization and many cell types are thought to be involved in this response, depending on the site of exposure and the individual's unique immune microenvironment.

Following epithelial access by an allergen, a variety of downstream effects can occur. In the context of hypersensitivity reactions, which indicate an augmented and potentially damaging immune response, there are four basic hypersensitivity reactions as classified by Patrick Gell and Robin Coombs (15). These distinct responses were characterized based on the primary effector molecules and immune cells thought to be involved in each reaction. A summary of the four hypersensitivity reactions can be found in Table 1.1. These reactions are grouped based on humoral (I-III) or cell-mediated (IV) primary effector mechanisms. Although it was proposed over 50 years ago and several revision attempts have been made to update the classification scheme, the Gell and Coombs hypersensitivity classification is still widely accepted as the most valid scheme for interpreting hypersensitivity reactions. 


\begin{tabular}{|c|c|c|c|c|}
\hline & Type I & Type II & Type III & Type IV \\
\hline Name & IgE-Mediated & $\begin{array}{l}\text { Antibody- } \\
\text { Mediated } \\
\text { Cytotoxic }\end{array}$ & $\begin{array}{l}\text { Immune Complex- } \\
\text { Mediated }\end{array}$ & $\begin{array}{c}\text { T Cell- } \\
\text { Mediated }\end{array}$ \\
\hline $\begin{array}{c}\text { Primary } \\
\text { Effector } \\
\text { Molecule/Cell }\end{array}$ & $\begin{array}{c}\text { IgE and Mast } \\
\text { Cells }\end{array}$ & $\begin{array}{l}\text { IgG or IgM and } \\
\text { Complement }\end{array}$ & $\begin{array}{l}\text { Complement, Mast } \\
\text { Cells, IgG or IgM, } \\
\text { and Leukocytes }\end{array}$ & $\begin{array}{c}\text { T cells }(\mathrm{Th} 1 \\
\left.\text { and } \mathrm{CD} 8^{+}\right) \text {and } \\
\text { Macrophages }\end{array}$ \\
\hline $\begin{array}{l}\text { Humoral or } \\
\text { Cellular }\end{array}$ & $\mathrm{H}$ & $\mathrm{H}$ & $\mathrm{H}$ & $\mathrm{C}$ \\
\hline Description & $\begin{array}{l}\text { Mast cell-bound } \\
\text { IgE is engaged } \\
\text { with its cognate } \\
\text { antigen, mast } \\
\text { cells } \\
\text { degranulate and } \\
\text { release allergic } \\
\text { mediators (e.g. } \\
\text { histamine } \\
\text { (immediate) and } \\
\text { leukotrienes } \\
\text { (delayed)) }\end{array}$ & $\begin{array}{l}\text { Antibody- antigen } \\
\text { recognition, } \\
\text { opsonization, } \\
\text { complement } \\
\text { activation, } \\
\text { neutrophil } \\
\text { chemotaxis }\end{array}$ & $\begin{array}{c}\text { An excess of } \\
\text { soluble antigen } \\
\text { leads to the } \\
\text { formation of small } \\
\text { immune complexes } \\
\text { which insert } \\
\text { themselves into } \\
\text { blood vessels, } \\
\text { joints, and } \\
\text { glomeruli. } \\
\text { Precipitation results } \\
\text { in complement } \\
\text { activation and a } \\
\text { pathogenic } \\
\text { inflammatory } \\
\text { response }\end{array}$ & $\begin{array}{c}\mathrm{CD}^{+} \mathrm{T} \text { cells } \\
\text { recognize } \\
\text { MHCII- } \\
\text { Antigen } \\
\text { complex on } \\
\text { APCs and } \\
\text { begin to } \\
\text { produce Th1 } \\
\text { cytokines. } \\
\text { Cytotoxic CD8 } \\
\text { cells kill target } \\
\text { cells and } \\
\text { macrophages } \\
\text { produce } \\
\text { hydrolytic } \\
\text { enzymes, } \\
\text { causing tissue } \\
\text { damage. }\end{array}$ \\
\hline $\begin{array}{c}\text { Clinical } \\
\text { Symptoms }\end{array}$ & $\begin{array}{l}\text { Anaphylactic } \\
\text { shock, } \\
\text { angiodema, } \\
\text { conjunctivitis, } \\
\text { urticaria, hives, } \\
\text { wheal and flare }\end{array}$ & $\begin{array}{c}\text { Hemolytic } \\
\text { anemia, } \\
\text { granulocytopenia, } \\
\text { thrombocytopenia }\end{array}$ & $\begin{array}{l}\text { Arthritis, chills, } \\
\text { edema, fever, } \\
\text { glomerulonephritis, } \\
\text { rash }\end{array}$ & Erythema \\
\hline $\begin{array}{l}\text { Associated } \\
\text { Conditions }\end{array}$ & $\begin{array}{l}\text { Anaphylaxis } \\
\text { (systemic or } \\
\text { local), asthma, } \\
\text { eczema, food } \\
\text { allergy, hay } \\
\text { fever }\end{array}$ & $\begin{array}{l}\text { Blood transfusion } \\
\text { reaction, Drug- } \\
\text { induced hemolytic } \\
\text { anemia, Rh } \\
\text { antigen reaction } \\
\text { (erythroblastosis } \\
\text { fetalis) }\end{array}$ & $\begin{array}{l}\text { Hypersensitivity } \\
\text { Pneumonitis, } \\
\text { Glomerulonephritis, } \\
\text { Serum Sickness }\end{array}$ & $\begin{array}{l}\text { Contact } \\
\text { Dermatitis, } \\
\text { Hashimoto's } \\
\text { thyroiditis, } \\
\text { Multiple } \\
\text { sclerosis }\end{array}$ \\
\hline
\end{tabular}

Table 1.1: Gell and Coomb's Hypersensitivity Reactions 


\subsubsection{Type I Hypersensitivity Reaction}

Type I hypersensitivity reactions are perhaps the most recognizable, due to an association with a number of prevalent allergic diseases and atopy. Type I reactions are mediated by IgE and mast cells and are sometimes called immediate-type hypersensitivity reactions. The progression of antigen recognition, $\mathrm{T}$ cell activation, and $\mathrm{B}$ cell antibody production is very similar to the classic mechanism that is observed in a general IgG-mediated humoral response; however, in a $\mathrm{T}$ ype I hypersensitivity response, the primary cytotropic antibody produced in response to antigen is

IgE. A type I reaction can be described beginning with the recognition and uptake of allergen by APCs, presentation of antigen fragments to $\mathrm{CD}^{+} \mathrm{T}$ cells via MHC II, and the initiation of a Th2 allergic response. Th2 cytokines such as IL-4 and IL-13 are produced and secreted by CD $4^{+}$T cells, leading to antibody class switching and IgE production by B cells. Once activated by the Th2 microenvironment, basophils are thought to play an important role in the secretion of allergic cytokines and antibody class switching (16).

Antibody class switching is a dynamic process that involves several steps; for IgE in particular two signals are required (16). The first is provided by IL-4 or IL-13 through binding to their respective receptors on $\mathrm{B}$ cells, leading to activation of transcription at the IgE-specific $\mathrm{S}_{\varepsilon}$ switch region. The second signal is provided by CD40 (on B cells) - CD40 ligand (on T cells) binding, which activates DNA switch recombination. Additional factors such as the expression of activation-induced deaminase (AID) influence class switching to IgE. IgE class switching is thought to occur primarily in the germinal centers of secondary lymphoid organs such as the lymph nodes during allergic responses (16). It is important to note that atopic individuals who are particularly susceptible to develop Type I reactions have high circulating levels of baseline IgE, which may be present prior to activation against a particular antigen initiating a Type I response. IgE is considered 
an allergic antibody due to its ability to bind to high affinity FceR1 receptors on mast cells and basophils (16). Once IgE is produced and secreted by plasma cells, it binds to mast cells and basophils via the high affinity FceR1 receptor. Allergen binds to cell-bound IgE, crosslinking the IgE and activating these cells.

Once activated, mast cells and basophils degranulate and release soluble allergic mediators such as histamine, heparin, cytokines, prostaglandins, leukotrienes, and proteases which act on smooth muscles, sensory nerves, mucous glands, arteries, and eosinophils $(16,17)$. The mechanisms of action of these mediators are listed in further detail in Table 1.2. Common clinical outcomes of Type I reactions include increased vascular permeability, smooth muscle cell contraction, and vasodilation, which can be experienced in one or more organs, depending on the site(s) and frequency of allergen exposure. From a broad perspective, it appears that Type I responses may have evolved in order to prevent pathogens from surviving in the respiratory and gastrointestinal (GI) tracts (18). Clinically, IgE-mediated responses are common in response to helminthic and parasitic infections but are not usually involved in responses to non-parasitic antigens. It is imperative to note that Type I reactions typically require a sensitization phase of initial antigen exposure in order to allow the immune system to develop clonal specificity and IgE responses upon secondary exposure, allowing for the effector phase of the Type I response. 


\begin{tabular}{|c|c|c|c|c|}
\hline Mediator & $\begin{array}{l}\text { Primary or } \\
\text { Secondary* }\end{array}$ & Receptor & Target Cells & Clinical Effects \\
\hline Bradykinin & Secondary & $\begin{array}{l}\text { Kinin } B_{1} \text { and } \\
B_{2} \text { receptors }\end{array}$ & $\begin{array}{l}\text { Endothelial } \\
\text { cells }\end{array}$ & $\begin{array}{l}\text { Increased vascular permeability } \\
\text { (vasodilation), Neutrophil } \\
\text { recruitment (via CXCL5) }\end{array}$ \\
\hline Cytokines & Secondary & Varies & Varies & Inflammatory cell influx \\
\hline $\begin{array}{l}\text { Eosinophil } \\
\text { Chemotactic } \\
\text { Factor (IL-5) }\end{array}$ & Primary & $\begin{array}{l}\text { Eosinophil } \\
\text { Chemotactic } \\
\text { Factor } \\
\text { Receptor } \\
\text { (IL-5R) }\end{array}$ & Eosinophils & Eosinophil recruitment \\
\hline Histamine & Primary & H Receptors & $\begin{array}{l}\text { Smooth } \\
\text { muscle and } \\
\text { endothelial }\end{array}$ & $\begin{array}{l}\text { Smooth muscle contraction, } \\
\text { Increased vascular permeability } \\
\text { (vasodilation), Increased goblet } \\
\text { cell mucus secretion }\end{array}$ \\
\hline Leukotrienes & Secondary & $\begin{array}{l}\text { BLT1, } \\
\text { BLT2, } \\
\text { CysLT1, } \\
\text { CysLT2 }\end{array}$ & $\begin{array}{l}\text { Leukocytes, } \\
\text { Endothelial } \\
\text { cells }\end{array}$ & $\begin{array}{l}\text { Bronchoconstriction, increased } \\
\text { vascular permeability } \\
\text { (vasodilation), increased mucus } \\
\text { secretion, Smooth muscle } \\
\text { contraction }\end{array}$ \\
\hline $\begin{array}{l}\text { Neutrophil } \\
\text { Chemotactic } \\
\text { Factor (IL-8) }\end{array}$ & Primary & $\begin{array}{l}\text { CXCR1, } \\
\text { CXCR2 }\end{array}$ & $\begin{array}{l}\text { Neutrophils } \\
\text { (primary), } \\
\text { endothelial } \\
\text { cells, other } \\
\text { granulocytes, } \\
\text { macrophages }\end{array}$ & $\begin{array}{l}\text { Neutrophil recruitment, Can } \\
\text { also recruit other granulocytes }\end{array}$ \\
\hline $\begin{array}{l}\text { Platelet- } \\
\text { activating } \\
\text { Factor }\end{array}$ & Secondary & $\begin{array}{l}\text { Platelet- } \\
\text { activating } \\
\text { factor } \\
\text { receptor }\end{array}$ & $\begin{array}{l}\text { Endothelial } \\
\text { cells, } \\
\text { leukocytes, } \\
\text { and platelets }\end{array}$ & $\begin{array}{c}\text { Increased vascular permeability } \\
\text { (vasodilation), Leukocyte } \\
\text { chemotaxis }\end{array}$ \\
\hline Prostaglandins & Secondary & $\begin{array}{l}\mathrm{DP}, \mathrm{EP}, \mathrm{FP}, \\
\mathrm{IP} \text {, and TP } \\
\text { receptor } \\
\text { families }\end{array}$ & $\begin{array}{c}\text { Smooth } \\
\text { muscle cells }\end{array}$ & $\begin{array}{l}\text { Increased smooth muscle } \\
\text { contraction, Increased vascular } \\
\text { permeability (vasodilation) }\end{array}$ \\
\hline Proteases & Primary & $\begin{array}{l}\text { Target } \\
\text { peptide } \\
\text { bonds }\end{array}$ & $\begin{array}{c}\text { Blood } \\
\text { vessels, } \\
\text { Complement } \\
\text { proteins }\end{array}$ & $\begin{array}{l}\text { Increased vascular permeability } \\
\text { (basement membrane } \\
\text { degradation), Catalyze the } \\
\text { complement cascade }\end{array}$ \\
\hline
\end{tabular}

Table 1.2: Secreted Mediators of Type I Hypersensitivity

*Primary and Secondary Mediator indicates whether the substance is made before degranulation (primary) or synthesized after cellular activation/released by the breakdown of membrane components during degranulation (secondary)

Adapted from (17) 


\subsubsection{Type II Hypersensitivity Reaction}

Type II hypersensitivity reactions are humorally-mediated, and are characterized by the production of antibodies that cause cellular destruction. Antibodies bound to cell surface antigens can activate the complement cascade, resulting in cellular damage via formation of pores in the cell membrane or antibody-dependent cell-mediated cytotoxicity (ADCC: natural killer cell or macrophage-mediated cell death) (17). Typically, neutrophils are recruited to opsonized antibodyantigen complexes and are major mediators of inflammatory symptoms. Clinical features of Type II reactions may include allergic hemolytic anemia, agranulocytosis, fever, purpura, and thrombocytopenia. An example of a Type II response is a penicillin reaction which is characterized by penicillin-red blood cell complexing, leading to an antibody response and activation of the complement cascade. Type II responses may have developed as a defense strategy against small extracellular pathogens that are susceptible to neutrophil-mediated killing (18).

\subsubsection{Type III Hypersensitivity Reaction}

Type III hypersensitivity reactions are mediated by the formation of antibody-antigen complexes, which typically lead to antigen clearance by phagocytic and red blood cells. In the case of a hypersensitivity reaction, large quantities of these immune complexes can lead to activation of the complement system and an inflammatory response characterized by neutrophil infiltration. This response can be very damaging to the body's tissues and both the magnitude and breadth of the reaction depends on the number of immune complexes and their location (localized or systemic). The immune complexes alone can cause tissue damage due to their deposition in blood vessel walls and other tissues. Additionally, the complement component $\mathrm{C} 3 \mathrm{~b}$ opsonizes the immune complexes, leading to attempted neutrophil binding. If the immune complexes are deposited on basement 
membranes then phagocytosis is impeded, leading to the release of large amounts of lytic enzymes that are very destructive to the surrounding tissue (17). The membrane attack complex (MAC) can also be formed, causing additional tissue destruction and cellular damage. A classic example of a Type III hypersensitivity reaction is serum sickness, which is caused by the introduction of foreign antiserum into an organism, resulting in the formation of antiserum-specific antibodies and immune complexes comprised of both self-antibodies and foreign antiserum. Serum sickness may lead to arthritis, fever, rashes, and vasculitis as a result of immune complex deposition and inflammatory mechanisms (17). This response typically develops in 9-11 days following the transfer of sera (19).

\subsubsection{Type IV Hypersensitivity Reaction}

The final hypersensitivity classification is characterized by $\mathrm{T}$ cell-mediated and delay observed between antigen exposure and outward symptoms. Many intracellular pathogens and contact antigens can induce Type IV responses, including Mycobacterium tuberculosis, Candida albicans, Variola spp. (Smallpox), and poison ivy (17). Type IV responses are diverse and involve a number of effector cells and molecules.

An initial sensitization phase is required following the first contact with antigen in order to activate $\mathrm{T}$ cells and allow for their clonal expansion. APC-T cell interaction is required for the development of Type IV responses via MHC presentation. Typically $\mathrm{CD} 4^{+} \mathrm{Th} 1$ cells are the primary $\mathrm{T}$ cell subset involved in Type IV responses but $\mathrm{Th} 2$ and $\mathrm{CD} 8^{+} \mathrm{T}$ cells have also been implicated in the development of Type IV responses $(1,17)$. Following effective sensitization, subsequent antigenic exposures result in the elicitation or effector phase of the Type IV response, characterized by the secretion of pro-inflammatory cytokines (GM-CSF, IFN $\gamma$, IL-3, IL-12, and TNF- $\beta$ ) by Th1 cells that activate and recruit macrophages and other immune cells. Due to the time it takes for these 
cytokines to attract and activate macrophages at sites of exposure the effector phase typically occurs 24 hours following exposure and it generally peaks in magnitude at 48-72 hours after exposure (17). This phase of the response is characterized by the action of both clonally-specific Th1 cells and nonspecific immune effectors such as macrophages. A well-managed Type IV response countering a pathogen can be beneficial to the host, resulting in pathogen clearance and minimal host cell damage; however, if the response is prolonged and not well controlled (as is the case in a hypersensitivity reaction) then severe tissue damage can occur. Contact dermatitis is an example of an allergeninduced Type IV hypersensitivity reaction. This condition can be caused by a variety of molecules, including metals, chemicals, and natural substances such as poison ivy. Many of these allergens are small in size and are able to permeate the skin and combine with skin proteins, forming antigenprotein complexes. These complexes are recognized by the immune system, allowing a Type IV response to develop.

Due to the known plasticity of $\mathrm{T}$ cell development and function, it can be assumed that numerous T-helper (Th) subsets can potentially be involved in Type IV responses. As previously mentioned, Th1, Th2, and cytotoxic $\mathrm{CD}^{+} \mathrm{T}$ cells have been associated with Type IV hypersensitivity reactions. Accordingly, four Type IV subclasses have been proposed due to the wide breadth of responses involved in this type of hypersensitivity. These subclasses include IVad. IVa reactions are thought to involve Th1 cells and monocytes and rely on the secretion of IL-1 and IL-2. IVb reactions are associated with Th2 cells and eosinophils along with the expression of IL4, IL-5, and IL-13. Skin sensitization and asthmatic reactions to toluene diisocyanate (TDI) likely involve Type IVb components, based on the strong Th2 response paired with the disputed role of IgE. The major effector cells of type IVc reactions are cytotoxic $\mathrm{CD} 8^{+} \mathrm{T}$ cells which utilize FasL, granzyme, and perforin for their cell contact- mediated effector functions. Lastly, Type IVd 
reactions involve T cells, neutrophils, and the production of IL-8, a neutrophil chemotactic factor. The necessity of multiple Type IV subtypes illustrates the diverse effector pathways involved in Type IV reactions. Even classical Type IV reactions encompass both IVa and IVc reactions, illustrating the complexity of these responses and the need for elucidation of the complete immunologic mechanisms underlying disease as diagnosis and treatment of these conditions will be greatly enhanced by increased understanding of these complex mechanisms.

\subsubsection{Gell and Coomb's Classification: Modern Validity?}

Although the Gell and Coomb's classification is a seminal work which has withstood decades of evolution in immunologic knowledge, its current validity has been questioned. The landscape of immunology has been dramatically altered since the 1960s when the classification was proposed; therefore, one would expect the need for mechanistic updates to the classification, which have been absent. In the context of drug reactions and chemical allergy, the Gell and Coombs classification does not encompass all reactions, including hypersensitivity pneumonitis and certain instances of chemical-induced asthma (19). The idea that more than one defined hypersensitivity mechanism may be involved in a given reaction has been proposed as well. Penicillin reactions have been shown to encompass a wide variety of defined hypersensitivity reactions, including anaphylaxis, angioneurotic edema, eosinophilia, fever, interstitial nephritis, respiratory symptoms, serum sickness, and skin rashes (20). This does not completely invalidate the hypersensitivity mechanisms presented by Gell and Coombs; rather, it emphasizes the flexibility of the classification system, which is not generally emphasized.

The Gell and Coombs classification is still valid for a number of reactions that are classically defined by the parameters initially set out by these two pioneers. While this is true for a number of 
conditions, the inverse also holds true; many conditions do not fit into the current classification based on specific immune effectors as defined by Gell and Coombs. The broad clinical usage of this classification presents several concerns, including the dismissal of underlying immune mechanisms involved in certain conditions based on their simple classification. Admittedly, the understanding of immunologic mechanisms underlying many hypersensitivity reactions remains limited; however, current knowledge points to the need for a reevaluation of the current classification system based on the complexity of hypersensitivity reactions. Type I-III reactions are defined based on the involvement of antibody. While this effector mechanism remains valid, the $\mathrm{T}$ cell response preceding the humoral reaction (and acting in concert with this reaction) is also of significance. Our current knowledge of immunology has revealed the dynamic nature of the immune system; the discovery of a multitude of $\mathrm{CD}^{+}{ }^{+} \mathrm{T}$ cell subsets involved in a wide spectrum of immune responses has necessitated the examination of this component of the immune system for inclusion in hypersensitivity classification. The model proposed by Gell and Coombs is still valid for many conditions but should not be utilized as a "one size fits all" classification system, as many conditions do not fall into the classification and much knowledge has been gained regarding the mechanisms of related immune responses.

\subsection{CHEMICAL-INDUCED SENSITIZATION}

As previously stated, allergens are commonly categorized as HMW or LMW; generally, protein allergens fall into the HMW range and chemical allergens are in the LMW range. These two classes of molecules differ in their reactivity and antigenicity. HMW protein allergens are functionally immunogenic due to their large size whereas LMW chemical allergens are not innately immunogenic due to their small size and are thought to react with self-proteins, forming 
immunogenic hapten complexes that serve as functioning antigens (21). Typically, IgE-mediated allergic responses are induced by HMW protein antigens but this type of immunologic response is also seen following exposure to certain LMW chemical allergens. Human studies have revealed that HMW-induced occupational asthma cases are generally characterized by an early or dual asthmatic reaction, while LMW-induced occupational asthma cases generally exhibit delayed reactions (6). Additionally, a recent study suggested that occupational asthma induced by LMW agents may be more severe than that caused by HMW agents, based on specific inhalation challenge results and diagnostic severity classification in a cohort of patients with asthma of each etiology (6).

Metal ions are constitute an additional type of allergen which includes chromium, cobalt, copper, nickel, palladium, platinum, and potassium dichromate; compared to protein allergens much less is known regarding the immune response underlying metal allergy $(22,23)$. Several metals including nickel sulfate, cobalt chloride, and potassium dichromate are significant causative agents of allergic contact dermatitis (22). Much like LMW chemical allergens, metal allergens such as nickel have displayed binding capabilities with MHC-bound proteins (usually via histidine residues) and in the case of nickel, this binding is hypothesized to occur on metal-binding motifs on selfpeptides complexed with the MHC molecule (22). This concept of direct and/or reversible MHC or TCR-to-drug binding (non-covalent) has been termed "p-i" or pharmacological interaction with immune receptors and has been well studied in terms of drug-induced hypersensitivity reactions; ultimately, this process may result in the activation of drug-specific T cells (24). Other metal allergens may induce these changes via MHC peptide stripping (palladium) or more indirect modifications of the self-peptide-MHC complexes (beryllium) (22). Common haptenation mechanisms may be at play for certain metal allergens; for example, nickel-reactive human $\mathrm{CD} 4^{+} \mathrm{T}$ cell clones display cross-reactivity with copper and palladium (25). Although generally protein, 
LMW chemical, and metal allergens likely utilize divergent mechanisms to cause allergic disease, co-exposures to multiple chemical classes and metals is a reality in the workplace and this may produce responses of altered severity with unique mechanisms.

Although many substances can cause allergic and hypersensitivity reactions mediated by sensitization, LMW chemical sensitizers represent a substantial portion of causative agents of allergic diseases. Typically, LMW chemical allergens cause dermal or respiratory allergic manifestations including contact dermatitis and asthma. While the most common cause of dermal sensitization leading to contact dermatitis is exposure to metal salts, exposure to various LMW chemicals such as rubber additives, plastics and resins, biocides, and cosmetics are also significant causes of allergic contact dermatitis (4), which accounts for 10-15\% of all occupational diseases (3). Additionally, it is estimated that the prevalence of contact allergy due to at least one sensitizing chemical in North America and Western Europe is approximately 20\% (26). Allergic respiratory diseases are associated with high levels of worker morbidity and are a global health burden; it is estimated that $9-25 \%$ of all cases of adult-onset asthma are associated with occupational exposures, which is equivalent to $250-300$ cases per million of occupational-related adult-onset asthma each year (3). Flour was the most common cause of occupational asthma in the UK in 1998; however, isoycanates represented the second most common cause, illustrating the relevance of chemicals as causative agents of occupational allergic disease. The range of LMW chemicals that can cause occupational allergy is wide and is summarized in Table 1.3. This table is not exhaustive yet it illustrates the fact that these sensitizing chemicals are utilized in a wide variety of industries and for a number of applications. 


\begin{tabular}{|c|c|c|c|c|}
\hline Specific Classification & Chemical Name & Product & Occupation & $\begin{array}{l}\text { Allergic } \\
\text { Disease } \\
\text { Caused } \\
\end{array}$ \\
\hline \multicolumn{5}{|c|}{ Acrylic Resin Monomers } \\
\hline Acrylates & & $\begin{array}{c}\text { Paints, Varnishes, } \\
\text { Glues, Inks }\end{array}$ & $\begin{array}{l}\text { Painters, Printers, } \\
\text { Cosmetics, Health } \\
\text { Care, Automobile } \\
\text { workers }\end{array}$ & $\begin{array}{l}\text { Asthma (12), } \\
\text { ACD (27) }\end{array}$ \\
\hline Acrylamides & & $\begin{array}{c}\text { Dyes, Polyacrylamide } \\
\text { synthesis }\end{array}$ & $\begin{array}{c}\text { Polymer synthesis, } \\
\text { Paper and Textile, } \\
\text { Waste Treatment }\end{array}$ & $\mathrm{ACD}(27)$ \\
\hline Cyanoacrylates & & Glues & Dentistry & $\begin{array}{l}\text { Asthma (28), } \\
\text { ACD (27) }\end{array}$ \\
\hline Methacrylates & & & & \\
\hline & $\begin{array}{l}\text { 2-hydroxyethyl } \\
\text { methacrylate } \\
\text { (2-HEMA) }\end{array}$ & $\begin{array}{l}\text { Glues, orthopedic and } \\
\text { dental surgical } \\
\text { devices/fillings }\end{array}$ & $\begin{array}{l}\text { Medicine and } \\
\text { Dentistry }\end{array}$ & $\mathrm{ACD}(27)$ \\
\hline & $\begin{array}{l}\text { Ethyleneglycol } \\
\text { dimethacrylate } \\
\text { (EGDMA) }\end{array}$ & $\begin{array}{c}\text { Glues, Polymer } \\
\text { synthesis intermediate }\end{array}$ & $\begin{array}{c}\text { Dentistry, Polymer } \\
\text { synthesis }\end{array}$ & $\operatorname{ACD}(27)$ \\
\hline & $\begin{array}{l}\text { 2-hydroxypropyl } \\
\text { methacrylate } \\
\text { (2-HPMA) }\end{array}$ & Glues, Drug carrier & $\begin{array}{c}\text { Dentistry, } \\
\text { Pharmaceutical }\end{array}$ & $\operatorname{ACD}(27)$ \\
\hline \multicolumn{5}{|c|}{ Amines } \\
\hline $\begin{array}{c}\text { Aliphatic Amines and } \\
\text { Polyamines }\end{array}$ & & & Chemical Workers & $\begin{array}{l}\text { Asthma (12), } \\
\text { ACD (29) }\end{array}$ \\
\hline $\begin{array}{c}\text { Cycloaliphatic } \\
\text { Polyamines }\end{array}$ & & & Chemical Workers & $\mathrm{ACD}(29)$ \\
\hline Aromatic Amines & & & Textiles, Pesticides & $\mathrm{ACD}(29)$ \\
\hline \multicolumn{5}{|c|}{ Anhydrides } \\
\hline Dioctyl-phthalate & & $\begin{array}{c}\text { Plastics, Wood } \\
\text { coatings, Medical } \\
\text { devices }\end{array}$ & PVC Production & Asthma (12) \\
\hline Acid Anhydrides & & Plastics, Epoxy resins & $\begin{array}{c}\text { Chemical workers, } \\
\text { Pharmaceuticals }\end{array}$ & $\begin{array}{l}\text { Asthma (30). } \\
\text { ACD (31) }\end{array}$ \\
\hline \multicolumn{5}{|c|}{ Biocides } \\
\hline Aldehydes & & & & \\
\hline & $\begin{array}{c}\text { Formaldehyde and } \\
\text { Formaldehyde-based } \\
\text { materials }\end{array}$ & $\begin{array}{c}\text { Adhesive resin, Fiber } \\
\text { board, Plywood, Glues, } \\
\text { Medical preservative, } \\
\text { Sterilizers }\end{array}$ & $\begin{array}{c}\text { Healthcare, Textile, } \\
\text { Automobile, } \\
\text { Hairdressers, Health } \\
\text { Care, Lab, } \\
\text { Construction }\end{array}$ & $\begin{array}{l}\text { Asthma (12, } \\
\text { 32), ACD } \\
\text { (33) }\end{array}$ \\
\hline & Furfuryl Alcohol & $\begin{array}{l}\text { Rocket engine fuel, } \\
\text { Solvent, Intermediate } \\
\text { in the manufacture of } \\
\text { various products }\end{array}$ & $\begin{array}{l}\text { Foundry Operations, } \\
\text { Paints }\end{array}$ & $\begin{array}{c}\text { Allergic } \\
\text { Airway } \\
\text { Hyperreactivit } \\
\text { y (Murine) } \\
(34)\end{array}$ \\
\hline Chloramine $\mathrm{T}$ & $\begin{array}{c}\text { N-chloro 4- } \\
\text { methylbenzenesulfon } \\
\text { amide sodium salt }\end{array}$ & Surface Disinfectant & $\begin{array}{l}\text { Manufacturing, } \\
\text { Chemical Factory, } \\
\text { Healthcare }\end{array}$ & $\begin{array}{l}\text { Asthma }(35, \\
36)\end{array}$ \\
\hline Dialdehydes & & & & \\
\hline & Glutaraldehyde & Disinfectant & Healthcare, Lab & $\begin{array}{l}\text { Asthma (12, } \\
\text { 32), ACD } \\
\text { (37) }\end{array}$ \\
\hline
\end{tabular}




\begin{tabular}{|c|c|c|c|c|}
\hline & $\begin{array}{c}\text { Ortho- } \\
\text { phthalaldehyde }\end{array}$ & Disinfectant & Healthcare, Lab & $\begin{array}{l}\text { Asthma and } \\
\text { ACD (38) }\end{array}$ \\
\hline Fungicides & & & & \\
\hline & $\begin{array}{l}\text { 1,2-benzisothiazolin- } \\
\text { 3-one }\end{array}$ & Paints & $\begin{array}{c}\text { Chemical Workers, } \\
\text { Painters }\end{array}$ & $\begin{array}{l}\text { Asthma (12), } \\
\text { ACD (39) }\end{array}$ \\
\hline & $\begin{array}{c}\text { Dyrene } \\
\text { (2,4-dichloro-6-(D- } \\
\text { chloroanilino)-s- } \\
\text { triazine) }\end{array}$ & Pesticide & Lawn Care & $\operatorname{ACD}(40)$ \\
\hline & Sulfites & $\begin{array}{l}\text { Food additive, } \\
\text { Preservative }\end{array}$ & $\begin{array}{c}\text { Factory, Food } \\
\text { Processing, Water } \\
\text { Treatment, } \\
\text { Pharmaceuticals }\end{array}$ & $\begin{array}{l}\text { Asthma (12), } \\
\operatorname{ACD}(41)\end{array}$ \\
\hline Isothiazolinones & & Antimicrobials & $\begin{array}{l}\text { Various Applications } \\
\text { (Cleaning Agent) }\end{array}$ & $\begin{array}{l}\text { Asthma (36, } \\
\text { 42), ACD } \\
\text { (43) }\end{array}$ \\
\hline $\begin{array}{l}\text { Quaternary Ammonium } \\
\text { Compounds }\end{array}$ & & Antimicrobials & $\begin{array}{c}\text { Healthcare, Cleaning } \\
\text { Agent }\end{array}$ & $\begin{array}{l}\text { Asthma (36, } \\
44)\end{array}$ \\
\hline \multicolumn{5}{|c|}{ Cosmetics } \\
\hline Cocamidopropyl betaine & & Surfactant & Hairdressers & ACD (45) \\
\hline $\begin{array}{c}\text { Dyes, Fragrances, and } \\
\text { Perfumes }\end{array}$ & & & Sales, Hairdressers & $\begin{array}{l}\text { Asthma (2, } \\
\text { 12), ACD } \\
(46)\end{array}$ \\
\hline Glyceryl thioglycolate & & Hair Perm Solutions & Hairdressers & ACD (47) \\
\hline $\begin{array}{c}\text { Methyldibromo } \\
\text { glutaronitrile }\end{array}$ & & Preservative & & $\mathrm{ACD}(48)$ \\
\hline Parabens & & Preservative & & $\mathrm{ACD}(49,50)$ \\
\hline p-Phenylenediamine & & Dye & $\begin{array}{c}\text { Hairdressers, } \\
\text { Polymer synthesis }\end{array}$ & $\mathrm{ACD}(51)$ \\
\hline Persulfates & & $\begin{array}{c}\text { Denture cleaner, } \\
\text { Curing agent, Bleach, } \\
\text { Detergent }\end{array}$ & $\begin{array}{l}\text { Hairdressers, Food } \\
\text { Processing, Polymer } \\
\text { synthesis }\end{array}$ & $\begin{array}{l}\text { Asthma (12, } \\
52) \text {. ACD } \\
\text { (53) }\end{array}$ \\
\hline \multicolumn{5}{|c|}{ Isocyanates } \\
\hline Diisocyanates & & & & \\
\hline & $\begin{array}{l}\text { Hexamethylene } \\
\text { Diisocyanate } \\
\text { (HDI) }\end{array}$ & $\begin{array}{l}\text { Polyurethane synthesis, } \\
\text { Paints, Foams, } \\
\text { Coatings, Insulation, } \\
\text { and Varnishes } \\
\end{array}$ & $\begin{array}{l}\text { Automobile, } \\
\text { Painters, Builders, } \\
\text { Manufacturing }\end{array}$ & $\begin{array}{l}\text { Asthma (12, } \\
54), \text { ACD } \\
\text { (55) }\end{array}$ \\
\hline & $\begin{array}{c}\text { Methylene } \\
\text { Bisphenol } \\
\text { Isocyanate } \\
\text { (MDI) }\end{array}$ & $\begin{array}{l}\text { Polyurethane synthesis, } \\
\text { Paints, Foams, } \\
\text { Coatings, Insulation, } \\
\text { and Varnishes } \\
\end{array}$ & $\begin{array}{l}\text { Automobile, } \\
\text { Painters, Builders, } \\
\text { Manufacturing }\end{array}$ & $\begin{array}{l}\text { Asthma (12), } \\
\text { ACD (56) }\end{array}$ \\
\hline & $\begin{array}{c}\text { Toluene } \\
\text { Diisocyanate (TDI) }\end{array}$ & $\begin{array}{l}\text { Polyurethane synthesis, } \\
\text { Paints, Foams, } \\
\text { Coatings, Insulation, } \\
\text { and Varnishes } \\
\end{array}$ & $\begin{array}{l}\text { Automobile, } \\
\text { Painters, Builders, } \\
\text { Manufacturing }\end{array}$ & $\begin{array}{l}\text { Asthma (12, } \\
\text { 57), ACD } \\
\text { (58) }\end{array}$ \\
\hline \multicolumn{5}{|c|}{ Hardeners } \\
\hline Polyfunctional aziridine & & $\begin{array}{c}\text { Paints, Coatings, } \\
\text { Varnishes, and Inks }\end{array}$ & Painters, Builders & $\begin{array}{l}\text { Asthma (59), } \\
\text { ACD (60) }\end{array}$ \\
\hline Triglycid isocyanurate & & $\begin{array}{c}\text { Paints, Laminates, and } \\
\text { Varnishes }\end{array}$ & Painters & $\begin{array}{l}\text { Asthma (61), } \\
\text { ACD (62) }\end{array}$ \\
\hline Acrylates & & $\begin{array}{l}\text { Paints, Varnishes, } \\
\text { Glues, Inks }\end{array}$ & $\begin{array}{c}\text { Painters, Printers, } \\
\text { Automobile Workers }\end{array}$ & $\begin{array}{l}\text { Asthma (12), } \\
\operatorname{ACD}(27)\end{array}$ \\
\hline
\end{tabular}




\begin{tabular}{|c|c|c|c|c|}
\hline Acrylamides & & & $\begin{array}{l}\text { Polymer synthesis, } \\
\text { Paper and Textile, } \\
\text { Waste Treatment }\end{array}$ & $\mathrm{ACD}(27)$ \\
\hline Cyanoacrylates & & Glues & Dentistry & $\begin{array}{c}\text { Asthma (28), } \\
\operatorname{ACD}(27)\end{array}$ \\
\hline Methacrylates & & & & \\
\hline & $\begin{array}{l}\text { 2-hydroxyethyl } \\
\text { methacrylate } \\
\text { (2-HEMA) }\end{array}$ & Glues & Dentistry & $\operatorname{ACD}(27)$ \\
\hline & $\begin{array}{c}\text { Ethyleneglycol } \\
\text { dimethacrylate } \\
\text { (EGDMA) }\end{array}$ & Glues & Dentistry & $\mathrm{ACD}(27)$ \\
\hline & $\begin{array}{l}\text { 2-hydroxypropyl } \\
\text { methacrylate } \\
\text { (2-HPMA) }\end{array}$ & Glues & Dentistry & $\mathrm{ACD}(27)$ \\
\hline Aliphatic Amines & & & & \\
\hline & $\begin{array}{c}\text { Aliphatic } \\
\text { Polyamines }\end{array}$ & & Chemical Workers & $\begin{array}{c}\text { Asthma (12), } \\
\text { ACD (29) }\end{array}$ \\
\hline & $\begin{array}{l}\text { Cycloaliphatic } \\
\text { Polyamines }\end{array}$ & & Chemical Workers & $\mathrm{ACD}(29)$ \\
\hline Aromatic Amines & & & Textiles, Pesticides & ACD (29) \\
\hline Anhydrides & & & & \\
\hline & Dioctyl-phthalate & & PVC Production & Asthma (12) \\
\hline & Acid Anhydrides & & $\begin{array}{l}\text { Chemical workers, } \\
\text { Pharmaceuticals }\end{array}$ & $\begin{array}{l}\text { Asthma (30). } \\
\text { ACD (31) }\end{array}$ \\
\hline $\begin{array}{l}\text { Epoxy and phenolic } \\
\text { monomers }\end{array}$ & & $\begin{array}{c}\text { Paints, Flooring } \\
\text { Products }\end{array}$ & Painters, Builders & $\begin{array}{l}\text { Asthma (63), } \\
\text { ACD (64) }\end{array}$ \\
\hline \multicolumn{5}{|c|}{ Rubber Additives } \\
\hline Accelerators & & & & \\
\hline & $\begin{array}{c}\text { Carbamates } \\
\text { (ex: Iodopropynyl } \\
\text { butylcarbamate) }\end{array}$ & $\begin{array}{l}\text { Cosmetics, } \\
\text { Insecticides, } \\
\text { Polyurethane } \\
\text { Synthesis, } \\
\text { Preservatives }\end{array}$ & $\begin{array}{l}\text { Farmer, Chemical } \\
\text { Workers }\end{array}$ & $\mathrm{ACD}(65)$ \\
\hline & $\begin{array}{l}\text { Mercaptobenzothiaz } \\
\text { ole }\end{array}$ & $\begin{array}{c}\text { Lubricants, } \\
\text { Metalworking Fluids, } \\
\text { Plastic and Rubber } \\
\text { Synthesis } \\
\end{array}$ & $\begin{array}{c}\text { Automobile, } \\
\text { Metallurgy, } \\
\text { Chemical Workers }\end{array}$ & $\mathrm{ACD}(66)$ \\
\hline & Thioureas & $\begin{array}{c}\text { Organic Synthesis, } \\
\text { Rubber Synthesis }\end{array}$ & Chemical Workers & $\mathrm{ACD}(67)$ \\
\hline & Thiurams & Rubber Synthesis & Chemical Workers & $\operatorname{ACD}(68,69)$ \\
\hline Antioxidants & & & & \\
\hline & $\begin{array}{c}\text { N-phenyl-N- } \\
\text { isopropyl- } \\
\text { paraphenylenediami } \\
\text { ne }\end{array}$ & $\begin{array}{l}\text { Rubber Synthesis, } \\
\text { Food Additives }\end{array}$ & $\begin{array}{c}\text { Chemical Workers, } \\
\text { Food Workers }\end{array}$ & ACD (70) \\
\hline
\end{tabular}

Table 1.3: Summary of LMW Chemicals Causing Occupational Allergy

The initiation of sensitization begins with exposure and antigen recognition. In order to gain access to the immune cells responsible for the commencement of sensitization, allergens must 
penetrate the epithelium. In the skin, LMW chemical allergens may be absorbed through the stratum corneum, hair follicles, and sebaceous glands (71), accessing internal cells without physical alteration of the epithelium due to their small size. This is a departure from the mechanism of HMW protein allergens which can physically disrupt the epithelium through the utilization of factors like proteases (72). Both HMW and LMW sensitizers may take advantage of a compromised epithelium. Absorbance of LMW chemical allergens may be increased following exposure to solvents which are commonly used in a variety of workplaces (1). A widely-accepted concept explaining the immunogenicity of LMW chemical allergens involves a haptenation step, combining with and altering a self-protein, causing an allergic response following recognition by antigen presenting cells (APCs) $(21,73,74)$. According to this hypothesis, in order for a LMW chemical to cause sensitization, skin penetration should occur at a rate that is quick enough to ensure that an ample amount of chemical may combine with self-proteins to produce sufficiently immunogenic conjugates sometimes involving conformational changes of the LMW chemical and the self-protein. Epithelial activation and disruption is an initial step in the activation of innate immune cells by secreted factors such as cytokines and chemokines, eventually involving APCs followed by an adaptive component. Following the establishment of sensitization, subsequent exposures may lead to elicitation, which is manifested in the form of allergic diseases like asthma and contact dermatitis. LMW chemicals have been reported to cause both contact dermatitis and occupational asthma, in the form of early and late asthmatic responses (75).

It should be noted that two additional classes of non-reactive chemical allergens exist; prohaptens are converted to reactive contact allergens by enzymes including those of the cytochrome P450 family in keratinocytes and dendritic cells and may be transported out of these cells via the 
multidrug-resistance related proteins and prehaptens may acquire allergenicity via auto-oxidation (13).

\subsubsection{Dermal and Respiratory Chemical Sensitizers}

As evidenced by Table 1.3, LMW chemical allergens are diverse in structure, reactivity, and application; however, there are several common attributes that are associated with immunogenicity including haptenation potential (protein reactivity), ability to access the epithelium, and irritancy induction (76). The route of exposure, exposure intensity, and duration/frequency of exposure are additional factors that impact chemical allergenicity (3). Traditionally, LMW chemical sensitizers have been classified as either respiratory or dermal sensitizers, based on their ability to sensitize via the respiratory tract or skin and their ability to induce Th2 or Th1-dominated immune responses, respectively (77). Thousands of chemicals have been identified as causative agents of skin sensitization resulting in allergic contact dermatitis such as dinitrochlorobenzene, while substantially fewer respiratory chemical allergens $(<100)$ have been identified as causative agents of respiratory sensitization preceding asthma $(78,79)$. Major chemical respiratory sensitizers include acid anhydrides, chloroplatinate salts, diisocyanates, and certain reactive dyes (80). In general, the majority of chemical sensitizers are capable of causing dermal sensitization but do not cause respiratory sensitization (76); however, many respiratory sensitizers can also cause skin sensitization, leading to both skin allergy and/or asthma following skin sensitization. These observations are intriguing, given the rigid skin/respiratory classification scheme that is commonly used to identify these agents based on their sensitization potential. It is important to note that many respiratory sensitizers that have not been observed to cause dermal allergy in humans (despite high potential for skin exposure) elicit positive reactions in animal-based models designed to screen for 
skin sensitization (76). Phthalic anhydride is a poignant example of this concept, as it has rarely been observed to be a human skin sensitizer yet it elicits a positive response in both guinea pig and mouse-based skin sensitization tests (76). The cause of this discrepancy has not yet been elucidated.

The juxtaposition between dermal and respiratory sensitizers has been investigated in a variety of contexts. This concept has been inspected in the realm of protein binding selectivity. It has been shown that contact sensitizers preferentially associate with cellular proteins, while respiratory sensitizers prefer to bind to soluble proteins (81). These observations require further analysis from a biologic perspective; however, protein binding selectivity may influence downstream allergic responses. In a related vein, both contact and respiratory sensitizers have been investigated in the context of preferential chemical reaction and mechanism. It has been suggested that the presence of multiple functional groups on a chemical may be directly related to its ability to cause respiratory sensitization. Contrary to this hypothesis several respiratory chemical sensitizers do not contain multiple functional groups such as abeitic acid, phthalic anhydride, and vinyl benzene (82). Further investigating the electrophilic chemical reactions associated with respiratory sensitization potential, one in silico study profiled the chemical reactions associated with 10 respiratory chemical sensitizers (82). This study revealed diverse mechanisms involved in chemical-protein interaction among respiratory sensitizers along with varying electrophilicity/cross-linking reactivity potential requirements needed to cause respiratory sensitization specific to each class of electrophilic reaction.

The divergence between dermal and respiratory sensitizers has also been investigated in the context of Langerhans cell activity following topical administration of a dermal (2,4dinitrochlorobenzene (DNCB)) and respiratory (trimellitic anhydride (TMA)) sensitizer (83). TMA was associated with early increased IL-10 expression (presumably resulting in decreased IL-12 levels, leading to decreased Th1 differentiation in the $\mathrm{dLN}$ ) while DNCB resulted in early IL-1 $\beta$ 
expression by Langerhans cells (leading to increased Th1 and Th17 differentiation in the dLN), illustrating early divergence in the innate immune response to both types of sensitizer. Langerhans cells exhibited delayed migration in response to TMA compared to DNCB; this was confirmed to be due to increased immunosuppressive IL-10 and decreased IL-1 $\beta$ expression following TMA exposure. The authors hypothesized that these dichotomous epidermal responses resulted in the altered polarization of the immune response following exposure to each of the representative sensitizers. Approaching the same concept from a different perspective, the DNA methylation status of the lymph node following cutaneous application of DNCB or TMA was investigated in a recent work by Chapman, et al. (84). This data revealed distinct DNA methylation patterns induced by chemical exposure, specifically in regard to key Th1 and Th2 -associated genes, implicating epigenetic factors in the development of contact or respiratory sensitization. In any case, the factors differentiating dermal and respiratory sensitizers are a subject of much discussion.

It has been established that dermal sensitizers preferentially elicit a Th1-mediated cellular immune response, while respiratory sensitizers preferentially elicit a Th2-mediated cellular immune response (85-87), yet the specific chemical properties that define each type of sensitizer have not been identified. Dermal sensitizers are thought to provoke a Th1-based immune response, grossly conforming to the Type IV hypersensitivity reaction described by Gell and Coombs (88). CD4 ${ }^{+}$Th1 and Th17 cells along with $\mathrm{CD} 8^{+} \mathrm{T}$ cells are commonly implicated as key players involved in the dermal sensitization response. Alternatively, respiratory sensitizers are thought to elicit a Th2-based immune response and are generally associated with the Type I atopic hypersensitivity reaction (88). These observations are true for both humans and rodents. The controversial role of $\operatorname{IgE}$ in the pathogenesis of many respiratory chemical sensitizers along with the mixed $\mathrm{Th} 1 / \mathrm{Th} 2$ response observed complicates this categorization of chemical respiratory sensitizers. As emphasized before, 
some of these reactions do not fit perfectly within the Gell and Coombs classification due to the complicating presence of a mixed $\mathrm{T}$ cell response in the case of certain respiratory sensitizers. Clearly, the dermal/respiratory classification scheme is useful in many regards but may be confusing and invalid as a rigid, mutually exclusive categorization system for all chemical sensitizers.

\subsubsection{Hazard Identification Strategies for Chemical Sensitizers}

Due to the environmental, occupational, and clinical significance of chemical sensitizers, the use of rapid and sensitive methods for hazard identification are necessary. A human -based assay known as the human repeated insult patch test (HIRPT) has been used to identify skin allergens; however, due to ethical concerns and alternate methods the use of this assay has been eliminated in many countries (87). Two guinea pig-based assays have been utilized to predict chemical sensitizers including the guinea pig maximization test (GPMT) and the Buehler assay; these assays are recommended for use by the Organization for Economic Cooperation and Development (OECD) guideline \#406 (89). The GPMT utilizes intradermal administration of a test chemical combined with or without Freund's complete adjuvant followed by topical administration of the test chemical. Two weeks post topical dosing the animals are challenged by patch test of the flank and the allergic reaction on the skin is assessed to measure sensitization potential (89). The Buehler assay also utilizes a guinea pig model of elicitation, animals are exposed to the test agent for 6 hours for three consecutive weeks and two weeks after the final patch exposure the animals are challenged by patch test of the flank for 6 hours (89). The GPMT and Buehler assays measure the elicitation phase of allergy, complicating these test models beyond the sensitization phase, which is a noted limitation of these assays. Further limitations of these assays include limited dose selection range (based on skin irritation threshold) and the use of single induction and challenge concentrations, providing no 
dose response or threshold data (90). In spite of these limitations, guinea pig-based sensitization assessment assays also have significant utility, including a substantial database of test data, allowing for comparisons to new test agents and information regarding the challenge phase of allergy (90).

Currently, the gold standard for hazard identification of dermal sensitizers is the local lymph node assay (LLNA). This assay has been validated by among independent laboratories (91, 92), with the USA-based Interagency Coordinating Committee on the Validation of Alternative Methods (ICCVAM) (93) and the European-based European Center for the Validation of Alternative Methods (ECVAM) (87). Additionally, in April 2002 the LLNA was incorporated into the Test Guideline 429 by the OECD (94). The LLNA is based on the concept that repeated dermal exposure to sensitizers causes lymphocyte proliferation in lymph nodes draining the site of chemical application and that this proliferation can be quantified by utilizing tritiated thymidine $\left({ }^{3} \mathrm{H}\right)$ which is incorporated into dLN DNA. Figure 1.1 illustrates the basic protocol of the LLNA. The assay utilizes female mice (preferably of the $\mathrm{CBA} / \mathrm{Ca}$ or $\mathrm{CBA} / \mathrm{J}$ strain) at a minimum of four per group. These mice are dermally exposed to $25 \mu \mathrm{L}$ of vehicle, increasing concentrations of the test agent (a minimum of three concentrations), and a positive control per ear for three consecutive days. After three days of rest (on day six) the mice are intravenously injected with ${ }^{3} \mathrm{H}$. Five hours following ${ }^{3} \mathrm{H}$ injection mice are euthanized and the dLNs are excised and processed into a single cell suspension. These suspensions are tested for ${ }^{3} \mathrm{H}$ incorporation based on disintegration per minute (DPM) readings as quantified using a liquid $\beta$-scintillation counter. Results are expressed as the stimulation index (SI) which is obtained by dividing the radioactive incorporation for each treatment group over each vehicle control group or alternatively, by dividing mean DPM/mouse within each treatment group by the mean DPM/mouse for the vehicle control group. A test substance is generally considered a sensitizer if it yields a stimulation index $\geq 3$ and exhibits a dose-responsive increase in dLN 
proliferation. This value indicates a three-fold or greater increase in $\mathrm{dLN}$ cell proliferation compared with vehicle-control mice. In general, predictive tests exhibit certain limitations and results must be interpreted accordingly. The LLNA is not effective in identifying nickel salts (presumably due to variation in TLR4 signaling between mice and humans), exhibits false positives (specifically regarding non-sensitizing irritants) $(94,95)$, and cannot distinguish dermal and respiratory sensitizers. Regardless, the LLNA exhibits many advantages over other sensitization assays, including quick turnover and cost effectiveness, less animal trauma, an end point directly associated with sensitization, dose response analysis yielding an index of potency (EC3 value), and close correlation between EC3 and human skin sensitization data (90).

\section{LLNA Overview}

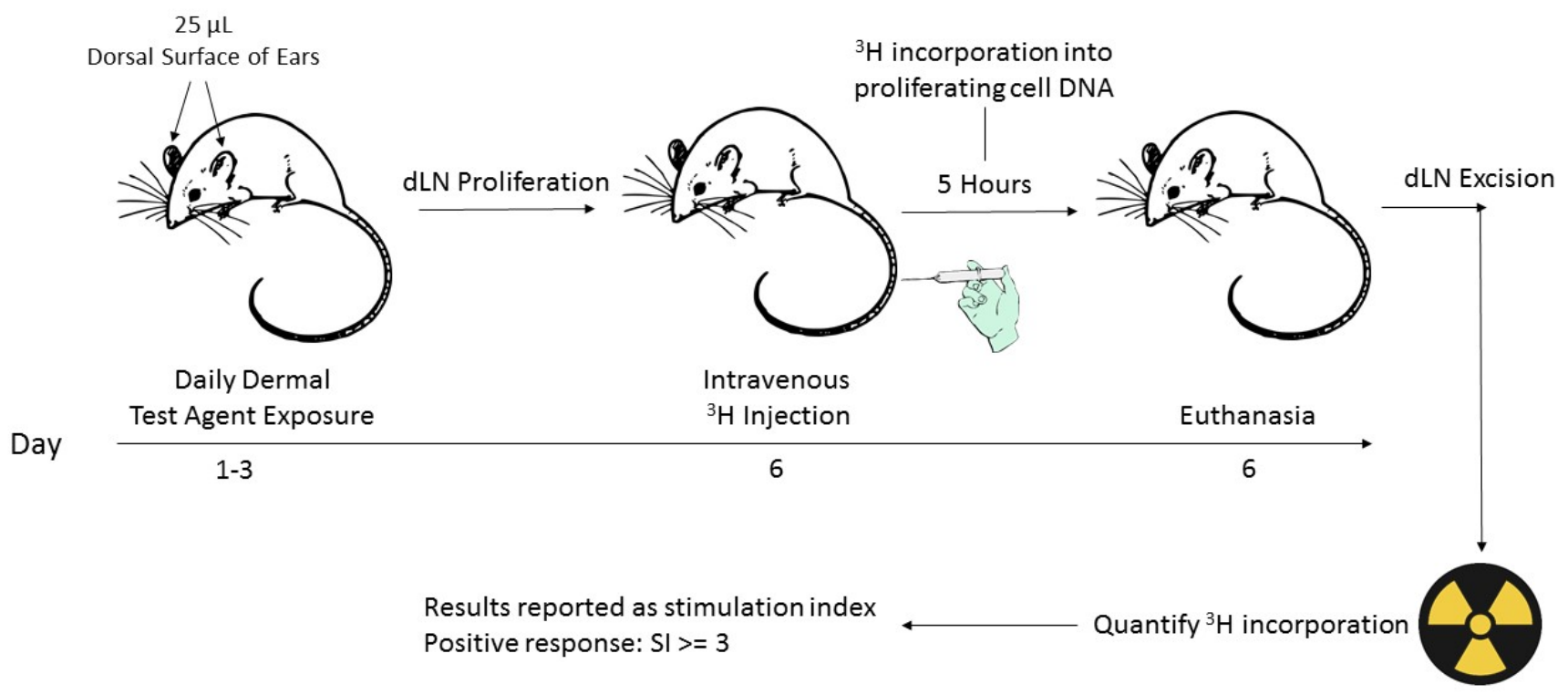

Figure 1.4 Pictorial overview of the LLNA

Recently, much experimental focus has been allocated to the development of non-animal alternatives to the LLNA. The major challenge in the development of in chemico, in silico, and in vitro alternatives for hazard identification of skin sensitizers is the ability to recapitulate the complex 
in vivo environment of an organism undergoing sensitization. In an effort to address this concept, several assays are being developed to model haptenation, keratinocyte activation, and dendritic and T cell proliferation and interaction (87). In silico methods focused on predicting chemical reactivity based on the known in vivo reactivity of chemicals bearing structural significance are known as quantitative structural activity relationship. Additional efforts have been made to determine the sensitization potential of a chemical based on its electrophilic reactivity (96). Perhaps the most well-developed in chemico assay showing potential for differentiation of respiratory chemical sensitizers is the Direct Peptide Reactivity Assay (DPRA). This assay characterizes the reactivity of chemicals with model peptides (synthetic cysteine and lysine solutions) as surrogate nucleophiles, mimicking the covalent binding of electrophilic chemical allergens to nucleophilic centers in selfproteins based on the hapten hypothesis of chemical immunogenicity. This assay was initially developed by Gerberick, et al in 2004 and has been refined since then (97). In 2013 this assay was recommended for use by the ECVAM in skin sensitization testing (98) and draft guidelines were approved in early 2015 (99). These guidelines recommended use of this assay with additional tests due to the complex nature of skin sensitization prediction. Several in vitro assays are in the process of development for the purpose of skin sensitization hazard identification. Many of these assays are based on immunologic events that take place during sensitization including keratinocyte and dendritic cell activation (87). Endpoints such as cytokine production and cellular phenotyping are frequently utilized with these assays. While these approaches are promising, the LLNA remains the preferred method of hazard identification for dermal chemical sensitizers. 


\subsubsection{Challenges Regarding the Investigation of Respiratory Chemical Sensitizers}

Not surprisingly, several characteristics of dermal and respiratory chemical sensitizers make these substances difficult to regulate. The lack of information regarding the immunologic mechanisms of respiratory sensitizers paired with the difficulty of setting reasonable exposure limits for these chemicals pose significant challenges for risk assessors and hazard identifiers when working with sensitizing chemicals. As described above, several validated hazard identification assays exist for skin sensitizers including the guinea pig maximization test and LLNA, among other assays (87). Although these assays are relatively effective and sensitive for dermal sensitizers, they are not validated for respiratory sensitizers.

Positive results in the LLNA are usually ascertained for respiratory sensitizers but this assay is not specific for respiratory responses and is conducted utilizing a dermal exposure model, creating problems regarding the interpretation and application of this assay to respiratory sensitizers. Modified lymph node proliferation-based assays have been tested for protein allergens following intratracheal and oropharyngeal aspiration exposures (100); however, these assays are hampered by concerns regarding vehicle and have yet to be established for respiratory chemical sensitizers. Another complicating factor contributing to the failure to develop a respiratory chemical allergen screening assay is the limited understanding of the mechanisms involved in sensitization (101). Because of this, there have been numerous experimental efforts to develop an assay capable of distinguishing respiratory sensitizers but none have been validated or universally applied.

Antibody production has been proposed as an endpoint for the identification of respiratory chemical sensitizers. The mouse IgE test is characterized by increases in total serum IgE following topical application as a function of a chemical's ability to cause respiratory sensitization. This test was initially developed in the early 1990s (102) and was complicated by variability in IgE expression 
among non-respiratory sensitizers and among different mouse strains (103). In a similar fashion, Maentz and Meade developed a comprehensive flow cytometry-based assay in 1999 meant to identify and differentiate chemicals based on their ability to elicit irritation, IgE- (respiratory), or T cell-(dermal) mediated hypersensitivity responses (103). This assay is based on ear swelling and the phenotype of dLN B220 ${ }^{+}$B cells, specifically, their expression of IgE following 10 days of dermal exposure to the chemical of interest. These studies revealed discriminatory expression of B220 and IgE, allowing for identification of respiratory or dermal sensitizers. B220 has also been utilized as a discriminatory marker to distinguish allergens and irritants in the LNNA as irritants may induce significant dLN proliferation, causing false positives in the LLNA (104).

Cytokine profiling, $\mathrm{T}$ cell fingerprinting, and $\mathrm{dLN}$ gene expression have been proposed as methods of differentiating dermal and respiratory chemical allergens due to the dichotomy in Th1 and Th2 responses observed for each class of chemical. A variety of murine in vivo experiments have demonstrated preferential lymph node protein expression of IFN-y and IL-12 (Th1-dermal) vs IL-4, IL-5, IL-10, and IL-13 (Th2-respiratory) following topical exposure to various panels of chemical sensitizers (101). Plitnick, et al. described a ribonuclease protection assay that quantified dLN cytokine messenger RNA (mRNA) levels from dermally exposed mice in an effort to distinguish contact and respiratory sensitizers $(105,106)$. These studies demonstrated differential Th1 and Th2-skewed dLN cytokine mRNA profiles following dermal and respiratory sensitizer application, suggesting the potential utility of this assay in the identification of respiratory chemical sensitizers. Unfortunately, dose selection parameters were difficult to pair with LLNA data and necessitated further modification. Additional efforts have been made to examine cytokine fingerprinting in the dLN following both respiratory and skin exposure to a panel of respiratory and dermal chemical sensitizers. Jong, et al. found that dLN IL-4 expression following either inhalation 
or epicutaneous exposure was predicative of most respiratory sensitizers (107). Additional studies measured gene expression responses in the dLN following the LLNA exposure protocol revealing differential gene expression for mast cell proteases in respiratory sensitizers compared to contact sensitizers (108). Accordingly, several authors have noted that an initial LLNA conducted prior to cytokine fingerprinting may aid in dose selection rationale and prescreening. This method was initially proposed over 15 years ago and has not been validated, presumably due to variability associated with cytokine detection methods and results.

While many in vitro assays have been proposed for skin sensitization as a replacement for in vivo assays such as the LLNA, few comparable assays have been developed specifically for respiratory chemical sensitizers. The DPRA has revealed altered amino acid preferences in some cases when comparing dermal and respiratory sensitizers; which seem to prefer to binding to cysteine and lysine residues, respectively (109). While this trend was repeated, it was not always followed by known respiratory sensitizers; diisocyanates displayed low levels of lysine depletion in comparison to cysteine depletion, indicating that these chemicals had a reactivity profile similar to dermal sensitizers (78). This phenomena may be explained by a process known as "isocyanate exchange" characterized by reversible covalent conjugation to cysteine thiol followed by hydrolysis and transfer to a lysine residue $(110,111)$. Thus, the reactivity between multiple nucleophiles must be considered when evaluating the DPRA as an assay for identification of respiratory sensitizers based on lysine preference. The data presented here show that the DPRA may be a useful supplemental assay in the identification of respiratory sensitizers based on reactivity profiling. It is important to note that this assay was validated for use in dermal sensitization studies, as mentioned in the previous section, but not specifically for respiratory sensitizers. 
Another recently developed in vitro assay has shown considerable promise in the identification of respiratory sensitizers; this assay is known as the Genomic Allergen Rapid Detection (GARD) assay. This assay was developed by Johansson, et al. and utilizes a human myeloid cell line, MUTZ-3, and a genomic biomarker signature following chemical stimulation (112). This assay was originally developed as an in vitro alternative to the LLNA but has shown utility in the identification of respiratory sensitizers with the use of a separate GARD Respiratory Prediction Signature (GRPS) (113). This assay demonstrated sensitivity, specificity, and accuracy values of $67 \%, 89 \%$, and $84 \%$, respectively, respectable metrics that surpass other attempted methods of hazard identification classification of respiratory sensitizers (113).

Although there continues to be progress made in the development of chemical sensitization identification assays, both in vitro and in vivo, the limited knowledge of the immunologic mechanisms of sensitization induced by chemical sensitizers continues to complicate the development of these assays. Currently, the LLNA remains the gold standard for LMW sensitizer hazard identification and additional strategies need to be investigated in order to differentiate respiratory and dermal sensitizers beyond this assay. Novel molecules and mechanisms involved in allergic disease should be examined in order to elucidate specific entities that can be utilized for the development of hazard identification assays for respiratory sensitizers.

\subsection{NOVEL MEDIATORS OF ALLERGIC DISEASE}

Recently, the emergence of many novel cellular subsets and molecules involved in immunological responses has occurred, shedding light on unexplored realms of the immune system and their potential involvement in a variety of disease states, including allergic disease. These novel mediators include innate lymphoid cells (ILCs), microRNAs (miRNAs), and additional Th subsets. 
Currently, the general understanding of the mechanisms of LMW chemical sensitization are limited to Gell and Coombs classification. Typically, dermal sensitizers are considered Type IV inducers and respiratory sensitizers are considered Type I inducers. While the respective immune mechanisms may be valid for certain chemical sensitizers, many do not induce immune responses that fit into these categories. For example, TDI is a potent respiratory sensitizer that evokes a mixed Th1/Th2 immune response, leading to sensitization via the skin or respiratory tract, and ultimately asthma. In murine models, IgE is a major player in the sensitization and elicitation process, but in human TDI asthmatics the role of IgE is contested, complicating the Type I classification of the immune response caused by this chemical. Due to the complexity of mechanisms involved in chemical allergy and the lack of knowledge regarding these mechanisms, the investigation of novel cellular subsets and molecules involved is imperative for the greater understanding of these conditions and the development of hazard identification strategies for chemical sensitizers.

$\mathrm{T}$ cells are recognized as important mediators of allergic responses and chemical sensitization. Many factors can influence the phenotype and function of a $\mathrm{T}$ cell, including the immune microenvironment, the level and duration of TCR signaling, and the presence of signaling molecules such as cytokines. The cellular phenotype and effector functions of a $\mathrm{T}$ cell help determine its unique subset. Our knowledge of $\mathrm{T}$ cells has increased exponentially in the past thirty years, since Mosmann and Coffmann proposed the seminal T cell classification scheme, including Th1 and Th2 cells (114). The existence of regulatory $\mathrm{T}$ cells $\left(\mathrm{T}_{\text {regs }}\right)$ had also been recognized at this time and this subset was known as the suppressor $\mathrm{T}$ cell subset. Currently, there are many generally recognized T cell subsets, including the $\mathrm{CD}^{+}{ }^{+} \mathrm{Th} 1, \mathrm{Th} 2$, Th9, Th17, Th22, $\mathrm{T}$ follicular helper $\left(\mathrm{T}_{\mathrm{FH}}\right)$, and $\mathrm{T}_{\text {regs, }}$, natural killer $\mathrm{T}$ cells (NKT), and cytotoxic $\mathrm{CD} 8^{+}$cells (See Table 1.4). 


\begin{tabular}{|c|c|c|c|c|}
\hline Subset & $\begin{array}{c}\text { Master } \\
\text { Transcription } \\
\text { Factor or } \\
\text { Marker } \\
\end{array}$ & Effector Function & $\begin{array}{c}\text { Inducer } \\
\text { Cytokines/Stimulus }\end{array}$ & Cytokines Produced \\
\hline Th1 & Stat4-Tbet & $\begin{array}{l}\text { Intracellular } \\
\text { pathogen defense }\end{array}$ & IL-12 & IFN $\gamma$, IL-10, TNF- $\beta$ \\
\hline Th2 & Stat6-Gata3 & $\begin{array}{l}\text { Large extracellular } \\
\text { pathogen defense, } \\
\text { Allergic reactions }\end{array}$ & IL-4 & $\begin{array}{l}\text { IL-4, IL-5, IL-9, IL-10, IL- } \\
\text { 13, IL-25 }\end{array}$ \\
\hline Th9 & $\begin{array}{lr}\text { Batf } & \text { (Stat6- } \\
\text { Gata3), } & \text { IRF4 } \\
\text { (TCR } & \text { signaling), } \\
\text { and } & \text { PU.1 } \\
\text { (encoded } & \text { by } \\
\text { Sfpi1) } & \\
\end{array}$ & $\begin{array}{lr}\text { Parasitic } & \text { helminth } \\
\text { defense, } & \text { Allergic } \\
\text { reactions } & \end{array}$ & IL-2,IL-4, TGF- $\beta$ & IL-9, IL-13 \\
\hline Th17 & Stat3-Roryt & $\begin{array}{l}\text { Mucosal immunity, } \\
\text { Autoimmunity }\end{array}$ & IL- 6 and TGF- $\beta$ & $\begin{array}{l}\text { IL-8, IL-17A and F, IL-21, } \\
\text { IL-22 }\end{array}$ \\
\hline Th22 & AHR & $\begin{array}{l}\text { Skin immunity and } \\
\text { inflammation }\end{array}$ & IL- $1 \beta$, IL- 6 , and TNF- $\beta$ & IL-13, IL-22, TNF- $\beta$ \\
\hline $\mathrm{T}_{\mathrm{FH}}$ & $\begin{array}{l}\text { Bcl6 (along with } \\
\text { CXCR5, ICOS, } \\
\text { and PD-1) }\end{array}$ & $\begin{array}{lr}\text { Mediate the } & \text { the } \\
\text { development } & \text { of } \\
\text { antigen-specific } \mathrm{B} \\
\text { cell immunity } \\
\text { originating in } \\
\text { germinal centers }\end{array}$ & ICOS, IL-6, IL-21 & $\begin{array}{l}\text { IFN- } \gamma, \text { IL-2, IL-4, IL-10, } \\
\text { IL-17, and IL-21 }\end{array}$ \\
\hline $\mathrm{T}_{\text {reg }}$ & Stat5-Foxp3 & \begin{tabular}{lr}
\multicolumn{2}{l}{ Maintenance } \\
immune & of \\
regulation & of \\
adaptive & immune \\
responses & \\
\end{tabular} & IL- 2 and TGF- $\beta$ & IL-10, TGF- $\beta$, IL-35 \\
\hline NKT & iTCR & $\begin{array}{l}\text { Prevention of } \\
\text { autoimmunity and } \\
\text { infection, involved } \\
\text { in allergic reactions }\end{array}$ & $\begin{array}{l}\text { Glycolipids presented } \\
\text { by CD1d }\end{array}$ & IFN- $\gamma$, IL-2, IL-4, TNF- $\alpha$ \\
\hline$\gamma \delta$ & $\gamma \delta$-TCR & Pathogen response & $\begin{array}{l}\text { Non-MHC I/II-bound } \\
\text { antigens, IL-2 }\end{array}$ & IFN- $\gamma$, IL-17, TNF \\
\hline $\mathrm{CD}^{+}$ & $\mathrm{CD} 8$ & $\begin{array}{l}\text { General infection } \\
\text { and immunity }\end{array}$ & IFN- $\gamma$, IL-2 & $\begin{array}{lll}\text { Granzyme } & \text { B, } & \text { IFN } \gamma, \\
\text { Perforin, XCL1 }\end{array}$ \\
\hline
\end{tabular}

Table 1.4: T Cell Subsets

While Th1, Th2, and cytotoxic $\mathrm{CD}^{+} \mathrm{T}$ cells have a recognized role in allergic disease and chemical sensitization, the roles of the remaining $\mathrm{T}$ cell subsets are largely unexplored. Th17 cells have been implicated in the pathogenesis of autoimmune diseases and the clearance of extracellular pathogens due to their ability to recruit and activate neutrophils, activate macrophages, and cause 
acute and chronic inflammation (115). Recently, these cells have also been associated with allergic diseases such as contact dermatitis and allergy. Increased IL-17 levels and neutrophils have been found in the lungs of patients with asthma and murine models suggest that Th17 cells can act in concert with Th2 cells to promote allergic responses and airway hyperresponsiveness (115). Additionally, IL-17 appears to be important in the recruitment of neutrophils to the mouse airway and overall pathogenesis following TDI exposure $(116,117)$. Th17 cells may also play a significant role in the pathogenesis of allergic contact dermatitis. IL-17 was first associated with skin allergy in 1999 in a report utilizing $\mathrm{Ni}^{2+}$-specific $\mathrm{T}$ cells isolated from patients with allergic contact dermatitis (118). Both human-derived $\mathrm{Ni}^{2+}$-specific $\mathrm{T}$ cells and keratinocytes were able to express IL-17 and $i l 17 r$, respectively. This study suggested that IL-17 was involved in T cell-mediated allergic responses in the skin. Several years later, IL-17-deficient mice were utilized in several allergic disease models in an effort to define the role of Th17 cells in these conditions (119). Chemical-induced contact hypersensitivity and an ovalbumin (OVA) -specific airway hypersensitivity model were reduced in magnitude in the absence of IL-17 and this was attributed to impaired antigen-specific T cell activation, further implicating Th17 cells and IL-17 as major players in allergic disease. The requirement of TGF- $\beta$ in Th17 cell differentiation is notable, especially considering it is also important for $\mathrm{T}_{\text {reg }}$ differentiation and signaling. True to their name, $\mathrm{T}_{\text {regs }}$ are a subset of $\mathrm{T}$ cells that are involved in the maintenance of immune tolerance and homeostasis. $\mathrm{T}_{\text {regs }}$ have been implicated as key players in allergic disease as well as potential therapeutic targets in a variety of disease states and will be discussed in more detail in Chapters 3 and 5 .

Th9 cells are characterized based on their production of IL-9, a cytokine that is recognized for the promotion of allergic responses. Th9 induction has been shown to be dependent on TGF- $\beta$ and IL-4 expression (120), two cytokines that are also positively involved in $\mathrm{T}_{\text {reg }}$ and $\mathrm{Th} 2$ 
development, respectively. In a murine model of ovalbumin-induced airway inflammation IL-9 neutralization resulted in reduced allergic symptoms and inflammation (121). Atopic human patients exhibit increased Th9 cell numbers compared to non-atopic patients, correlating with increased IgE levels (122). In the same study, a murine model of house dust mite allergic airway inflammation was established and revealed rapid Th9 expansion (quicker than Th2 cells) resulting in mast cell recruitment and activation. This concept has been demonstrated experimentally, with IL-9 enhancing the survival of mast cells, stimulating the production of mast cell proteases, and generally priming the mast cells response in an allergic environment (120). Th9 cells can be identified in the peripheral blood of allergic patients and in healthy and inflamed skin (123). The stability of Th9 cells in vivo is a contested matter; however, the recent development of an IL-9 fluorescent reporter mouse will aid in studies designed to address this issue. There is still much to be learned about Th9 cells, both in general and in the context of allergic disease. Further characterization of this subset and increased knowledge of its role in allergic disease is important to our understanding of the mechanisms involved in allergic disease and chemical sensitization.

Another newly characterized $\mathrm{T}$ cell subset thought to play a role in allergic disease is the Th22 subset. Th22 cells are identified by production of IL-22 and their differentiation and activation depends on engagement of the aryl hydrocarbon receptor (AHR), leading to an increase in IL-22 production and Th22 expansion (124). Along with allergic disease, Th22 cells have been implicated in arthritis, autoimmunity, cancer, and infection. IL-22 levels are increased in the skin of patients with atopic dermatitis, allergic contact dermatitis, and allergic asthma (124). In a murine model of ovalbumin-induced allergic asthma, the external addition of IL-22 results in decreased asthmatic symptoms, implicating this cytokine as a protective factor in asthma which may be mediated through the inhibition of CCL17 and IL-25 from lung epithelial cells (124). Much remains to be investigated 
regarding the role of Th22 cells in allergic disease, including the overall role of this cell type, the specific effector mechanisms involved in modulating allergic disease, and the potential interaction with additional cell types with recognized involvement in allergic disease.

Humoral immunity plays an important part in many immune responses, including multiple types of allergic disease. While B cells and antibody production are the main effector molecules involved in this type of immune reaction, $\mathrm{T}$ cells are known to be a prerequisite for the development of humoral immunity in many situations. $\mathrm{T}_{\mathrm{FH}}$ cells are a recently characterized $\mathrm{T}$ cell subset that are named based on their presence in germinal centers within B cell follicles of secondary lymphoid organs, where they exert their effector function of aiding the development of B cell antibody responses. $\mathrm{T}_{\mathrm{FH}}$ cells are considered imperative for the generation of almost all isotype switched and affinity matured antibodies, demonstrating their significant role in a variety of immune responses including allergy, autoimmunity, vaccine-induced immunity, and protective responses against pathogens (125). Regarding allergy, $\mathrm{T}_{\mathrm{FH}}$ cells have been loosely implicated in the pathogenesis of allergic protein-induced asthma, highlighted in a recent work illustrating the role of $\mathrm{T}_{\mathrm{FH}}$ cells in the process of IL-4 and IL-13 production and eosinophil recruitment, contributing to the overall pathogenesis of house dust mite antigen-induced asthma (126). Further emphasizing the integral role for $\mathrm{T}_{\mathrm{FH}}$ cells in the development of allergic asthma, $\mathrm{T}_{\mathrm{FH}}$ depletion during the sensitization phase of the response prevented Th2-mediated responses in a house dust mite allergy model (assessed via Th2 allergic cytokine expression) (126). This study demonstrates the important role of $\mathrm{T}_{\mathrm{FH}}$ cells in the development of Th2 responses during sensitization to protein allergens and in the overall pathogenesis of allergic asthma. The role of this subset should be further investigated in additional models of allergic disease, including skin disorders and chemical-induced allergy. This data may 
also help to elucidate the role of B cells and antibody in chemical sensitization, which is currently contested for sensitizers such as TDI.

Lastly, NKT cells are a unique subset of $\mathrm{T}$ cells that exhibit features of both $\mathrm{T}$ cells and natural killer cells. NKT cells express the $\alpha \beta \mathrm{T}$ cell receptor and can be single positive or double negative for CD4 and/or CD8 (127). These cells also express an invariant TCR (iTCR) and recognize glycolipid antigens via CD1d on APCs, bypassing the traditional MHC-mediated antigen presentation strategy utilized by other T cell subsets (127). iTCR activation results in rapid and large-scale production of cytokines like IFN- $\gamma$ and IL-4 (127), allowing these cells to participate in innate immune responses and help initiate adaptive responses. NKT cells have been shown to play a part in a variety of disease states, including allergic disease, autoimmunity, infection responses, systemic lupus erythematosus, and transplant tolerance (127). In the context of allergy, NKT cells have been implicated as key players most likely due to their ability to rapidly secrete large amounts of effector cytokines. Specifically, studies have solidified their pathogenic role in animal models of airway hyperreactivity and human patients with asthma, even demonstrating that NKT cells alone are sufficient to induce airway hyperreactivity following a glycolipid challenge in a murine model (127). Chemical-induced delayed type hypersensitivity skin reactions are partially mediated by NKT cells, which stimulate B-1 cells to produce IgM, leading to T cell recruitment to participate in the hypersensitivity response (128). Further research on natural ligands of the iTCR, therapeutic targeting of NKT cells, and methods of NKT activation and effector mechanisms are necessary in order to fully understand the mechanisms responsible for NKT cell involvement in allergic diseases.

NKT cells represent a class of cells that primarily exert their effector mechanism during the innate phase of the immune response, leading to the development of an adaptive response. Innate lymphoid cells (ILCs) are another class of cells in this same functional categorization, encompassing 
the innate response and helping to initiate the adaptive one. ILCs are non-T, non-B cells that do not possess rearranged antigen-specific receptors; they participate in innate reactions in response to a large range of innate signals (129). ILCs are classified based on their phenotype and effector functions, and the current classification scheme is reflective of the $\mathrm{CD}^{+}$Th paradigm in the context of Th1, Th2, Th17, and Th22 cells. The commonalities between ILCs and CD4 ${ }^{+}$Th cells are fascinating and illustrate the worlds of innate and adaptive immunity, which coexist both uniquely and synergistically, influencing each other yet performing separate functions via unique mechanisms. Current ILC subclasses include natural killer (NK) cells, ILC1s, ILC2s, and ILC3s. NK cells produce IFN- $\gamma$, express tbet, and exhibit cytolytic activity (129). Based on these functional attributes, NK cells have been implicated in innate viral defense, tumor surveillance, and both organ and hematopoietic stem cell transplantation (130). ILC1s are related to NK cells, which is evident based on their production of IFN- $\gamma$ and expression of tbet, but are distinct as they do not express granzyme B, killer-cell immunoglobulin-like receptors, nor perforin, and they respond to IL-7 rather than IL-15 (129). ILC1s are involved in inflammatory responses, including pathogen defense. ILC2s have been called nuocytes or natural helper cells, required ror $\alpha$ and gata3 transcription factors for their expression, they produce IL-5, IL-9, and IL-13 (129), explaining their involvement in helminth infection and allergy. ILC3s require roryt and gata3 transcription factors for their development and are divided into several subtypes. Overall, ILC3s can produce IL-17 and IL-22 and may be involved in lymphoid organogenesis, host defense at mucosal sites, and inflammatory and allergic diseases (129).

ILC2s are the ILC subtype most commonly associated with allergic disease. Initially this subset was described fairly rudimentarily, as a non-T not B cell subset associated with a Th2 response; later, this subset was further investigated and was found to express CD25 (high affinity 
IL-2 receptor $\alpha$ ), CD90 (Thy1), CD117 (c-kit), CD127 (IL-7 receptor $\alpha$ ), CD278 (Inducible T-cell costimulator (ICOS)), ST2 (IL-33 receptor), and IL-17 receptor $\beta$ and to produce IL-5 and IL-13 in response to IL-25 and IL-33 (129). ILC2s increase during helminth infections, inflammatory lung disease, and allergic conditions, and proliferate in response to pathogenic insults. In a murine model of OVA-induced allergic asthma, ILC2-derived IL-33 was found to be important for maintenance of allergic cytokine secretion, inflammatory, and airway hyperreactivity, although not as important as Th2 responses (129). Ultimately, ILC2s have been shown to be present and involved in models of allergic lung disease as well as in human patients; however, it remains to be seen whether these cells are absolutely required for the development and maintenance of these conditions. ILC1 and ILC3s may also have specific roles in allergic disease; however, they have not been studied extensively in this context. Further study of all subtypes of ILCs in the realm of allergic disease and chemical sensitization will greatly contribute to our understanding of the mechanisms responsible for these conditions and potential therapeutic strategies for allergic diseases. The scarcity of research regarding the role of ILCs in chemical-induced allergy is striking and as more experimental tools are available to facilitate the study of these cells they should be characterized in relevant models of chemical-induced asthma and skin disease, as they likely play important roles in these conditions.

Epigenetic mechanisms are commonly defined as alterations in gene expression due to changes in DNA binding elements (which can be influenced by environmental factors) as opposed to changes in the basic DNA sequence (131). These mechanisms include DNA methylation, histone modification, and noncoding RNA regulation. Yang and Schwartz suggest that epigenetic changes may be at least partially responsible for the recent increasing prevalence of asthma. In a related murine study, Th2 cytokine genes (such as IL-4, -5 , and -13) and the pathogenesis of allergic asthma were shown to be regulated by the Th2 locus control region (LCR), involving histone modification 
and DNA methylation (132). Numerous studies have demonstrated the link between histone modification and DNA methylation and allergic asthma in animal models. There have also been demonstrations of the link between miRNAs and allergic asthma, which will be discussed below. In human studies, the statistical association between epigenetic elements including DNA methylation, histone modification, and noncoding RNAs and asthma has been demonstrated (131); however, there remains much ground to be covered in the investigation of these components of allergic disease and the study of epigenetics itself is complicated by many factors such as diet, environmental influences, in utero exposures, aging, and comorbidities.

Noncoding RNA elements such as microRNAs (miRNA), transfer RNAs, small interfering RNAs, ribosomal RNAs, and long noncoding RNAs (lncRNA) are molecules that have exhibited great regulatory potential in a variety of conditions and models. Many of these noncoding RNA structures have been shown to exhibit particular functions, contributing to homeostasis, regulatory processes, and a variety of disease states. Recently the perspective on eukaryotic noncoding RNAs has shifted from that of performing generic cellular functions (for example: ribosomal and transfer RNA involved in mRNA translation, small nuclear RNAs involved in RNA splicing, and small nucleolar RNAs involved in ribosomal RNA modification) to performing diverse regulatory and biological functions normally reserved for proteins (133). These RNA molecules are not translated into protein like messenger RNA (mRNA) typically would be. Noncoding RNAs can exert functional effects by regulation of gene expression during chromatin remodeling, transcription, RNA splicing, editing, translation, and turnover (133). Specifically, regulatory RNA molecules function by base paring with complementary sequences on other RNAs or DNAs to form complexes that are recognized by RNA-induced silencing complexes (RISCs) or RNA-editing enzymes (133). The role of miRNAs in allergic disease has been demonstrated in a number of studies including the elucidation 
of the role of miR-126 in a model of house dust mite allergy and miR-145 in eosinophilic inflammation, mucus production, and Th2 cytokine production. The functional role of noncoding RNA molecules in chemical sensitization and allergy has not been investigated. Anderson et al. investigated the global dLN miRNA expression profile in a murine model of dermal TDI sensitization (134); however, the specific roles for these differentially expressed miRNAs were not identified. Pertinent functional investigations are carried out in Chapter 4.

\subsection{CONCLUSIONS}

The burden of occupational allergic disease is widespread. Occupational allergic conditions are multifactorial and are the result of complicated immunologic events. As illustrated in Section 1.1, a plethora of allergic diseases can be caused by workplace exposures to both protein and chemical allergens. Although Gell and Coombs hypersensitivity classification is helpful in the description of the mechanisms of many allergic reactions, this system is not fully inclusive. Many allergic reactions, especially those precipitated by drug and chemical exposures cannot be comprehensively defined within the constraints of this classification system. This illustrates the need for increased research pertaining to the mechanisms behind sensitization and allergic disease as well as the development of updated hypersensitivity classifications.

Chemical sensitizers are utilized in virtually every industry worldwide. Typically these compounds are LMW molecules that are known as dermal or respiratory sensitizers, depending on the route of sensitization. Although this classification typically predicts the type of allergic response induced (Th1 vs Th2, respectively), this paradigm is not always valid. Many chemical sensitizers can induce sensitization via dermal and respiratory routes and/or induce a mixed $\mathrm{Th} 1 / \mathrm{Th} 2$ response. Furthermore, there are no validated hazard identification assays for respiratory sensitizers. The 
perennial question of "what makes a chemical an allergen" is persistently asked and may be answered with diligent and focused mechanistic research. This inquiry is given greater weight due to the current focus on developing in vitro assays for the identification of chemical sensitizers. The identification of novel mechanisms of allergic disease is paramount to the objective of answering the questions of what makes a chemical and allergen and what are the immunologic events that differentiate contact and respiratory allergens. Furthermore, the investigation of innate events preceding full sensitization such as danger signals, cytokine and chemokine signaling, and APC phenotype and function is also necessary to answer this question.

As exemplified above, the discovery of novel mechanisms of allergic disease, specifically relating to chemical sensitization, is necessary to further the development of preventative and therapeutic strategies to combat allergic disease. Having a more complete view of the immunologic events taking place during both sensitization and elicitation will be achieved by investigating novel cellular subsets and players potentially involved in these events. There are numerous "suspects" in this regard as mentioned above; however, many of these have not been investigated in chemical allergy. The role of $\mathrm{T}_{\text {regs }}$ and miRNAs are explored in this work yet these represent only a fraction of the immunological players involved. Optimistically, the discovery of novel players will broaden the general classification schemes and views of chemical allergy as a whole. This could represent a paradigm shift that may greatly improve allergy research and understanding by clinicians, toxicologists, basic researchers, students, etc. 


\subsection{REFERENCES}

1. Anderson, S. E., and B. J. Meade. 2014. Potential Health Effects Associated with Dermal Exposure to Occupational Chemicals. Environmental Health Insights: 51-62.

2. Pralong, J. A., A. Cartier, O. Vandenplas, and M. Labrecque. 2012. Occupational asthma: new low-molecular-weight causal agents, 2000-2010. Journal of allergy 2012: 597306.

3. Dotson, G. S., A. Maier, P. D. Siegel, S. E. Anderson, B. J. Green, A. B. Stefaniak, C. D. Codispoti, and I. Kimber. 2015. Setting Occupational Exposure Limits for Chemical Allergens-Understanding the Challenges. Journal of occupational and environmental hygiene 12 Suppl 1: S82-98.

4. Sasseville, D. 2008. Occupational Contact Dermatitis. Allergy, Asthma, and Clinical Immunology : Official Journal of the Canadian Society of Allergy and Clinical Immunology 4: 59-65.

5. Cashman, M. W., P. A. Reutemann, and A. Ehrlich. 2012. Contact dermatitis in the United States: epidemiology, economic impact, and workplace prevention. Dermatologic clinics 30: 87-98, viii.

6. Meca, O., M.-J. Cruz, M. Sánchez-Ortiz, F.-J. González-Barcala, I. Ojanguren, and X. Munoz. 2016. Do Low Molecular Weight Agents Cause More Severe Asthma than High Molecular Weight Agents? PLoS ONE 11: e0156141.

7. Macan, J., B. Kanceljak-Macan, and S. Milkovic-Kraus. 2012. Pyroglyphid mites as a source of work-related allergens. Arhiv za higijenu rada i toksikologiju 63 Suppl 1: 5766.

8. Jin, H. J., J.-E. Kim, J.-H. Kim, Y.-M. Ye, and H.-S. Park. 2011. New Sensitization to House Dust Mites in Cefteram-Induced Occupational Asthma: A Case Report. Allergy, Asthma \& Immunology Research 3: 132-134.

9. Barbaud, A., C. Poreaux, E. Penven, and J. Waton. 2015. Occupational protein contact dermatitis. European journal of dermatology : EJD.

10. Peden, D., and C. E. Reed. 2010. Environmental and occupational allergies. The Journal of allergy and clinical immunology 125: S150-160.

11. Stern, A., B. Wuthrich, and G. Mullner. 2000. Successful treatment of occupational allergy to bumblebee venom after failure with honeybee venom extract. Allergy 55: 8891.

12. Mapp, C. E. 2001. Agents, Old and New, Causing Occupational Asthma. Occupational and Environmental Medicine 58: 354-354.

13. Martin, S. F., P. R. Esser, F. C. Weber, T. Jakob, M. A. Freudenberg, M. Schmidt, and M. Goebeler. 2011. Mechanisms of chemical-induced innate immunity in allergic contact dermatitis. Allergy 66: 1152-1163.

14. Frimat, P., W. Boughattas, and D. Even. 2015. Atopic dermatitis: professional orientation. European journal of dermatology : EJD 25: 3-6.

15. Coombs, P. G. H. G. a. R. R. A. 1963. The classification of allergic reactions underlying disease. In Clinical Aspects of Immunology. P. G. H. Gell, ed. Blackwell, Oxford.

16. Stone, K. D., C. Prussin, and D. D. Metcalfe. 2010. IgE, Mast Cells, Basophils, and Eosinophils. The Journal of allergy and clinical immunology 125: S73-S80.

17. Kindt, T. J., R. A. Goldsby, B. A. Osborne, and J. Kuby. 2007. Kuby Immunology. W. H. Freeman. 
18. Rajan, T. V. 2003. The Gell-Coombs classification of hypersensitivity reactions: a reinterpretation. Trends in immunology 24: 376-379.

19. Descotes, J., and G. Choquet-Kastylevsky. 2001. Gell and Coombs's classification: is it still valid? Toxicology 158: 43-49.

20. Katzung, B. G., S. B. Masters, and A. J. Trevor. 2012. Basic \& clinical pharmacology. McGraw-Hill Medical ; McGraw-Hill [distributor], New York; London.

21. Chipinda, I., J. M. Hettick, and P. D. Siegel. 2011. Haptenation: chemical reactivity and protein binding. Journal of allergy 2011: 839682.

22. Schmidt, M., and M. Goebeler. 2015. Immunology of metal allergies. Journal der Deutschen Dermatologischen Gesellschaft = Journal of the German Society of Dermatology : JDDG 13: 653-660.

23. Budinger, L., and M. Hertl. 2000. Immunologic mechanisms in hypersensitivity reactions to metal ions: an overview. Allergy 55: 108-115.

24. Pichler, W. J., A. Beeler, M. Keller, M. Lerch, S. Posadas, D. Schmid, Z. Spanou, A. Zawodniak, and B. Gerber. 2006. Pharmacological interaction of drugs with immune receptors: the p-i concept. Allergology international : official journal of the Japanese Society of Allergology 55: 17-25.

25. Moulon, C., J. Vollmer, and H. U. Weltzien. 1995. Characterization of processing requirements and metal cross-reactivities in $\mathrm{T}$ cell clones from patients with allergic contact dermatitis to nickel. European journal of immunology 25: 3308-3315.

26. Ainscough, J. S., G. Frank Gerberick, R. J. Dearman, and I. Kimber. 2013. Danger, intracellular signaling, and the orchestration of dendritic cell function in skin sensitization. Journal of immunotoxicology 10: 223-234.

27. Aalto-Korte, K., M.-L. Henriks-Eckerman, O. Kuuliala, and R. Jolanki. 2010. Occupational methacrylate and acrylate allergy - cross-reactions and possible screening allergens. Contact Dermatitis 63: 301-312.

28. Quirce, S., M. L. Baeza, P. Tornero, A. Blasco, R. Barranco, and J. Sastre. 2001. Occupational asthma caused by exposure to cyanoacrylate. Allergy 56: 446-449.

29. Kanerva, L., T. Estlander, and R. Jolanki. 1996. Occupational allergic contact dermatitis caused by 2,4,6-tris-(dimethylaminomethyl)phenol, and review of sensitizing epoxy resin hardeners. International journal of dermatology 35: 852-856.

30. Zeiss, C. R. 2002. Advances in acid anhydride induced occupational asthma. Current opinion in allergy and clinical immunology 2: 89-92.

31. Helaskoski, E., O. Kuuliala, and K. Aalto-Korte. 2009. Occupational contact urticaria caused by cyclic acid anhydrides. Contact Dermatitis 60: 214-221.

32. Gannon, P. F., P. Bright, M. Campbell, S. P. O'Hickey, and P. S. Burge. 1995. Occupational asthma due to glutaraldehyde and formaldehyde in endoscopy and $\mathrm{x}$ ray departments. Thorax 50: 156-159.

33. Fowler, J. F., Jr., S. M. Skinner, and D. V. Belsito. 1992. Allergic contact dermatitis from formaldehyde resins in permanent press clothing: an underdiagnosed cause of generalized dermatitis. Journal of the American Academy of Dermatology 27: 962-968.

34. Franko, J., L. G. Jackson, A. Hubbs, M. Kashon, B. J. Meade, and S. E. Anderson. 2012. Evaluation of furfuryl alcohol sensitization potential following dermal and pulmonary exposure: enhancement of airway responsiveness. Toxicological sciences : an official journal of the Society of Toxicology 125: 105-115. 
35. Blomqvist, A. M., I. G. Axelsson, D. Danielsson, J. Kiviloog, A. Ulander, and O. Zetterstrom. 1991. Atopic allergy to chloramine-T and the demonstration of specific IgE antibodies by the radioallergosorbent test. International archives of occupational and environmental health 63: 363-365.

36. Quirce, S., and P. Barranco. 2010. Cleaning agents and asthma. Journal of investigational allergology \& clinical immunology 20: 542-550; quiz 542p following 550.

37. Shaffer, M. P., and D. V. Belsito. 2000. Allergic contact dermatitis from glutaraldehyde in health-care workers. Contact Dermatitis 43: 150-156.

38. Robitaille, C., and L.-P. Boulet. 2015. Occupational asthma after exposure to orthophthalaldehyde (OPA). Occupational and Environmental Medicine.

39. Damstra, R. J., W. A. van Vlotten, and C. J. van Ginkel. 1992. Allergic contact dermatitis from the preservative 1,2-benzisothiazolin-3-one (1,2-BIT; Proxel): a case report, its prevalence in those occupationally at risk and in the general dermatological population, and its relationship to allergy to its analogue Kathon CG. Contact Dermatitis 27: 105109.

40. Mathias, C. G. 1997. Allergic contact dermatitis from a lawn care fungicide containing dyrene. American journal of contact dermatitis : official journal of the American Contact Dermatitis Society 8: 47-48.

41. Vally, H., and N. L. A. Misso. 2012. Adverse reactions to the sulphite additives. Gastroenterology and Hepatology From Bed to Bench 5: 16-23.

42. Bourke, S. J., R. P. Convery, S. C. Stenton, R. M. Malcolm, and D. J. Hendrick. 1997. Occupational asthma in an isothiazolinone manufacturing plant. Thorax 52: 746-748.

43. Quenan, S., P. Piletta, and A. M. Calza. 2015. Isothiazolinones: sensitizers not to miss in children. Pediatric dermatology 32: e86-88.

44. Purohit, A., M. C. Kopferschmitt-Kubler, C. Moreau, E. Popin, M. Blaumeiser, and G. Pauli. 2000. Quaternary ammonium compounds and occupational asthma. International archives of occupational and environmental health 73: 423-427.

45. Mowad, C. M. 2001. Cocamidopropyl betaine allergy. American journal of contact dermatitis : official journal of the American Contact Dermatitis Society 12: 223-224.

46. Larsen, W. G. 1985. Perfume dermatitis. Journal of the American Academy of Dermatology 12: 1-9.

47. Storrs, F. J. 1984. Permanent wave contact dermatitis: contact allergy to glyceryl monothioglycolate. Journal of the American Academy of Dermatology 11: 74-85.

48. Williams, J. D., K. E. Frowen, and R. L. Nixon. 2007. Allergic contact dermatitis from methyldibromo glutaronitrile in a sanitary pad and review of Australian clinic data. Contact Dermatitis 56: 164-167.

49. Mowad, C. M. 2000. Allergic contact dermatitis caused by parabens: 2 case reports and a review. American journal of contact dermatitis : official journal of the American Contact Dermatitis Society 11: 53-56.

50. Hafeez, F., and H. Maibach. 2013. An overview of parabens and allergic contact dermatitis. Skin therapy letter 18: 5-7.

51. Gupta, M., V. K. Mahajan, K. S. Mehta, and P. S. Chauhan. 2015. Hair dye dermatitis and p-phenylenediamine contact sensitivity: A preliminary report. Indian Dermatology Online Journal 6: 241-246.

52. Parra, F. M., J. M. Igea, S. Quirce, M. C. Ferrando, J. A. Martin, and E. Losada. 1992. Occupational asthma in a hairdresser caused by persulphate salts. Allergy 47: 656-660. 
53. Kanerva, L., K. Alanko, R. Jolanki, K. Aalto-Korte, and T. Estlander. 1999. Occupational allergic contact dermatitis from potassium persulfate. Contact Dermatitis 40: 116-117.

54. Innocenti, A., A. Mariano, and M. Valiani. 1986. Occupational hexamethylene diisocyanate (HDI) asthma. La Medicina del lavoro 77: 191-194.

55. Morgan, C. J., and A. E. Haworth. 2003. Allergic contact dermatitis from 1,6hexamethylene diisocyanate in a domestic setting. Contact Dermatitis 48: 224.

56. Hannu, T., T. Estlander, and R. Jolanki. 2005. Allergic contact dermatitis due to MDI and MDA from accidental occupational exposure. Contact Dermatitis 52: 108-109.

57. Padoan, M., V. Pozzato, M. Simoni, L. Zedda, G. Milan, I. Bononi, C. Piola, P. Maestrelli, P. Boschetto, and C. E. Mapp. 2003. Long-term follow-up of toluene diisocyanate-induced asthma. The European respiratory journal 21: 637-640.

58. Bello, D., C. A. Herrick, T. J. Smith, S. R. Woskie, R. P. Streicher, M. R. Cullen, Y. Liu, and C. A. Redlich. 2007. Skin exposure to isocyanates: reasons for concern. Environmental health perspectives 115: 328-335.

59. Sartorelli, P., P. Pistolesi, F. Cioni, R. Napoli, A. G. Sisinni, L. Bellussi, G. C. Passali, E. Cherubini Di Simplicio, and L. Flori. 2003. [Skin and respiratory allergic disease caused by polyfunctional aziridine]. La Medicina del lavoro 94: 285-295.

60. Ingram, J. R., T. M. Hughes, and N. M. Stone. 2008. Occupational allergic contact dermatitis to polyfunctional aziridine crosslinker in a 'tufter'. Contact Dermatitis 58: 172173.

61. Piirila, P., T. Estlander, H. Keskinen, R. Jolanki, A. Laakkonen, P. Pfaffli, O. Tupasela, M. Tuppurainen, and H. Nordman. 1997. Occupational asthma caused by triglycidyl isocyanurate (TGIC). Clinical and experimental allergy : journal of the British Society for Allergy and Clinical Immunology 27: 510-514.

62. Wigger-Alberti, W., M. Hofmann, and P. Elsner. 1997. Contact dermatitis caused by triglycidyl isocyanurate. American journal of contact dermatitis : official journal of the American Contact Dermatitis Society 8: 106-107.

63. Hannu, T., H. Frilander, P. Kauppi, O. Kuuliala, and K. Alanko. 2009. IgE-mediated occupational asthma from epoxy resin. International archives of allergy and immunology 148: 41-44.

64. Romyhr, O., A. Nyfors, H. L. Leira, and H. T. Smedbold. 2006. Allergic contact dermatitis caused by epoxy resin systems in industrial painters. Contact Dermatitis 55: 167-172.

65. Martin-Gorgojo, A., and J. D. Johansen. 2013. Contact dermatitis caused by iodopropynyl butylcarbamate in Denmark. Contact Dermatitis 69: 78-85.

66. Lear, J. T., and J. S. English. 1996. Hand involvement in allergic contact dermatitis from mercaptobenzothiazole in shoes. Contact Dermatitis 34: 432.

67. Kohli, N., and S. Habbal. 2010. Occupational allergic contact dermatitis due to thioureas. Dermatitis : contact, atopic, occupational, drug 21: E5-6.

68. Munk, R., D. Sasseville, P. D. Siegel, B. F. Law, and L. Moreau. 2013. Thiurams in shoe contact dermatitis - a case series. Contact dermatitis 68: 185-187.

69. Cao, L. Y., J. S. Taylor, A. Sood, D. Murray, and P. D. Siegel. 2010. Allergic contact dermatitis to synthetic rubber gloves: Changing trends in patch test reactions to accelerators. Archives of Dermatology 146: 1001-1007. 
70. Kiec-Swierczynska, M., B. Krecisz, and D. Swierczynska-Machura. 2007. [Contact allergy to paraphenylenediamine: a 10-year observation held in the Nofer Institute of Occupational Medicine, Lodz]. Medycyna pracy 58: 215-222.

71. Nayak, A. P., J. M. Hettick, P. D. Siegel, S. E. Anderson, C. M. Long, B. J. Green, and D. H. Beezhold. 2014. Toluene diisocyanate (TDI) disposition and co-localization of immune cells in hair follicles. Toxicological sciences : an official journal of the Society of Toxicology 140: 327-337.

72. van Ree, R., L. Hummelshoj, M. Plantinga, L. Poulsen, and E. Swindle. 2014. Allergic sensitization: host-immune factors. Clinical and Translational Allergy 4: 12.

73. Landsteiner, K., and J. Jacobs. 1935. STUDIES ON THE SENSITIZATION OF ANIMALS WITH SIMPLE CHEMICAL COMPOUNDS. The Journal of Experimental Medicine 61: 643-656.

74. Kohler, J., S. Martin, U. Pflugfelder, H. Ruh, J. Vollmer, and H. U. Weltzien. 1995. Cross-reactive trinitrophenylated peptides as antigens for class II major histocompatibility complex-restricted T cells and inducers of contact sensitivity in mice. Limited T cell receptor repertoire. European journal of immunology 25: 92-101.

75. Bernstein, J. A. 1996. Overview of diisocyanate occupational asthma. Toxicology 111: 181-189.

76. Kimber, I., and R. J. Dearman. 2005. What makes a chemical a respiratory sensitizer? Current opinion in allergy and clinical immunology 5: 119-124.

77. Dearman, R. J., D. A. Basketter, and I. Kimber. 1996. Characterization of chemical allergens as a function of divergent cytokine secretion profiles induced in mice. Toxicology and applied pharmacology 138: 308-316.

78. Lalko, J. F., I. Kimber, G. F. Gerberick, L. M. Foertsch, A. M. Api, and R. J. Dearman. 2012. The Direct Peptide Reactivity Assay: Selectivity of Chemical Respiratory Allergens. Toxicological Sciences 129: 421-431.

79. Jarvis, J., M. J. Seed, R. Elton, L. Sawyer, and R. Agius. 2005. Relationship between chemical structure and the occupational asthma hazard of low molecular weight organic compounds. Occup Environ Med 62: 243-250.

80. Basketter, D. A., and I. Kimber. 2016. Phthalic anhydride: Illustrating a conundrum in chemical allergy. Journal of immunotoxicology: 1-3.

81. Hopkins, J. E., D. J. Naisbitt, N. R. Kitteringham, R. J. Dearman, I. Kimber, and B. K. Park. 2005. Selective haptenation of cellular or extracellular protein by chemical allergens: association with cytokine polarization. Chemical research in toxicology 18: 375-381.

82. Enoch, S. J., D. W. Roberts, and M. T. Cronin. 2009. Electrophilic reaction chemistry of low molecular weight respiratory sensitizers. Chemical research in toxicology 22: 14471453.

83. Cumberbatch, M., K. Clelland, R. J. Dearman, and I. Kimber. 2005. Impact of cutaneous IL-10 on resident epidermal Langerhans' cells and the development of polarized immune responses. Journal of immunology (Baltimore, Md. : 1950) 175: 43-50.

84. Chapman, V. L., T. Zollinger, R. Terranova, J. Moggs, I. Kimber, and R. J. Dearman. 2014. Chemical allergen induced perturbations of the mouse lymph node DNA methylome. Toxicological sciences : an official journal of the Society of Toxicology 139: 350-361. 
85. Dearman, R. J., and I. Kimber. 1991. Differential stimulation of immune function by respiratory and contact chemical allergens. Immunology 72: 563-570.

86. Kimber, I., and R. J. Dearman. 1992. The mechanisms and evaluation of chemically induced allergy. Toxicology letters 64-65 Spec No: 79-84.

87. Anderson, S. E., P. D. Siegel, and B. J. Meade. 2011. The LLNA: A Brief Review of Recent Advances and Limitations. Journal of allergy 2011: 424203.

88. Boverhof, D. R., R. Billington, B. B. Gollapudi, J. A. Hotchkiss, S. M. Krieger, A. Poole, C. M. Wiescinski, and M. R. Woolhiser. 2008. Respiratory sensitization and allergy: current research approaches and needs. Toxicology and applied pharmacology 226: 1-13.

89. Frankild, S., A. Volund, J. E. Wahlberg, and K. E. Andersen. 2000. Comparison of the sensitivities of the Buehler test and the guinea pig maximization test for predictive testing of contact allergy. Acta dermato-venereologica 80: 256-262.

90. Kimber, I., D. A. Basketter, K. Berthold, M. Butler, J. L. Garrigue, L. Lea, C. Newsome, R. Roggeband, W. Steiling, G. Stropp, S. Waterman, and C. Wiemann. 2001. Skin sensitization testing in potency and risk assessment. Toxicological sciences : an official journal of the Society of Toxicology 59: 198-208.

91. Kimber, I., J. Hilton, R. J. Dearman, G. F. Gerberick, C. A. Ryan, D. A. Basketter, L. Lea, R. V. House, G. S. Ladics, S. E. Loveless, and K. L. Hastings. 1998. Assessment of the skin sensitization potential of topical medicaments using the local lymph node assay: an interlaboratory evaluation. Journal of toxicology and environmental health. Part A 53: 563-579.

92. Loveless, S. E., G. S. Ladics, G. F. Gerberick, C. A. Ryan, D. A. Basketter, E. W. Scholes, R. V. House, J. Hilton, R. J. Dearman, and I. Kimber. 1996. Further evaluation of the local lymph node assay in the final phase of an international collaborative trial. Toxicology 108: 141-152.

93. Dean, J. H., L. E. Twerdok, R. R. Tice, D. M. Sailstad, D. G. Hattan, and W. S. Stokes. 2001. ICCVAM evaluation of the murine local lymph node assay. Conclusions and recommendations of an independent scientific peer review panel. Regulatory toxicology and pharmacology : RTP 34: 258-273.

94. Kimber, I., D. A. Basketter, G. F. Gerberick, C. A. Ryan, and R. J. Dearman. 2011. Chemical allergy: translating biology into hazard characterization. Toxicological sciences : an official journal of the Society of Toxicology 120 Suppl 1: S238-268.

95. Montelius, J., H. Wahlkvist, A. Boman, and J. E. Wahlberg. 1998. Murine local lymph node assay for predictive testing of allergenicity: two irritants caused significant proliferation. Acta dermato-venereologica 78: 433-437.

96. Chipinda, I., R. O. Ajibola, M. K. Morakinyo, T. B. Ruwona, R. H. Simoyi, and P. D. Siegel. 2010. Rapid and simple kinetics screening assay for electrophilic dermal sensitizers using nitrobenzenethiol. Chemical research in toxicology 23: 918-925.

97. Gerberick, G. F., J. D. Vassallo, R. E. Bailey, J. G. Chaney, S. W. Morrall, and J.-P. Lepoittevin. 2004. Development of a Peptide Reactivity Assay for Screening Contact Allergens. Toxicological Sciences 81: 332-343.

98. ECVAM. 2012. Direct peptide reactivity assay (DPRA) validation study report. E. U. R. Library, ed. European Union, Ispra, Italy. 74.

99. OECD. Test No. 442C: In Chemico Skin Sensitisation. OECD Publishing. 
100. Boverhof, D. R., B. B. Gollapudi, J. A. Hotchkiss, M. Osterloh-Quiroz, and M. R. Woolhiser. 2010. A draining lymph node assay (DLNA) for assessing the sensitizing potential of proteins. Toxicology letters 193: 144-151.

101. Dearman, R. J., C. J. Betts, N. Humphreys, B. F. Flanagan, N. J. Gilmour, D. A. Basketter, and I. Kimber. 2003. Chemical Allergy: Considerations for the Practical Application of Cytokine Profiling. Toxicological Sciences 71: 137-145.

102. Dearman, R. J., D. A. Basketter, and I. Kimber. 1992. Variable effects of chemical allergens on serum IgE concentration in mice. Preliminary evaluation of a novel approach to the identification of respiratory sensitizers. Journal of applied toxicology: JAT 12: 317-323.

103. Manetz, T. S., and B. J. Meade. 1999. Development of a flow cytometry assay for the identification and differentiation of chemicals with the potential to elicit irritation, IgEmediated, or T cell-mediated hypersensitivity responses. Toxicological sciences : an official journal of the Society of Toxicology 48: 206-217.

104. Gerberick, G. F., L. W. Cruse, C. A. Ryan, B. C. Hulette, J. G. Chaney, R. A. Skinner, R. J. Dearman, and I. Kimber. 2002. Use of a B cell marker (B220) to discriminate between allergens and irritants in the local lymph node assay. Toxicological sciences : an official journal of the Society of Toxicology 68: 420-428.

105. Plitnick, L. M., S. E. Loveless, G. S. Ladics, M. P. Holsapple, R. J. Smialowicz, M. R. Woolhiser, P. K. Anderson, C. Smith, and M. J. Selgrade. 2003. Identifying airway sensitizers: cytokine mRNA profiles induced by various anhydrides. Toxicology 193: 191-201.

106. Plitnick, L. M., S. E. Loveless, G. S. Ladics, M. P. Holsapple, M. J. Selgrade, D. M. Sailstad, and R. J. Smialowicz. 2002. Cytokine profiling for chemical sensitizers: application of the ribonuclease protection assay and effect of dose. Toxicology and applied pharmacology 179: 145-154.

107. De Jong, W. H., J. H. Arts, A. De Klerk, M. A. Schijf, J. Ezendam, C. F. Kuper, and H. Van Loveren. 2009. Contact and respiratory sensitizers can be identified by cytokine profiles following inhalation exposure. Toxicology 261: 103-111.

108. Adenuga, D., M. R. Woolhiser, B. B. Gollapudi, and D. R. Boverhof. 2012. Differential gene expression responses distinguish contact and respiratory sensitizers and nonsensitizing irritants in the local lymph node assay. Toxicological sciences : an official journal of the Society of Toxicology 126: 413-425.

109. Cochrane, S. A., J. H. E. Arts, C. Ehnes, S. Hindle, H. M. Hollnagel, A. Poole, H. Suto, and I. Kimber. 2015. Thresholds in chemical respiratory sensitisation. Toxicology 333: 179-194.

110. Fleischel, O., E. Gimenez-Arnau, and J. P. Lepoittevin. 2009. Nuclear magnetic resonance studies on covalent modification of amino acids thiol and amino residues by monofunctional aryl 13C-isocyanates, models of skin and respiratory sensitizers: transformation of thiocarbamates into urea adducts. Chemical research in toxicology 22: 1106-1115.

111. Wisnewski, A. V., J. M. Hettick, and P. D. Siegel. 2011. Toluene diisocyanate reactivity with glutathione across a vapor/liquid interface and subsequent transcarbamoylation of human albumin. Chemical research in toxicology 24: 1686-1693. 
112. Johansson, H., A. S. Albrekt, C. A. Borrebaeck, and M. Lindstedt. 2013. The GARD assay for assessment of chemical skin sensitizers. Toxicology in vitro : an international journal published in association with BIBRA 27: 1163-1169.

113. Forreryd, A., H. Johansson, A. S. Albrekt, C. A. Borrebaeck, and M. Lindstedt. 2015. Prediction of chemical respiratory sensitizers using GARD, a novel in vitro assay based on a genomic biomarker signature. PLoS One 10: e0118808.

114. Eyerich, K., and S. Eyerich. 2015. Th22 cells in allergic disease. Allergo journal international 24: 1-7.

115. Cosmi, L., F. Liotta, E. Maggi, S. Romagnani, and F. Annunziato. 2011. Th17 cells: new players in asthma pathogenesis. Allergy 66: 989-998.

116. Oboki, K., T. Ohno, H. Saito, and S. Nakae. 2008. Th17 and Allergy. Allergology International 57: 121-134.

117. Kim, S. R., K. S. Lee, S. J. Park, K. H. Min, K. Y. Lee, Y. H. Choe, Y. R. Lee, J. S. Kim, S. J. Hong, and Y. C. Lee. 2007. PTEN Down-Regulates IL-17 Expression in a Murine Model of Toluene Diisocyanate-Induced Airway Disease. The Journal of Immunology 179: 6820-6829.

118. Albanesi, C., A. Cavani, and G. Girolomoni. 1999. IL-17 Is Produced by Nickel-Specific T Lymphocytes and Regulates ICAM-1 Expression and Chemokine Production in Human Keratinocytes: Synergistic or Antagonist Effects with IFN- $\gamma$ and TNF- $\alpha$. The Journal of Immunology 162: 494-502.

119. Nakae, S., Y. Komiyama, A. Nambu, K. Sudo, M. Iwase, I. Homma, K. Sekikawa, M. Asano, and Y. Iwakura. 2002. Antigen-Specific T Cell Sensitization Is Impaired in IL-17Deficient Mice, Causing Suppression of Allergic Cellular and Humoral Responses. Immunity 17: 375-387.

120. Vock, C., H.-P. Hauber, and M. Wegmann. 2010. The Other T Helper Cells in Asthma Pathogenesis. Journal of allergy 2010: 519298.

121. Schmitt, E., M. Klein, and T. Bopp. Th9 cells, new players in adaptive immunity. Trends in immunology 35: 61-68.

122. Jones, C. P., L. G. Gregory, B. Causton, G. A. Campbell, and C. M. Lloyd. 2012. Activin $A$ and TGF- $\beta$ promote $\mathrm{T}(\mathrm{H}) 9$ cell-mediated pulmonary allergic pathology. The Journal of allergy and clinical immunology 129: 1000-1010.e1003.

123. Kaplan, M. H. 2013. Th9 cells: differentiation and disease. Immunological reviews 252: 104-115.

124. Jia, L., and C. Wu. 2014. The biology and functions of Th22 cells. Advances in experimental medicine and biology 841: 209-230.

125. Crotty, S. T Follicular Helper Cell Differentiation, Function, and Roles in Disease. Immunity 41: 529-542.

126. Ballesteros-Tato, A., Troy D. Randall, Frances E. Lund, R. Spolski, Warren J. Leonard, and B. León. T Follicular Helper Cell Plasticity Shapes Pathogenic T Helper 2 CellMediated Immunity to Inhaled House Dust Mite. Immunity.

127. Stock, P., and O. Akbari. 2008. Recent advances in the role of NKT cells in allergic diseases and asthma. Current allergy and asthma reports 8: 165-170.

128. Campos, R. A., M. Szczepanik, A. Itakura, M. Akahira-Azuma, S. Sidobre, M. Kronenberg, and P. W. Askenase. 2003. Cutaneous Immunization Rapidly Activates Liver Invariant V 14 NKT Cells Stimulating B-1 B Cells to Initiate T Cell Recruitment 
for Elicitation of Contact Sensitivity. The Journal of Experimental Medicine 198: 17851796.

129. Yu, S., H. Y. Kim, Y. J. Chang, R. H. DeKruyff, and D. T. Umetsu. 2014. Innate lymphoid cells and asthma. The Journal of allergy and clinical immunology 133: 943950; quiz 951.

130. Vivier, E., E. Tomasello, M. Baratin, T. Walzer, and S. Ugolini. 2008. Functions of natural killer cells. Nature immunology 9: 503-510.

131. Yang, I. V., and D. A. Schwartz. 2012. Epigenetic mechanisms and the development of asthma. The Journal of allergy and clinical immunology 130: 1243-1255.

132. Koh, B. H., S. S. Hwang, J. Y. Kim, W. Lee, M. J. Kang, C. G. Lee, J. W. Park, R. A. Flavell, and G. R. Lee. 2010. Th2 LCR is essential for regulation of Th2 cytokine genes and for pathogenesis of allergic asthma. Proceedings of the National Academy of Sciences of the United States of America 107: 10614-10619.

133. Mattick, J. S., and I. V. Makunin. 2006. Non-coding RNA. Human Molecular Genetics 15: R17-R29.

134. Anderson, S. E., K. Beezhold, E. Lukomska, J. Richardson, C. Long, K. Anderson, J. Franko, B. J. Meade, and D. H. Beezhold. 2013. Expression kinetics of miRNA involved in dermal toluene 2,4-diisocyanate sensitization. Journal of immunotoxicology. 


\section{CHAPTER 2}

\section{Toluene Diisocyanate (TDI)}




\subsection{INTRODUCTION}

Isocyanates are a group of chemicals that contain at least one isocyanate group $(-\mathrm{N}=\mathrm{C}=\mathrm{O})$. These chemicals are utilized in a variety of industries due to their high reactivity. This characteristic is attributed primarily to their isocyanate side chains, which are capable of reacting with active hydrogen atoms, readily forming crosslinks (1). Common reactions of the isocyanate group encompass interactions with hydroxyls resulting in the formation of urethanes, with amines resulting in urea derivatives, and with water forming carbon dioxide and the corresponding amine (2). Isocyanates are primarily utilized in the manufacture of polyurethane and associated products and workers may be exposed in a variety of jobs, including: painting, polyurethane manufacture (factory/chemical plant) and foam application. Many isocyanates can cause allergic disease and some may also be carcinogenic (3). Commonly used diisocyanates include hexamethylene diisocyanate (HDI), methyl diphenyl diisocyanate (MDI), and toleuene diisocyanate (TDI). For the purposes of the work reported in this dissertation, TDI will be the primary focus due to its establishment in animal models of allergic disease, occupational relevance, and correlation with human allergic illness.

TDI is a low molecular weight diisocyanate utilized in the automobile industry and in the manufacture of polyurethane foams, paints, elastomers, and coatings. The two most common isomers of TDI are 2,4 and 2,6 which vary in the location of their isocyanate side groups; typically a mix of these isomers are utilized in a workplace setting. At room temperature TDI is a clear liquid with a pungent odor. Pure TDI will decompose in water but is very soluble in acetone and benzene and is miscible with additional chemicals (4). TDI is widely used throughout the United States and around the globe; the U.S. Environmental Protection Agency reports that U.S. production and importation of 2-4 and 2-6 TDI isomers rose above 1 billion pounds in 2006 (4). TDI is a potent 
allergen and irritant; dermal and inhalation exposure can lead to a variety of allergic diseases including asthma, hypersensitivity pneumonitis, rhinitis, and contact dermatitis $(1,5)$. These diseases can be disabling and extremely severe, potentially resulting in lifelong illness and/or death (6). TDI is generally classified as primarily a respiratory $(\operatorname{IgE} / \mathrm{Th} 2)$-mediated sensitizer with a $\mathrm{Th} 1$ mediated component (7), yet the pathogenic mechanisms of sensitization are not fully understood (8).

\subsection{OCCUPATIONAL EXPOSURE TO TDI}

As a result of its widespread industrial use and potent sensitizing capability, TDI is a major causative agent of occupational asthma $(1,9)$. Although exact worker exposure numbers are currently unknown, NIOSH has estimated that 280,000 US workers are potentially exposed to isocyanates (10) and this estimate has likely increased due to the recent increased industrial use of isocyanates (5). Both the respiratory tract and skin are documented sites of diisocyanate exposure, which can occur in aerosol, liquid, or vapor forms (11). Recently, the potential for dermal diisocyanate exposure leading to the elicitation of diisocyanate-induced asthma has been noted and there has been an increasing amount of data being released regarding this concept (5). This will be further addressed in Section 2.4. Due to its high volatility, TDI exposure may occur in all stages of manufacture and use; workers may be exposed to TDI during production, handling, and processing of TDI or during the production of products made with TDI such as foams and coated fabrics (4). Worker exposure has been confirmed via TDI adducts in the plasma and urine; toluene diamine, a hydrolysis product of TDI, has been measured in the plasma of exposed workers after acid hydrolysis as an alternate marker of exposure (4). It is difficult to monitor and control occupational TDI exposures due to the mixed species of TDI commonly used in workplaces along with the lack of 
well-defined exposure data (11). Despite gaps in the literature regarding TDI exposure it is clear that reduced exposure levels lead to lower cases of TDI-induced asthma.

Limiting the development and incidence of occupational allergic disease is key to maintaining the health, safety, and vitality of workers. One strategy utilized in the pursuit of this goal is the establishment of occupational exposure limits (OEL). The current TDI OEL set by the Occupational Safety and Health Administration (OSHA) is $0.02 \mathrm{ppm}$ (approximately $140 \mu \mathrm{g} / \mathrm{m}^{3}$ ) and $2.5 \mathrm{ppm}$ is considered Immediately Dangerous to Life and Health (IDLH). Workplace air concentrations can range from $<1$ to $>1,000 \mu \mathrm{g} / \mathrm{m}^{3}$, based on various reports (4). Typically these limits are set by risk assessors based on experimental data and human health studies (covering effects and exposures) encompassing carcinogenesis, portal of entry irritation, and systemic effects (12). Frequently OELs are not adequate for protecting workers from chemical-induced allergy due to limited human data and the complexity of the sensitization response. Several of the key challenges associated with setting OELs for chemical allergens are: selection of sensitization or elicitation to serve as the basis of the OEL, temporal factors involved in the allergic response, individual susceptibility and reaction to sensitization, and examination of the relevant routes of exposure (12). Furthermore, once sensitization has occurred, exposure to very low levels of TDI (below the accepted OELs) may elicit symptoms, making regulation extremely difficult (11). Asthmatic responses have been demonstrated in sensitized workers following inhalation challenge of $\leq 1-5$ parts per billion (ppb) TDI, which is at or below the current American Conference of Governmental Industrial Hygienists (ACGIH) threshold limit value time weighted average of 5 ppb (12). Clearly, prevention of sensitization is the ideal outcome of regulation; however, if this isn't feasible early diagnosis and removal from any exposure would be the best course of action for a sensitized worker. 


\subsection{TDI SENSITIZATION}

The TDI sensitization response is characterized by a tightly regulated and coordinated immune response involving a variety of cellular subsets and signaling molecules (13); however, much is still unknown regarding the immunologic events that take place following TDI exposure and during sensitization. Both dermal and respiratory sensitization are capable of priming the body for TDI asthma, highlighting the systemic nature of sensitization $(14,15)$. The realization that dermal sensitization may result in respiratory allergic disease has significant implications for risk management and preventative measures in the workplace, as skin protection may be just as, or more important than respiratory protection, which is discussed in further detail in Section 2.4.

In a typical T-cell mediated response involving dermal or respiratory exposure to a protein allergen, following access to the epithelium, allergen fragments are taken up by APCs. It is believed that LMW chemicals like TDI pass through the stratum corneum then form complexes with selfproteins, acquiring immunogenicity that is similar to that intrinsically exhibited by peptide fragments of protein allergens. Following APC-antigen uptake these specialized cells migrate to the lymphatics, particularly the dLNs, where the allergen fragments are presented to T cells via MHCmediated antigen presentation. This is thought to be the case for protein and chemical allergens. APC activation and mobilization are important events that may play an important part in the development of sensitization. These events are modulated primarily via increased local cytokine and chemokine expression such as caspase-1, IL-1 $\beta$, IL-18, and TNF- $\alpha$ along with danger signaling following chemical exposure in the case of sensitization precluding contact dermatitis in both humans and mice $(14,16)$. In mouse skin, three major types of dendritic cells are thought to be important APCs involved in chemical sensitization: Langerhans cells $\left(\right.$ Langerin $\left.^{+} \mathrm{CD} 103^{+}\right)$, and two subsets of dermal dendritic cells (Langerin ${ }^{-} \mathrm{CD} 103^{-}$and Langerin ${ }^{+} \mathrm{CD} 103^{-}$). This event causes $\mathrm{T}$ cells 
to proliferate and differentiate into a number of different $\mathrm{CD} 4^{+} \mathrm{T}$-helper (Th) and $\mathrm{CD} 8^{+}$effector subsets including Th1, Th2, Th17, $\mathrm{T}_{\text {reg, }}$, and cytotoxic $\mathrm{T}$ cells. In a chemical-induced contact dermatitis, preferential expansion of Th1, $\mathrm{T}_{\text {reg, }}$, and cytotoxic $\mathrm{CD} 8^{+}$cells is observed (16). These activated $\mathrm{T}$ cells can migrate through the lymphatics, blood, and local tissues; orchestrating an adaptive immune response against the allergen. This process characterizes the sensitization response and repeated exposures can cause the sensitized $\mathrm{T}$ cells to produce specific cytokines capable of skewing the immune response to a Th1/cytotoxic (contact dermatitis-dermal sensitizer) or Th2 (asthma-respiratory sensitizer) - mediated pathway. Th1 cells are characterized by production and secretion of interferon-y (IFN-y), IL-2, and tumor necrosis factor $\alpha$ (TNF- $\alpha$ ), while Th2 cells are characterized by production and secretion of IL-4, IL-5, IL-6, IL-10, and IL-13 (17). A mixed Th1/Th2 response is observed in both animal models and humans exposed to diisocyanates like TDI (18). Diisocyanate-specific T cells and Th1 and Th2 cytokines have been observed in the respiratory mucosa of diisocyanate-exposed workers and this concept has been ratified in animal models of TDI sensitization and asthma, furthering the importance of Th1 and Th2 cells and associated cytokines. Activated T-cells and an allergic microenvironment may also stimulate B cells to become plasma cells and secrete antibody.

Once the elicitation phase begins, a coordinated cellular response occurs and the allergic response ensues. This response involves re-exposure to the haptenated complex as an antigen, causing crosslinking of the antigen with antibody, binding to mast cells and basophils, leading to degranulation, the production of additional antigen-specific allergic antibody, and the proliferation of antigen-specific $\mathrm{T}$ cells and the involvement of memory $\mathrm{T}$ cells. The elicitation response is responsible for the symptoms of allergic disease such as asthma, which may involve airway hyperreactivity, inflammation, and mucus secretion. The clinical pathogenesis of TDI-induced 
asthma is not fully understood; however, observational data has been collected describing the physiological features of individuals suffering this condition. Following an initial period of sensitization and latency which may last for months to years following initial TDI exposure, asthmatic symptoms typically begin to appear. Overall, the clinical presentation of TDI-induced asthma is variable, which often complicates diagnosis and treatment (11). Early symptoms include chest tightness, cough, shortness of breath, and wheezing and may appear anywhere from $<1$ hour to 2-4 hours following workplace TDI exposure (11). Clinical features of TDI-induced asthma are similar to those of atopic asthma and include bronchial hyperreactivity and inflammatory infiltrate, goblet cell hyperplasia, increased airway mucus production, and subepithelial fibrosis (11). An ideal animal model of TDI asthma would recapitulate airway narrowing and bronchial inflammation along with hyperreactivity following sensitization and airway-based challenge (19). TDI-induced asthma can be fatal; in one case, an autopsy of a patient with TDI-induced asthma revealed symptoms similar to those found in status asthmaticus (2). These findings included excessive mucus production, overinflated lungs, epithelial desquamation, bronchial wall thickening, and lymphocyte infiltration in the lamina propria. Allergic rhinitis has also been reported as a comorbidity and sometimes a preceding condition in patients with TDI asthma and rhinitis may cost more in terms of lost productivity and time at work compared to asthma (18). Due to the similarities between the upper and lower respiratory tracts in regards to fundamental allergic susceptibility many of the factors involved in TDI sensitization and asthma are thought to play a role in TDI rhinitis.

Additional factors have been implicated as risk factors for human TDI sensitization including cigarette smoking and polymorphisms in the glutathione $S$-transferase, $\mathrm{N}$-acetyltransferase, and MHC class II genes (14), shedding light on potential mechanisms and pathways involved in this process. Interestingly, there has been no consistent link between IgE or atopy and TDI in humans. 
The lack of association between IgE production and TDI sensitization and asthma is intriguing considering the well-established link between atopy and other chemical allergens, including acid anhydrides, platinum salts, and dyes (14).

\subsection{DERMAL TDI SENSITIZATION}

The epithelium plays a significant role in the early stages of sensitization, acting as a physical barrier to allergens and a site of immune surveillance (20). The skin, in particular, serves as a protective layer for our bodies from the outside environment. As the largest organ in the body, the skin is an extremely important player in relation to allergic disease. The skin is made up of the epidermis and the dermis. The epidermis represents the outermost portion of the skin and is comprised of cornified lipids and proteins such as keratin and filaggrin (21), forming a protective barrier for the rest of the body. The inner layer, or dermis, is comprised of lymphatic vessels, hair follicles, sebaceous glands, nerve fibers, connective tissue, and blood vessels (21), effectively cellularly connecting the skin to the rest of the body. The presence of multiple innate immune factors present in the skin including leukocytes, complement factors, antimicrobial peptides, and pattern recognition receptors (22) allow the skin to be a site of immune surveillance and tolerance yet these factors may also contribute to the development of allergic disease. Not only is the skin involved in the development of dermal sensitization, it has recently been implicated in the development of systemic sensitization leading to elicitation at various sites in the body, including the respiratory tract (5). This has been demonstrated in animal studies involving both protein and chemical allergens. Ovalbumin and isocyanates are perhaps the most well-studied models exhibiting skin sensitization leading to asthma $(21,23)$ but this has been demonstrated in a rat model of TMA sensitization as well (24). In humans, several studies have linked isocyanate skin exposure to asthma risk and prevalence $(21,25)$. These studies face severe limitations, including the limited methods of skin 
exposure quantitation, timing of sample collection, the diverse nature of dermal exposures and chemical composition (including mixed exposures), influence of personal protective equipment (PPE), and risk assessment challenges (21). Regarding isocyanates specifically, the reliance upon free unreacted isocyanate groups for sampling methods further complicates the accurate documentation of isocyanate skin exposure (26).

Due to occupational activities, the epithelium may be compromised and workers may be exposed to a variety of potential allergens, leading to increased risk of an allergic reaction to these substances. Loss of barrier function has been identified as an important factor in the development of various allergic diseases including asthma, atopic dermatitis, and sensitization (21). This concept has been elegantly demonstrated with animal and human-based studies involving filaggrin, a protein involved in the formation of the epidermis (27-29). Genetic variability in barrier protein genes, solvent and soap exposure, excessive hand washing, existing skin conditions, humidity, temperature, physical trauma, and glove use are all factors that can influence skin barrier function, which is a known factor in the development of allergic disease (21). Barrier disruption and dysfunction followed by allergen exposure may allow the perturbing agent to activate the epithelium, leading to the production of cytokines such as IL-33 and thymic stromal lymphopoetin (TSLP), which are directly involved in the stimulation of Th2 responses $(30,31)$. Barrier dysfunction also allows dermal dendritic cells and Langerhans cells to come into contact with allergens and become activated, also potentially impacting the development of $\mathrm{Th} 2$ responses.

Dermal isocyanate exposure has been a fairly recent topic of concern in relation to the historical perception that respiratory exposure primarily leads to asthma. Several cases of skin sensitization leading to asthma have been surmised in humans and this concept has been demonstrated in animal models (21). In a workplace setting, the likelihood of dermal contact with 
isocyanates may be high, further supporting the idea that dermal exposures may lead to respiratory allergic disease. In addition to their probability of occurrence in the workplace, isocyanate skin exposures also have the potential for high dose-delivery in comparison to inhalation exposures (5). From a regulatory perspective, there are few standards for skin isocyanate exposure in comparison to respiratory guidelines (5). Although skin exposure as a route of sensitization has been noted and is a generally accepted concept among experts, there are no dermal exposure limits for di- or polyisocyanates including TDI.

Chemical potency in relation to sensitization potential may also be affected by the route of exposure. The studies described in this dissertation utilize a single exposure TDI sensitization model. This model was developed on the basis of extensive experimental sensitization confirmation as well as historical literature suggesting that single isocyanate exposure is sufficient to lead to sensitization in mouse models $(5,21)$. Several murine studies have demonstrated the ability of a single dermal exposure of TDI ( $1 \%$ and $0.3 \%)$ to induce respiratory allergic symptoms such as lung associated lymph node cytokine secretion, serum IgE, and airway inflammation and hyperreactivity after subsequent respiratory challenge $(32,33)$. Similar results have been ascertained utilizing HDI (34) and MDI (35), two related diisocyanates. As our studies and others' have demonstrated, doses ranging from $1-100 \mu \mathrm{mol}$ isocyanate in the form of $1-10 \%$ solution are sufficient to induce sensitization in a murine model and are representative of a realistic occupational exposure of a few droplets of diluted diisocyanate solution (5). These realistic exposure scenarios are compounded by human case reports suggesting development of diisocyanate asthma in occupational settings with very low or undetectable air isocyanate levels, implicating dermal sensitization in these workers (5). In addition to animal models and human case reports, several epidemiologic studies have linked skin diisocyanate exposure and asthma risk together, further strengthening the concept of dermal 
sensitization causing a systemic immune response that can lead to asthma and other Th2-mediated allergic diseases. This data emphasizes the need for more focused research in order to elucidate mechanisms involved in this phenomenon. The lack of suitable workplace exposure limits for respiratory sensitizers that may sensitize dermally as well is a problem that needs to be addressed in order to limit unsafe exposures. Clearly, the study of skin exposure-respiratory elicitation relationships has revealed interesting data yet there is still much to be researched in order to properly protect workers utilizing chemical and protein sensitizers.

\subsubsection{Animal models of Dermal TDI sensitization}

Karol, et al first demonstrated that TDI skin sensitization is capable of priming the immune system for subsequent respiratory asthmatic responses in guinea pigs (15). Following this study, other investigators have demonstrated skin exposure to TDI leading to sensitization, followed by inhalation challenge, resulting in an asthmatic response $(19,32,36,37)$. Vanoirbeek, et al. proposed a model of dermal TDI sensitization (ear; three consecutive days of dosing with $0.3 \%$ or $3 \%$ TDI or one single dose of $1 \% \mathrm{TDI}$ ) followed by a dermal "boost" at day 7 (same concentration as initial dosing) and intranasal challenge at day $10(0.1 \%$ TDI or vehicle $)(19)$. These dosing regimens were followed by whole body plesthysmography (40 min following intranasal challenge) and methacholine challenge (24 hours later). Terminal endpoints were bronchoalveolar lavage (BAL) and histology. All mice that were dermally sensitized with TDI exhibited elevated enhanced pause (PenH) following intranasal TDI and/or methacholine challenge. This alteration in ventilatory function was paired with increased neutrophil inflammation with the exception of mice dermally sensitized with 3\% TDI (high dose) and given the day 7 dermal "boost". This observation led the authors to conclude that immunological tolerance may be responsible for the lack of a respiratory 
response following intranasal challenge in this group, introducing an important concentrationdependent response relationship between TDI and allergic reactions, as has been noted for protein allergens. The efficacy of dermal sensitization has also been demonstrated for other chemicals such as trimellitic anhydride and protein allergens such as ovalbumin that can cause respiratory allergic disease $(5,24,38)$. Another notable study was performed by Matheson, et al. that involved repeat subcutaneous TDI sensitization followed by repeat inhalation challenge (39). This model revealed increased methacholine airway reactivity and nasal and tracheal inflammation in wild-type mice sensitized with TDI, exhibiting the effective sensitizing potential of the subcutaneous route.

Some important considerations regarding murine models of dermal TDI sensitization include potential differences in skin permeability between mice and humans and the relevance of exposure site and dose compared to real world exposures. While the ability of TDI to penetrate both mouse and human skin is not in question, potential variability in skin permeability between the two organisms are important to remember when translating the value of these studies. In a manuscript examining dermal penetration of perfluorooctanoic acid in mouse and human epidermal membranes Anderson, et al. observed slight variations in chemical penetration in mouse (39\%) and human (24\%) skin following perfluorooctanoic acid (PFOA) application (40). Additionally, the total absorbable amount was $50 \%$ in mouse skin and $69 \%$ in human skin. These findings illustrate potential discrepancies between mouse and human skin permeability and chemical uptake, which are important to consider when choosing doses for experimental studies and extrapolating murine results to human data. The route of exposure and site of exposure should also be kept in consideration when interpreting murine studies. Many dermal TDI sensitization models are carried out using ear pinnae exposures, which are experimentally sound and necessitated yet may not accurately represent realworld exposures which presumably take place at other sites on the body (hands, arms, etc.). 
Additionally, subcutaneous injection models are a departure from most realistic exposure scenarios but may mimic exposure in the presence of skin abrasions and epidermal lesions. Regardless of the site and route of exposure, dermal TDI sensitization models are valuable tools utilized for the investigation of this immune response. Dose selection is also an important aspect of murine TDI sensitization models. For many studies, the aim of dose selection is to induce a significant state of sensitization, while others seek to mimic real-world exposures. We should be careful in interpreting exact doses from murine to human exposures due to the factors mentioned above including dermal penetration variability and route/site of exposure in mice and humans.

Skin sensitization has been proposed to be an extremely effective route of allergic sensitization, in some cases it has been suggested to be more effective than respiratory sensitization regarding the downstream elicitation of asthma. In a study evaluating four different models of MDIinduced respiratory sensitization in guinea pigs, epicutaneous and intradermal MDI exposure were reported to be more effective at sensitizing the respiratory tract than inhalation MDI exposure (41), indicating that skin sensitization is a relevant and powerful route of exposure in relation to respiratory chemical sensitization. More recent studies have bolstered this concept, including a TDI sensitization study that focused on a variety of sensitization exposure scenarios (epicutaneous, subcutaneous, and intradermal) followed by respiratory challenge in mice, revealing that epicutanous sensitization resulted in the most clinically relevant pathophysiological response in the lungs while inhalation sensitization was, in comparison, not an effective route of sensitization (32). Observations with formaldehyde suggested that dermal sensitization was far more effective than respiratory sensitization, which did not occur following comparable formaldehyde exposures yielding similar irritation responses (42). Similar investigations were completed utilizing the potent respiratory sensitizer glutaraldehyde and they revealed clear skin sensitization and the absence of respiratory 
sensitization, despite an irritant response in both tissues (42). The authors hypothesized that the hydrophilic and highly reactive glutaraldehyde dissolves in the mucus of the airways where it reacts with the dissolved lysine-rich proteins in this fluid, preventing immunologic activation by APCs which are required to induce sensitization (42). This observation may be unique to aldehydes; other LMW sensitizers may be less reactive and more lipophilic and in turn less affected by the mucus layer in terms of sensitization potential (42). In contrast, the skin does not contain a mucus layer, allowing LMW chemicals to more readily access APCs and initiate sensitization. Interestingly, it has been reported that thiol-rich proteins in the stratum corneum may act as a barrier against dinitrothiocyanobenzene (DNTB) which contains highly reactive -SCN groups (42). It appears that the unique environments of the skin and the respiratory tract are important factors in the development of LMW chemical-induced sensitization and these tissues exhibit unique characteristics that may impact the sensitization potential of chemicals depending on a number of factors.

\subsection{IMMUNOLOGIC FACTORS INVOLVED IN TDI-INDUCED}

\section{ALLERGIC DISEASE}

TDI-induced sensitization and asthma are complex and multi-factorial conditions. TDI sensitization is characterized by repeated exposures leading to the establishment of the allergic threshold. Typically, these exposures are cumulative and may occur for weeks to years, allowing the sensitization response to develop. Once the elicitation threshold has been met, exposure to minute amounts of TDI can lead to severe asthmatic responses. Although pathologically similar to atopic asthma, several key discrepancies have been identified in clinical studies, including a mixed Th1/Th2 response, low association with atopy and specific IgE antibodies, and high numbers of antigen-specific $\mathrm{CD} 8^{+} \mathrm{T}$ cells (7). While the mechanisms of sensitization and elicitation have not 
been fully elucidated for TDI-induced allergic disease, there are a number of immune mediators that have been suggested to play a role in these processes.

\subsubsection{Antigenicity and APCs}

TDI-induced asthma differs in the process of antigenicity compared to protein allergens, presumably by forming haptens with self-proteins such as albumins and keratins. The high crosslinking potential of diisocyanates like TDI contribute to their industrial utility but also to their immunotoxicity. The electrophilic nature of TDI allows this chemical's isocyanate side chains to react with hydroxyl, amino, and thiol groups on proteins, forming covalent bonds with self-proteins (11); in a process known as haptenation. This event likely alters the mechanism of sensitization compared to that of protein allergens. TDI is thought to bind to actin, albumin, glutathione, hemoglobin, keratin, laminin and tubulin in vivo based on numerous studies $(11,43,44)$. This binding may result in cellular damage and immune cell recognition of TDI-protein conjugates, fully initiating the TDI sensitization immune response. The isocyanate groups in TDI can react with amine groups to form ureas, hydroxyl groups to form urethanes, and/or thiol groups to from thioureas (43). The antigenic portion of TDI-hapten complexes are poorly understood along with the overall process in vivo. This is a challenging subject as TDI and reactive diisocyanates can self-polymerize and haptenate proteins at single or multiple locations, creating a complex chemical environment (43). A greater understanding of this process will likely aid in the understanding of the immunologic basis for TDI sensitization and that of LMW chemicals in general.

It has been demonstrated that TDI-protein complexes interact with Langerhans cells in the skin (specifically, in the hair follicles) and dendritic cells in the dLN in a murine model of epicutaneous TDI sensitization (45). This interaction illustrates the initial step in the initiation of an 
adaptive immune response, antigen presenting cell-antigen interaction. In an elegant study conducted to analyze binding of the hapten-major histocompatibility complex class II (MHC II) complexes to antigen-specific T cells, Kohler, et al. demonstrated that hapten-peptide complexes of trinitrophenyl (TNP) bound to a variety of proteins (both mouse self-proteins such as albumins as well as non-mouse proteins) accounted for the majority of epitopes recognized by TNP-specific $\mathrm{CD}^{+} \mathrm{T}$ cells (46). This landmark study demonstrated the role of the chemical-peptide hapten complex in the induction of sensitization. Following APC uptake of the hapten complex, these cells may migrate to the lymphatics and interact with $\mathrm{T}$ cells, initiating an adaptive response. Uncertainty regarding the exact structure and identity of TDI hapten complexes that are relevant in vivo have posed challenges for diagnosis and understanding of the mechanisms driving TDI-induced sensitization and asthma.

\subsubsection{The Role of IgE in Respiratory Chemical Sensitization and Asthma}

Unlike atopic asthma induced by protein allergens, IgE has not been definitively implicated as an integral immune mediator in all cases of chemical-induced asthma, even though clinical symptoms are similar for both types of asthma (47). For example, the consistent expression of IgE in murine models of TDI allergy (48) is not reflected in human studies, as many individuals with diagnosed TDI-induced asthma do not have increased levels of TDI-albumin conjugate-specific IgE in their blood (49). As few as 5-30\% of symptomatic workers have detectable levels of diisocyanatespecific IgE (11). Levels of diisocyanate-specific antibodies typically do not correlate with development of reactive airway disease (50) and atopy has not been identified as a risk factor for diisocyanate-induced asthma (11). Additionally, during the elicitation phase of diisocyanateinduced asthma, isolated "early" reactions occurring $<1$ hour following diisocyanate exposure are 
less prevalent than that observed in protein induced asthma (11) (although they have been reported) suggesting that diisocyanate induced asthma is not solely IgE-mediated, as this response alone would be immediate. As IgE is a hallmark of the humoral response induced by Th2 responses (51), this data suggests that either TDI-specific IgE is not capable of being properly detected or an IgEindependent allergic mechanism is involved in human TDI sensitization. The hypothesis regarding limited TDI detection is an interesting concept, given the uncertainty regarding the specific identification of the TDI-hapten complex responsible for antigenicity. Several components of antibody composition, including appropriate selection of hapten-protein conjugates and the molar substitution ratio, along with the time of blood collection in relation to chemical exposure are important in the detection of IgE in chemical allergy (14). The temporal component of IgE detection also seems to play an important role in this process, in serum radioallergosorbent tests (RAST) from patients with documented diisocyante-induced asthma specific IgE measures were more likely to be detected if the samples had been collected within 30 days of the last exposure to diisocyanate (52). The requirement of a Th2 response for respiratory chemical sensitization and allergy, which has been well demonstrated in animal models and humans, suggests that IgE-independent mechanisms could be at play. Further complicating this concept, a strong association between $\operatorname{IgE}$ and chemicalinduced asthma has been made for several chemicals, including methyltetrahydrophthalic anhydride (53). The relationship between IgE and TDI sensitization is complicated and is not fully understood. There remains doubt as to the efficiency of hapten-specific $\operatorname{IgE}$ detection as well as the true role of IgE in TDI sensitization and allergic disease. Further insight into this concept will be valuable for toxicological evaluation, prediction, and risk assessment.

\subsubsection{Immune Factors Involved in TDI Sensitization and Elicitation}


A hallmark of isocyanate-induced allergic disease in both humans and mice is an active Th2 adaptive immune response. This response also involves a Th1 component, but this is generally thought to be less dominant. Increased levels of a variety of cytokines (IL-1 $\beta$, IL-4, IL-5, IL-6, IL15 , and TNF- $\alpha$ ) and immune cell subsets (CD4 ${ }^{+}$and $\mathrm{CD} 8^{+} \mathrm{T}$ cells) have been documented in the BAL and sputum of patients with diisocyanate-induced asthma (2). These data illustrate the mixed Th1/Th2 response that takes place in this response. In a murine model of inhalation sensitization (6 weeks, 5 days/week, 4 hours/day) and challenge (following a 14 day rest period, 1 hour), adaptive immune components of TDI asthma were examined (7). Following TDI sensitization and challenge CD4- and CD8-deficient mice displayed significant reductions in PenH, an indirect measure of airway hyperreactivity, following a nonspecific methacholine challenge. CD4 knockout mice exhibited reduced serum total IgE and undetectable total IgG levels following TDI sensitization and challenge compared to increased levels of both antibodies in TDI sensitized and challenged control animals. CD8 knockout mice displayed similar reductions in IgE but did not show any significant decrease in total IgG levels nor any changes in specific IgG isotypes. CD4 and CD8 knockout mice sensitized and challenged with TDI also experienced reduced levels of lung histopathological changes that were seen in TDI sensitized and challenged control mice; these changes include goblet metaplasia, epithelial damage, and cellular infiltration. Th1 and Th2 cytokine mRNA expression was not elevated in CD4 and CD8 knockout mice following TDI sensitization and challenge, while control mice undergoing TDI sensitization and challenge exhibited increased levels of both Th1 and Th2 cytokine mRNA. The authors also utilized mice deficient in IFNy, IL-4, IL-13, and IL-4+IL13 in their TDI sensitization and challenge model in an effort to establish the importance of these signaling molecules in the pathogenesis of TDI-induced asthma. Following TDI sensitization and challenge all cytokine knockout mice exhibited reduced airway hyperreactivity following a 
nonspecific methacholine challenge compared to control mice. Total IgE antibodies were significantly decreased in the serum of IFNy, IL-4, and IL-4+IL-13 knockout mice following TDI sensitization and challenge, while all knockout groups exhibited lower IgG levels. The histopathologic changes seen in cytokine knockout groups were less pronounced than that of the control TDI sensitized and challenged control mice. A decrease in BAL eosinophilia was noted in CD4, CD8, IL-4, IL-13, and IL-4+IL-13 knockout mice following TDI sensitization and challenge, indicating that both CD4 and CD8-mediated mechanisms may play a role in TDI-induced asthma pathogenesis. In summary, this seminal study emphasizes the importance of the $\mathrm{T}$ cell response in the pathogenesis of TDI-induced sensitization and asthma. Specifically, this work demonstrated the requirement of the $\mathrm{CD} 4^{+} \mathrm{Th} 2$-mediated response and the less critical but still significant role of $\mathrm{CD} 4^{+}$ Th1 cells and $\mathrm{CD} 8^{+} \mathrm{T}$ cells in this response. The synergistic role of Th1 and Th2 cells in asthma pathogenesis has been proposed in models of protein allergy and appears to be a component of this study.

Additionally, the role of B cells in TDI-induced asthma is a relevant topic, considering the controversial role of IgE in this condition. In a recent work by De Vooght, et al., a dermal, murine TDI sensitization model was utilized to exhibit the importance of B cells in the allergic response following TDI challenge (54). Adoptive transfer of B cells from TDI-sensitized mice into naïve, Bcell knockout, and severe combined immunodeficiency (SCID) mice resulted in asthmatic symptoms following oropharyngeal TDI challenge; these observations suggest a T cell-independent capability of $\mathrm{B}$ cells to induce allergic outcomes. Between this data and the questionable role of $\operatorname{IgE}$ in diisocyanate-induced asthma, B cells should be further investigated in chemical-induced allergic disease, specifically in human patients or human-like animal models in order to recapitulate the specific mechanisms of B cell activity in these conditions. 
TNF- $\alpha$ is a Th1-associated cytokine that is pleiotropic and is a central regulator of inflammatory responses. This cytokine has been implicated as a significant player in TDI-induced asthma due to its inflammatory nature and its potential effects on dendritic cells. In a murine model of subcutaneous TDI sensitization and inhalation challenge TNF- $\alpha$ neutralization (via TNF-targeting antibody or TNFR1/2 knockout) reduced airway dendritic cell migration, inflammation, pathology, and hyperreactivity (following a methacholine challenge) (55). Interestingly, serum TDI-specific IgG and total IgE levels were not affected by TNF- $\alpha$ neutralization, suggesting a role for this cytokine in the early inflammatory phase of the allergic response. This data along with additional studies demonstrate essential role for Th1 cells in the progression of TDI-induced asthma. Although there has been limited investigation regarding the potential role of other T cell subsets in TDI sensitization and allergic disease, upregulation of $\mathrm{T}_{\text {reg }}$ and Th17-associated cytokines (IL-10 and IL-17, respectively) were observed in the auricular lymph nodes of dermally sensitized mice receiving a single oropharyngeal aspiration challenge of TDI (56). This data suggests a potential role for additional $\mathrm{T}$ cell subsets in TDI allergic disease and prompts investigation of these subsets in both animal models and humans.

Neutrophils, mast cells, and eosinophils are additional immune cell populations thought to play a role in TDI-induced sensitization and asthma pathogenesis. Clinical human studies support this concept, finding increased neutrophil activation and IL-8 levels in sputum samples (8), elevated eosinophil levels in the bronchial mucosa (47), and elevated mast cell numbers in the airway mucosa of TDI asthmatics (57). Neutrophil involvement marks a key difference in TDI-induced and proteininduced asthma; several studies have demonstrated the presence of airway neutrophilia during TDI asthma in both mice and humans (11), suggesting that the pathogenic mechanisms differ between these two conditions. In a murine model of TDI asthma de Vooght, et al. depleted granulocytes and 
neutrophils prior to airway (oropharyngeal aspiration) TDI challenge using a variety of strategies including chemical and antibody-mediated depletion (58). Neutrophil depletion ameliorated airway hyperreactivity, suggesting that this cellular compartment is involved in the pathogenesis of TDIinduced asthma.

A loss of functional airway epithelium is also observed in isocyanate asthma. An in vitro study demonstrated disintegration of tight junctions between human bronchial epithelium cells, cytotoxicity, and increased mucus secretion following exposure to TDI. This study also found damage to cilia and impairment of their function at increasing concentrations of TDI, explained by an interaction between the isocyanate groups of TDI and structural filaments like tubulin (59). Another factor that may contribute to airway epithelium damage is isocyanate-glutathione binding (2). This action may lead to the loss of glutathione-mediated protection against oxidative stress. Interestingly, several studies have demonstrated a connection between polymorphisms in glutathione S-transferase supergene family genes (GSTM1, GSTP1) and the risk for developing diisocyanateinduced asthma (2). These enzymes are responsible for catalyzing the conjugation of glutathione to electrophilic substances like TDI (60), indicating that glutathione may play a protective role in the pathogenesis of TDI-induced asthma. The extracellular matrix (ECM) of the lungs can be disturbed during asthma, characterized by bronchial remodeling. Matrix metalloproteinases (MMPs) are proteases whose primary function is to break down the ECM (61); MMPs and their inhibitors are important players in the homeostasis of the ECM under normal and perturbed conditions. MMP-9 is known to cause bronchial remodeling in allergic asthma and it also induces the movement of granulocytes across basement membranes (62). Due to the known roles of MMPs in allergic asthma, the role of these enzymes in a murine model of TDI-induced asthma was investigated by Lee, et al. (62). Mice were sensitized to TDI by intranasal administrations for five consecutive days; following 
three weeks of rest, mice were further sensitized for 5 more days. A week after the second sensitization exposure regimen mice were challenged via inhalation. After establishing their model of TDI asthma, the authors observed increased levels of MMPs (including MMP-9) in BAL of TDIexposed mice. After treating mice with a MMP-9 inhibitor three times at one day intervals beginning 30 minutes before TDI challenge the lung inflammatory cell infiltrate was decreased (total cells, neutrophils, and eosinophils) and mice displayed reduced airway hyperreactivity following a nonspecific methacholine challenge compared to mice exposed to TDI and not receiving MMP-9 inhibitor. This data demonstrates a role for MMPs, specifically MMP-9, in the pathogenesis of TDIinduced asthma. Based on known mechanistic data, the authors postulate that MMP-9 activity alters the ECM, allowing the migration of inflammatory cells into the airways (62).

Oxidative stress is known to play a pathogenic role in a variety of conditions, including respiratory illnesses such as contact dermatitis, asthma, and chronic obstructive pulmonary disease $(63,64)$. The anti-oxidant defenses in the body exist to protect various tissues such as the lungs and the skin from oxidant insults such as cigarette smoke, UV radiation, combustion products, and homeostatic cellular processes. These defenses include glutathione, vitamins A and E, catalase, superoxide dismutase, transferrin, haem oxygenase-1, and redox proteins $(63,65)$. Elevated transferrin and decreased ferritin levels were observed in the serum of TDI asthmatics compared to asymptomatic exposed control subjects and non-exposed control subjects $(63,66)$. Ferritin's role in detoxifying inflammatory-induced oxidative stress and transferrin's antioxidant capabilities suggest altered oxidative defense capabilities during TDI asthma. Following further investigation, expression of ferritin light chain and the antioxidant protein heme oxidase-1 was inhibited in human airway epithelial cells in culture following TDI exposure (63). This was demonstrated to take place via MAPK signaling inhibition which resulted in defective downstream Nrf2 nuclear translocation 
(63). These TDI-induced signaling alterations may result in a significantly impaired anti-oxidant defense repertoire due to the inability of $\mathrm{Nrf} 2$ to translocate to the nucleus, bind to anti-oxidant response elements, and induce transcription of numerous genes important to cellular defense against oxidative stress (67). Importantly, cellular treatment with a PPAR- $\gamma$ agonist, activating another important antioxidant signaling molecule, was able to rescue the expression of heme oxygenase-1 and ferritin light chain which was formerly inhibited by TDI (63). Additional studies investigating the therapeutic potential of epigallocatechin-3-gallate, a compound found in tea that has exhibited anti-allergic properties, revealed that this compound reduced murine TDI-induced asthma severity via regulation of inflammatory cell migration (68). This may be mediated via suppression of MMP9 and reactive oxygen species (ROS) (68), two key mediators of ECM injury and oxidative stress which are known to play a role in TDI asthma (62). These studies reveal the therapeutic potential of targeting antioxidant mechanisms in the treatment of TDI-induced asthma.

In contrast to TDI elicitation, little is known regarding the role of oxidative stress during TDI sensitization. Oxidative stress is known to cause apoptosis, specifically in $T_{\text {regs, }}$ which have been shown to be critically involved in a murine model of epicutaneous TDI sensitization (69). Additionally, oxidative stress induced by food contaminants and environmental chemicals contribute to the adjuvant effect of these molecules during the sensitization phase of OVA-induced allergic airway inflammation (70). Both in vitro and in vivo studies reveal that exposure to these contaminants promote Th2 differentiation and induce $\mathrm{Th} 1$ and $\mathrm{T}_{\text {reg }}$ apoptosis via induction of oxidative stress (specifically by glutathione depletion), ultimately promoting Th2-mediated allergic inflammation (70). Interestingly, in vivo studies involved oral exposure to these contaminants, leading to oxidative stress in secondary lymphoid organs (70). The effects of these compounds on sensitization were not observed when exposure occurred during the elicitation phase of allergic 
disease, suggesting a potential role for these antioxidant defense supplementation during sensitization not elicitation.

AMP-activated protein kinase (AMPK) is a widely expressed molecule involved in a variety of cellular processes including ATP depletion, apoptosis, proliferation, and protein synthesis (71). AMPK can influence inflammatory signaling by suppressing proinflammatory responses, promoting anti-inflammatory macrophage polarization, and inhibiting production of ROS in neutrophils (71). AMPK can be activated by 5-aminoimidazole-4-carboxamide-1- $\beta$-D-ribofunanoside (AICAR), which enters cells, is converted to the equivalent monophosphorylated nucleotide, ZMP, which mimics AMP and activates AMPK without changing levels of ATP, ADP, or AMP (71). AMPK activation via AICAR administration has been shown to reduce inflammation and tissue injury in a number of experimental models including experimental autoimmune encephalomyelitis and LPSand viral-induced lung inflammation. Another signaling pathway thought to be involved in inflammation, hyperresponsiveness, and remodeling, specifically in the airway, is mediated by vascular endothelial growth factor A (VEGFA) (71). VEGFA is produced by human airway smooth muscle cells in response to a variety of Th2-related cytokines and has been implicated as a major component of TDI-induced asthma in a murine model (71). Using a murine model of TDI-induced asthma to investigate the role of AMPK and VEGFA on airway inflammation and other asthmarelated symptoms, the authors found that activation of AMPK via AICAR resulted in decreased TDIinduced airway inflammation and hyperresponsiveness and increased levels of VEGFA (71). These data indicate that AMPK activation has a negative effect on airway inflammation during TDIinduced asthma and this is mediated by the VEGFA pathway, primarily by reducing vascular permeability and ROS production. This study reveals a potential therapeutic avenue for the treatment of TDI-induced asthma and outlines significant regulatory processes involved in this condition. 
Several genetic factors have been investigated as sources of susceptibility to isocyanateinduced allergic disease. Because of the known role of APCs in the uptake and presentation of TDIprotein complexes (45) the influence of human leukocyte antigen (HLA) genes, which encode the major histocompatibility complex (MHC) in humans, have been investigated in the context of susceptibility to diisocyanate asthma. One study carried out by Mapp, et al. involving TDI-exposed workers demonstrated that the HLA class II genotypes $D Q A 1 * 0104$ and $D Q B 1 * 0503$ were overrepresented in asthmatic workers compared to asymptomatic workers (72). An earlier study by the same group demonstrated a positive association of $D Q B 1 * 0503$ with TDI asthmatics compared to individuals in control groups who had been exposed to TDI but were asymptomatic or had never been exposed to TDI and were asymptomatic (73). This study utilized a different cohort of workers and contributed to the hypothesis that HLA-DQB1*0503 is involved in conferring susceptibility to TDI-induced asthma. Additionally, the authors discovered that residue 57 of the $D Q B 1$ allele may play a particularly important role in this process. These studies, among others, have demonstrated the involvement of HLA variability in TDI-induced asthma susceptibility. TCR expression of V $\beta$ gene repertoires was investigated in a cohort of diisocyanate asthmatics in an effort to investigate the hypothesis that diisocyanate asthma-susceptible workers process antigen differently than nonsymptomatic workers due to differences in TCR V $\beta$ gene repertoires $(74,75)$. Following coincubation with diisocyanate-conjugated proteins, mRNA was isolated from peripheral bloodderived lymphocytes from diisocyanate asthmatics, asymptomatic diisocyanate-exposed workers, subjects without occupational asthma, and unexposed subjects free of symptoms. Polymerase chain reaction (PCR) was performed before and after diisocyanate stimulation in order to profile each TCR on the basis of $\mathrm{V} \beta$ gene segment expression. Before in vitro diisocyanate stimulation lymphocytes from diisocyante asthmatics exhibited significantly decreased $\mathrm{V} \beta 1$ and $\mathrm{V} \beta 5$ expression compared to 
control groups; however, following stimulation these cells exhibited selective increases in $\mathrm{V} \beta 1$ and $\mathrm{V} \beta 5$ expression compared to controls. These studies suggest that antigen-specific $\mathrm{T}$ cells may express varying TCR V $\beta$ gene expression in response to diisocyanate exposure.

Additional genetic risk factors that have been identified for diisocyanate-induced asthma are mannose-binding lectin (MBL) polymorphisms (76). MBL is a component of the complement pathway, serving as the initiation step of the innate lectin complement cascade that follows the opsonization of a pathogen-derived carbohydrate structure. Increased levels of MBL have been found in the BAL fluid of children with airway infections and this compound appears to be protective in inflammatory environments, reducing inflammation induced by oxidative stress (76). MBL2 polymorphisms have been linked to altered MBL serum levels and were shown to be associated with increased risk for severe airway hyperresponsiveness in diisocyanate asthmatics. Additionally, there was an increased frequency of haplotype 2 expression among diisocyanate asthmatics compared to asymptomatic exposed controls (76). This data sheds an important light on the influence of genetic variability on TDI-induced asthma as well as potential effector mechanisms involved in this condition.

\subsection{CONCLUSIONS}

TDI is a potent allergic sensitizer widely used in the manufacture of a variety of polyurethane products. Workplace exposures result in a high number of occupational allergic disease cases each year. The impact of isocyanate-induced allergic disease is geographically broad; exposures occur worldwide in a variety of industries and occupations. The high reactivity of isocyanate groups on TDI molecules allows this chemical to bind to self-proteins following dermal or respiratory exposure, leading to immunogenicity and allergic sensitization. The concept of dermal sensitization 
leading to respiratory elicitation is an important one. This has been proven in animal models and human epidemiological data supports this concept. The lack of exposure limits relevant to skin exposure and the limited understanding of the immunologic mechanisms involved in this process necessitate further investigation into this concept in both animal models and observational human studies.

In rodents and humans TDI is considered to be a "mixed" Th1/Th2 sensitizer, exhibiting increased Th1 and Th2 T cell polarization, cytokine secretion, and effector mechanisms leading to conditions like asthma. This mixed response is fairly unique among allergic sensitizers and is not currently encompassed by any formal hypersensitivity classification, which is a confounding variable in the study and treatment of TDI-induced allergic disease. Additionally, the problem of not knowing the true TDI-hapten "antigen" structure contributes to the limited understanding of the mechanisms of sensitization of TDI and chemical allergens in general. Although monoclonal antibodies against TDI-self-protein antigens have been produced and albumin is thought to be a primary soluble protein isocyanate target (77), the comprehensive in vivo TDI-hapten antigen landscape has not been fully elucidated and remains hampered by several factors including variation in murine and human TDI sensitization responses and limited isocyanate-specific reagent availability. Another contentious concept in the TDI community is the IgE conundrum; this refers to the lack of consistent TDI-specific IgE in TDI asthmatics regardless of the proven importance of this isotype in murine models of TDI sensitization and asthma. Whether this antibody is not able to be detected due to reagent limitations, testing is done at times when $\operatorname{IgE}$ levels are not detectibly above baseline, or there is truly no TDI-specific IgE increase in this condition, the IgE conundrum remains unsolved. Consistent increases in IgG suggest that this isotype may be a main effector antibody involved in TDI sensitization and asthma in humans, or at least a potential marker of TDI 
exposure. This may be reflective of the influence of the Th1 component of the immune response. The role of IgE in TDI sensitization and allergic disease needs to be investigated further in order to fully elucidate the immunologic mechanisms of this condition.

The lack of knowledge regarding the complete immunologic mechanisms of TDI sensitization and elicitation paired with the lack of validated hazard identification assays for respiratory sensitizers like TDI illustrate the need for the investigation of novel immune mediators of TDI-induced allergic disease. As discussed in Chapter 1, there are a plethora of potential novel mediators of allergic disease that may be involved in TDI-induced conditions. While some of these players such as Th1 and Th2 cells have been thoroughly investigated and others like miRNAs (78) and $\mathrm{T}_{\text {regs }}(69)$ have been explored (preliminarily, much work remains to be done), many others such at $\mathrm{T}_{\mathrm{FH}}$ and ILCs have not been investigated in TDI sensitization. Work involving these novel molecules should be supported and pursued as it may lead to the further understanding of factors involved in TDI-induced allergic disease. This, in turn, may aid in the development of hazard identification strategies for respiratory sensitizers, preventative, and therapeutic strategies for sensitizers like TDI. Despite the many unresolved issues relevant to the study of isocyanate-induced allergic disease much progress has been made in the investigation of this condition both due to the use of animal models and observations in human patients.

As previously stated, the pathologic features of TDI-induced asthma are typically similar to those found in atopic asthma. TDI asthmatics typically express high numbers of inflammatory cells in the airway mucosa, increased eosinophils, mast cells, and leukocytes in the epithelium, and mast cell degranulation (79). To reiterate, several key differences between TDI-induced and atopic asthma should be noted, including: low association with atopy and $\operatorname{IgE}$, a mixed Th1/Th2 response, and high numbers of antigen-specific $\mathrm{CD}^{+} \mathrm{T}$ cells (7). These discrepancies, along with a lack of 
comprehensive knowledge of the pathogenic mechanisms of TDI-induced asthma warrant further study of the immunological mechanisms of TDI-induced asthma. 


\subsection{REFERENCES}

1. Mapp, C. E. 2001. Agents, Old and New, Causing Occupational Asthma. Occupational and Environmental Medicine 58: 354-354.

2. $\quad$ Fisseler-Eckhoff, A., H. Bartsch, R. Zinsky, and J. Schirren. 2011. Environmental Isocyanate-Induced Asthma: Morphologic and Pathogenetic Aspects of an Increasing Occupational Disease. International Journal of Environmental Research and Public Health 8: 3672-3687.

3. Bolognesi, C., X. Baur, B. Marczynski, H. Norppa, O. Sepai, and G. Sabbioni. 2001. Carcinogenic risk of toluene diisocyanate and 4,4'-methylenediphenyl diisocyanate: epidemiological and experimental evidence. Critical reviews in toxicology 31: 737-772.

4. NTP. 2011. Report on Carcinogens. 12 ed. P. H. S. U.S. Department of Health and Human Services, National Toxicology Program, ed, Research Triangle Park, NC. 499.

5. Bello, D., C. A. Herrick, T. J. Smith, S. R. Woskie, R. P. Streicher, M. R. Cullen, Y. Liu, and C. A. Redlich. 2007. Skin exposure to isocyanates: reasons for concern. Environmental health perspectives 115: 328-335.

6. Fabbri, L. M., D. Danieli, S. Crescioli, P. Bevilacqua, S. Meli, M. Saetta, and C. E. Mapp. 1988. Fatal asthma in a subject sensitized to toluene diisocyanate. The American review of respiratory disease 137: 1494-1498.

7. Matheson, J. M., V. J. Johnson, and M. I. Luster. 2005. Immune Mediators in a Murine Model for Occupational Asthma: Studies with Toluene Diisocyanate. Toxicological Sciences 84: 99-109.

8. Liu, Q., and A. V. Wisnewski. 2003. Recent developments in diisocyanate asthma. Annals of Allergy, Asthma \& Immunology 90: 35-41.

9. Anderson, S. E., and B. J. Meade. 2014. Potential Health Effects Associated with Dermal Exposure to Occupational Chemicals. Environmental Health Insights: 51-62.

10. NIOSH. 1996. Preventing Asthma and Death from Diisocyanate Exposure. N. I. f. O. S. a. Health, ed. National Institute for Occupational Safety and Health, Cincinnati, OH.

11. Redlich, C. A., and M. H. Karol. 2002. Diisocyanate asthma: clinical aspects and immunopathogenesis. International immunopharmacology 2: 213-224.

12. Dotson, G. S., A. Maier, P. D. Siegel, S. E. Anderson, B. J. Green, A. B. Stefaniak, C. D. Codispoti, and I. Kimber. 2015. Setting Occupational Exposure Limits for Chemical Allergens-Understanding the Challenges. Journal of occupational and environmental hygiene 12 Suppl 1: S82-98.

13. Kimber, I., M. A. Travis, S. F. Martin, and R. J. Dearman. 2012. Immunoregulation of skin sensitization and regulatory T cells. Contact Dermatitis 67: 179-183.

14. Kimber, I., D. A. Basketter, G. F. Gerberick, C. A. Ryan, and R. J. Dearman. 2011. Chemical allergy: translating biology into hazard characterization. Toxicological sciences : an official journal of the Society of Toxicology 120 Suppl 1: S238-268.

15. Karol, M. H., E. J. Hauth, C. M. Riley, and Magreni. 1981. Dermal contact with toluene diisocyanate (TDI) produces respiratory tract hypersensitivity in guinea pigs. Toxicology and applied pharmacology 58: 221-230.

16. Ainscough, J. S., G. Frank Gerberick, R. J. Dearman, and I. Kimber. 2013. Danger, intracellular signaling, and the orchestration of dendritic cell function in skin sensitization. Journal of immunotoxicology 10: 223-234. 
17. Dearman, R. J., C. J. Betts, N. Humphreys, B. F. Flanagan, N. J. Gilmour, D. A. Basketter, and I. Kimber. 2003. Chemical Allergy: Considerations for the Practical Application of Cytokine Profiling. Toxicological Sciences 71: 137-145.

18. Johnson, V. J., B. Yucesoy, J. S. Reynolds, K. Fluharty, W. Wang, D. Richardson, and M. I. Luster. 2007. Inhalation of toluene diisocyanate vapor induces allergic rhinitis in mice. Journal of immunology (Baltimore, Md. : 1950) 179: 1864-1871.

19. Vanoirbeek, J. A., M. Tarkowski, J. L. Ceuppens, E. K. Verbeken, B. Nemery, and P. H. Hoet. 2004. Respiratory response to toluene diisocyanate depends on prior frequency and concentration of dermal sensitization in mice. Toxicological sciences : an official journal of the Society of Toxicology 80: 310-321.

20. van Ree, R., L. Hummelshoj, M. Plantinga, L. Poulsen, and E. Swindle. 2014. Allergic sensitization: host-immune factors. Clinical and Translational Allergy 4: 12.

21. Redlich, C. A. 2010. Skin Exposure and Asthma: Is There a Connection? Proceedings of the American Thoracic Society 7: 134-137.

22. Bangert, C., P. M. Brunner, and G. Stingl. 2011. Immune functions of the skin. Clinics in dermatology 29: 360-376.

23. Herrick, C. A., L. Xu, A. N. McKenzie, R. E. Tigelaar, and K. Bottomly. 2003. IL-13 is necessary, not simply sufficient, for epicutaneously induced $\mathrm{Th} 2$ responses to soluble protein antigen. Journal of immunology (Baltimore, Md. : 1950) 170: 2488-2495.

24. Zhang, X. D., J. S. Fedan, D. M. Lewis, and P. D. Siegel. 2004. Asthmalike biphasic airway responses in Brown Norway rats sensitized by dermal exposure to dry trimellitic anhydride powder. The Journal of allergy and clinical immunology 113: 320-326.

25. Arrandale, V., T. Meijster, A. Pronk, G. Doekes, C. A. Redlich, D. L. Holness, and D. Heederik. 2013. Skin symptoms in bakery and auto body shop workers: associations with exposure and respiratory symptoms. International archives of occupational and environmental health 86: 167-175.

26. Redlich, C. A., and C. A. Herrick. 2008. Lung/skin connections in occupational lung disease. Current opinion in allergy and clinical immunology 8: 115-119.

27. Palmer, C. N., T. Ismail, S. P. Lee, A. Terron-Kwiatkowski, Y. Zhao, H. Liao, F. J. Smith, W. H. McLean, and S. Mukhopadhyay. 2007. Filaggrin null mutations are associated with increased asthma severity in children and young adults. The Journal of allergy and clinical immunology 120: 64-68.

28. Palmer, C. N., A. D. Irvine, A. Terron-Kwiatkowski, Y. Zhao, H. Liao, S. P. Lee, D. R. Goudie, A. Sandilands, L. E. Campbell, F. J. Smith, G. M. O'Regan, R. M. Watson, J. E. Cecil, S. J. Bale, J. G. Compton, J. J. DiGiovanna, P. Fleckman, S. Lewis-Jones, G. Arseculeratne, A. Sergeant, C. S. Munro, B. El Houate, K. McElreavey, L. B. Halkjaer, H. Bisgaard, S. Mukhopadhyay, and W. H. McLean. 2006. Common loss-of-function variants of the epidermal barrier protein filaggrin are a major predisposing factor for atopic dermatitis. Nature genetics 38: 441-446.

29. Oyoshi, M. K., G. F. Murphy, and R. S. Geha. 2009. Filaggrin-deficient mice exhibit TH17-dominated skin inflammation and permissiveness to epicutaneous sensitization with protein antigen. The Journal of allergy and clinical immunology 124: 485-493, 493.e481.

30. Marshall, N. B., E. Lukomska, C. M. Long, M. L. Kashon, D. D. Sharpnack, A. P. Nayak, K. L. Anderson, B. J. Meade, and S. E. Anderson. 2015. Triclosan induces thymic stromal lymphopoietin in skin promoting Th2 allergic responses. Toxicological Sciences. 
31. Islam, S. A., and A. D. Luster. 2012. T cell homing to epithelial barriers in allergic disease. Nature medicine 18: 705-715.

32. Ban, M., G. Morel, I. Langonne, N. Huguet, E. Pepin, and S. Binet. 2006. TDI can induce respiratory allergy with Th2-dominated response in mice. Toxicology 218: 39-47.

33. Tarkowski, M., J. A. Vanoirbeek, H. M. Vanhooren, V. De Vooght, C. M. Mercier, J. Ceuppens, B. Nemery, and P. H. Hoet. 2007. Immunological determinants of ventilatory changes induced in mice by dermal sensitization and respiratory challenge with toluene diisocyanate. American journal of physiology. Lung cellular and molecular physiology 292: L207-214.

34. Herrick, C. A., L. Xu, A. V. Wisnewski, J. Das, C. A. Redlich, and K. Bottomly. 2002. A novel mouse model of diisocyanate-induced asthma showing allergic-type inflammation in the lung after inhaled antigen challenge. The Journal of allergy and clinical immunology 109: 873-878.

35. Pauluhn, J. 2008. Brown Norway rat asthma model of diphenylmethane-4,4'-diisocyanate (MDI): impact of vehicle for topical induction. Regulatory toxicology and pharmacology : RTP 50: 144-154.

36. Erjefalt, I., and C. G. Persson. 1992. Increased sensitivity to toluene diisocyanate (TDI) in airways previously exposed to low doses of TDI. Clinical and experimental allergy : journal of the British Society for Allergy and Clinical Immunology 22: 854-862.

37. Scheerens, H., T. L. Buckley, T. L. Muis, J. Garssen, J. Dormans, F. P. Nijkamp, and H. Van Loveren. 1999. Long-term topical exposure to toluene diisocyanate in mice leads to antibody production and in vivo airway hyperresponsiveness three hours after intranasal challenge. American journal of respiratory and critical care medicine 159: 1074-1080.

38. Fukuyama, T., H. Ueda, K. Hayashi, Y. Tajima, Y. Shuto, T. R. Saito, T. Harada, and T. Kosaka. 2008. Use of long term dermal sensitization followed by intratracheal challenge method to identify low-dose chemical-induced respiratory allergic responses in mice. Toxicology letters 181: 163-170.

39. Matheson, J. M., R. W. Lange, R. Lemus, M. H. Karol, and M. I. Luster. 2001. Importance of inflammatory and immune components in a mouse model of airway reactivity to toluene diisocyanate (TDI). Clinical and experimental allergy : journal of the British Society for Allergy and Clinical Immunology 31: 1067-1076.

40. Franko, J., B. J. Meade, H. F. Frasch, A. M. Barbero, and S. E. Anderson. 2012. Dermal penetration potential of perfluorooctanoic acid (PFOA) in human and mouse skin. Journal of toxicology and environmental health. Part A 75: 50-62.

41. Rattray, N. J., P. A. Botham, P. M. Hext, D. R. Woodcock, I. Fielding, R. J. Dearman, and I. Kimber. 1994. Induction of respiratory hypersensitivity to diphenylmethane-4,4'diisocyanate (MDI) in guinea pigs. Influence of route of exposure. Toxicology 88: 15-30.

42. van Triel, J. J., B. W. van Bree, D. W. Roberts, H. Muijser, E. Duistermaat, R. A. Woutersen, and C. F. Kuper. 2011. The respiratory allergen glutaraldehyde in the local lymph node assay: sensitization by skin exposure, but not by inhalation. Toxicology 279: 115-122.

43. Ruwona, T. B., V. J. Johnson, D. Schmechel, R. H. Simoyi, D. Beezhold, and P. D. Siegel. 2010. Monoclonal antibodies against toluene diisocyanate haptenated proteins from vapor-exposed mice. Hybridoma (2005) 29: 221-229. 
44. Hulst, A. G., D. R. Verstappen, D. van der Riet-Van Oeveren, N. P. Vermeulen, and D. Noort. 2015. Mass spectrometric identification of isocyanate-induced modifications of keratins in human skin. Chemico-biological interactions 237: 141-150.

45. Nayak, A. P., J. M. Hettick, P. D. Siegel, S. E. Anderson, C. M. Long, B. J. Green, and D. H. Beezhold. 2014. Toluene diisocyanate (TDI) disposition and co-localization of immune cells in hair follicles. Toxicological sciences : an official journal of the Society of Toxicology 140: 327-337.

46. Kohler, J., S. Martin, U. Pflugfelder, H. Ruh, J. Vollmer, and H. U. Weltzien. 1995. Cross-reactive trinitrophenylated peptides as antigens for class II major histocompatibility complex-restricted T cells and inducers of contact sensitivity in mice. Limited T cell receptor repertoire. European journal of immunology 25: 92-101.

47. Bentley, A. M., P. Maestrelli, M. Saetta, L. M. Fabbri, D. S. Robinson, B. L. Bradley, P. K. Jeffery, S. R. Durham, and A. B. Kay. 1992. Activated T-lymphocytes and eosinophils in the bronchial mucosa in isocyanate-induced asthma. The Journal of allergy and clinical immunology 89: 821-829.

48. Potter, D. W., and K. S. Wederbrand. 1995. Total IgE antibody production in BALB/c mice after dermal exposure to chemicals. Fundamental and applied toxicology : official journal of the Society of Toxicology 26: 127-135.

49. Park, H. S., H. Y. Kim, D. H. Nahm, J. W. Son, and Y. Y. Kim. 1999. Specific IgG, but not specific IgE, antibodies to toluene diisocyanate-human serum albumin conjugate are associated with toluene diisocyanate bronchoprovocation test results. The Journal of allergy and clinical immunology 104: 847-851.

50. Herrick, C. A., J. Das, L. Xu, A. V. Wisnewski, C. A. Redlich, and K. Bottomly. 2003. Differential roles for CD4 and CD8 T cells after diisocyanate sensitization: Genetic control of TH2-induced lung inflammation. Journal of Allergy and Clinical Immunology 111: 1087-1094.

51. Deo, S. S., K. J. Mistry, A. M. Kakade, and P. V. Niphadkar. 2010. Role played by Th2 type cytokines in IgE mediated allergy and asthma. Lung India : Official Organ of Indian Chest Society 27: 66-71.

52. Kimber, I., and R. J. Dearman. 2002. Chemical respiratory allergy: role of IgE antibody and relevance of route of exposure. Toxicology 181-182: 311-315.

53. Yokota, K., K. Yamaguchi, T. Takeshita, and K. Morimoto. 1998. The significance of specific IgG4 antibodies to methyltetrahydrophthalic anhydride in occupationally exposed subjects. Clinical and experimental allergy : journal of the British Society for Allergy and Clinical Immunology 28: 694-701.

54. De Vooght, V., V. Carlier, F. C. Devos, S. Haenen, E. Verbeken, B. Nemery, P. H. M. Hoet, and J. A. J. Vanoirbeek. 2013. B-lymphocytes as Key Players in Chemical-Induced Asthma. PLoS ONE 8: e83228.

55. Matheson, J. M., R. Lemus, R. W. Lange, M. H. Karol, and M. I. Luster. 2002. Role of tumor necrosis factor in toluene diisocyanate asthma. American journal of respiratory cell and molecular biology 27: 396-405.

56. De Vooght, V., J. A. Vanoirbeek, S. Haenen, E. Verbeken, B. Nemery, and P. H. Hoet. 2009. Oropharyngeal aspiration: an alternative route for challenging in a mouse model of chemical-induced asthma. Toxicology 259: 84-89.

57. Di Stefano, A., M. Saetta, P. Maestrelli, G. Milani, F. Pivirotto, C. E. Mapp, and L. M. Fabbri. 1993. Mast cells in the airway mucosa and rapid development of occupational 
asthma induced by toluene diisocyanate. The American review of respiratory disease 147: 1005-1009.

58. De Vooght, V., S. Smulders, S. Haenen, J. Belmans, G. Opdenakker, E. Verbeken, B. Nemery, P. H. M. Hoet, and J. A. J. Vanoirbeek. 2013. Neutrophil and Eosinophil Granulocytes as Key Players in a Mouse Model of Chemical-Induced Asthma. Toxicological Sciences 131: 406-418.

59. Lange, R. W., R. C. Lantz, D. B. Stolz, S. C. Watkins, P. Sundareshan, R. Lemus, and M. H. Karol. 1999. Toluene diisocyanate colocalizes with tubulin on cilia of differentiated human airway epithelial cells. Toxicological sciences : an official journal of the Society of Toxicology 50: 64-71.

60. Oakley, A. 2011. Glutathione transferases: a structural perspective. Drug metabolism reviews 43: 138-151.

61. Visse, R., and H. Nagase. 2003. Matrix Metalloproteinases and Tissue Inhibitors of Metalloproteinases: Structure, Function, and Biochemistry. Circulation Research 92: 827-839.

62. Lee, Y. C., C. H. Song, H. B. Lee, J. L. Oh, Y. K. Rhee, H. S. Park, and G. Y. Koh. 2001. A murine model of toluene diisocyanate-induced asthma can be treated with matrix metalloproteinase inhibitor. The Journal of allergy and clinical immunology 108: 10211026.

63. Kim, S. H., G. S. Choi, Y. M. Ye, I. Jou, H. S. Park, and S. M. Park. 2010. Toluene diisocyanate (TDI) regulates haem oxygenase-1/ferritin expression: implications for toluene diisocyanate-induced asthma. Clinical and experimental immunology 160: 489497.

64. Nakai, K., K. Yoneda, and Y. Kubota. 2012. Oxidative stress in allergic and irritant dermatitis: from basic research to clinical management. Recent patents on inflammation \& allergy drug discovery 6: 202-209.

65. Yu, B. P. 1994. Cellular defenses against damage from reactive oxygen species. Physiological reviews 74: 139-162.

66. Hur, G. Y., G. S. Choi, S. S. Sheen, H. Y. Lee, H. J. Park, S. J. Choi, Y. M. Ye, and H. S. Park. 2008. Serum ferritin and transferrin levels as serologic markers of methylene diphenyl diisocyanate-induced occupational asthma. The Journal of allergy and clinical immunology 122: 774-780.

67. Reddy, R. C., and T. J. Standiford. 2010. Nrf2 and PPAR $\gamma$. American journal of respiratory and critical care medicine 182: 134-135.

68. Kim, S. H., H. J. Park, C. M. Lee, I. W. Choi, D. O. Moon, H. J. Roh, H. K. Lee, and Y. M. Park. 2006. Epigallocatechin-3-gallate protects toluene diisocyanate-induced airway inflammation in a murine model of asthma. FEBS letters 580: 1883-1890.

69. Long, C. M., N. B. Marshall, E. Lukomska, M. L. Kashon, B. J. Meade, H. Shane, and S. E. Anderson. 2016. A Role for Regulatory T Cells in a Murine Model of Epicutaneous Toluene Diisocyanate Sensitization. Toxicological sciences : an official journal of the Society of Toxicology.

70. Kato, T., S. Tada-Oikawa, L. Wang, M. Murata, and K. Kuribayashi. 2013. Endocrine disruptors found in food contaminants enhance allergic sensitization through an oxidative stress that promotes the development of allergic airway inflammation. Toxicology and applied pharmacology 273: 10-18. 
71. Park, S. J., K. S. Lee, S. R. Kim, H. J. Chae, W. H. Yoo, D. I. Kim, M. S. Jeon, and Y. C. Lee. 2012. AMPK activation reduces vascular permeability and airway inflammation by regulating HIF/VEGFA pathway in a murine model of toluene diisocyanate-induced asthma. Inflammation research : official journal of the European Histamine Research Society ... [et al.] 61: 1069-1083.

72. Mapp, C. E., B. Beghe, A. Balboni, G. Zamorani, M. Padoan, L. Jovine, O. R. Baricordi, and L. M. Fabbri. 2000. Association between HLA genes and susceptibility to toluene diisocyanate-induced asthma. Clinical and experimental allergy : journal of the British Society for Allergy and Clinical Immunology 30: 651-656.

73. Balboni, A., O. R. Baricordi, L. M. Fabbri, E. Gandini, A. Ciaccia, and C. E. Mapp. 1996. Association between toluene diisocyanate-induced asthma and DQB1 markers: a possible role for aspartic acid at position 57. The European respiratory journal 9: 207210.

74. Bernstein, J. A. 1996. Overview of diisocyanate occupational asthma. Toxicology 111: 181-189.

75. Bernstein, J. A., J. Munson, Z. L. Lummus, K. Balakrishnan, and G. Leikauf. 1997. Tcell receptor $\mathrm{V}$ beta gene segment expression in diisocyanate-induced occupational asthma. The Journal of allergy and clinical immunology 99: 245-250.

76. Kim, S. H., S. J. Bae, S. Palikhe, Y. M. Ye, and H. S. Park. 2015. Effects of MBL2 polymorphisms in patients with diisocyanate-induced occupational asthma. Experimental \& molecular medicine 47: e157.

77. Wisnewski, A. V., L. Xu, E. Robinson, J. Liu, C. A. Redlich, and C. A. Herrick. 2011. Immune sensitization to methylene diphenyl diisocyanate (MDI) resulting from skin exposure: albumin as a carrier protein connecting skin exposure to subsequent respiratory responses. Journal of Occupational Medicine and Toxicology 6: 1-12.

78. Anderson, S. E., K. Beezhold, E. Lukomska, J. Richardson, C. Long, K. Anderson, J. Franko, B. J. Meade, and D. H. Beezhold. 2013. Expression kinetics of miRNA involved in dermal toluene 2,4-diisocyanate sensitization. Journal of immunotoxicology.

79. Saetta, M., A. Di Stefano, P. Maestrelli, N. De Marzo, G. F. Milani, F. Pivirotto, C. E. Mapp, and L. M. Fabbri. 1992. Airway mucosal inflammation in occupational asthma induced by toluene diisocyanate. The American review of respiratory disease 145: 160168. 


\section{CHAPTER 3}

General Expression Kinetics, Phenotype, and Functional

$$
\text { Characterization of } \mathbf{T}_{\text {regs }} \text { During TDI Sensitization }
$$

Toxicological Sciences. 2016 April 21. 10.1093/toxsci/kfw074 
A Role for Regulatory T Cells in a Murine Model of Epicutaneous Toluene Diisocyanate Sensitization

Carrie Mae Long ${ }^{* \dagger}$, , Nikki B Marshall ${ }^{*}$, Ewa Lukomska ${ }^{*}$, Michael L Kashon ${ }^{\ddagger}$, B. Jean Meade ${ }^{*}$, Hillary Shane*, Stacey E Anderson*

*- Allergy and Clinical Immunology Branch, Health Effects Laboratory Division, National Institute for Occupational Safety and Health, Centers for Disease Control and Prevention, Morgantown, WV 26505

$\uparrow$ - West Virginia University School of Medicine, Immunology and Microbial Pathogenesis Graduate Program, Morgantown, WV 26505

‡- Biostatics and Epidemiology Branch, Health Effects Laboratory Division, National Institute for Occupational Safety and Health, Centers for Disease Control and Prevention, Morgantown, WV 26505

Corresponding author: Carrie Mae Long, CDC-NIOSH, 1095 Willowdale Road, Mailstop 4020, Morgantown, WV 26505, CMLong@,cdc.gov, (304) 293-6106

Running Title (40 characters): Regulatory T Cells in TDI Sensitization 


\section{ABSTRACT}

Toluene diisocyanate (TDI) is a leading cause of chemical-induced occupational asthma which impacts workers in a variety of industries worldwide. Recently, the robust regulatory potential of regulatory $T$ cells $\left(\mathrm{T}_{\text {regs }}\right)$ has become apparent, including their functional role in the regulation of allergic disease; however, their function in TDI-induced sensitization has not been explored. To elucidate the kinetics, phenotype, and function of $\mathrm{T}_{\text {regs }}$ during TDI sensitization, $\mathrm{BALB} / \mathrm{c}$ mice were dermally exposed (on each ear) to a single application of TDI $(0.5-4 \% \mathrm{v} / \mathrm{v})$ or acetone vehicle and endpoints were evaluated via RT-PCR and flow cytometry. The draining lymph node (dLN) $\mathrm{T}_{\text {reg }}$ population expanded significantly 4 , 7, and 9 days after single 4\% TDI exposure. This population was identified using a variety of surface and intracellular markers and was found to be phenotypically heterogeneous based on increased expression of markers including CD103, CCR6, CTLA4, ICOS, and Neuropilin-1 during TDI sensitization. T $_{\text {regs }}$ isolated from TDI-sensitized mice were significantly more suppressive compared to their control counterparts, further supporting a functional role for $\mathrm{T}_{\text {regs }}$ during TDI sensitization. Lastly, $\mathrm{T}_{\text {regs }}$ were depleted prior to TDI sensitization and an intensified sensitization response was observed. Collectively, these data indicate that $T_{\text {regs }}$ exhibit a functional role during TDI sensitization. Because the role of $T_{\text {regs }}$ in TDI sensitization has not been previously elucidated, these data contribute to the understanding of the immunologic mechanisms of chemical induced allergic disease.

Key Words: Chemical sensitization, isocyanate, TDI, chemical allergy, regulatory $\mathrm{T}$ cells, hypersensitivity 


\subsection{INTRODUCTION}

Toluene diisocyanate (TDI) is a low molecular weight, highly reactive chemical utilized in the automobile industry and in the manufacture of polyurethane, foams, paints, and coatings. The U.S. Environmental Protection Agency reports that domestic production and importation of 2,4- and 2,6- TDI isomers rose above 1 billion pounds in 2006 (1). TDI is a potent sensitizer and irritant; repeat dermal and/or inhalation exposure can lead to a variety of allergic diseases including asthma, hypersensitivity pneumonitis, rhinitis, and contact dermatitis (2-4) These diseases can be disabling and extremely severe, potentially resulting in lifelong illness and/or death (5). TDI is generally classified as primarily a respiratory, Th2-mediated sensitizer with a Th1 component (6). Although the murine local lymph node assay (LLNA) is validated for the identification of chemicals that preferentially elicit dermal allergic disease, it is not validated for chemicals that preferentially elicit respiratory disease (7). In light of this challenge, further mechanistic insight into the role of immunologically relevant cellular subsets (in addition to Th1 and Th2), involved in respiratory sensitization may ultimately contribute to the development of improved predictive models based on cellular phenotype, secreted cytokine expression, or other related parameters. Recent immunological developments such as the discovery of novel $\mathrm{T}$ cell subsets including Th17, T follicular helper, Th22, $\mathrm{Th} 9$, and $\mathrm{T}_{\text {reg, }}$, cells support the potential for the utilization of novel mediators of allergic disease (8).

Classical $\mathrm{T}_{\text {regs }}\left(\mathrm{CD}^{+} \mathrm{CD} 25^{+}\right)$were initially identified based on their suppressive capabilities which contributed to the maintenance of immune tolerance in mice (9). Following this discovery, a transcription factor known as forkhead box p3 (Foxp3) was identified as the master transcription factor of $T_{\text {regs, }}$ allowing for their identification and functional manipulation (10). Both naturally

occurring $\mathrm{T}_{\text {regs }}\left(\mathrm{nT}_{\text {regs }}\right)$ that develop in the thymus and inducible $\mathrm{T}_{\text {regs }}\left(\mathrm{iT}_{\text {regs }}\right)$ that develop in the periphery are involved in the maintenance of immune tolerance. Functionally, $\mathrm{T}_{\text {regs }}$ have 
demonstrated a critical role in the development of immune tolerance and can serve as effectors helping to prevent overzealous adaptive responses to foreign antigens and allergens $(11,12)$. This suppressive function is mediated by a variety of mechanisms including, but not limited to, the control of conventional $\mathrm{T}$ cell proliferation through the inhibition of co-stimulation via cytotoxic $\mathrm{T}$ lymphocyte associated protein 4 (CTLA4) expression and/or IL-2 consumption, immunosuppressive cytokine secretion (IL-10 and TGF- $\beta$ ), metabolic interference, and disruption of dendritic cell function (12-14).

Although a functional role for $\mathrm{T}_{\text {regs }}$ has been suggested in models of chemical-induced contact hypersensitivity (15), this cellular subset has not been investigated in TDI sensitization. Vanoirbeek and colleagues observed suspected immune tolerance induced by high dose (3\% TDI in acetone-olive oil) dermal sensitization followed by intranasal challenge resulting in the absence of airway hyperreactivity, contrasted with low dose $(0.3 \%$ TDI in acetone-olive oil) dermal sensitization resulting in airway hyperreactivity following intranasal challenge (16). Although not explicitly stated in the manuscript, this seminal study suggested a role for $\mathrm{T}_{\text {regs }}$ in TDI sensitization. The collection of data regarding $\mathrm{T}_{\text {regs }}$ and chemical allergy is growing but remains limited. In order to elucidate the immunologic mechanisms involved in TDI sensitization, the biological functions of pertinent immune cell subsets need to be delineated. It is important to note that although a variety of regulatory $\mathrm{T}$ cells may be involved in chemical sensitization, this study focuses on classical $\mathrm{T}_{\text {regs }}$ $\left(\mathrm{CD}^{+} \mathrm{CD}^{+} \mathrm{CD} 25^{+} \mathrm{Foxp}^{+}\right)$due to their well-documented regulatory potential in a variety of disease states, including allergy and asthma (17), and to the lack of data regarding these cells in models of low molecular weight chemical allergy. Here, we utilize a murine model of dermal TDI sensitization in order to elucidate the expression kinetics, phenotype, and functional role of $\mathrm{T}_{\text {regs }}$ during chemical sensitization. 


\subsection{MATERIALS AND METHODS}

\subsubsection{Mice}

Female BALB/c mice (6-8 weeks of age) purchased from Taconic (Germantown, NY) were acclimated for 5 days and then randomly assigned to treatment group. Homogenous weight distribution was insured across treatment groups. BALB/c mice were selected on the basis of their Th2 bias, robust IgE production, and the historical use of these mice in the laboratory to investigate chemical sensitization (18). Mice were housed in ventilated plastic shoebox cages with hardwood chip bedding at a maximum of five animals per cage. A NIH-31 modified $6 \%$ irradiated rodent diet (Harlan Teklad) and tap water were administered ad libitum. Housing facilities were maintained at $68-72^{\circ} \mathrm{F}$ and $36-57 \%$ relative humidity, and a 12 hour light-dark cycle was maintained. All animal experiments were performed in the Association for Assessment and Accreditation of Laboratory Animal Care (AAALAC) accredited National Institute for Occupational Safety and Health (NIOSH) animal facility in accordance with an Institutional Animal Care and Use Committee-approved protocol.

\subsubsection{TDI Sensitization Model}

Toluene 2,4-diisocyanate (TDI, CAS\# 584-84-9) was purchased from Sigma-Aldrich Chemical Company (Milwaukee, WI). Animals $(n=4-5)$ were exposed to a single dose of $0.5-4 \%$ TDI (v/v) on the dorsal surface of each ear $(25 \mu \mathrm{L}$ per ear). The highest concentration $(4 \% \mathrm{v} / \mathrm{v}$; the

maximum sensitizing concentration with minimal toxicity) and dosing regimen was previously shown to induce sensitization (19) and sensitization was confirmed in the lower dose based on total serum IgE levels and dLN allergic cytokine mRNA expression $(0.5 \% \mathrm{v} / \mathrm{v}$; data not shown). Acetone 
was selected as the vehicle control to minimize chemical reactivity as diisocyanates react with $\mathrm{OH}$ groups which are present in other potential vehicles such as olive oil. Ear thickness was measured 4 days following TDI exposure using a modified engineer's micrometer (Mitutoyo Corporation, Japan) and measurements were collected in millimeters ( $\mathrm{mm})$. Average ear swelling was calculated as previously described (20). Mice were euthanized via $\mathrm{CO}_{2}$ asphyxiation at time points ranging from 1 - 11 days post chemical exposure.

\subsubsection{Euthanasia, Tissue Collection, and Processing}

Animals were weighed, euthanized via $\mathrm{CO}_{2}$ asphyxiation, and examined for gross pathology at the designated time point. Left and right superficial parotid draining lymph nodes (dLNs; drain site of chemical application (21)) were collected in sterile phosphate-buffered saline (pH 7.4) and manually dissociated using the frosted ends of two microscope slides. dLN cellularity was determined using a Cellometer (Nexcelom Bioscience, Lawrence, Massachusetts) with size exclusion parameters (3.5 to $36 \mu \mathrm{m})$ and a combined Acridine Orange/Propidium Iodide (AO/PI) solution to identify viable cells. Blood was collected via cardiac puncture, placed into serum collection tubes, centrifuged, and serum was removed and stored at $-80^{\circ} \mathrm{C}$ for subsequent total $\operatorname{IgE}$ analysis via ELISA. Ears were collected in $1 \mathrm{~mL}$ RNALater (Ambion, Pittsburgh, PA), stored at $80^{\circ} \mathrm{C}$ for subsequent gene expression analysis or processed for flow cytometric analysis. For flow cytometric analysis of the skin (Figure 5.4 and Appendix 5.1), ear cell suspensions were prepared by splitting ears into ventral and dorsal halves, mincing into $1 \mathrm{cmx} 1 \mathrm{~cm}$ pieces followed by an enzymatic digestion for $90 \mathrm{~min}$ at $37^{\circ} \mathrm{C}$ with $0.25 \mathrm{mg} / \mathrm{ml}$ Liberase-TL Research grade (Roche) in RPMI with 100ug/ml DNase I (Sigma). Following digestion cells were passed through a 70 um cell 
strainer to make a single cell solution, washed with RPMI $+10 \%$ FBS, then live cells were counted on a Cellometer (Nexcelom) using AO/PI.

\subsubsection{RNA Isolation and Reverse Transcription}

Ears were processed for RNA isolation using a Tissue Lyser II in Qiagen lysis buffer. Total RNA was isolated from the ears and dLN using the Qiagen RNeasy and miRNeasy kits respectively. A QiaCube (Qiagen, Hilden, Germany) automated RNA isolation machine was utilized in conjunction with the specified RNA isolation kits. A DNase treatment was performed for removal of residual DNA. The concentration and purity of the RNA was determined using a ND-1000 spectrophotometer (Thermo Scientific Nanodrop, Wilmington, DE). First strand cDNA synthesis was performed using a High-Capacity cDNA Synthesis Kit (Applied Biosystems, Carlsbad, California) according to manufacturer recommendations. Ultimately, the cDNA was analyzed for mRNA expression as described in the real-time PCR methods section below.

\subsubsection{Real Time PCR (RT-PCR)}

For analysis of mRNA expression, TaqMan Universal Fast master mix (Applied Biosystems, Calsbad, California), cDNA, and mouse-specific mRNA primers (TaqMan Custom PCR Arrays, Carlsbad, California) were combined and PCR was performed according to manufacturer protocol. Primers used include: $i l-1 \beta$, il-6, and $t n f-\alpha$. Master mix, primers, and cDNA were added to a MicroAmp Fast Optical 96-well reaction plate and analyzed on an Applied Biosystems 7500 Fast Real Time PCR system using cycling conditions as specified by the manufacturer. $\beta$-actin was used as the endogenous reference control gene as expression was determined to be stable following chemical exposure (data not shown). RT-PCR data were collected and represented as relative fold 
change over vehicle control, calculated by the following formula: $2^{-\Delta \Delta \mathrm{Ct}}=\Delta \mathrm{Ct}_{\text {Sample }}-\Delta \mathrm{Ct}_{\text {Control }}$. $\Delta \mathrm{Ct}=\mathrm{Ct}_{\text {Target }}-\mathrm{Ct}_{\beta-\mathrm{ACTIN}}$, where $\mathrm{Ct}=$ cycle threshold.

\subsubsection{Flow Cytometric Analysis}

Single cell suspensions were prepared from tissues and a minimum of 150,000 dLN and 1,000,000 ear skin cells were aliquoted into 96-well U-bottom plates and washed in FACS staining buffer (PBS $+1 \%$ bovine serum albumin $+0.1 \%$ sodium azide). Cells were resuspended in staining buffer containing anti-mouse CD16/32 antibody (clone 2.4G2; BD Biosciences, San Jose, CA) for blocking of $F_{c}$ receptors to minimize nonspecific binding. Cells were resuspended in staining buffer containing a cocktail of fluorochrome-conjugated antibodies specific for cell surface antigens including: CCR6 (clone: 29-2L17, fluorophore: BV605, BioLegend), CD3 (500A2, V500, BD), CD4 (RM4-5, AF700, BD), CD8a (53-6.7, AF488, BioLegend), CD25 (PC61, APC Cy7, BioLegend), CD45 (30-F11, PE, BD), CD103 (2E7, PerCP Cy5.5, BioLegend), ICOS (C938.4A, PE Cy7, eBioscience), Neu-1 (3E12, PE, BioLegend), and Ter-119 (TER-119, FITC, eBioscience). Following surface staining, cells were washed in staining buffer and fixed using the Foxp3 fixation buffer set (eBioscience, San Diego, CA). After overnight incubation in staining buffer, cells were permeablilized using the Foxp3 fixation buffer set (eBioscience, San Diego, CA) and re-suspended in permeabilization buffer containing a cocktail of fluorochrome-conjugated antibodies specific for intracellular antigens including: CTLA4 (UC10-4B9, BV421, BioLegend), Foxp3 (FLK-16s, eF450 and APC, eBioscience), Gata3 (TWAJ, eF660, eBioscience), Roryt (Q31-378, PerCP Cy5.5, eBioscience), and Tbet (4B10, PE Cy7, eBioscience). Following staining, cells were re-suspended in staining buffer and analyzed on an LSR II flow cytometer using FacsDiva software (BD Biosciences). Data analysis was performed with FlowJo 10.0 software (TreeStar Inc., Ashland, OR). 
A minimum of 10,000 events were captured for each sample. Leukocytes were first identified by their expression of $\mathrm{CD} 45$. The $\mathrm{T}_{\text {reg }}$ subset was further identified as $\mathrm{CD} 3^{+} \mathrm{CD} 4^{+} \mathrm{CD} 8^{-} \mathrm{CD} 25^{+} \mathrm{Foxp}^{+}$. Numerical population values were calculated by applying subset frequencies to the initial cell count obtained following lymph node homogenization. Compensation controls were performed using single stained cellular suspensions and OneComp beads (eBioscience, San Diego, CA) and fluorescence minus one (FMO) staining controls were included to help set gating boundaries.

\subsection{7. $T_{\text {reg }}$ Suppression Assay}

The suppressive ability of $\mathrm{T}_{\text {regs }}$ was analyzed using an ex vivo $\mathrm{T}_{\text {reg }}$ suppression assay as described by Kruisbeek, et al (22) and Marshall, et al (23) with some modifications. This assay evaluates the ability of naïve, conventional dLN-derived $\mathrm{T}$ cells $\left(\mathrm{T}_{\text {cons }}\right)$ to proliferate in the presence of varying numbers of $\mathrm{T}_{\text {regs }}$ isolated from acetone- or TDI-exposed mice. Mice were exposed to acetone $(\mathrm{n}=7-11)$ or TDI $(4 \%)(\mathrm{n}=4-5)$ as previously described and following sacrifice at 4 and 7 days post TDI (peak of the expansion) exposure the dLN and spleens were removed. $T_{\text {regs }}$ $\left(\mathrm{CD}^{+} \mathrm{CD}^{-} 5^{+}\right)$and $\mathrm{T}_{\text {cons }}\left(\mathrm{CD} 4^{+} \mathrm{CD} 25^{-}\right)$were isolated from the lymph nodes and $\mathrm{CD} 4^{-}$accessory cells were isolated from naïve spleens using CD4 negative and CD25 positive selection-based magnetic separation kits (Stemcell, Vancouver, BC). Average $T_{\text {reg }}$ purity is as follows for 4 days: Acetone$70.65 \%$ of $\mathrm{CD}^{+} \mathrm{CD}^{+}$cells and $4 \%$ TDI- $63.05 \%$ of $\mathrm{CD}^{+} \mathrm{CD}^{+}$cells and 7 days: Acetone- $91.35 \%$ of $\mathrm{CD}^{+} \mathrm{CD}^{+}$cells and $4 \%$ TDI- $82.8 \%$ of $\mathrm{CD}^{+}{ }^{+} \mathrm{CD} 4^{+}$cells post $4 \%$ TDI exposure. Following isolation from naïve mouse dLNs, $\mathrm{T}_{\text {cons }}$ were labeled with $2 \mu \mathrm{M}$ carboxyfluorescein succinimidyl ester (CFSE). $\mathrm{T}_{\text {cons }}$ and $\mathrm{T}_{\text {regs }}$ were cultured in a 96-well U-bottom plate with anti-CD3 $(0.2 \mu \mathrm{g} / \mathrm{mL}$; BD Biosciences) and accessory cells at a variety of $\mathrm{T}_{\text {con }}: \mathrm{T}_{\text {reg }}$ ratios $(1: 1,2: 1,4: 1$, and 8:1). Naïve $\mathrm{CD}^{-}$splenocytes were treated with Mitomycin C (Sigma Aldrich, Saint Louis, MO) and utilized as 
accessory cells. Additional controls included stimulated $\mathrm{T}_{\text {cons }}$ only to assess baseline proliferation, $\mathrm{T}_{\text {regs }}$ only, accessory cells only, and $\mathrm{T}_{\text {cons }}$ only with no stimulation nor accessory cells. Cells from each treatment group were pooled and added to triplicate wells of the culture plate. 72 hours following plating, cells were stained with anti-CD4 and Live/Dead Violet (Life Technologies, Carlsbad, CA). $\mathrm{T}_{\text {cons }}$ were defined as $\mathrm{CD}^{+} \mathrm{CFSE}^{+}$cells and suppression was measured based on changes in the frequency of dividing $\mathrm{CFSE}^{+}$cells based on the dilution of CFSE. $\mathrm{T}_{\text {regs }}$ were analyzed for purity based on their expression of $\mathrm{CD} 3, \mathrm{CD} 4$, and Foxp3 as determined by flow cytometric analysis as previously described.

\subsubsection{In vivo Anti-CD25 Antibody Treatment}

In order to deplete $\mathrm{T}_{\text {regs }}$ before and during TDI sensitization, InvivoMAb anti $\mathrm{m} \mathrm{CD25}$ (BioXCell, PC-61.5.3) was administered in vivo. The use of this antibody as a $\mathrm{T}_{\text {reg }}$ depletion strategy is validated in vivo $(24,25)$. InVivoMAb Rat $\operatorname{IgG}_{1}$ (Bioxcell, HRPN) was utilized as a negative, isotype control. Treatment groups for this study ( $\mathrm{n}=5$ mice) are as follows: isotype/acetone, isotype/0.5\% TDI, isotype/2\% TDI, anti-CD25/acetone, anti-CD25/0.5\% TDI, and anti-CD25/2\% TDI. $200 \mu \mathrm{g}$ of the respective antibody in USP grade saline was administered intraperitoneally at days -11 and -8 during the depletion study (see Figure 6A for study timeline). Animal weights were recorded throughout the duration of the experiment to monitor potential toxicity. In order to confirm the effectiveness of the antibody, blood was collected from the lateral tail vein at days -2 and 7 , and $\mathrm{T}_{\text {regs }}$ were measured by flow cytometry as previously described. Baseline blood $\mathrm{T}_{\text {reg }}$ levels were assayed at day -12 to ensure equal pre-treatment frequencies across all groups. Mice were exposed to a single dermal application of $0.5 \%$ or $2 \%$ TDI on day 0 . The high dose of $2 \%$ TDI was selected in an effort to allow for a measurable increase in the sensitization response, as $4 \%$ TDI elicits a 
maximum sensitization response. Mice were euthanized 7 days following dermal chemical exposure. Specific measures of sensitization were evaluated, including examination of the Th2 population by flow cytometry $\left(\mathrm{CD}^{+} \mathrm{CD}^{+} \mathrm{Gata}^{+}\right)$, IL-4 dLN mRNA levels by RT-PCR, and total IgE levels in the serum. Total serum IgE was quantified following serum separation from whole blood (centrifugation) and analysis using a Mouse IgE Ready-SET-Go! Kit (Affymetrix eBioscience, San Diego, CA) according to the manufacturer's protocol. Absorbance was determined using a Spectramax Vmax plate reader (Molecular Devices, Sunnyvale, California) at 450 and 650 nm. Data analysis was performed using the IBM Softmax Pro 3.1 program (Molecular Devices, Sunnyvale, California) and the IgE concentrations for each sample were interpolated from a standard curve derived from multipoint analysis.

\subsubsection{Statistical Analysis}

Statistical analyses were generated using SAS/STAT software, version 9.3 (SAS Institute, Cary, NC) and GraphPad Prism version 5.0 (San Diego, CA). For irritancy and inflammatory gene expression analysis (Figure 1), a one way analysis of variance (ANOVA) was conducted. If the ANOVA showed significance at $\mathrm{p}<0.05$ or less, the Dunnett's Multiple Comparison Test was used to compare values from groups of mice treated with varying concentrations of TDI to the acetone control group. Figures 2-6 and Table 2 were analyzed by analysis of variance using PROC MIXED. In some cases, data were transformed using the natural log to meet the assumptions of the analysis. Significant interactions were explored utilizing the "slice" option in PROC MIXED and pairwise differences were assessed using a Fishers Least Significant Difference Test. Supplemental data was analyzed by a Student $t$-test comparing groups as indicated in the figure legends. All differences 
were considered significant at $\mathrm{p}<0.05$; representative significance symbols varied by figure, as indicated in the figure legend.

\subsection{RESULTS}

\subsubsection{Examination of Sensitization and Skin Irritancy Potential of TDI}

To confirm that a single dose exposure to TDI ( 0.5 and $4 \%)$ would sensitize animals, total serum IgE was evaluated following TDI exposure. Although not initially statistically significant, IgE levels appeared to increase in a dose-dependent manner, reaching significance following $4 \%$ exposure (Figure 3.1 A). Because TDI is a known irritant (26), the selected doses of TDI (0.5-4\% $\mathrm{v} / \mathrm{v}$ ) were assayed for dermal irritancy potential via ear swelling measurements and ear inflammatory cytokine mRNA production quantified via RT-PCR. Average ear swelling was significantly increased four days following 2 and 4\% TDI exposure (Figure 3.1 B); however, neither 0.5 nor 1\% TDI exposure induced significant increases in ear swelling (Figure 3.1 B). Inflammatory cytokine (IL-1 $\beta$, IL-6, and TNF- $\alpha$ ) mRNA levels were significantly increased in the ear four days following 4\% TDI exposure (Figure 3.1 C-E). These data suggest that 2 and 4\% TDI exposure induce a significant irritation response in the ear compared to 0.5 and $1 \%$ TDI exposure. Based on this data, 0.5 and $4 \%$ TDI were selected as the exposure concentrations in subsequent studies to represent sensitizing concentrations that encompassed both a low dose exhibiting a lack of irritation $(0.5 \%)$ along with a high dose exhibiting significant irritation (4\%). 
A

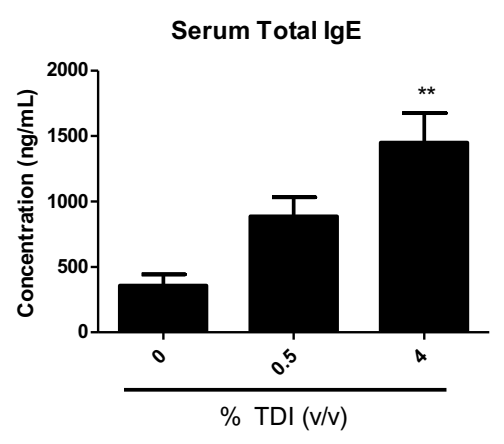

C

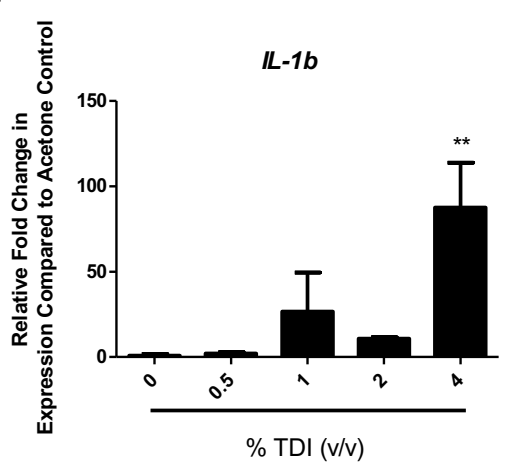

B

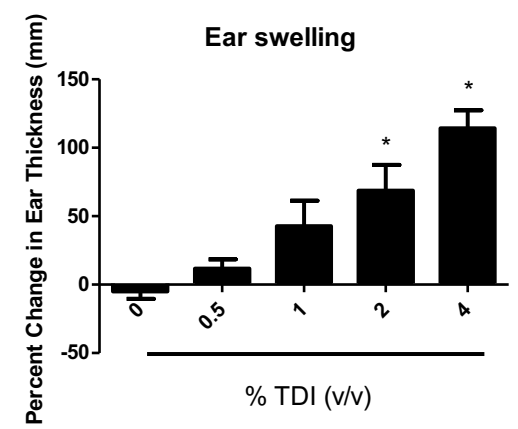

D

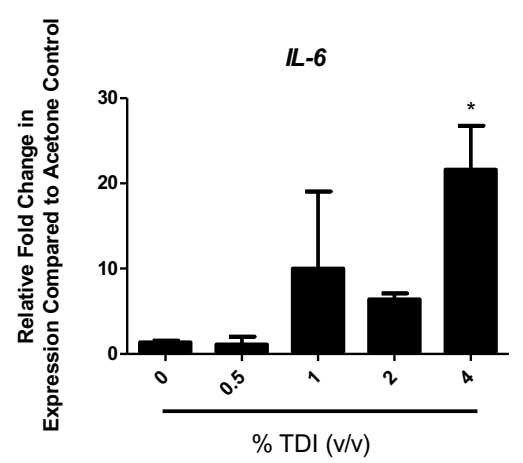

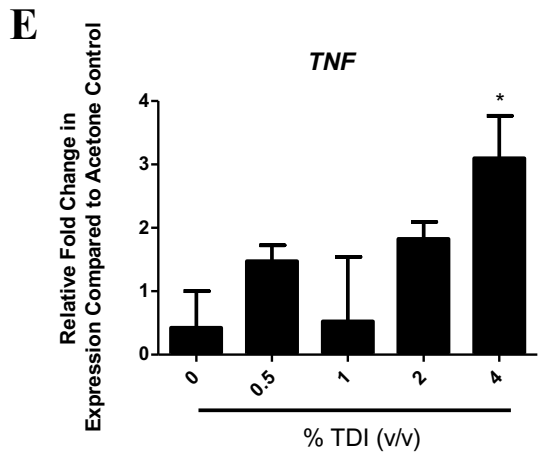

Figure 3.1: Confirmation of Sensitization and Evaluation of Skin Irritancy Following Dermal TDI

\section{Exposure}

ELISA analysis of total serum IgE levels 11 days following single TDI exposure at the indicated concentration (A). Percent change in ear thickness as determined 4 days following TDI exposure (B). Ear mRNA expression of the inflammatory cytokines $I l-1 \beta(\mathrm{C})$, il-6 (D), and $t n f-\alpha(\mathrm{E})$ as determined 4 days following TDI exposure via RT-PCR. Bars represent mean $( \pm \mathrm{SE})$ of $4-5$ mice per group. Statistical significance is indicated by (*) at a $p$ value $<0.05$ and (**) at a $p$ value $<0.01$. 


\subsection{2. dLN $T_{\text {reg }}$ Expression Kinetics Reveal an Expansion of this Population During TDI Sensitization}

In order to profile the expression kinetics of the $\mathrm{T}_{\text {reg }}$ subset during TDI sensitization we examined dLN cell populations at 1,2,4,7, and 9 days post TDI exposure (See Table 3.1 for markers utilized). $\mathrm{T}_{\text {regs }}$ were identified as $\mathrm{CD} 3^{+} \mathrm{CD} 4^{+} \mathrm{CD} 25^{+} \mathrm{Foxp}^{+}$cells by flow cytometry (Figure $3.2 \mathrm{~A}$ ). The frequency of $\mathrm{T}_{\text {regs }}$ was unchanged compared to control cells from acetone-treated mice during $0.5 \%$ TDI sensitization; however, $\mathrm{T}_{\text {reg }}$ frequency increased significantly at 4,7 , and 9 days post $4 \%$ TDI exposure (Figure 3.2 B). $\mathrm{T}_{\text {regs }}$ also significantly increased in number at all time points analyzed during 0.5 and $4 \%$ TDI sensitization (Figure $3.2 \mathrm{C}$ ). The peak numbers of $\mathrm{T}_{\text {regs }}$ in the $\mathrm{dLN}$ appeared to occur at day 4 post TDI exposure for both concentrations (mean \pm SEM; $1.17 \times 10^{6}$ cells \pm 0.08 $(0.5 \%)$ and $1.7 \times 10^{6}$ cells $\left.\pm 0.08(4 \%)\right)$ compared to the acetone control $\left(0.18 \times 10^{6}\right.$ cells \pm 0.02$)$. The $\mathrm{T}_{\text {reg }}$ population remained elevated compared to the acetone control, but began to retract at days $7\left(0.5 \%\right.$ TDI- $0.88 \times 10^{6} \pm 0.09$, and $4 \%$ TDI- $\left.1.39 \times 10^{6} \pm 0.1\right)$ and $9\left(0.5 \%\right.$ TDI- $0.37 \times 10^{6} \pm 0.06$ and $4 \%$ TDI- $0.79 \times 10^{6} \pm 0.05$ ) following TDI exposure relative to their peak at day 4.

In order to better elucidate the origin of the $\mathrm{T}_{\text {regs }}$ involved in the TDI sensitization response, natural $\mathrm{T}_{\text {regs }}\left(\mathrm{nT}_{\text {regs }}\right)$ were identified based on their expression of neuropilin-1 (27). Interestingly, the frequency of the $n T_{\text {reg }}$ subset as a percentage of total $T_{\text {regs }}$ significantly decreased at 7 and 9 days during $0.5 \%$ and $4 \%$ TDI sensitization (Figure 3.2a C). Although the frequency of this subset decreased in relation to the acetone control group, the numbers of $\mathrm{nT}_{\text {regs }}$ in the $\mathrm{dLN}$ increased during 0.5 and $4 \%$ TDI sensitization (Figure 3.2a D). This increase was significant for 4-9 days during $0.5 \%$ TDI sensitization and at all time points measured during 4\% TDI sensitization. It is important to note that both the $n T_{\text {reg }}$ and the neuropilin- $1^{\text {neg }} T_{\text {reg }}$ population (presumably induced $\mathrm{T}_{\text {regs }}\left(\mathrm{iT}_{\text {regs }}\right)$ ) were represented as co-expressing populations examined using additional markers. 


\begin{tabular}{|c|c|c|c|c|}
\hline Marker & Abbreviation & $\begin{array}{l}\text { Surface or } \\
\text { Intracellular } \\
\text { Detection }\end{array}$ & Significance & $\begin{array}{c}\text { T Cell } \\
\text { Populations } \\
\text { Expressing }\end{array}$ \\
\hline $\begin{array}{c}\text { Cluster of } \\
\text { Differentiation } 3\end{array}$ & $\mathrm{CD} 3$ & $\mathrm{~S}$ & Pan T cell marker & All T cells \\
\hline $\begin{array}{c}\text { Cluster of } \\
\text { Differentiation } 4\end{array}$ & CD4 & $S$ & $\mathrm{CD}^{+}{ }^{+} \mathrm{T}$ cell marker & $\mathrm{CD}^{+}{ }^{+} \mathrm{T}$ cells \\
\hline $\begin{array}{c}\text { Cluster of } \\
\text { Differentiation } 25 \\
\text { / IL2 } 2 \text { } \alpha\end{array}$ & CD25 & $\mathrm{S}$ & $\begin{array}{l}\text { High affinity IL-2 } \\
\text { receptor } \alpha, \mathrm{T} \text { and B cell } \\
\text { growth factor (via IL-2 } \\
\text { binding) }(28,29)\end{array}$ & $\begin{array}{c}\mathrm{T}_{\text {regs, }} \text { some } \\
\text { activated } \mathrm{T} \text { cells } \\
\left.\text { (non- } \mathrm{T}_{\text {regs }}\right)\end{array}$ \\
\hline $\begin{array}{c}\text { Forkhead Box } \\
\text { Protein } 3\end{array}$ & Foxp3 & IC & $\begin{array}{c}\text { Master } \mathrm{T}_{\text {reg }} \text { transcription } \\
\text { factor }(10)\end{array}$ & $\mathrm{T}_{\text {regs }}$ \\
\hline $\begin{array}{l}\text { Chemokine (CC- } \\
\text { Motif) Receptor } 6\end{array}$ & CCR6 & $\mathrm{S}$ & $\begin{array}{c}\text { Lymphocyte } \\
\text { chemoattractant CCL20 } \\
\text { is its ligand (30) }\end{array}$ & $\begin{array}{l}\text { Migratory Effector } \\
\mathrm{T}_{\text {regs }}(31,32) \text { and } \\
\mathrm{CD}^{+} \mathrm{T} \text { cells }(33)\end{array}$ \\
\hline $\begin{array}{c}\text { Cluster of } \\
\text { Differentiation } \\
103\end{array}$ & CD103 & $S$ & $\begin{array}{l}\text { Integrin involved in } \\
\text { epithelial } \mathrm{T} \text { cell migration } \\
\text { and retention (34) }\end{array}$ & $\begin{array}{c}\text { Migratory Effector } \\
\mathrm{T}_{\text {regs }}(35) \text { and tissue } \\
\text { resident } C D 8^{+} \mathrm{T} \\
\text { Cells }(36)\end{array}$ \\
\hline $\begin{array}{c}\text { Cytotoxic T- } \\
\text { Lymphocyte } \\
\text { Associated Protein } \\
4\end{array}$ & CTLA4/CD152 & IC & $\begin{array}{l}\text { Member of the CD28 } \\
\text { family that is a potent } \\
\text { inhibitor of T cell } \\
\text { costimulation }(37)\end{array}$ & $\begin{array}{l}\mathrm{T}_{\text {regs }} \text { and activated } \\
\mathrm{T} \text { cells (non- } \mathrm{T}_{\text {regs }} \text { ) }\end{array}$ \\
\hline $\begin{array}{l}\text { Inducible T-Cell } \\
\text { Costimulator }\end{array}$ & ICOS/CD278 & S & $\begin{array}{l}\text { Member of the CD28 } \\
\text { family that has } \\
\text { costimulatory } \\
\text { functionality during T cell } \\
\text { activation (38) }\end{array}$ & $\begin{array}{c}\text { Migratory Effector } \\
\mathrm{T}_{\text {regs }}(39-41) \text { and } \\
\text { activated } \mathrm{T} \text { cells } \\
\text { (41) }\end{array}$ \\
\hline Neuropilin-1 & Neuropilin-1 & $S$ & $\begin{array}{c}\text { Receptor for vascular } \\
\text { endothelial growth } \\
\text { factors and semaphorins } \\
(42)\end{array}$ & $\begin{array}{c}\mathrm{n}^{\prime} \mathrm{T}_{\text {regs }}(11,43), \mathrm{T}_{\mathrm{FH}} \\
\text { cells }(44), \text { and } \\
\mathrm{CD}^{+} \mathrm{T} \text { cells }(45)\end{array}$ \\
\hline
\end{tabular}

Table 3.1 $T_{\text {reg }}$ Flow Cytometry Phenotyping Marker Guide

$d L N T_{\text {reg }}$ subsets were further phenotyped by flow cytometry (Table 1). The phenotyping analysis revealed a number of $\mathrm{T}_{\text {reg }}$ subpopulations that exhibited the potential to be functionally diverse in relation to their mechanism(s) of suppression (Table 1 and A3.1). An expansion in the frequency and number of the CTLA $-4^{+} \mathrm{T}_{\text {reg }}$ population was observed at all measured time points following both 0.5 and 4\% TDI exposure (Figure 3.2a A and B). This population peaked in 
expression of both frequency (Figure 3.2a A) and number (Figure 3.2a B) at day 4 post TDI exposure. The emergence of the CTLA $4^{+} \mathrm{T}_{\text {reg }}$ population during TDI sensitization suggests the engagement of CTLA-4, a negative costimulatory molecule, as a potential suppressive mechanism during this response (46). As expected, presumably due to compensatory mechanisms during $\mathrm{T}$ cell activation, there was also an increase in CTLA4 expression in $\mathrm{CD}^{+}$non- $\mathrm{T}_{\text {regs; }}$ however, at the peak of expression (4 days) the mean frequency of expression among all $\mathrm{CD} 4^{+}$cells was $0.54 \% \pm 0.024$ for acetone, $4.6 \% \pm 0.24$ for $0.5 \% \mathrm{TDI}$, and $7.85 \% \pm 0.66$ for $4 \%$ TDI groups. Compared to the $\mathrm{T}_{\text {regs }}$ expressing CTLA4 at the same time point, these numbers reveal a sizably smaller frequency of non$\mathrm{T}_{\text {regs }}$ expressing this marker, emphasizing the specificity of this marker to the $\mathrm{T}_{\text {reg }}$ population during this response.

In addition to the CTLA4 ${ }^{+} \mathrm{T}_{\text {regs }}$ and $\mathrm{nT}_{\text {regs }}$, cells expressing the homing molecules CD103, CCR6, and ICOS were analyzed during TDI sensitization. $\mathrm{T}_{\text {reg }}$ expression of CD103, CCR6, and ICOS increased in both frequency and number throughout 0.5 and 4\% TDI sensitization (Table 3.2). The CCR $6^{+}$population's expression frequency was highest at 7 days post TDI exposure, while the $\mathrm{CD}_{103}{ }^{+}$and $\mathrm{ICOS}^{+}$populations' frequency peaked at 4 days post exposure. It is important to note that while there are significant changes in these subsets, they represent a small portion of the total $\mathrm{CD}^{+}$population, as their expression is presented on $\mathrm{T}_{\text {regs, }}$, which themselves constitute a minority of the total $\mathrm{CD}^{+}$population. Although there was robust $\mathrm{T}_{\text {reg }}$ expression of CD103, CCR6, and ICOS as single markers, there was a significant population of $\mathrm{dLN} \mathrm{T}_{\text {regs }}$ that co-expressed these molecules (Figure 3.2b A and B) with kinetics were similar to those exhibited by each single marker. This population likely represents a migratory subset of effector $T_{\text {regs }}$ that have been activated during TDI sensitization. This co-expressing population expanded in the dLN in both number and percent during TDI sensitization and represented $6.34 \% \pm 1.2$ of $\mathrm{T}_{\text {regs }}$ following acetone exposure, $12.82 \% \pm 1.2$ of 
$\mathrm{T}_{\text {regs }}$ during $0.5 \%$ TDI sensitization and $20.7 \% \pm 1.8$ of $\mathrm{T}_{\text {regs }}$ during $4 \%$ TDI sensitization at 7 days post exposure (peak expression). Ear-derived $\mathrm{T}_{\text {regs }}$ were also examined by flow cytometric analysis and the corresponding data (Figure 5.4) will be discussed in Chapter 5.

A
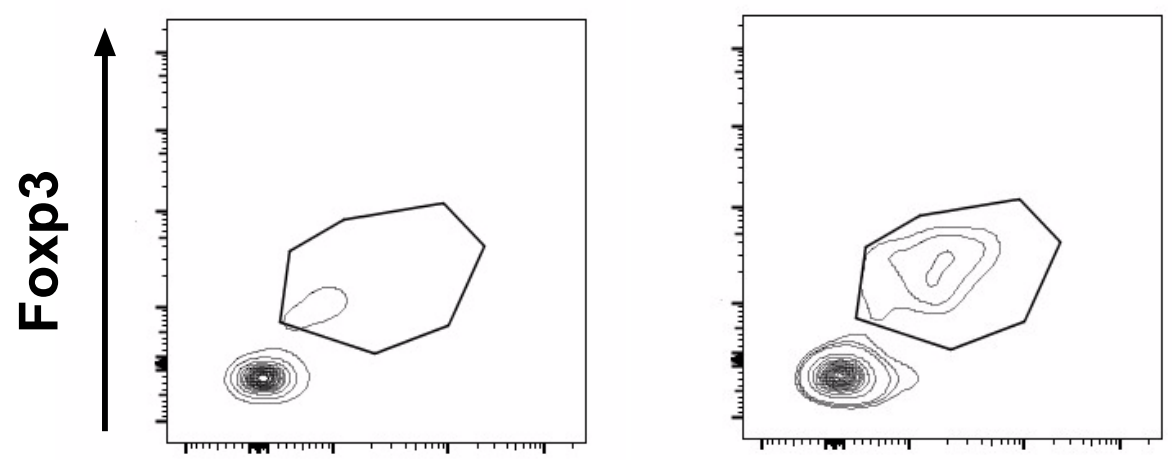

\section{CD25}

B

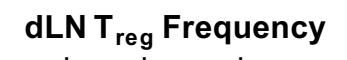
$\left(\mathrm{CD}^{+}{ }^{+} \mathrm{CD}^{+} \mathrm{CD}^{+} 5^{+} \mathrm{Foxp}^{+}\right)$

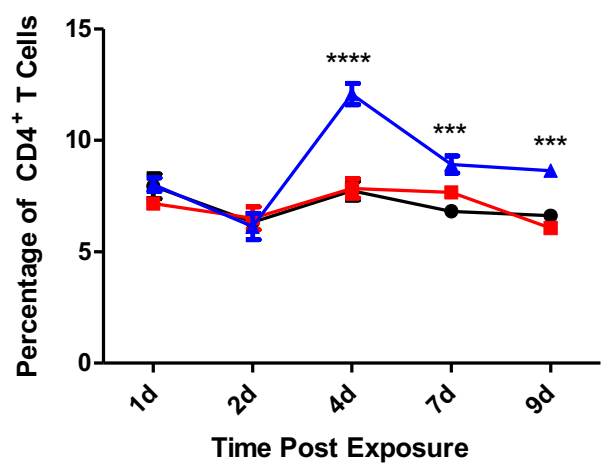

C
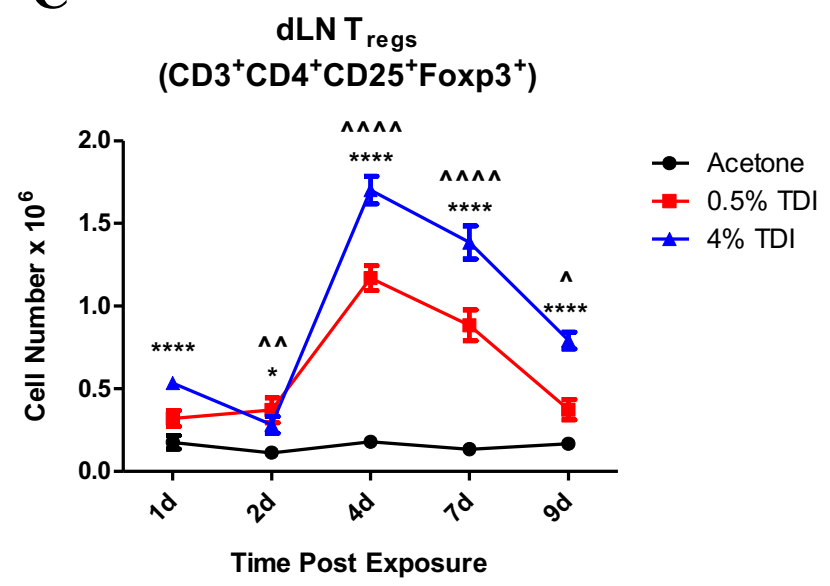

Figure 3.2 $T_{\text {reg }}$ Subset Expands During Dermal TDI Sensitization

Flow cytometric analysis of $T_{\text {regs }}$ following dermal TDI sensitization (A) $T_{\text {regs }}$ were first gated on their expression of $\mathrm{CD} 3$ and $\mathrm{CD} 4$, then were further identified by CD25 and Foxp3 expression at indicated time points. dLN $\mathrm{T}_{\text {reg frequency }}(\mathrm{B})$ and number $(\mathrm{C})$ were determined based on flow cytometry analysis and extrapolation of this data with total dLN cellularity. Graph symbols represent 
mean $( \pm \mathrm{SE})$ of 5 mice per group. $P$ values are represented by ${ }^{\wedge}(0.5 \% \mathrm{TDI})$ and asterisks $(4 \% \mathrm{TDI})$ $(P<0.05)$. Significance is indicated as follows: $\mathrm{P} \leq .05(*), \mathrm{P} \leq .01(* *), \mathrm{P} \leq .001(* *)$, and $\mathrm{P} \leq .0001$ $(* * * *)$ for $4 \%$ TDI or $\mathrm{P} \leq .05\left({ }^{\wedge}\right), \mathrm{P} \leq .01\left(^{\wedge \wedge}\right), \mathrm{P} \leq .001\left(^{\wedge \wedge \wedge}\right)$, and $\mathrm{P} \leq .0001\left(^{\wedge \wedge \wedge}\right)$ for $0.5 \%$ TDI. Dermal treatment groups are indicated by the following symbols: circle- acetone, square- $0.5 \% \mathrm{TDI}$, and triangle- $4 \%$ TDI. 
A

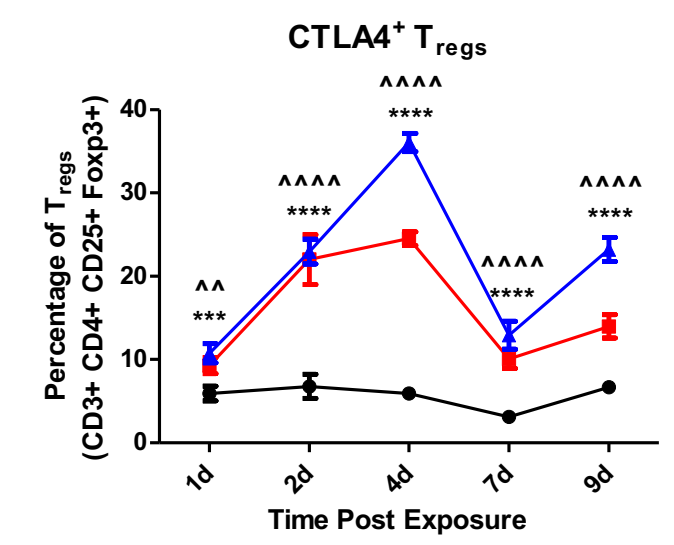

C

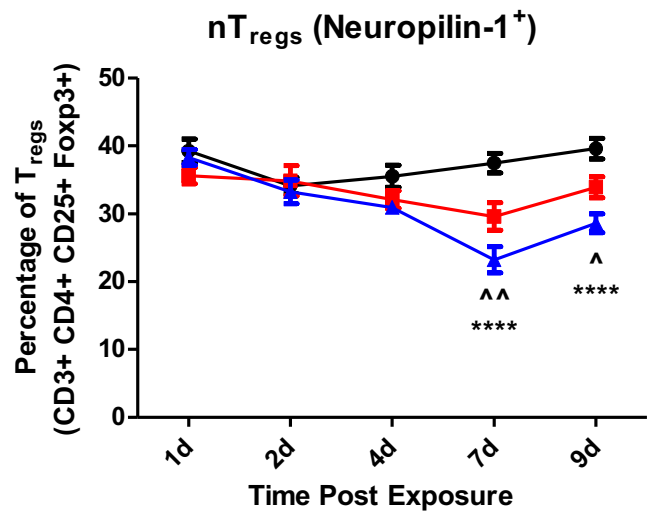

B
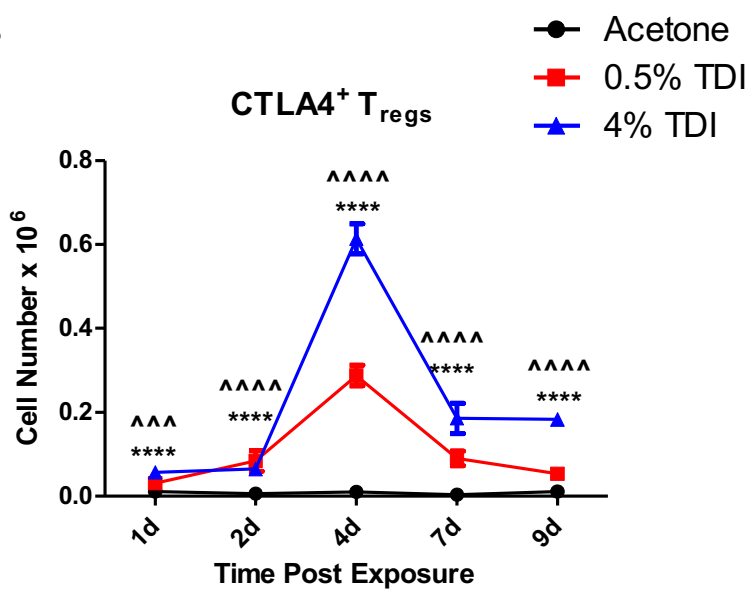

D

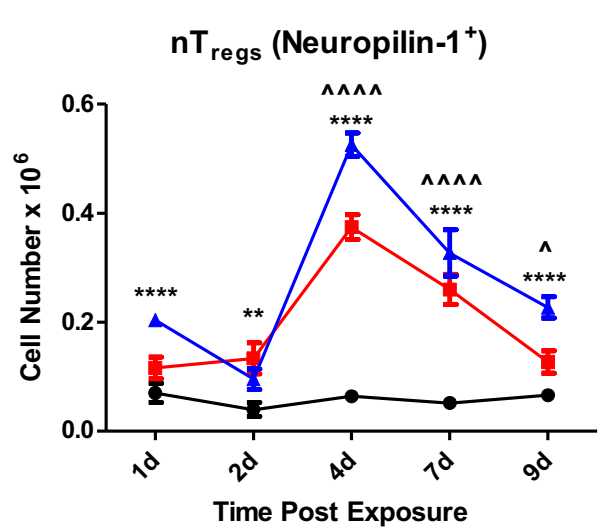

Figure 3.2a Expansion of CTLA4 $4^{+}$and $n T_{\text {reg }}$ Populations During TDI Sensitization

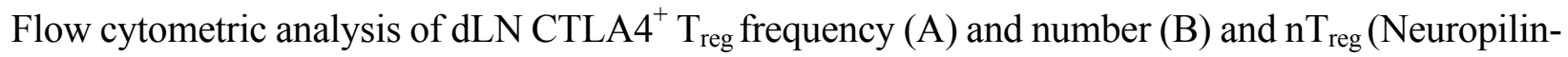
$1^{+}$) frequency (C) and number (D) following TDI sensitization. Bars represent mean ( \pm SE) of 5 mice per group. $P$ values are represented by $\wedge(0.5 \%$ TDI $)$ and asterisks $(4 \%$ TDI $)(P<0.05)$. Significance is indicated as follows: $\mathrm{P} \leq .05\left(^{*}\right), \mathrm{P} \leq .01(* *), \mathrm{P} \leq .001(* * *)$, and $\mathrm{P} \leq .0001(* * * *)$ for $4 \%$ TDI or $\mathrm{P} \leq .05\left(^{\wedge}\right), \mathrm{P} \leq .01\left(^{\wedge \wedge}\right), \mathrm{P} \leq .001\left(^{(\wedge \wedge}\right)$, and $\mathrm{P} \leq .0001\left({ }^{\wedge \wedge \wedge}\right)$ for $0.5 \%$ TDI. Dermal treatment groups are indicated by the following symbols: circle- acetone, square- $0.5 \%$ TDI, and triangle- $4 \%$ TDI. 


\begin{tabular}{|c|c|c|c|c|c|}
\hline $\begin{array}{l}\text { CCR6 }^{+} \% \\
\left(\text { of } T_{\text {regs }}\right)\end{array}$ & 1 day & $\underline{2 \text { day }}$ & $\underline{4 \text { day }}$ & 7 day & 9 day \\
\hline Acetone & $11.14 \pm 0.7$ & $12.72 \pm 1.03$ & $10.86 \pm 0.55$ & $18.22 \pm 1.36$ & $9.23 \pm 0.8$ \\
\hline $0.5 \%$ TDI & $10.22 \pm 0.68$ & $17.7 \pm 1.64^{* *}$ & $20.58 \pm 0.84 * * * *$ & $\begin{array}{l}26.54 \quad \pm \\
0.68^{* * * *}\end{array}$ & $14.82 \pm 0.99 * *$ \\
\hline $4 \%$ TDI & $10.02 \pm 0.92$ & $10.2 \pm 1.1$ & $30.7 \pm 1.75^{* * * *}$ & $\begin{array}{l}40.42 \pm \\
1.87^{* * * *}\end{array}$ & $\begin{array}{l}25.02 \pm \\
1.98^{* * * *}\end{array}$ \\
\hline $\begin{array}{l}\text { CCR6 }^{+} \# \\
\left(\times 10^{5} \text { cells }\right)\end{array}$ & & & & & \\
\hline Acetone & $0.2 \pm 0.05$ & $0.14 \pm 0.04$ & $0.19 \pm 0.02$ & $0.24 \pm 0.04$ & $0.16 \pm 0.03$ \\
\hline $0.5 \%$ TDI & $0.34 \pm 0.06^{*}$ & $0.61 \pm 0.12^{* * * *}$ & $2.41 \pm 0.19 * * * *$ & $2.35 \pm 0.28^{* * * *}$ & $0.57 \pm 0.13^{* * * *}$ \\
\hline $4 \%$ TDI & $\begin{array}{l}0.533 \pm \\
0.05^{* * * *}\end{array}$ & $0.3 \pm 0.07^{* *}$ & $5.25 \pm 0.48^{* * * *}$ & $5.59 \pm 0.41 * * * *$ & $1.99 \pm 0.2^{* * * *}$ \\
\hline $\begin{array}{c}\mathrm{CD} 103^{+} \% \\
\text { (of } \mathrm{T}_{\text {regs }} \text { ) }\end{array}$ & 1 day & 2 day & $\underline{4 \text { day }}$ & 7 day & 9 day \\
\hline Acetone & $22.86 \pm 0.75$ & $18.88 \pm 4.24$ & $20.82 \pm 0.94$ & $28.44 \pm 2$ & $21.18 \pm 0.92$ \\
\hline $0.5 \%$ TDI & $18.38 \pm 0.84$ & $24.44 \pm 2.99 *$ & $35.88 \pm 0.84^{* * * *}$ & $38.8 \pm 1.1^{* * *}$ & $\begin{array}{l}32.72 \pm \\
2.23^{* * * *}\end{array}$ \\
\hline $4 \%$ TDI & $19.62 \pm 1.25$ & $16.5 \pm 1.64$ & $43.18 \pm 1.78^{* * * *}$ & $\begin{array}{l}52.12 \pm \\
1.36^{* * * *}\end{array}$ & $\begin{array}{ll}44.64 & \pm \\
1.45^{* * * *} & \end{array}$ \\
\hline $\begin{array}{l}\mathrm{CD} 103^{+} \# \\
\left(\times 10^{5} \text { cells }\right)\end{array}$ & & & & & \\
\hline Acetone & $0.41 \pm 0.09$ & $0.16 \pm 0.03$ & $0.37 \pm 0.04$ & $0.38 \pm 0.07$ & $0.36 \pm 0.06$ \\
\hline $0.5 \%$ TDI & $0.59 \pm 0.1$ & $0.83 \pm 0.15^{* * * *}$ & $4.21 \pm 0.33^{* * * *}$ & $3.47 \pm 0.45^{* * * *}$ & $1.22 \pm 0.23^{* * * *}$ \\
\hline $4 \%$ TDI & $1.04 \pm 0.06^{* * * *}$ & $0.48 \pm 0.11^{* * * *}$ & $7.4 \pm 0.63^{* * * *}$ & $7.23 \pm 0.56^{* * * *}$ & $3.53 \pm 0.23^{* * * *}$ \\
\hline
\end{tabular}




\begin{tabular}{|c|c|c|c|c|c|}
\hline $\begin{array}{l}\mathrm{ICOS}^{+\%} \% \\
\left(\text { of } T_{\text {regs }}\right)\end{array}$ & 1 day & 2 day & 4 day & 7 day & 9 day \\
\hline Acetone & $13.38 \pm 0.36$ & $15.92 \pm 1.21$ & $13.56 \pm 0.41$ & $18.7 \pm 1.22$ & $15.98 \pm 1.24$ \\
\hline $0.5 \%$ TDI & $14.06 \pm 1.03$ & $\begin{array}{l}36.42 \pm \\
2.16^{* * * * *}\end{array}$ & $47.8 \pm 1.15^{* * * *}$ & $\begin{array}{l}38.38 \pm \\
1.72^{* * * *}\end{array}$ & $33.36 \pm 2^{* * * *}$ \\
\hline $4 \%$ TDI & $16.68 \pm 1.45$ & $\begin{array}{l}33.18 \pm \\
1.27^{* * * * *}\end{array}$ & $62.64 \pm 1.03 * * * *$ & $\begin{array}{ll}55.02 & \pm \\
2.12^{* * * *} & \end{array}$ & $\begin{array}{ll}45.54 & \pm \\
1.78^{* * * *} & \end{array}$ \\
\hline $\begin{array}{c}\text { ICOS }^{+} \# \\
\text { (x 105 cells) }\end{array}$ & & & & & \\
\hline Acetone & $0.23 \pm 0.05$ & $0.17 \pm 0.04$ & $0.24 \pm 0.02$ & $0.25 \pm 0.04$ & $0.28 \pm 0.5$ \\
\hline $0.5 \%$ TDI & $0.46 \pm 0.09 * *$ & $1.31 \pm 0.27^{* * * *}$ & $5.61 \pm 0.45^{* * * *}$ & $3.42 \pm 0.45^{* * * *}$ & $1.27 \pm 0.26^{* * * *}$ \\
\hline $4 \%$ TDI & $0.88 \pm 0.09 * * * *$ & $0.94 \pm 0.18^{* * * *}$ & $10.68 \pm 0.62^{* * * *}$ & $7.62 \pm 0.62^{* * * *}$ & $3.62 \pm 0.29 * * * *$ \\
\hline
\end{tabular}

Table 3.2 dLN Migratory Effector $T_{\text {reg }}$ Population Expands During TDI Sensitization

Data represents mean frequency and number of each $T_{\text {reg }}$ population 1-9 days following chemical exposure. Significance is indicated as follows: $\mathrm{P} \leq .05(*), \mathrm{P} \leq .01(* *), \mathrm{P} \leq .001(* * *)$, and $\mathrm{P} \leq .0001$ $(* * * *)$ for each group compared to the acetone control value from the matching time point. 

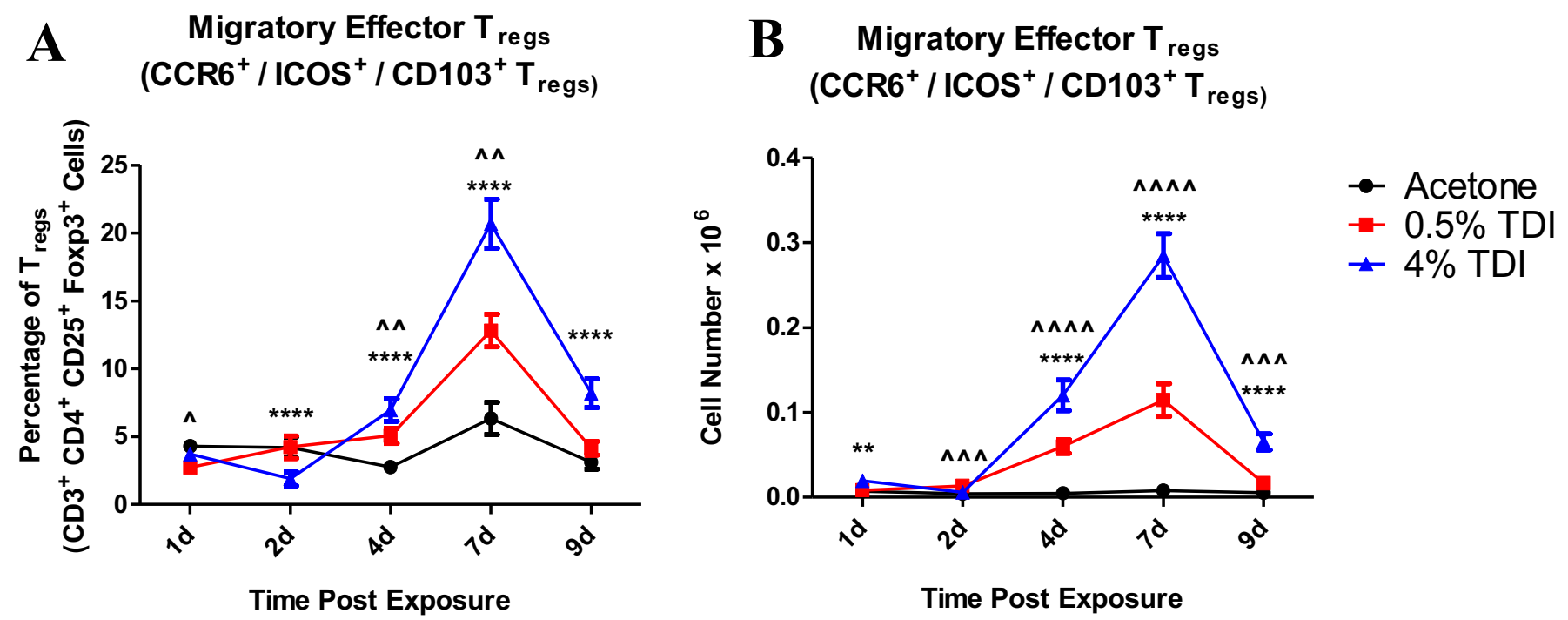

Figure 3.2b $d L N$ Migratory Effector $T_{\text {reg }}$ Population Expands During TDI Sensitization (CoExpression)

$\mathrm{dLN}_{\mathrm{CCR}}{ }^{+} \mathrm{CD} 103^{+} \mathrm{ICOS}^{+} \mathrm{T}_{\text {reg }}$ frequency (A) and number (B) were determined based on flow cytometry analysis and extrapolation of this data with total dLN cellularity. Bars represent mean $( \pm$ SE) of 5 mice per group. $P$ values are represented by $\wedge(0.5 \%$ TDI $)$ and asterisks $(4 \%$ TDI $)(P<0.05)$.

Significance is indicated as follows: $\mathrm{P} \leq .05(*), \mathrm{P} \leq .01(* *), \mathrm{P} \leq .001(* * *)$, and $\mathrm{P} \leq .0001(* * * *)$ for $4 \%$ TDI or $\mathrm{P} \leq .05\left(^{\wedge}\right), \mathrm{P} \leq .01\left(^{\wedge \wedge}\right), \mathrm{P} \leq .001\left({ }^{\wedge \wedge \wedge}\right)$, and $\mathrm{P} \leq .0001\left({ }^{\wedge \wedge \wedge}\right)$ for $0.5 \%$ TDI. Dermal treatment groups are indicated by the following symbols: circle- acetone, square- $0.5 \%$ TDI, and triangle- $4 \%$ TDI. 


\subsection{3. $T_{\text {regs }}$ Exhibit Potent Suppressive Ability During TDI Sensitization}

Because the $T_{\text {reg }}$ population expanded during TDI sensitization, the functional role of $\mathrm{T}_{\text {regs }}$ was further examined by performing a CFSE-based $\mathrm{T}_{\text {reg }}$ suppression assay with $\mathrm{T}_{\text {regs }}$ isolated from acetone or TDI-treated mice (Figure $3.3 \mathrm{~A}$ ). $\mathrm{T}_{\text {regs }}$ from acetone-treated mice were significantly suppressive at all $\mathrm{T}_{\text {con }}: \mathrm{T}_{\text {reg }}$ ratios tested when isolated at 4 (Figure $3.3 \mathrm{~B}$ ) and 7 days (Figure 3.3 C)

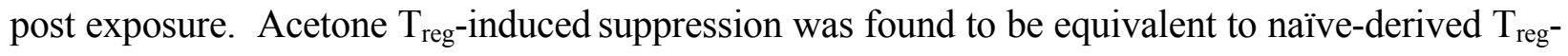
induced suppression (data not shown). $\mathrm{T}_{\text {regs }}$ from TDI-exposed mice exhibited increased suppressive ability compared to the acetone controls when isolated at both 4 (Figure $3.3 \mathrm{~B}$ ) and 7 days (Figure 3.3 C) at all $\mathrm{T}_{\text {con }}: \mathrm{T}_{\text {reg }}$ ratios tested. The heightened suppressive ability of $\mathrm{T}_{\text {regs }}$ was surprising, given the progression of sensitization at the selected concentrations of TDI. This data suggested a functional, suppressive role for $\mathrm{T}_{\text {regs }}$ in TDI sensitization. 
A

No Anti-CD3 No Accessory Cells

1:0

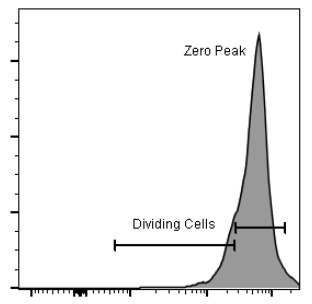

$1: 1$
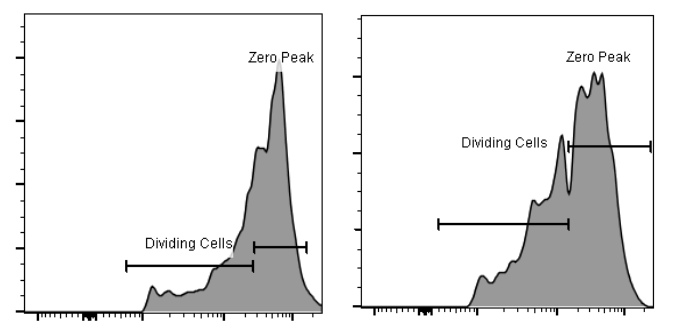

B

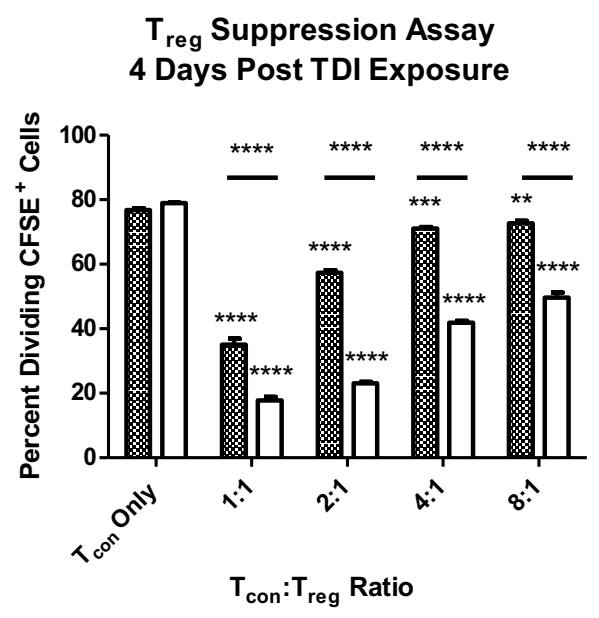

2:1
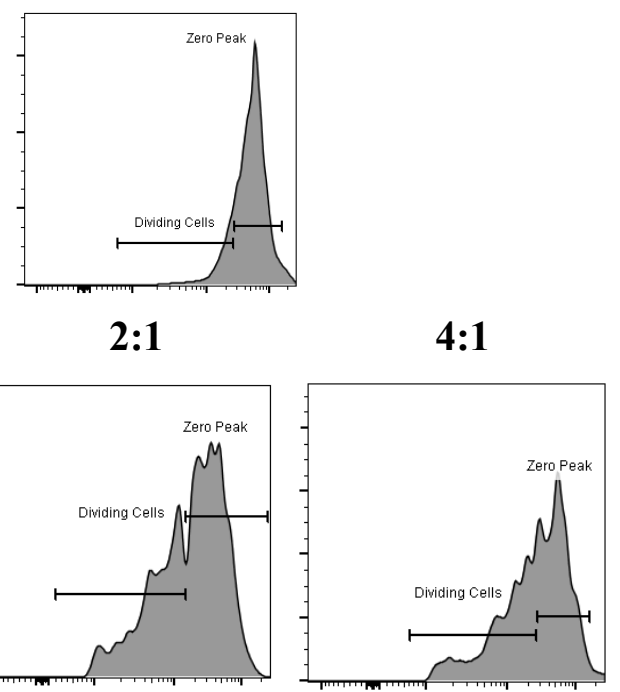

$4: 1$

C

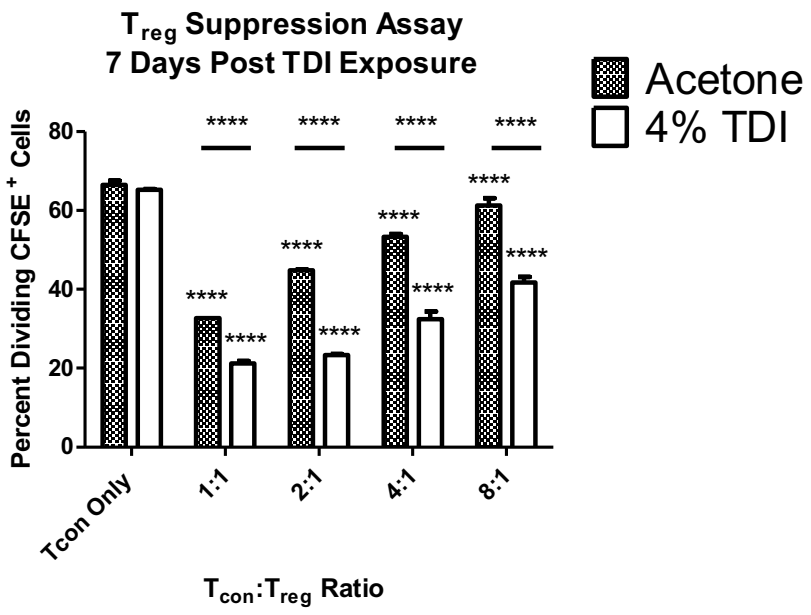

Figure 3.3 $T_{\text {reg }}$ Suppression Assay Reveals Increased Suppressive Ability of $T_{\text {regs }}$ During TDI

\section{Sensitization}

A CFSE-based $\mathrm{T}_{\text {reg }}$ suppression assay was performed and percent dividing $\mathrm{CFSE}^{+}$cells were quantified as illustrated in (A). The zero peak represents the cell population that retained all original CFSE stain. The percent dividing $\mathrm{CFSE}^{+}$cells $\left(\mathrm{T}_{\text {cons }}\right.$ ) are represented in combination with $\mathrm{T}_{\text {regs }}$ from 
mice 4 (B) and 7 (C) days following TDI exposure at a variety of $\mathrm{T}_{\text {con }}: \mathrm{T}_{\text {reg }}$ ratios. For $(\mathrm{B})$ and $(\mathrm{C}) 3$ plate replicates were utilized from groups of 4-11 mice, as described in the materials and method's section. Significance is indicated as follows: $\mathrm{P} \leq .05(*), \mathrm{P} \leq .01(* *), \mathrm{P} \leq .001(* * *)$, and $\mathrm{P} \leq .0001$

(****). $P$ values are represented by asterisks (comparison of each treatment group to $\mathrm{T}_{\text {con }}$ only from the same chemical treatment group) or horizontal bars with asterisks above (comparison of identical ratios between different chemical treatment groups).

\subsubsection{Depletion of $T_{\text {regs }}$ Before and During TDI Sensitization Augments the $T$ cell-mediated}

\section{Allergic Response}

In order to analyze the functional potential of $\mathrm{T}_{\text {regs }}$ in vivo during TDI sensitization, this subset was depleted by injecting mice with anti-CD25 antibody days -11 and -8 prior to TDI exposure (Figure 3.4 A). The high dose of 2\% TDI was selected in an effort to allow for a measurable increase in the sensitization response, as 4\% TDI elicits a maximum sensitization response. The basal levels of $\mathrm{T}_{\text {regs }}$ in the blood of mice were determined to be comparable among all groups prior to dosing (A3.2 A) and depletion was confirmed in the blood (A3.2 A) at days -2 and 7 and in the dLN (A3.2 B) at day 7. Mice dosed with 2\% TDI that received anti-CD25 lost significantly more body weight (grams; mean decrease $5.33 \% \pm 3.9$ ) than mice exposed to $2 \%$ TDI and isotype control antibody (mean increase $1.01 \% \pm 4.3$ ), suggesting enhanced toxicity following $\mathrm{T}_{\text {reg }}$ depletion and high-dose TDI administration. Because local irritation is thought to influence allergic sensitization (47) and TDI is a known irritant (48), we analyzed the dermal irritation response at the site of TDI exposure by ear swelling measurements following $\mathrm{T}_{\text {reg }}$ depletion. As expected, there was a doseresponsive increase (Linear trend test $\mathrm{p}<0.01$ ) in ear swelling following exposure to TDI for both 
the isotype control and anti-CD25 groups (Figure 3.4 B). Although not statistically significant, ears from animals treated with anti-CD25 and either concentration of TDI exhibited increased swelling $(12.4 \% \pm 3.7$ for $0.5 \% ; 54.4 \% \pm 10.7$ for $2 \%$ TDI) compared to their isotype-treated counterparts $(1.4 \% \pm 6.6$ for $0.5 \% ; 35.6 \% \pm 8.9$ for $2 \%$ TDI $)$. Compared to values at day -11 , total body weight decreased significantly in both groups treated with $2 \%$ TDI; however, the anti-CD25-treated group exhibited weight loss that was significant beyond that of the isotype control (A3.3 A). At day 7, dLN cellularity increased dose-responsively (Linear trend test $p<0.05$ ) for both the isotype control and anti-CD25-treated groups during TDI sensitization (Figure $3.4 \mathrm{C}$ ). For both the $0.5 \%$ and $2 \%$ TDI-treated groups statistically significant increases in the dLN cellularity with anti-CD25 treatment compared to isotype were observed. Another effector $\mathrm{CD} 4^{+} \mathrm{T}$ cell subset, Th2, which play an important role in allergic responses, was identified by GATA-3 expression and was found to doseresponsively expand in number during $0.5 \%$ and $2 \%$ TDI sensitization for both the isotype and antiCD25-treated groups (Figure 3.4 D; Linear trend test $\mathrm{p}<0.01$ ). When comparisons were made between the isotype control and anti-CD25 treated groups this population appeared to further expand during TDI sensitization, although these perceived trends were not statistically significant. Similar observations were made for the Th2 population's frequency (A3.3 B). Interestingly, the Gata3 mean fluorescence intensity (MFI) was significantly augmented following anti-CD25 treatment in the 0.5 and 2\%-treated groups, indicating increased brightness on a cell-per-cell basis (A3.3 C). IL-4 mRNA expression levels increased dose-responsively in the $\mathrm{dLN}$ following $0.5 \%$ and $2 \%$ TDI exposure (Linear trend test $\mathrm{p}<0.05$; isotype and anti-CD25 groups) and were significantly augmented in groups treated with anti-CD25 compared to isotype-treated controls (Figure 3.4 E). Similarly, dose-responsive increases in total $\operatorname{IgE}$ levels in the blood appeared to occur at 7 days following exposure to TDI in mice treated with both isotype control and anti-CD25, although significance was 
only observed for the $2 \%$ TDI anti-CD25-treated group (Linear trend test $\mathrm{p}<0.01$; Figure $3.4 \mathrm{~F}$ ). Statistically significant increases in serum IgE levels were observed after anti-CD25 treatment following exposure to 0.5 and $2 \%$ TDI.

Other T cell-related dLN phenotyping was performed at day 7 including CD3, CD4, and CD8 expression, along with other effector $\mathrm{CD}^{+} \mathrm{Th} 1$ and $\mathrm{Th} 17$ populations based on their expression of Tbet and Roryt, respectively (A3.4). $\mathrm{CD}^{+}, \mathrm{CD}^{+} \mathrm{CD}^{+}, \mathrm{CD}^{+} \mathrm{CD}^{+}$, Th1 and Th17 cells doseresponsively expanded in number during $0.5 \%$ and $2 \%$ TDI sensitization and anti-CD25 depleted animals exhibited higher numbers of cells during TDI sensitization (A3.4 B, D, F, H, J). dLN CD3 ${ }^{+}$ cellular frequency decreased in isotype and anti-CD25-treated groups during $0.5 \%$ and $2 \%$ TDI sensitization compared to their respective acetone control (A3.4 A). Interestingly, CD3 ${ }^{+}$cellular frequency was significantly increased in groups treated with anti-CD25 compared to isotype controls for acetone and $0.5 \% \mathrm{TDI}$, indicating that anti-CD25 treatment did not affect general $\mathrm{T}$ cell frequencies in the $\mathrm{dLN}$. $\mathrm{CD} 4^{+}$and $\mathrm{CD} 8^{+} \mathrm{T}$ cell frequency (as a percentage of $\mathrm{CD} 3^{+}$cells) remained stable during TDI sensitization; however, the CD4+ frequency decreased following anti-CD25 treatment while the CD8+ frequency increased $\mathrm{A} 3.4 \mathrm{C}$ and $\mathrm{E})$. The Th1 dLN population significantly expanded in frequency during TDI sensitization (A3.4 C). This subset further expanded in mice treated with anti-CD25 in frequency (2\%) compared to the isotype control groups. The Th17 subset was also profiled and was not significantly altered in frequency during TDI sensitization in the isotype control treated groups; however, the frequency of Th17 cells was significantly increased above both the corresponding acetone and isotype-treated control groups during $2 \%$ TDI sensitization following anti-CD25 treatment (A3.4 D). 


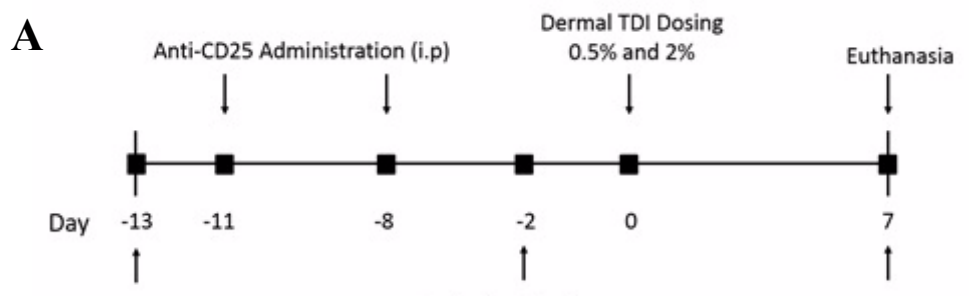

Depletion Checks

B

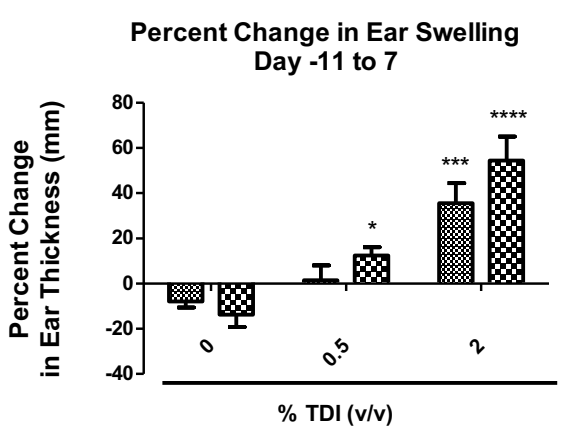

D

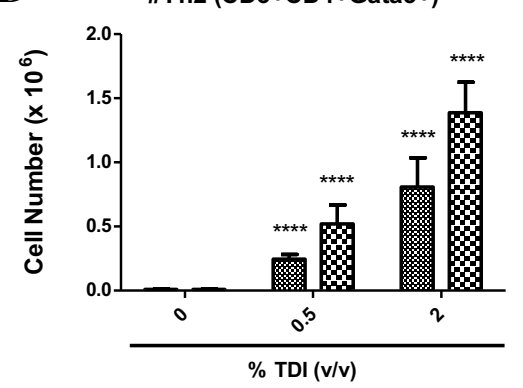

$\mathbf{E}$

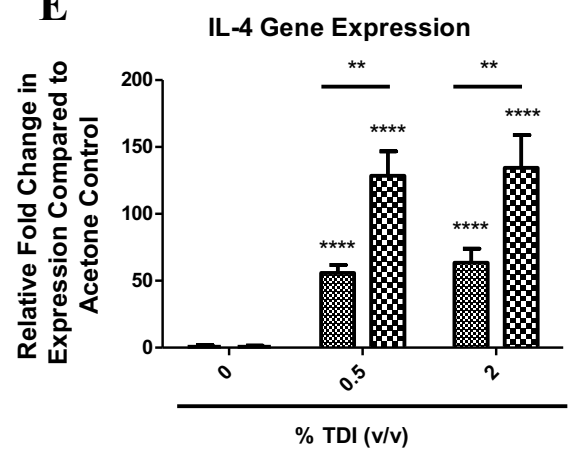

C
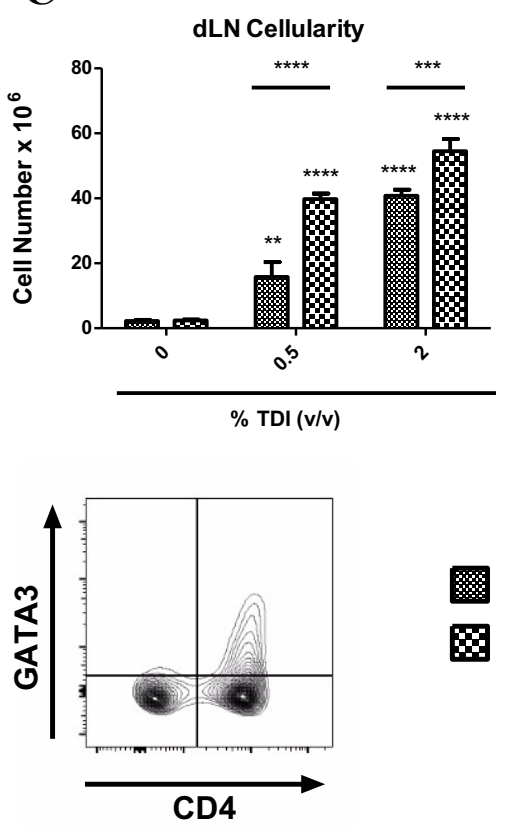

Isotype

A Anti-CD25

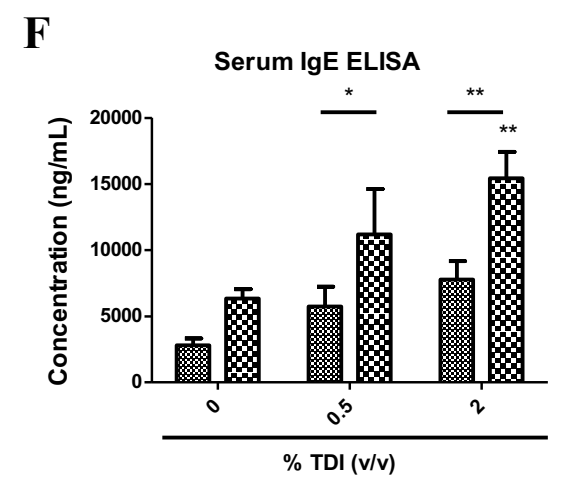

Figure 3.4 The Severity of the Sensitization Response is Intensified in the Absence of $T_{\text {regs }}$ During

\section{TDI Sensitization}

$\mathrm{T}_{\text {regs }}$ were depleted in mice prior to and during dermal TDI sensitization (A). Evaluation of dermal irritancy (B), dLN cellularity (C), dLN Th2 population (D), dLN IL-4 gene expression (E), and 
serum total IgE $(\mathrm{F})$ were evaluated following a single exposure of $0.5 \%$ or $2 \%$ TDI with isotype control or anti-CD25. Bars represent mean $( \pm \mathrm{SE})$ of 5 mice per group. Significance is indicated as follows: $\mathrm{P} \leq .05(*), \mathrm{P} \leq .01(* *), \mathrm{P} \leq .001(* * *)$, and $\mathrm{P} \leq .0001(* * * *) . P$ values are represented by asterisks (comparison of acetone to TDI-exposed group from the same antibody treatment regimen) or horizontal bars with asterisks above (comparison of antibody and isotype-treated groups receiving identical chemical treatment).

\subsection{DISCUSSION}

Occupational exposure to sensitizing chemicals that are capable of inducing allergic disease is increasing globally and is an important public health concern. Although there continues to be progress made in the area of hazard identification, the limited knowledge of the immunologic mechanisms of sensitization induced by respiratory sensitizers such as TDI, continues to complicate the development of these assays. Novel molecules and mechanisms involved in allergic disease need to be investigated in order to elucidate specific entities that can be utilized for the development of hazard identification assays for respiratory sensitizers. Due to the recognized role of $\mathrm{T}_{\text {regs }}$ in related allergic disease states, we chose to investigate the expression kinetics, phenotype, and functional capability of $\mathrm{T}_{\text {regs }}$ in a murine model of dermal TDI sensitization. To our knowledge, this is the first study that investigates the expression and functionality of $T_{\text {regs }}$ in Th2-mediated chemical sensitization.

$\mathrm{T}_{\text {reg }}$ involvement has been suggested in the prevention of the development of allergic disease in both mouse and human models of allergy, specifically impacting Th2-related responses (49). Murine $\mathrm{CD} 4{ }^{+} \mathrm{CD} 25^{+} \mathrm{T}$ cells can prevent the transition of naïve $\mathrm{CD} 4^{+} \mathrm{T}$ cells to $\mathrm{Th} 2$ cells in vitro (50). In a model of house dust mite antigen-induced airway inflammation decreased airway 
pathology and ex vivo-derived splenic IL-4 and IL-13 levels were observed following $\mathrm{T}_{\text {reg }}$ adoptive transfer (51). Additionally, $\mathrm{T}_{\text {regs }}$ have been implicated in in vivo-induced tolerance following inhaled ovalbumin exposure (52), highlighting the importance of these cells in the prevention of allergic disease. Supporting human studies have demonstrated the expansion of $\mathrm{T}_{\text {regs }}$ in the nasal mucosa following allergen immunotherapy and noted their association with the efficacy of treatment, suggesting a role for $\mathrm{T}_{\text {regs }}$ in the development of antigen-specific tolerance in allergic humans (53). In addition to their direct actions on $\mathrm{Th} 2$ cells, $\mathrm{T}_{\text {regs }}$ have also demonstrated the ability to suppress allergic disease by influencing granulocytes, antibody-producing B cells, and resident tissue cells (54). In addition, $\mathrm{T}_{\text {regs }}$ have demonstrated involvement in maintaining tolerance and controlling the allergic response during the sensitization phase of both ovalbumin-induced allergic airway inflammation (55) and hapten-induced $\mathrm{CD}^{+} \mathrm{T}$ cell-dependent contact hypersensitivity response (Christensen et al., 2015).

In an effort to explore the role of $\mathrm{T}_{\text {regs }}$ in TDI sensitization, this population was profiled following epicutaneous TDI exposure. Several basic $T_{\text {reg }}$ markers (CD3/CD4/CD25/Foxp3) were used to define the classical $T_{\text {reg }}$ population but it is important to note that some $T_{\text {reg }}$ subsets do not express CD25 and/or Foxp3 such as Tr1 (56) and Th3 (57) cells which typically exhibit TGF- $\beta$ and IL-10-mediated suppression. Due to the use of CD25 as a functional tool in these studies, we have chosen to focus on classical $T_{\text {regs. }}$. The basic $T_{\text {reg }}$ population encompasses numerous subpopulations including, but not limited to, $\mathrm{nT}_{\text {regs }}, \mathrm{iT}_{\text {regs }}$, migratory and homing $\mathrm{T}_{\text {regs }}$, and IL-10 secreting $\mathrm{T}_{\text {regs. }}$. Beyond the $n \mathrm{~T}_{\text {regs }}$ and $\mathrm{i} \mathrm{T}_{\text {regs }}$, these subsets are not mutually exclusive, so while phenotyping markers may be presented alone, many of these populations are co-expressers of a variety of markers. In general, the $T_{\text {reg }}$ populations (basic and specialized; Table 1) were identified to expand in both number and frequency, peaking around 4-7 days and beginning to retract around 7-9 days following 
TDI exposure. This retraction may be due to the early importance of this population in the dLN or may also be mediated by other compensatory or regulatory elements. Interestingly, the general $\mathrm{T}_{\mathrm{reg}}$ population's frequency did not significantly increase following $0.5 \%$ TDI exposure (Figure $3.2 \mathrm{~B}$ ), potentially implicating a role for the irritant response in both the induction of $\mathrm{T}_{\text {regs }}$ and as a precursor to the initiation of sensitization.

Further support for a role for $\mathrm{T}_{\text {regs }}$ in TDI sensitization was identified following in vivo administration of anti-CD25 treatment. In this $\mathrm{T}_{\text {reg }}$ depletion study, augmentations in traditional $\mathrm{Th} 2$ allergic markers (dermal irritation, dLN cellularity, Th2 population, IL-4 mRNA expression, and serum total IgE production) were observed. Dose-responsive increases in dLN cellularity, IL4, Th2 cells, and IgE were also observed and were further augmented following anti-CD25 treatment indicating increased sensitization in the absence of $\mathrm{T}_{\text {regs. }}$ dLN cellularity was measured as a gross marker of sensitization intensity, as this parameter is traditionally utilized in the standard sensitization assay known as the local lymph node assay (Anderson et al., 2011). The dLN Th2 cellular subset was examined as the main effector $\mathrm{T}$ cell subset traditionally thought to be involved in allergic responses, with the allergic cytokine IL-4 being primarily produced by this subset, influencing the development and homeostasis of the allergic microenvironment (58). IgE expression indicates the development of an allergic humoral response. While $\mathrm{T}_{\text {reg }}$ depletion was identified to promote a Th2 response, the findings from the $T_{\text {reg }}$ suppression assay suggested that $T_{\text {regs }}$ isolated from the TDI-sensitized animals were more suppressive compared to their acetone counterparts. These data suggest a significant role for $\mathrm{T}_{\text {regs }}$ in the regulation of chemical-induced allergy, implying that their presence may delay or reduce the intensity of sensitization.

Typically, the development of allergic disease is thought to involve an imbalance between Th1 and Th2 responses to allergens (59), resulting in an "overzealous" Th2 response. While the Th2 response 
is an important mediator of TDI sensitization, it is important to note that TDI sensitization and resultant allergic disease also contain Th1 and Th17 components (A 3.4 G-J) (8). $T_{\text {regs }}$ are capable of suppressing both Th1 $(60,61)$ and Th17 $(62)$-mediated responses, indicating that they may be influencing these components of the TDI sensitization response. Selective suppression of the Th1 response during TDI sensitization could further enhance the development of Th2-mediated sensitization based on the Th1/Th2 imbalance hypothesis.

While $\mathrm{T}_{\text {regs }}$ isolated from TDI sensitized mice were identified to be more suppressive than acetone-derived $T_{\text {regs, }}$, this was reported based as a combined function for all populations of $\mathrm{T}_{\text {regs. }}$ This is important to note because TDI-induced $T_{\text {regs }}$ were identified to be phenotypically heterogeneous. While the kinetics of the specialized $\mathrm{T}_{\text {reg }}$ populations generally mimic that of the basic $T_{\text {reg }}$ population several discrepancies were identified that may provide insight into the mechanisms driving this response. The $\mathrm{CTLA} 4^{+} \mathrm{T}_{\text {reg }}$ population was identified to increase in number and frequency earlier than the general $\mathrm{T}_{\text {reg }}$ population with significant increases identified one day post exposure (Fig 3.2a A and B). The early expansion of this subset was intriguing, given the lack of any data implying a role for CTLA4-mediated suppression in chemical-induced allergy, although this population has been noted to play an immunosuppressive role in the sensitization phase of the ovalbumin-induced allergic response (63). This population participates in contact-mediated suppression by binding to the B7 costimulatory complex expressed on APCs, thus inhibiting T cell activation in a highly suppressive manner (64). Based on the early expansion of this subset, it is possible that these cells are interacting with APCs in the early phase of the sensitization response. $\mathrm{nT}_{\text {regs }}$ are thymus-derived cells whose counterparts are inducible $\mathrm{T}_{\text {regs }}\left(\mathrm{iT}_{\text {regs }}\right)$ generated in the periphery; $\mathrm{nT}_{\text {regs }}$ are identified by neuropilin-1 expression $(11,43)$. Interestingly, the $\mathrm{nT}_{\text {reg frequency }}$ significantly decreased between 7-9 days following TDI exposure compared to the acetone-treated 
population (Fig 3.2a C). This decrease may be attributed to the efflux of cells from the dLN into peripheral tissues and/or the influx and expansion of $\mathrm{iT}_{\text {regs }}$ in the $\mathrm{dLN}$. Because certain populations of $\mathrm{T}_{\text {regs }}$ are known to possess migratory capabilities, the $\mathrm{T}_{\text {reg }}$ phenotyping panel included several markers associated with $\mathrm{T}_{\text {reg }}$ migration and effector capabilities including CCR6, CD103, and ICOS. $\mathrm{T}_{\text {regs }}$ expressing any or all of these markers were defined as migratory effector $\mathrm{T}_{\text {regs }}$ due to the noted homing capabilities and the effector functions $(31,32,35,39,65)$. The expansion of $\mathrm{T}_{\text {regs }}$ expressing CCR6, CD103, and/or ICOS (Table 3.2) may represent subsets that have acquired effector functions, such as IL-10 production, and possess migratory capabilities. Taken together, these findings suggest that $\mathrm{T}_{\text {regs }}$ likely utilize a variety of suppressive mechanisms as indicated by their phenotypic diversity. This could be a potential explanation for why TDI sensitized $\mathrm{T}_{\text {regs }}$ were identified as more suppressive than their acetone control counterparts.

These studies reveal an important role for $\mathrm{T}_{\text {regs }}$ in a murine model of TDI sensitization. Elucidation of the role of $T_{\text {regs }}$ in this response will result in a better understanding of the immunologic mechanisms involved chemical sensitization. Due to the complexity of mechanisms involved in chemical allergy, the investigation of novel cellular subsets and mediators of allergic disease is imperative for the greater understanding of these conditions and the development of hazard identification strategies for respiratory chemical sensitizers. In conclusion, we have demonstrated that $T_{\text {regs }}$ are a phenotypically heterogeneous population that expand, suppress, and play a part in controlling the allergic response during TDI sensitization. 


\subsection{REFERENCES}

1. NTP. 2011. Report on Carcinogens. 12 ed. P. H. S. U.S. Department of Health and Human Services, National Toxicology Program, ed, Research Triangle Park, NC. 499.

2. Bello, D., C. A. Herrick, T. J. Smith, S. R. Woskie, R. P. Streicher, M. R. Cullen, Y. Liu, and C. A. Redlich. 2007. Skin exposure to isocyanates: reasons for concern. Environmental health perspectives 115: 328-335.

3. Mapp, C. E. 2001. Agents, Old and New, Causing Occupational Asthma. Occupational and Environmental Medicine 58: 354-354.

4. Anderson, S. E., and B. J. Meade. 2014. Potential Health Effects Associated with Dermal Exposure to Occupational Chemicals. Environmental Health Insights: 51-62.

5. Fabbri, L. M., D. Danieli, S. Crescioli, P. Bevilacqua, S. Meli, M. Saetta, and C. E. Mapp. 1988. Fatal asthma in a subject sensitized to toluene diisocyanate. The American review of respiratory disease 137: 1494-1498.

6. Matheson, J. M., V. J. Johnson, and M. I. Luster. 2005. Immune Mediators in a Murine Model for Occupational Asthma: Studies with Toluene Diisocyanate. Toxicological Sciences 84: 99-109.

7. Anderson, S. E., P. D. Siegel, and B. J. Meade. 2011. The LLNA: A Brief Review of Recent Advances and Limitations. Journal of allergy 2011: 424203.

8. Liu, Q., and A. V. Wisnewski. 2003. Recent developments in diisocyanate asthma. Annals of Allergy, Asthma \& Immunology 90: 35-41.

9. Sakaguchi, S., N. Sakaguchi, M. Asano, M. Itoh, and M. Toda. 1995. Immunologic selftolerance maintained by activated T cells expressing IL-2 receptor alpha-chains (CD25). Breakdown of a single mechanism of self-tolerance causes various autoimmune diseases. Journal of immunology (Baltimore, Md. : 1950) 155: 1151-1164.

10. Hori, S., T. Nomura, and S. Sakaguchi. 2003. Control of regulatory T cell development by the transcription factor Foxp3. Science 299: 1057-1061.

11. Yadav, M., C. Louvet, D. Davini, J. M. Gardner, M. Martinez-Llordella, S. BaileyBucktrout, B. A. Anthony, F. M. Sverdrup, R. Head, D. J. Kuster, P. Ruminski, D. Weiss, D. Von Schack, and J. A. Bluestone. 2012. Neuropilin-1 distinguishes natural and inducible regulatory $\mathrm{T}$ cells among regulatory $\mathrm{T}$ cell subsets in vivo. The Journal of Experimental Medicine 209: 1713-1722.

12. Sojka, D. K., Y.-H. Huang, and D. J. Fowell. 2008. Mechanisms of regulatory T-cell suppression - a diverse arsenal for a moving target. Immunology 124: 13-22.

13. Corthay, A. 2009. How do Regulatory T Cells Work? Scandinavian Journal of Immunology 70: 326-336.

14. Kimber, I., M. A. Travis, S. F. Martin, and R. J. Dearman. 2012. Immunoregulation of skin sensitization and regulatory T cells. Contact dermatitis 67: 179-183.

15. Christensen, A. D., S. Skov, P. H. Kvist, and C. Haase. 2015. Depletion of regulatory T cells in a hapten-induced inflammation model results in prolonged and increased inflammation driven by T cells. Clinical and experimental immunology 179: 485-499.

16. Vanoirbeek, J. A. J., M. Tarkowski, J. L. Ceuppens, E. K. Verbeken, B. Nemery, and P. H. M. Hoet. 2004. Respiratory Response to Toluene Diisocyanate Depends on Prior Frequency and Concentration of Dermal Sensitization in Mice. Toxicological Sciences 80: 310-321. 
17. Robinson, D. S. 2009. Regulatory T cells and asthma. Clinical and experimental allergy : journal of the British Society for Allergy and Clinical Immunology 39: 1314-1323.

18. Anderson, S. E., C. Umbright, R. Sellamuthu, K. Fluharty, M. Kashon, J. Franko, L. G. Jackson, V. J. Johnson, and P. Joseph. 2010. Irritancy and allergic responses induced by topical application of ortho-phthalaldehyde. Toxicological sciences : an official journal of the Society of Toxicology 115: 435-443.

19. Anderson, S. E., K. Beezhold, E. Lukomska, J. Richardson, C. Long, K. Anderson, J. Franko, B. J. Meade, and D. H. Beezhold. 2013. Expression kinetics of miRNA involved in dermal toluene 2,4-diisocyanate sensitization. Journal of immunotoxicology.

20. Anderson, S. E., J. Franko, L. G. Jackson, J. R. Wells, J. E. Ham, and B. J. Meade. 2012. Irritancy and Allergic Responses Induced by Exposure to the Indoor Air Chemical 4Oxopentanal. Toxicological Sciences 127: 371-381.

21. Van den Broeck, W., A. Derore, and P. Simoens. 2006. Anatomy and nomenclature of murine lymph nodes: Descriptive study and nomenclatory standardization in BALB/cAnNCrl mice. Journal of immunological methods 312: 12-19.

22. Kruisbeek, A. M., E. Shevach, and A. M. Thornton. 2001. Proliferative Assays for T Cell Function. In Current Protocols in Immunology. John Wiley \& Sons, Inc.

23. Marshall, N. B., W. R. Vorachek, L. B. Steppan, D. V. Mourich, and N. I. Kerkvliet. 2008. Functional Characterization and Gene Expression Analysis of CD4 +CD25+

Regulatory T Cells Generated in Mice Treated with 2,3,7,8-Tetrachlorodibenzo-p-Dioxin. Journal of Immunology: 2382-2391.

24. Setiady, Y. Y., J. A. Coccia, and P. U. Park. 2010. In vivo depletion of CD4+FOXP3+ Treg cells by the PC61 anti-CD25 monoclonal antibody is mediated by FcgammaRIII+ phagocytes. European journal of immunology 40: 780-786.

25. Felonato, M., A. Pina, E. F. d. Araujo, F. V. Loures, S. B. Bazan, C. Feriotti, and V. L. G. Calich. 2012. Anti-CD25 Treatment Depletes Treg Cells and Decreases Disease Severity in Susceptible and Resistant Mice Infected with $<$ italic $>$ Paracoccidioides brasiliensis </italic >. PLOS ONE 7: e51071.

26. Daftarian, H. S., B. D. Lushniak, C. M. Reh, and D. M. Lewis. 2002. Evaluation of SelfReported Skin Problems Among Workers Exposed to Toluene Diisocyanate (TDI) at a Foam Manufacturing Facility. Journal of Occupational and Environmental Medicine 44: 1197-1202.

27. Lin, X., M. Chen, Y. Liu, Z. Guo, X. He, D. Brand, and S. G. Zheng. 2013. Advances in distinguishing natural from induced Foxp3(+) regulatory T cells. International journal of clinical and experimental pathology 6: 116-123.

28. Fontenot, J. D., J. P. Rasmussen, M. A. Gavin, and A. Y. Rudensky. 2005. A function for interleukin 2 in Foxp3-expressing regulatory T cells. Nature immunology 6: 1142-1151.

29. Lowenthal, J. W., R. H. Zubler, M. Nabholz, and H. R. MacDonald. 1985. Similarities between interleukin-2 receptor number and affinity on activated $\mathrm{B}$ and $\mathrm{T}$ lymphocytes. Nature 315: 669-672.

30. Schutyser, E., S. Struyf, and J. Van Damme. 2003. The CC chemokine CCL20 and its receptor CCR6. Cytokine \& growth factor reviews 14: 409-426.

31. Kleinewietfeld, M., F. Puentes, G. Borsellino, L. Battistini, O. Rötzschke, and K. Falk. 2005. CCR6 expression defines regulatory effector/memory-like cells within the CD25+CD4+ T-cell subset. Blood 105: 2877-2886. 
32. Yamazaki, T., X. O. Yang, Y. Chung, A. Fukunaga, R. Nurieva, B. Pappu, N. MartinOrozco, H. S. Kang, L. Ma, A. D. Panopoulos, S. Craig, S. S. Watowich, A. M. Jetten, Q. Tian, and C. Dong. 2008. CCR6 Regulates the Migration of Inflammatory and Regulatory T Cells. Journal of immunology (Baltimore, Md. : 1950) 181: 8391-8401.

33. Kondo, T., H. Takata, and M. Takiguchi. 2007. Functional expression of chemokine receptor CCR6 on human effector memory CD8+ T cells. European journal of immunology 37: 54-65.

34. Anz, D., W. Mueller, M. Golic, W. G. Kunz, M. Rapp, V. H. Koelzer, J. Ellermeier, J. W. Ellwart, M. Schnurr, C. Bourquin, and S. Endres. 2011. CD103 is a hallmark of tumorinfiltrating regulatory $\mathrm{T}$ cells. International journal of cancer. Journal international du cancer 129: 2417-2426.

35. Matsushima, H., and A. Takashima. 2010. Bidirectional homing of Tregs between the skin and lymph nodes. The Journal of Clinical Investigation 120: 653-656.

36. Mackay, L. K., A. Rahimpour, J. Z. Ma, N. Collins, A. T. Stock, M.-L. Hafon, J. VegaRamos, P. Lauzurica, S. N. Mueller, T. Stefanovic, D. C. Tscharke, W. R. Heath, M. Inouye, F. R. Carbone, and T. Gebhardt. 2013. The developmental pathway for CD103+CD8+ tissue-resident memory T cells of skin. Nature immunology 14: 12941301.

37. Frauwirth, K. A., and C. B. Thompson. 2002. Activation and inhibition of lymphocytes by costimulation. The Journal of Clinical Investigation 109: 295-299.

38. Hutloff, A., A. M. Dittrich, K. C. Beier, B. Eljaschewitsch, R. Kraft, I. Anagnostopoulos, and R. A. Kroczek. 1999. ICOS is an inducible T-cell co-stimulator structurally and functionally related to CD28. Nature 397: 263-266.

39. Vocanson, M., A. Rozieres, A. Hennino, G. Poyet, V. Gaillard, S. Renaudineau, A. Achachi, J. Benetiere, D. Kaiserlian, B. Dubois, and J. F. Nicolas. 2010. Inducible costimulator (ICOS) is a marker for highly suppressive antigen-specific T cells sharing features of TH17/TH1 and regulatory T cells. The Journal of allergy and clinical immunology 126: 280-289, 289.e281-287.

40. Burmeister Y, e. a. 2007. ICOS Controls the Pool Size of Effector-Memory and Regulatory T Cells. Journal of Immunology: 8.

41. Busse, M., M. Krech, A. Meyer-Bahlburg, C. Hennig, and G. Hansen. 2012. ICOS mediates the generation and function of CD4+CD25+Foxp3+ regulatory $\mathrm{T}$ cells conveying respiratory tolerance. Journal of immunology (Baltimore, Md. : 1950) 189: 1975-1982.

42. Gu, C., E. R. Rodriguez, D. V. Reimert, T. Shu, B. Fritzsch, L. J. Richards, A. L. Kolodkin, and D. D. Ginty. 2003. Neuropilin-1 conveys semaphorin and VEGF signaling during neural and cardiovascular development. Developmental cell 5: 45-57.

43. Weiss, J. M., A. M. Bilate, M. Gobert, Y. Ding, M. A. Curotto de Lafaille, C. N. Parkhurst, H. Xiong, J. Dolpady, A. B. Frey, M. G. Ruocco, Y. Yang, S. Floess, J. Huehn, S. Oh, M. O. Li, R. E. Niec, A. Y. Rudensky, M. L. Dustin, D. R. Littman, and J. J. Lafaille. 2012. Neuropilin 1 is expressed on thymus-derived natural regulatory T cells, but not mucosa-generated induced Foxp3+ T reg cells. The Journal of Experimental Medicine 209: 1723-1742.

44. Renand, A., P. Milpied, J. Rossignol, J. Bruneau, F. Lemonnier, M. Dussiot, S. Coulon, and O. Hermine. 2013. Neuropilin-1 Expression Characterizes T Follicular Helper (Tfh) 
Cells Activated during B Cell Differentiation in Human Secondary Lymphoid Organs. PLoS ONE 8: e85589.

45. Jackson, S. R., M. Berrien-Elliott, J. Yuan, E. C. Hsueh, and R. M. Teague. 2014. Neuropilin-1 expression is induced on tolerant self-reactive CD8+ T cells but is dispensable for the tolerant phenotype. PLoS One 9: e110707.

46. Kolar, P., K. Knieke, J. K. Hegel, D. Quandt, G. R. Burmester, H. Hoff, and M. C. Brunner-Weinzierl. 2009. CTLA-4 (CD152) controls homeostasis and suppressive capacity of regulatory T cells in mice. Arthritis and rheumatism 60: 123-132.

47. Pauluhn, J. 2014. Development of a respiratory sensitization/elicitation protocol of toluene diisocyanate (TDI) in Brown Norway rats to derive an elicitation-based occupational exposure level. Toxicology 319: 10-22.

48. Duprat, P., D. Gradiski, and B. Marignac. 1976. [The irritant and allergenic action of two isocyanates: toluene diisocyanate (TDI) and diphenylmethane diisocyanate (MDI)]. European journal of toxicology and environmental hygiene. Journal europeen de toxicologie 9: 43-53.

49. Robinson, D. S., M. Larché, and S. R. Durham. 2004. Tregs and allergic disease. Journal of Clinical Investigation 114: 1389-1397.

50. Stassen, M., H. Jonuleit, C. Muller, M. Klein, C. Richter, T. Bopp, S. Schmitt, and E. Schmitt. 2004. Differential regulatory capacity of CD25+ T regulatory cells and preactivated CD25+ T regulatory cells on development, functional activation, and proliferation of Th2 cells. Journal of immunology (Baltimore, Md. : 1950) 173: 267-274.

51. Chen, W., W. Jin, N. Hardegen, K.-j. Lei, L. Li, N. Marinos, G. McGrady, and S. M. Wahl. 2003. Conversion of Peripheral CD4(+)CD25(-) Naive T Cells to CD4(+)CD25(+) Regulatory T Cells by TGF- $\beta$ Induction of Transcription Factor Foxp3. The Journal of Experimental Medicine 198: 1875-1886.

52. Ostroukhova, M., C. Seguin-Devaux, T. B. Oriss, B. Dixon-McCarthy, L. Yang, B. T. Ameredes, T. E. Corcoran, and A. Ray. 2004. Tolerance induced by inhaled antigen involves CD4(+) T cells expressing membrane-bound TGF-beta and FOXP3. J Clin Invest 114: 28-38.

53. Radulovic, S., M. R. Jacobson, S. R. Durham, and K. T. Nouri-Aria. 2008. Grass pollen immunotherapy induces Foxp3-expressing CD4+ CD25+ cells in the nasal mucosa. The Journal of allergy and clinical immunology 121: 1467-1472, 1472.e1461.

54. Palomares, O., G. Yaman, A. K. Azkur, T. Akkoc, M. Akdis, and C. A. Akdis. 2010. Role of Treg in immune regulation of allergic diseases. European journal of immunology 40: 1232-1240.

55. Baru, A. M., A. Hartl, K. Lahl, J. K. Krishnaswamy, H. Fehrenbach, A. O. Yildirim, H. Garn, H. Renz, G. M. Behrens, and T. Sparwasser. 2010. Selective depletion of Foxp3+ Treg during sensitization phase aggravates experimental allergic airway inflammation. European journal of immunology 40: 2259-2266.

56. Passerini, L., S. Di Nunzio, S. Gregori, E. Gambineri, M. Cecconi, M. G. Seidel, G. Cazzola, L. Perroni, A. Tommasini, S. Vignola, L. Guidi, M. G. Roncarolo, and R. Bacchetta. 2011. Functional type 1 regulatory T cells develop regardless of FOXP3 mutations in patients with IPEX syndrome. European journal of immunology 41: 11201131. 
57. Carrier, Y., J. Yuan, V. K. Kuchroo, and H. L. Weiner. 2007. Th3 Cells in Peripheral Tolerance. I. Induction of Foxp3-Positive Regulatory T Cells by Th3 Cells Derived from TGF- $\beta$ T Cell-Transgenic Mice. The Journal of Immunology 178: 179-185.

58. Brown, M. A. 2008. IL-4 Production by T Cells: You Need a Little to Get a Lot. The Journal of Immunology 181: 2941-2942.

59. Akdis, M., J. Verhagen, A. Taylor, F. Karamloo, C. Karagiannidis, R. Crameri, S. Thunberg, G. Deniz, R. Valenta, H. Fiebig, C. Kegel, R. Disch, C. B. Schmidt-Weber, K. Blaser, and C. A. Akdis. 2004. Immune responses in healthy and allergic individuals are characterized by a fine balance between allergen-specific T regulatory 1 and $\mathrm{T}$ helper 2 cells. J Exp Med 199: 1567-1575.

60. Xu, W., Q. Lan, M. Chen, H. Chen, N. Zhu, X. Zhou, J. Wang, H. Fan, C. S. Yan, J. L. Kuang, D. Warburton, D. Togbe, B. Ryffel, S. G. Zheng, and W. Shi. 2012. Adoptive transfer of induced-Treg cells effectively attenuates murine airway allergic inflammation. PLoS One 7: e40314.

61. Xu, D., H. Liu, M. Komai-Koma, C. Campbell, C. McSharry, J. Alexander, and F. Y. Liew. 2003. CD4+CD25+ regulatory $\mathrm{T}$ cells suppress differentiation and functions of Th1 and Th2 cells, Leishmania major infection, and colitis in mice. Journal of immunology (Baltimore, Md. : 1950) 170: 394-399.

62. Jaffar, Z., M. E. Ferrini, T. A. Girtsman, and K. Roberts. 2009. Antigen-specific Treg regulate Th17-mediated lung neutrophilic inflammation, B cell recruitment and polymeric IgA and IgM levels in the airways. European journal of immunology 39: 33073314.

63. Hellings, P. W., P. Vandenberghe, A. Kasran, L. Coorevits, L. Overbergh, C. Mathieu, and J. L. Ceuppens. 2002. Blockade of CTLA-4 enhances allergic sensitization and eosinophilic airway inflammation in genetically predisposed mice. European journal of immunology 32: 585-594.

64. Tai, X., F. Van Laethem, L. Pobezinsky, T. Guinter, S. O. Sharrow, A. Adams, L. Granger, M. Kruhlak, T. Lindsten, C. B. Thompson, L. Feigenbaum, and A. Singer. 2012. Basis of CTLA-4 function in regulatory and conventional CD4(+) T cells. Blood 119: 5155-5163.

65. Chang, L. Y., Y. C. Lin, C. W. Kang, C. Y. Hsu, Y. Y. Chu, C. T. Huang, Y. J. Day, T. C. Chen, C. T. Yeh, and C. Y. Lin. 2012. The indispensable role of CCR5 for in vivo suppressor function of tumor-derived $\mathrm{CD} 103+$ effector/memory regulatory $\mathrm{T}$ cells. Journal of immunology (Baltimore, Md. : 1950) 189: 567-574. 


\section{CHAPTER 4}

Investigation of the Expression and Potential Targets of microRNA 210 During

\section{TDI Sensitization}

In preparation - Invited Submission. Genes. 


\section{Potential Inhibitory Influence of miRNA 210 on Regulatory T Cells During Epicutaneous Chemical Sensitization}

Carrie Mae Long ${ }^{* \dagger}$, Ewa Lukomska ${ }^{\dagger}$, Nikki B Marshall ${ }^{\dagger}$, Ajay Nayak $^{\dagger}$, Stacey Anderson ${ }^{\dagger}$

*West Virginia University, Immunology and Microbial Pathogenesis Graduate Program, Morgantown, WV 26505

$†$ Centers for Disease Control and Prevention, National Institute for Occupational Safety and Health, Allergy and Clinical Immunology Branch, Morgantown, WV, 26505

Correspondence should be addressed to Stacey Anderson, CDC-NIOSH, 1095 Willowdale Rd, Mailstop 4020, Morgantown, WV 26505, (304) 285-6024, dbx7@cdc.gov

Running Title (40 characters): miR-210 May Target $\mathrm{T}_{\text {regs }}$ in TDI Sensitization 


\section{ABSTRACT}

Toluene diisocyanate (TDI) is a potent low molecular weight chemical sensitizer and a leading cause of chemical-induced occupational asthma. The regulatory potential of microRNAs (miRNAs) has been recognized in a variety of disease states, including allergic disease; however, the roles of miRNAs in chemical sensitization is unknown. In a previous work, increased expression of multiple miRNAs during TDI sensitization was observed and several putative mRNA targets identified for these miRNAs were directly related to $T_{\text {reg }}$ differentiation and function including foxp3 and runx3. In this work, we show that miR-210 expression is increased in the mouse $\mathrm{dLN}$ and $\mathrm{T}_{\text {reg }}$ subsets during TDI sensitization. Alterations in dLN mRNA and protein expression of $\mathrm{T}_{\text {reg }}$ related genes/putative miR-210 targets (foxp3, runx3, ctla4, and cd25) were observed at multiple time points following TDI exposure and in ex vivo systems. A $\mathrm{T}_{\text {reg }}$ suppression assay, including a miR-210 mimic, was utilized to investigate the suppressive ability of $\mathrm{T}_{\text {regs. }}$ TDI derived cells treated with miR-210 mimic had less expression of miR-210 compared to the acetone control suggesting other factors, such as additional miRNAs, might be involved in the regulation of the functional capabilities of these cells. These novel findings indicate that miR210 may have an inhibitory role in $\mathrm{T}_{\text {reg }}$ function during TDI sensitization. Because the functional roles of miRNAs have not been previously elucidated in a model of chemical sensitization, these data contribute to the understanding of the immunologic mechanisms of chemical induced allergic disease and may aid in the development of preventative strategies. 


\subsection{INTRODUCTION}

Occupational allergic disease is a significant health burden. A variety of diseases can be caused by workplace chemical exposures, including asthma, conjunctivitis, dermatitis, rhinitis, and urticaria (1). Diisocyanates are a group of highly reactive chemicals characterized by the presence of double isocyanate functional groups; many of these chemicals are potent sensitizers and major causative agents of occupational allergic disease (2-4). Toluene diisocyanate (TDI) is frequently utilized in the automobile industry and in the manufacture of polyurethane foams, paints, and coatings (5-8). TDI is widely used throughout the United States (U.S.) and around the globe; the U.S. Environmental Protection Agency reports that U.S. production and importation of 2-4 and 2-6 TDI isomers rose above 1 billion pounds in 2006 (6). The principal routes of human exposure to TDI are inhalation and dermal contact (6). While TDI has generally been classified as a T-helper type 2 (Th2) sensitizer, the immune response following exposure is more accurately characterized as a mixed Th1/Th2 response in both rodents and humans $(1,2,9)$. Both respiratory and dermal sensitization have been documented $(7,10)$ and can lead to allergic disease once the elicitation threshold has been reached. Skin sensitization is thought to be sufficient for subsequent allergic disease of the respiratory tract (7), illustrating the systemic nature of TDI sensitization. Although TDI-induced asthma is an extremely relevant occupational health concern, the pathogenic mechanisms of diisocyanate-induced asthma are not fully understood (5) and the identification of novel mediators of allergic disease may be necessary to obtain a full and complete understanding of the disease. Because of the clinical significance of and lack of validated identification strategies for chemical respiratory sensitizers like TDI $(4,11)$, it is necessary to investigate and identify functional pathways and mechanisms that are involved in TDI sensitization. Specific understanding of disease mechanism may have direct implications in risk assessment, hazard communication and guidance 
used in the selection of safe products, the identification of safer alternatives, and preclinical biomarker discovery.

An emerging class of epigenetic regulatory elements that have been the subject of recent scientific focus are microRNAs (miRNAs). These molecules are single stranded, noncoding RNA molecules that are approximately 19-23 nucleotides long (12). They are processed by Drosha and Dicer nucleases preceding their mature form (13). MiRNAs exhibit functional significance though posttranscriptional gene regulation due to their ability to bind to the target messenger RNA (mRNA) and destabilize and decrease protein translation when in complex with argonaute proteins and the RNA-induced silencing complex (RISC). The seed sequence of a mature miRNA can interact with a portion of the target mRNA, typically within the 3' untranslated region, nucleotide base paring can occur, and this may lead to the translational repression or degradation of the target mRNA, influencing gene expression. Recently, it has been shown that miRNAs play a major role in a variety of immune responses (14-17). These emerging regulatory factors have not been functionally investigated in the context of chemical sensitization, with the exception of recent work by our group that profiled the general expression kinetics of miRNAs involved in TDI sensitization (1) and research profiling miRNA expression in both human and murine diphenylcyclopropenone-induced dermatitis (18).

The identification of increased expression of several miRNAs in the draining lymph nodes (dLN) of mice during epicutaneous TDI sensitization prompted further investigation into the potential functional roles of these molecules in the allergic response. Target analysis for these upregulated miRNAs revealed several putative and confirmed regulatory $\mathrm{T}$ cell $\left(\mathrm{T}_{\text {reg }}\right)$-related targets for miR-21, $-22,-27 b,-31,-155,-210$, and $-301 \mathrm{a}$ in murine and human genomes (1). Several molecules including the transcription factors foxp3 and runx 3 and the signaling molecules CD25 
and CTLA4 are integral to $\mathrm{T}_{\text {reg }}$ differentiation and function. The expression of these molecules allows this subset to differentiate in response to allergens and exert immune regulatory functions, dampening inappropriate inflammatory and adaptive immune responses. Additional miRNAs potentially involved in TDI sensitization have been implicated as regulators of $T_{\text {regs }}$ in a variety of contexts including miR-31 and $-155(19,20)$. A role for $T_{\text {regs }}$ has been suggested in models of chemical-induced contact hypersensitivity $(21,22)$ and in a recent manuscript, Long, et al. demonstrated the increased expression and functional capability of $\mathrm{T}_{\text {regs }}$ during TDI sensitization (22). While the collection of data regarding $T_{\text {regs }}$ and chemical allergy is growing, it is still limited. Similarly, data regarding the role of miRNAs in chemical allergy is very limited. While our data suggests an important role for $\mathrm{T}_{\text {regs }}$ in dermal TDI sensitization, the interaction between these cells and selected miRNAs has not been investigated. While miR-210 is well characterized in the hypoxia response, its specific role in allergic disease has not yet been defined. In the present study we utilized a murine model of epicutaneous TDI sensitization in order to elucidate the expression kinetics and role of miR-210 and its putative mRNA targets in a murine model of epicutaneous TDI sensitization, specifically in relation to the $\mathrm{T}_{\text {reg }}$ subset.

\subsection{MATERIALS AND METHODS}

\subsubsection{Mice}

Female BALB/c mice (6-8 weeks of age) obtained from Taconic (Germantown, NY), acclimated for 5 days, and then randomly assigned to treatment group; homogenous weight distribution was insured across treatment groups. BALB/c mice were selected on the basis of their Th2 bias, robust IgE production, and the historical use of these mice in the laboratory to investigate 
TDI sensitization $(1,23)$. Mice were housed in ventilated plastic shoebox cages with hardwood chip bedding at a maximum of five animals per cage. A NIH-31 modified $6 \%$ irradiated rodent diet (Harlan Teklad) and filtered tap water were administered ad libitum. Housing facilities were maintained at $68-72^{\circ} \mathrm{F}$ and $36-57 \%$ relative humidity, and a 12 hour light-dark cycle was maintained. All animal experiments were performed in the Association for Assessment and Accreditation of Laboratory Animal Care (AAALAC) accredited National Institute for Occupational Safety and Health (NIOSH) animal facility in accordance with an Institutional Animal Care and Use Committee-approved protocol.

\subsubsection{TDI Sensitization Model}

Toluene 2,4-diisocyanate (TDI, CAS\# 584-84-9) was obtained from Sigma-Aldrich (Milwaukee, WI). Animals were exposed to a single dose of $0,0.5$, and $4 \%$ TDI ( $/ / \mathrm{v})$ on the dorsal surface of each ear $(25 \mu \mathrm{L}$ per ear). The chosen TDI concentrations ( 0.5 and $4 \% \mathrm{v} / \mathrm{v})$ and dosing regimen was previously shown to induce sensitization $(1,22)$ and $4 \%$ TDI was previously reported as the minimum single dose concentration of TDI that could induce maximum sensitization in the absence of systemic toxicity (1). Acetone was selected as the vehicle control and has been historically utilized in our laboratory to evaluate chemical sensitization (22-24).

\subsubsection{Euthanasia, Tissue Collection, and Processing}

Animals were weighed, euthanized via $\mathrm{CO}_{2}$ asphyxation at time points ranging from 1 to 11 days post chemical exposure, and examined for gross pathology. Left and right auricular draining lymph nodes (dLNs; drain the site of chemical application) were collected in $4 \mathrm{~mL}$ sterile phosphatebuffered saline ( $\mathrm{pH}$ 7.4) and manually dissociated using the frosted ends of two microscope slides. 
Cells were counted using a Cellometer (Nexcelom Bioscience, Lawrence, Massachusetts) and size exclusion parameters (3.5 to $36 \mu \mathrm{m})$ with a combined acridine orange/propidium iodide solution to identify viable cells. For isolation of specific cellular subsets Stemcell magnetic isolation kits (Vancouver, BC) were utilized, including the $\mathrm{T}_{\text {reg }}$ isolation kit (CD4 negative and CD25 positive selection).

\subsubsection{Ex vivo miRNA Transfection Assays}

Following dLN processing and counting miR-31, -155, and -210 mimics (25 pmol in Lipofectamine transfection reagent, ThermoFisher, Waltham, MA) were reverse transfected in flatbottom 24-well plates. $1.5 \times 10^{6}$ naïve or acetone-treated dLN cells/mL (in RPMI-1640 media) were added to plates followed by general T cell stimulation $(2 \mu \mathrm{g} / \mathrm{mL} \alpha-C D 3,1 \mu \mathrm{g} / \mathrm{mL} \alpha-C D 28)$. Plates were incubated for 72 hours at $37^{\circ} \mathrm{C}$ and $5 \% \mathrm{CO}_{2}$. Following a 72 hour incubation, cells were washed with RPMI-1640 and RNA was isolated as described in the following section. RNA was assayed for intracellular miRNA expression to conform the intracellular uptake of miRNA mimics as well as

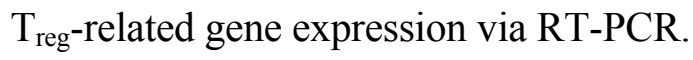

\subsubsection{RNA Isolation, Reverse Transcription, and RT-PCR}

Total RNA was isolated from the ears and dLN using the Qiagen RNeasy and miRNeasy kits respectively according to the manufacturer's directions. A QiaCube (Qiagen, Hilden, Germany) automated RNA isolation machine was utilized in conjunction with the specified RNA isolation kits. A DNase treatment was included in the RNeasy protocol for the removal of residual DNA. The concentration and purity of the RNA was determined using a ND-1000 spectrophotometer (Thermo Scientific Nanodrop, Wilmington, DE). For gene and primary miRNA expression analysis, first 
strand cDNA synthesis was performed using a High-Capacity cDNA Synthesis Kit (Applied Biosystems, Carlsbad, California) according to manufacturer recommendations. For mature miRNA reverse transcription TaqMan MicroRNA Assays (looped-primer RT-PCR; Applied Biosystems, Carlsbad, California) were utilized according to manufacturer recommendations (both multiplex and singleplex protocols were utilized).

For analysis of mRNA and primary miRNA expression, TaqMan Universal Fast master mix (Life Technologies, Calsbad, California), cDNA, and mouse-specific mRNA primers (TaqMan Custom PCR Arrays, Carlsbad, California) were combined and PCR was performed according to manufacturer protocol (TaqMan Gene Expression Analysis). For analysis of miRNA expression, TaqMan Universal 2x master mix, No AmpErase UNG (Life Technologies, Calsbad, California), cDNA, and mouse-specific miRNA primers (TaqMan Custom PCR Arrays, Carlsbad, California) were combined and PCR was performed according to manufacturer protocol (TaqMan miRNA Assays both Single- and Multi-Plex). $\quad$ Primers used include: $\beta$-actin, cd25 (il2ra), ctla4, foxp3, mature miR-21, -22, -27b, -31, -126, -155, -210, and -301a, primary miR-210, runx3, and sno234. MicroAmp Fast Optical 96-well reaction plates were analyzed on an Applied Biosystems 7500 Fast Real Time PCR system using cycling conditions as specified by the manufacturer. $\beta$-actin (mRNA and primary miRNA) and snoRNA234 (miRNA) were used as the endogenous reference control gene as expression was determined to be stable following chemical exposure (data not shown). RTPCR data were collected and represented as relative fold change over vehicle control, calculated by the following formula: $2^{-\Delta \Delta \mathrm{Ct}}=\Delta \mathrm{Ct}_{\text {Sample }}-\Delta \mathrm{Ct}_{\text {Control }} . \quad \Delta \mathrm{Ct}=\mathrm{Ct}_{\text {Target }}-\mathrm{Ct}_{\beta \text {-ACTIN }}$, where $\mathrm{Ct}=$ cycle threshold as defined by manufacturer. 


\subsubsection{Flow Cytometric Analysis and $T_{\text {reg }}$ Phenotyping}

Single cell suspensions were prepared from tissues and a minimum of $150,000 \mathrm{dLN}$ cells were aliquoted into 96-well U-bottom plates and washed in FACS staining buffer (PBS $+1 \%$ bovine serum albumin $+0.1 \%$ sodium azide). Cells were resuspended in staining buffer containing antimouse CD16/32 antibody (clone 2.4G2; BD Biosciences, San Jose, CA) for blocking of $\mathrm{F}_{\mathrm{c}}$ receptors to minimize nonspecific binding. Cells were resuspended in staining buffer containing a cocktail of fluorochrome-conjugated antibodies specific for cell surface antigens including: CD3 (500A2, V500, BD Biosciences, Franklin Lanes, NJ), CD4 (RM4-5, AF700, BD), CD8a (53-6.7, AF488, BioLegend, San Diego, CA), CD25 (PC61, APC Cy7, BioLegend), CD45 (30-F11, PE, BD). Following surface staining, cells were washed in staining buffer and fixed using the Foxp3 fixation buffer set (eBioscience, San Diego, CA). After overnight incubation in staining buffer, cells were permeablilized using the Foxp3 fixation buffer set (eBioscience, San Diego, CA) and re-suspended in permeabilization buffer containing a cocktail of fluorochrome-conjugated antibodies specific for intracellular antigens including: RUNX3 (R3-5G4, PE, BD), Foxp3 (FLK-16s, eF450 and APC, eBioscience, San Diego, CA). Following staining, cells were re-suspended in staining buffer and analyzed on an LSR II flow cytometer using FacsDiva software (BD Biosciences). Data analysis was performed with FlowJo 10.0 software (TreeStar Inc., Ashland, OR). A minimum of 10,000 events were captured for each sample. Leukocytes were first identified by their expression of CD45. The $\mathrm{T}_{\text {reg }}$ subset was further identified as $\mathrm{CD}^{+} \mathrm{CD} 4^{+} \mathrm{CD} 8^{-} \mathrm{CD} 25^{+} \mathrm{Foxp}^{+}$. Numerical population values were calculated by applying subset frequencies to the initial cell count obtained following lymph node homogenization. Compensation controls were performed using single stained cellular suspensions and OneComp beads (eBioscience, San Diego, CA) and fluorescence minus one (FMO) staining controls were included to help set gating boundaries. 


\subsection{7. $T_{\text {reg }}$ Suppression Assay}

The suppressive ability of $\mathrm{T}_{\text {regs }}$ was analyzed using an ex vivo $\mathrm{T}_{\text {reg }}$ suppression assay as described by Long, et al. (22). This assay evaluates the ability of naïve, conventional dLN-derived $\mathrm{T}$ cells $\left(\mathrm{T}_{\text {cons }}\right)$ to proliferate in the presence of varying numbers of $\mathrm{T}_{\text {regs }}$ isolated from acetone- or TDI-exposed mice. Mice were exposed to acetone $(n=7-11)$ or TDI $(4 \%)(n=4-5)$ as previously described and following sacrifice at 7 days post TDI (peak of the expansion) exposure the dLN and spleens were removed. $\mathrm{T}_{\text {regs }}\left(\mathrm{CD} 4^{+} \mathrm{CD} 25^{+}\right)$and $\mathrm{T}_{\text {cons }}\left(\mathrm{CD} 4^{+} \mathrm{CD} 25^{-}\right)$were isolated from the lymph nodes and $\mathrm{CD}^{-}$accessory cells were isolated from naïve spleens using CD4 negative and CD25 positive selection-based magnetic separation kits (Stemcell, Vancouver, BC). Average $\mathrm{T}_{\text {reg }}$ purity is as follows for 7 days: Acetone-96.5\% \pm 0.8 of $\mathrm{CD}^{+} \mathrm{CD}^{+}$cells and $4 \%$ TDI-97.35\% \pm 0.25 of $\mathrm{CD}^{+} \mathrm{CD}^{+}$cells. Following isolation from naïve mouse dLNs, $\mathrm{T}_{\text {cons }}$ were labeled with $2 \mu \mathrm{M}$ carboxyfluorescein succinimidyl ester (CFSE). miR-210 mirVana mimic (2 pmol; ThermoFisher) in Lipofectamine RNAiMAX (ThermoFisher) or Lipofectamine only control (LO) were added to a 96-well U-bottom plate in order to reverse transfect cells. $\mathrm{T}_{\text {cons }}$ and $\mathrm{T}_{\text {regs }}$ were cultured in a 96-well U-bottom plate with anti-CD3 $(0.2 \mu \mathrm{g} / \mathrm{mL}$; BD Biosciences) and accessory cells (naïve CD4 splenocytes treated with Mitomycin $C)$ at a variety of $\mathrm{T}_{\text {con }}: \mathrm{T}_{\text {reg }}$ ratios $(1: 1,2: 1,4: 1$, and 8:1). Additional controls included stimulated $\mathrm{T}_{\text {cons }}$ only to assess baseline proliferation, $\mathrm{T}_{\text {regs }}$ only, accessory cells only, and $\mathrm{T}_{\text {cons }}$ only with no stimulation nor accessory cells. Cells from each treatment group were pooled and added to triplicate wells of the culture plate. 72 hours following plating, cells were stained with anti-CD4 and Live/Dead Violet (Life Technologies, Carlsbad, CA). $\mathrm{T}_{\text {cons }}$ were defined as $\mathrm{CD}^{+} \mathrm{CFSE}^{+}$cells and suppression was measured based on changes in the frequency of dividing $\mathrm{CFSE}^{+}$cells based on the dilution of CFSE. $\mathrm{T}_{\text {regs }}$ were analyzed for purity 
based on their expression of CD3, CD4, and Foxp3 as determined by flow cytometric analysis as previously described.

\subsubsection{Statistical Analysis}

Statistical analyses were generated using GraphPad Prism version 5.0 (San Diego, CA). Data was analyzed by a Student $t$-test comparing groups as indicated in the figure legends. Figure $4.4 \mathrm{C}$ was analyzed by analysis of variance using PROC MIXED. In some cases, data were transformed using the natural log to meet the assumptions of the analysis. Significant interactions were explored utilizing the "slice" option in PROC MIXED and pairwise differences were assessed using a Fishers Least Significant Difference Test. All differences were considered significant at $p<0.05$; representative significance symbols varied by figure, as indicated in the figure legend.

\subsection{RESULTS}

\subsubsection{Examination of miR-210 Expression during TDI Sensitization}

The kinetics of mature miR-210 expression were investigated via RT-PCR in the dLN following $0.5 \%$ and $4 \%$ TDI exposure. As previously reported (1), dLN miR-210 increased at various time points during 0.5 and 4\% TDI sensitization, including $4(4 \%), 7$, and $9(0.5$ and $4 \%)$ days post single exposure, with expression appearing to peak at 4 days post $4 \%$ TDI exposure (Figure 4.1A). Primary miRNA (pri-miRNA) transcripts represent the early precursor stage of mature miRNA structure prior to modification and cleavage by Drosha and Dicer. Pri-miR-210 levels were analyzed in the dLN 4 days post TDI exposure, which represents the relative peak of dLN miR-210 expression. Although expression of pri-miR-210 was detected in the $\mathrm{dLN}$, no significant alterations 
were observed. Alternatively, pri-miR-210 expression significantly decreased in the $\mathrm{CD} 4^{+}$subset during 4\% TDI sensitization (Figure 4.1 B)

A

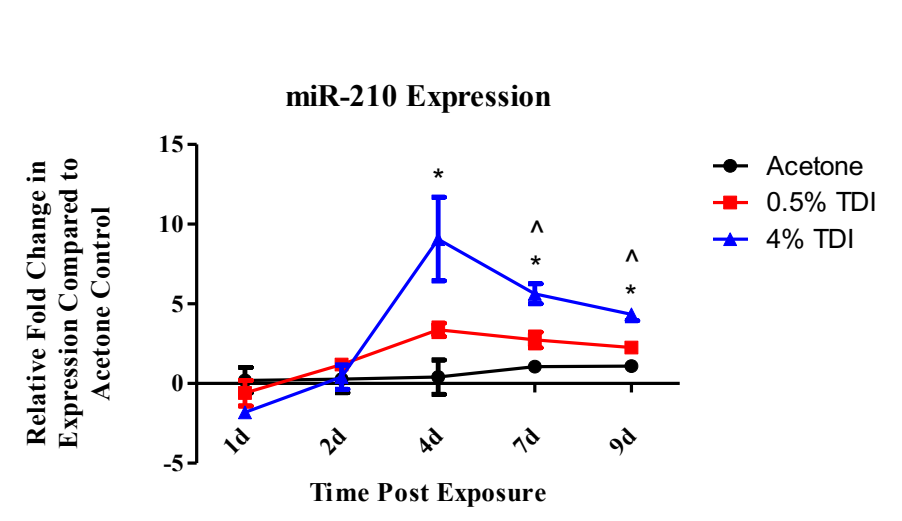

B

Primary miR-210 Expression

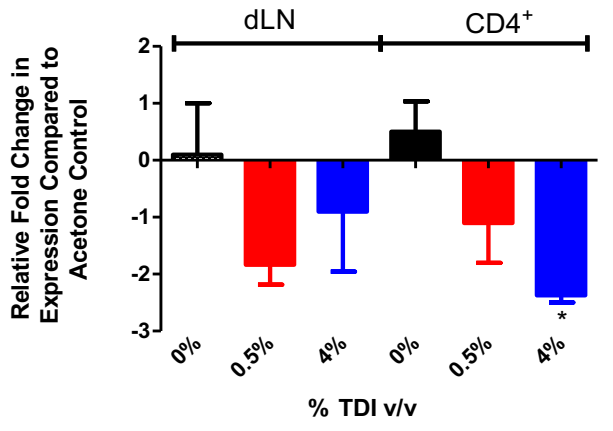

Figure 4.1 Mature miR-210 expression increases during TDI sensitization

RT-PCR analysis of mature miR-210 expression in the dLN at various time points post TDI exposure (A). Primary miR-210 expression in the whole $\mathrm{dLN}$ and $\mathrm{dLN} \mathrm{CD} 4^{+}$subset 4 days post TDI exposure (B). Cellular purity was assessed via flow cytometric staining for $\mathrm{CD} 4^{+}$Cells $\left(\% \mathrm{CD} 4^{+}\right.$of all cells; Acetone: $89.6 \% \pm 2.2,0.5 \%$ TDI: $91.5 \% \pm 0.3$, and $4 \%$ TDI: $90.4 \% \pm 0.3$ ). Bars represent mean relative fold change $( \pm \mathrm{SE})$ of $3-5$ mice per group. $P$ values are represented by $\wedge(0.5 \% \mathrm{TDI})$ and $*$ (4\% TDI) $(P<0.05)$. Dermal treatment groups are indicated by the following symbols: circleacetone, square- $0.5 \% \mathrm{TDI}$, and triangle- $4 \% \mathrm{TDI}$. 


\subsubsection{Ex vivo miR-210 Mimic Transfection Reveals Potential Inhibitory Effect of miR-210 on $T_{\text {reg-related Genes }}$}

Due to the putative link between miR-210 and $\mathrm{T}_{\text {reg-related targets in both human and mouse- }}$ based studies and target algorithms (1), an ex vivo transfection and stimulation assay was set up to

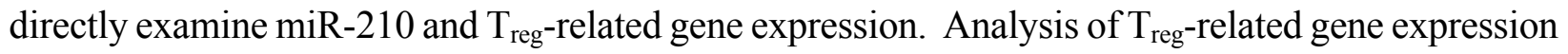
induced by the addition of excess levels of miR-210 was examined. Although not statistically significant, Figure 4.2 A reveals increased miR-210 expression in cells treated with miR-210 mimic (101 fold) as compared to lipofectamine only (LO) control (1.2 fold). Analysis of $\mathrm{T}_{\text {reg-related genes }}$ revealed decreased trends of expression of $\mathrm{T}_{\text {reg }}$-related genes following miR-210 mimic transfection compared to the LO control, including foxp3 ( -2.0 fold compared to 0.6 fold $)$ and $c d 25((\sim-3.2$ fold compared to 0.2 fold) (Figure 4.2 B)). No apparent changes in runx3 nor ctla4 were observed (data not shown).

A

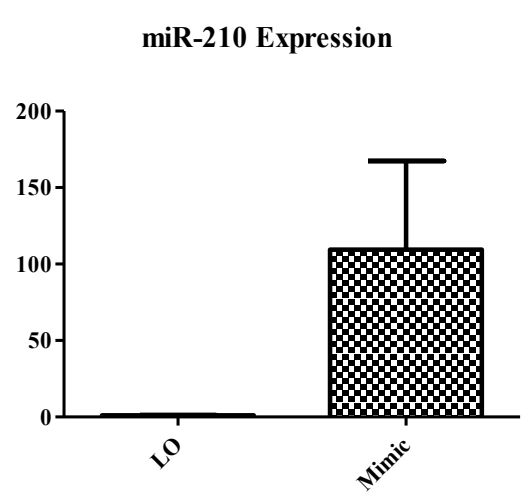

B

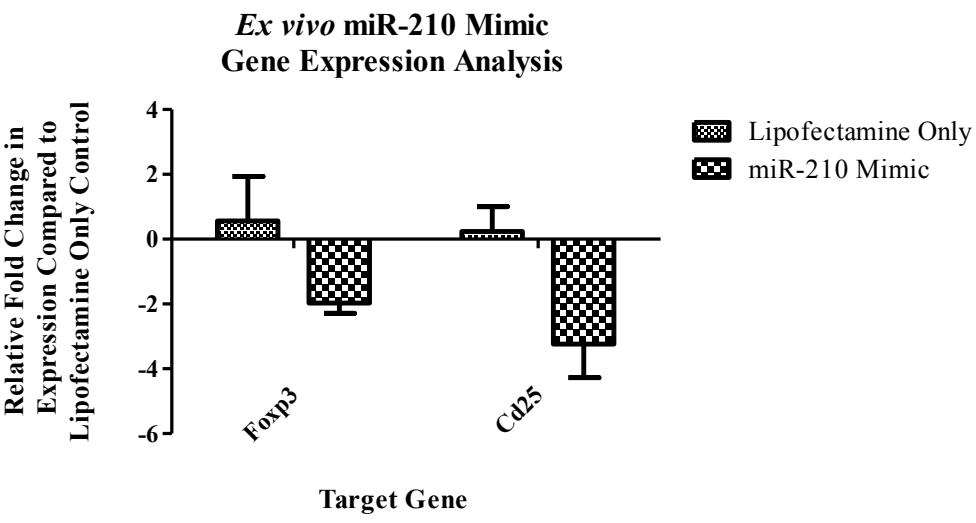

Figure 4.2 Ex vivo Data Reveals Potential Inhibitory Effect of miR-210 on $T_{\text {reg-related Genes }}$ Intracellular miR-210 (A) was quantified via RT-PCR in ex vivo stimulated samples 72 hours following transfection with lipofectamine control (LO) or miR-210 mimic. In (B) foxp3 and 
$c d 25$ (il2r $\alpha$ ) were investigated as potential miRNA targets via RT-PCR. Bars represent mean relative fold change $( \pm \mathrm{SE})$ of 3 replicates per group. Data represents two independent experiments.

\subsubsection{In vivo dLN Target Expression Reveals Decreased Expression of Several Key $\mathbf{T}_{\text {reg-related }}$} Genes

The expression of potential miR-210 targets and key $\mathrm{T}_{\text {reg }}$ genes potentially affected by miR210 was investigated in the whole dLN at various time points following 4\% TDI exposure. Similar to the findings of the ex vivo study and previously reported findings, dLN target/key player mRNA expression was significantly decreased at 4 (runx3), 7 (foxp3), and 9 (foxp3) days post 4\% TDI exposure (Figure 4.3 A and B). Foxp3 expression was decreased by approximately threefold in comparison to the acetone control at 7 and 9 days post TDI exposure (Figure 4.3 A). Early statistically significant increases in foxp3 (1day) and run3 (2 day) were also observed but only for a single time point and not determined to be of biological significance. dLN ctla4 and $c d 25$ expression significantly increased with peak expression at 4 and 2 days post 4\% TDI exposure, respectively. However, these increases in expression were not maintained at later time points (Figure $4.3 \mathrm{C}$ and D). 
A

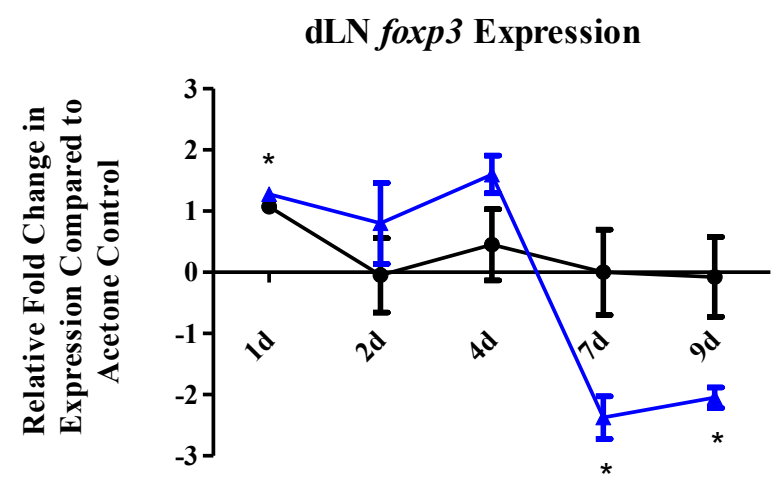

Time Post Exposure

C

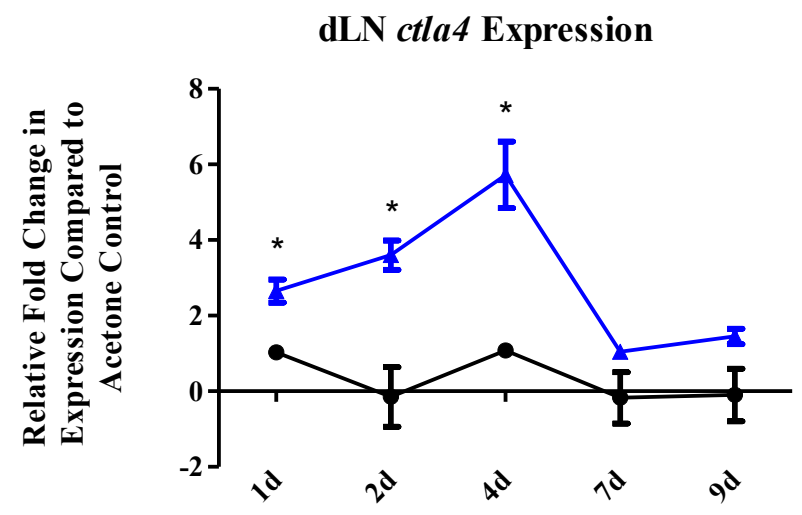

Time Post Exposure
B

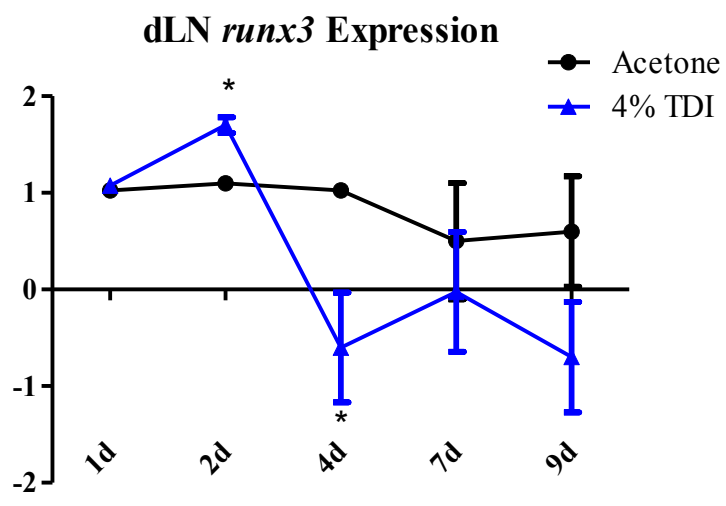

Time Post Exposure

D

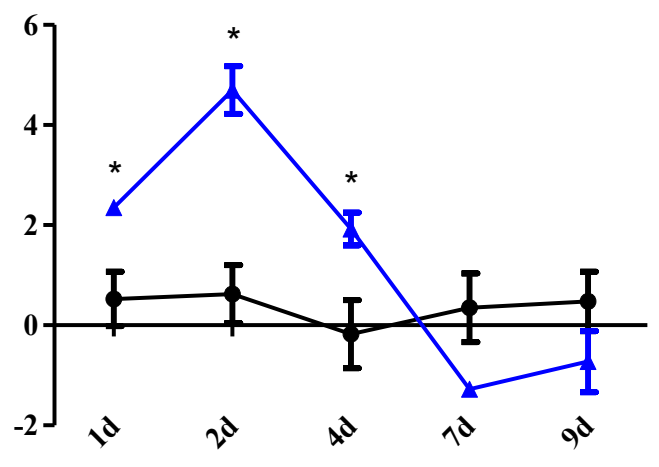

Time Post Exposure

Figure 4.3 In vivo Target mRNA Expression

RT-PCR analysis of foxp3 (A), runx3 (B), ctla4 (C), and cd25 (D) expression in the whole dLN at various time points post 0 and $4 \%$ TDI exposure. Bars represent mean relative fold change of 5 mice per group. Statistical significance is represented by $*(P<0.05)$. 


\subsection{4. $T_{\text {reg-Specific miRNA and Gene Expression }}$}

Due to the suspected influence of miR-210 on $\mathrm{T}_{\text {regs }}$ the levels of this miRNA were examined in $\mathrm{T}_{\text {regs }}\left(\mathrm{CD} 4^{+} \mathrm{CD} 25^{+}\right)$from the dLN of mice treated with $0,0.5$, and $4 \%$ TDI at 2 and 7 days post exposure. These time points were selected to reflect early and peak miR-210 and $\mathrm{T}_{\text {reg }}$ responses in the dLN (Figure 4.1 A and (1)). While no statistically significant changes were observed following 2 days of exposure, miR-210 levels were significantly increased in $\mathrm{T}_{\text {regs }}$ during 0.5 and $4 \%$ TDI sensitization in a dose responsive fashion at 7 days post exposure (Figure $4.4 \mathrm{~A}$ ). Expression of $\mathrm{T}_{\text {reg }^{-}}$ related genes was also examined in isolated $\mathrm{T}_{\text {regs }}$ following TDI exposure. Significant decreases in foxp3, ctla4, runx3, and cd25 were observed at both concentrations (except for ctla4 at 4\%) at 2days post exposure. Similarly, significant decreases in foxp3, ctla4, and $c d 25$ mRNA were observed in $\mathrm{T}_{\text {regs }}$ from 4\% TDI-exposed mice at 7 days post 4\% TDI exposure (Figure $4.4 \mathrm{~B}$ ), further indicating

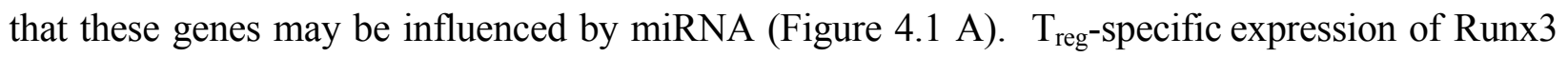
was assayed in $\mathrm{dLN} \mathrm{T}_{\text {regs }}$ during TDI sensitization. In contrast to the mRNA levels, increases in frequency and numbers of Runx $3^{+} \mathrm{T}_{\text {regs }}$ at all time points were observed following 0.5 and $4 \%$ TDI exposure (Figure 4.4 C). 


\section{$T_{\text {reg }}$ miR-210 Expression}

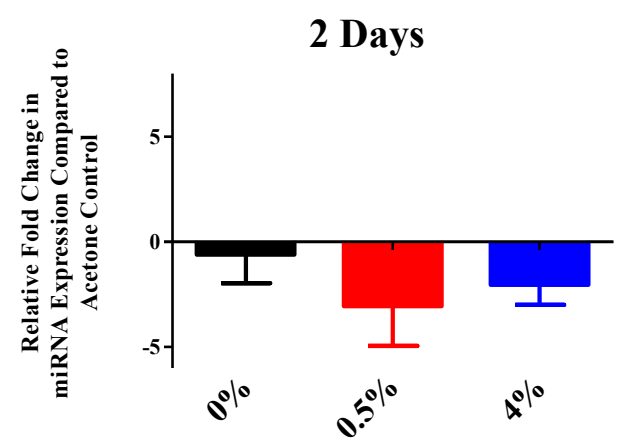

7 Days

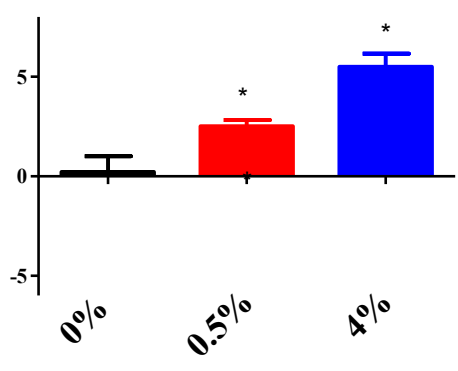

\% TDI (v/v)

B
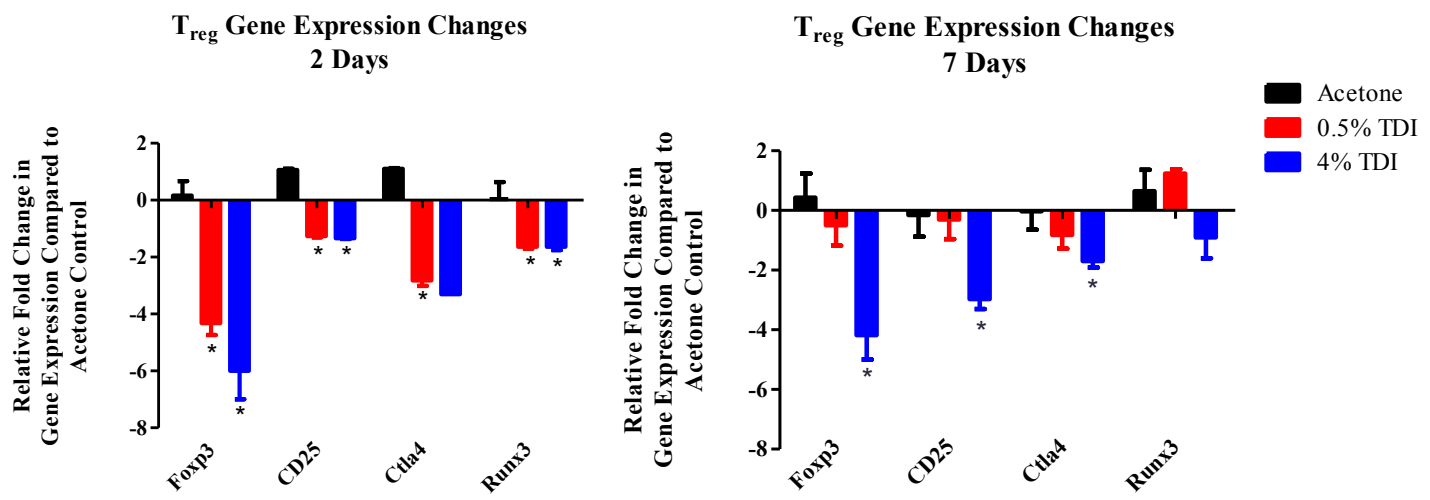

C
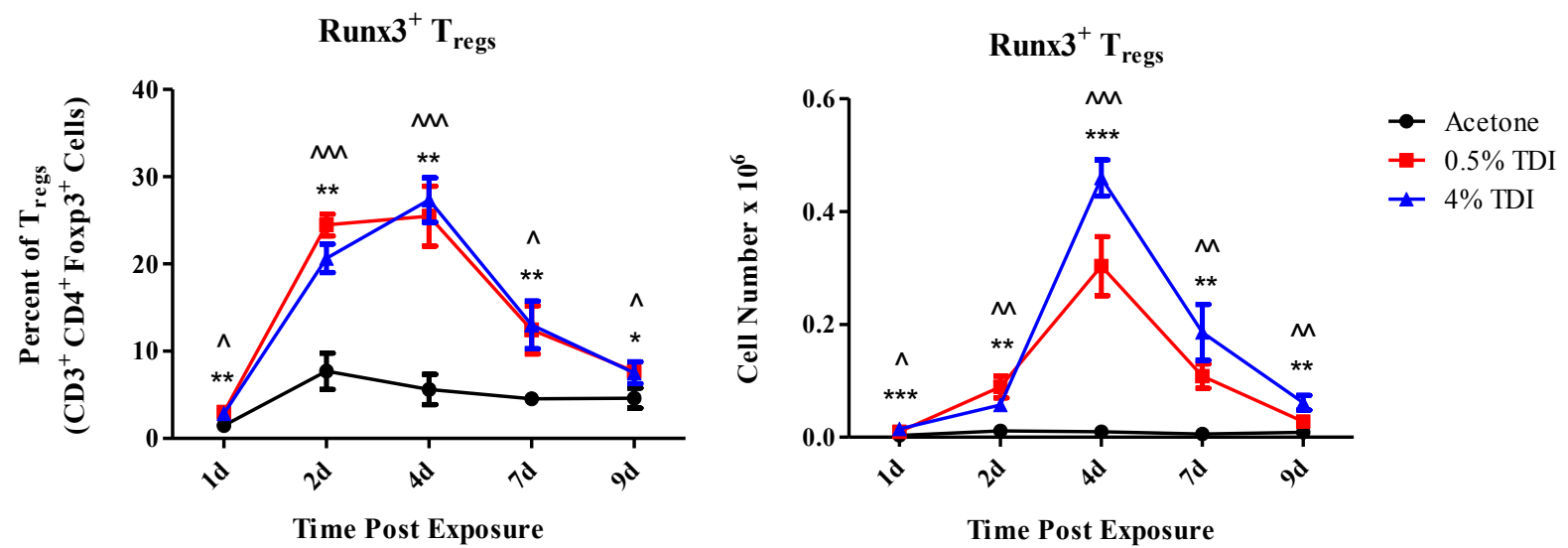
Figure 4.4 Mature miRNA expression increases in $T_{\text {regs }}$ during TDI sensitization

RT-PCR analysis of -210 (A and B) and $\mathrm{T}_{\text {reg }}-$ related gene (C and D) expression in the dLN $\mathrm{T}_{\text {reg }}$ subset at 2 and 7 days post TDI exposure. $\mathrm{T}_{\text {regs }}$ were isolated as $\mathrm{CD} 4{ }^{+} \mathrm{CD} 25^{+}$cells and cellular purity was assessed via flow cytometric staining for $\mathrm{CD}^{+} \mathrm{CD}^{+} \mathrm{Foxp}^{+}$events (2 days: $\% \mathrm{~T}_{\text {regs }}$ of all $\mathrm{CD} 4^{+}$ events, mean, $\mathrm{n}=4-5$ per group: Acetone: $83.8 \% \pm 1.6,0.5 \%$ TDI: $67.1 \% \pm 4.2$, and $4 \%$ TDI: $72.3 \%$ $\pm 1.9 ; 7$ days: $\% \mathrm{~T}_{\text {regs }}$ of all $\mathrm{CD}^{+}$events, one representative sample: Acetone: $91 \%, 0.5 \% \mathrm{TDI}$ : $88.4 \%$, and $4 \%$ TDI: $86.7 \%$ ). Flow cytometric analysis of dLN Runx $3^{+} \mathrm{T}_{\text {reg }}$ frequency and number (C) following TDI sensitization. Bars represent mean relative fold change ( \pm SE) of 4-5 mice per group. For A and B, $P$ values are represented by ${ }^{\wedge}(0.5 \%$ TDI $)$ and asterisks $(4 \%$ TDI $)(P<0.05)$. For $\mathrm{C}$, Significance is indicated as follows: $\mathrm{P} \leq .05(*), \mathrm{P} \leq .01(* *), \mathrm{P} \leq .001(* *)$, and $\mathrm{P} \leq .0001$ $(* * * *)$ for $4 \%$ TDI or $\mathrm{P} \leq .05(\wedge), \mathrm{P} \leq .01\left(^{\wedge \wedge}\right), \mathrm{P} \leq .001\left(^{\wedge \wedge \wedge}\right)$, and $\mathrm{P} \leq .0001\left(^{\wedge \wedge \wedge}\right)$ for $0.5 \%$ TDI. Dermal treatment groups are indicated by the following symbols: circle- acetone, square- $0.5 \% \mathrm{TDI}$, and triangle- $4 \%$ TDI.

\subsubsection{The Ex Vivo Suppressive Capability of $T_{\text {regs }}$ is Influenced by miR-210 Levels}

In order to examine the suspected inhibitory role of miR-210 on $\mathrm{T}_{\text {regs }}$ during TDI sensitization, the functional capabilities of $\mathrm{T}_{\text {regs }}$ were tested in an ex vivo suppression assay. miR210 mimic was transfected in selected wells utilizing a lipid-based transfection strategy and intracellular miR-210 mimic uptake was confirmed in these wells at the time of cellular harvest (Figure $4.5 \mathrm{~A}$ ). Interestingly, following addition of the miR-210 mimic, miRNA-210 levels were almost 10-fold higher in wells containing acetone $\mathrm{T}_{\text {regs }}$ compared to those with TDI $\mathrm{T}_{\text {regs }}$ (Figure 4.5 A). No differences were noted between miR-210 levels among the acetone and TDI groups treated with LO (Figure $4.5 \mathrm{~A}$ ). Significant baseline $\mathrm{T}_{\text {reg }}$ suppressive ability was observed in wells with 
Lipofectamine onle and acetone-derived $\mathrm{T}_{\text {regs }}$ as well as $4 \%$ TDI-derived $\mathrm{T}_{\text {regs }}$ (data not shown). This was not altered significantly upon the addition of miR-210 mimic with the exception of the 1:1 ratio in wells with $4 \%$ TDI-derived $\mathrm{T}_{\text {regs }}$ (data not shown). As previously evidenced (22), TDI-derived $\mathrm{T}_{\text {regs }}$ exhibited greater suppressive capability than acetone-derived $\mathrm{T}_{\text {regs }}$ in mimic-treated wells for the 1:1, 2:1, 4:1, and 8:1 ratios (Figure 4.5 B). This increased function was observed in the presence of lower miR-210 levels suggesting that TDI might induce additional factors that might influence that functionally capabilities of the $T_{\text {regs. }}$.

A

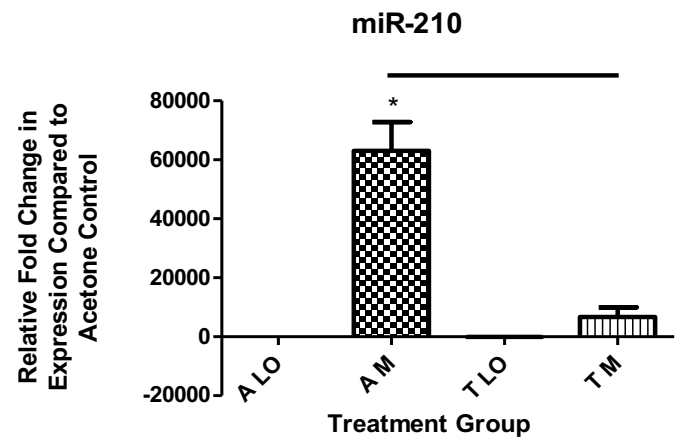

B

$\mathrm{T}_{\text {reg }}$ Suppression Assay

with miR-210 Mimic

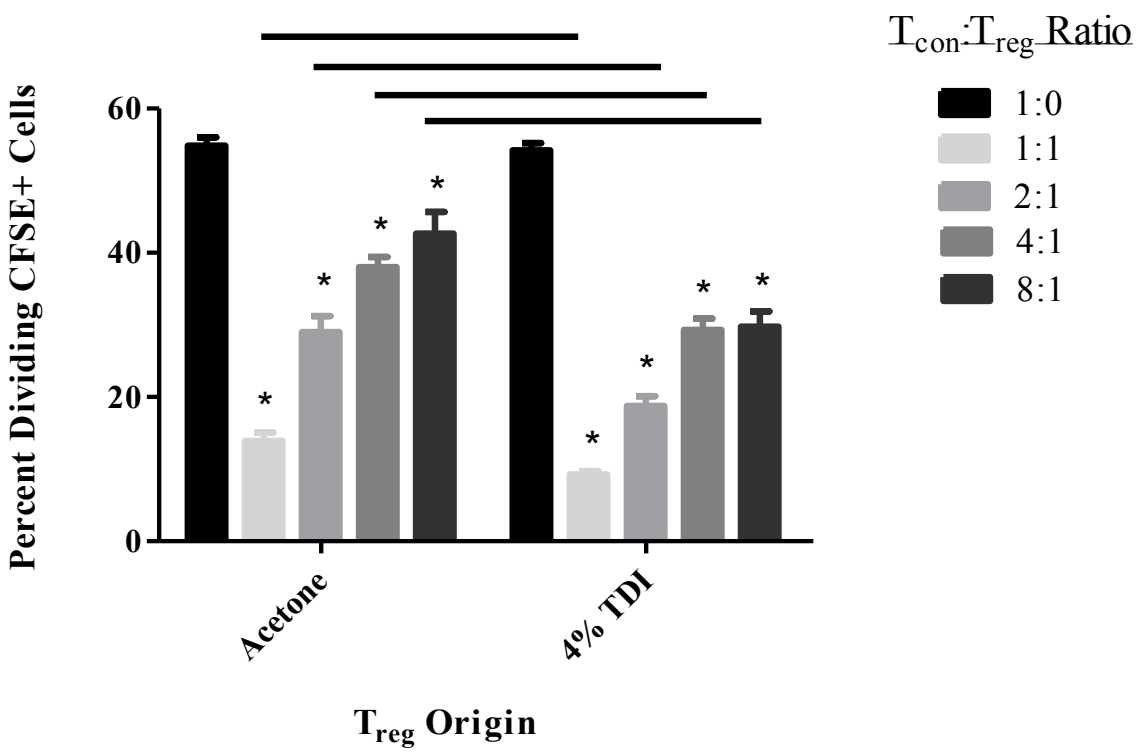


Figure 4.5 Increased $T_{\text {reg }}$ Suppression is Associated with Decreased miR-210 levels

A CFSE-based $\mathrm{T}_{\text {reg }}$ suppression assay was performed with $\mathrm{T}_{\text {regs }}$ from mice treated with acetone or TDI (7 days post exposure) and the addition of miR-210 mimic. RT-PCR analysis of intracellular miR-210 expression (A) in pooled wells from each indicated group was performed (one replicate from each ratio was included for the 1:0, 1:1, 2:1, and 4:1 $\mathrm{T}_{\text {con }}: \mathrm{T}_{\text {reg }}$ ratios.) A CFSE-based $\mathrm{T}_{\text {reg }}$ suppression assay with the addition of miR-210 mimic was performed and percent dividing $\mathrm{CFSE}^{+}$ cells were quantified (B). For (B) 3 plate replicates were utilized from groups of 5-10 mice, as described in section 4.2. $P$ values are represented by asterisks $(P<0.05$; comparison of each treatment group to $\mathrm{T}_{\text {con }}$ only from the same chemical treatment group) or horizontal bars with asterisks above (comparison of identical ratios between different $\mathrm{LO} /$ mimic treatment groups). Bars represent mean relative fold change ( $\pm \mathrm{SE}$ ) of 3 replicates per group. $P$ values are represented by horizontal lines and asterisks $(P<0.05)$.

\subsubsection{Further Investigation of miR-31 and -155 Suggest Additional Regulation of the TDI Sensitization Response, Potentially Impacting miR-210 and $\mathbf{T}_{\text {regs }}$}

Evaluation of additional miRNAs was performed in an attempt to identify other potential factors that might influence miR-210 and $\mathrm{T}_{\text {reg }}$ function. MiR-31 and -155 were selected since they have been identified to significantly increase in dLN expression earlier in TDI sensitization compared to miRNA-210 (Figure $4.6 \mathrm{~A}$ and B). Ex vivo target analysis was performed utilizing additional miRNA mimics including miR-31 and -155 in order to further pursue the potential regulation of the $T_{\text {reg }}$ subset by these miRNAs in addition to miR-210. Significantly increased intracellular levels of -31 (Figure 4.6 C) and -155 (Figure 4.6 D) were confirmed 72 hours following transfection and stimulation. Although not statistically significant, apparent decreases in foxp 3 
expression were observed following miR-31 (Figure $4.6 \mathrm{E}$ ) and -155 (Figure $4.6 \mathrm{~F}$ ) mimic transfection. No changes in expression were observed for runx3, ctla4, or $c d 25$ following mimic addition (data not shown).

A

B
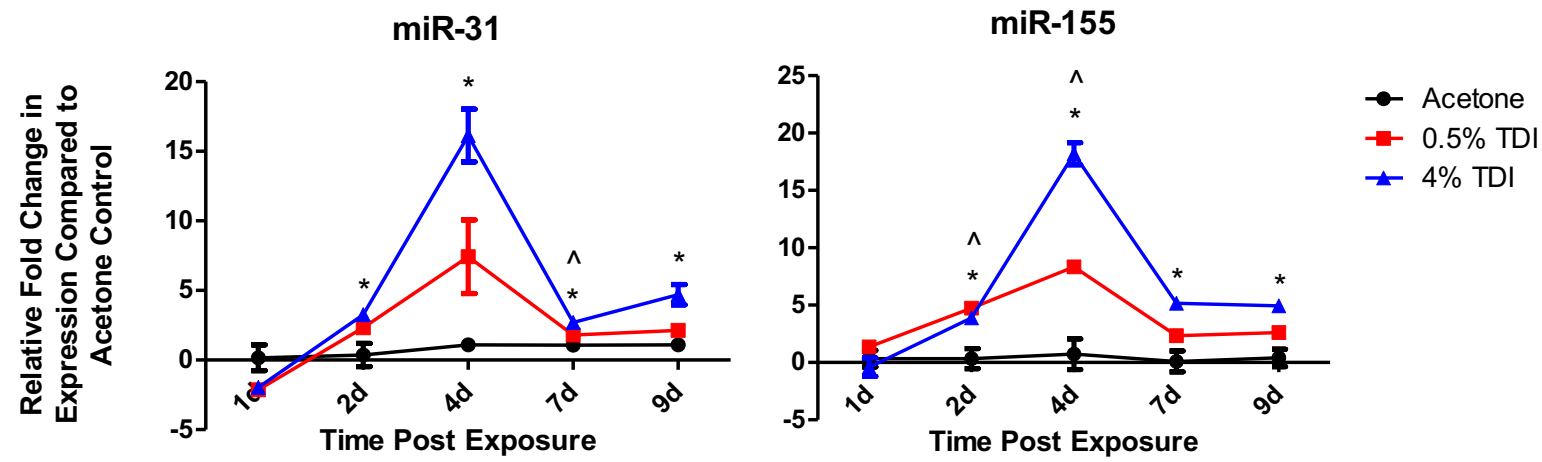

C

D
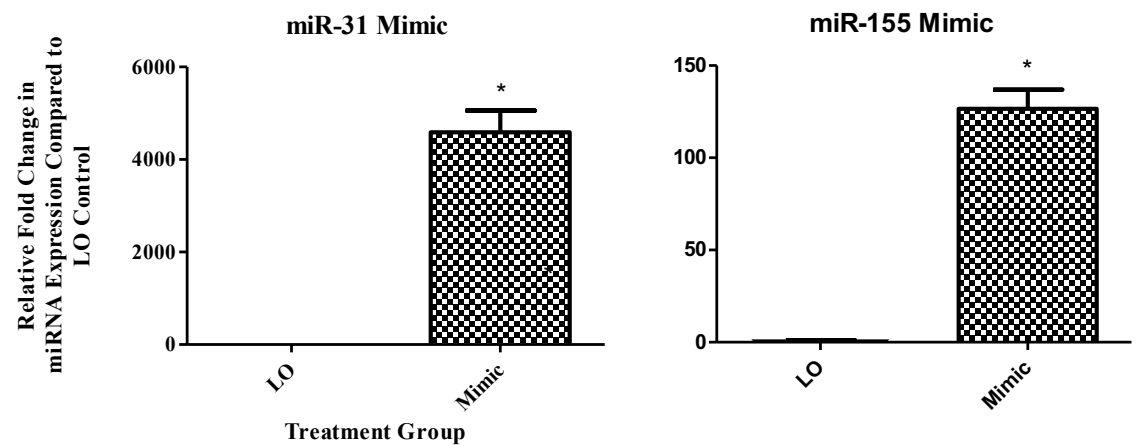
$\mathbf{E}$

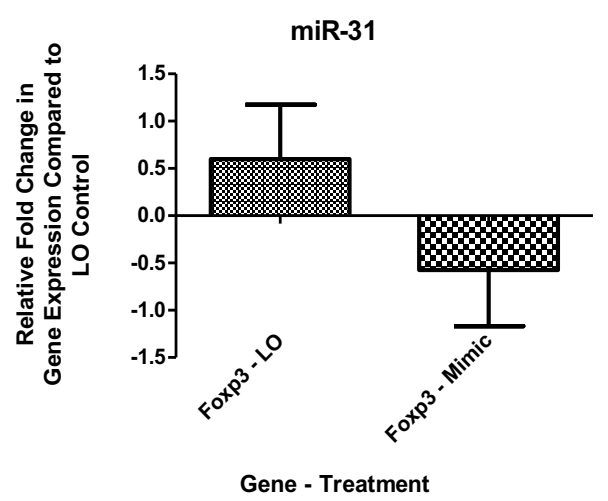

$\mathbf{F}$

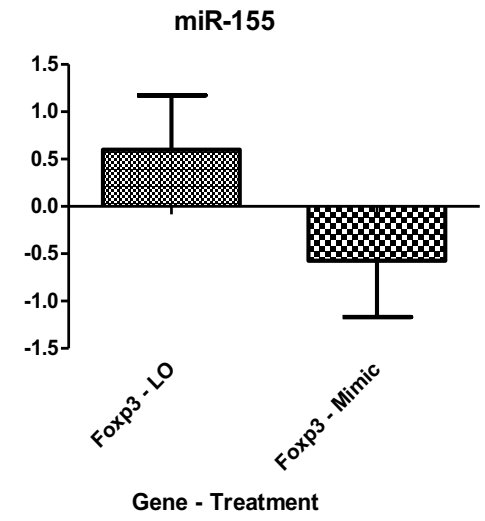

Figure 4.6 In vivo dLN miR-31 and-155 Levels Increase During TDI Sensitization

Whole dLN miR-31 (A) and -155 (B) levels were quantified via RT-PCR at various time points post TDI sensitization. Intracellular miR-31 (C), -155 (D) was quantified via RT-PCR in ex vivo stimulated samples (with miR-31 or -155 mimic addition, respectively) after 72 hours. In D-F foxp3 expression was investigated in cultures following miR-31 (D) and -155 (E) mimic treatment. Bars represent mean relative fold change $( \pm \mathrm{SE})$ of 3 replicates per group. $P$ values are represented by $\wedge(0.5 \%$ TDI $)$ and $*(4 \%$ TDI $)(P<0.05)$.

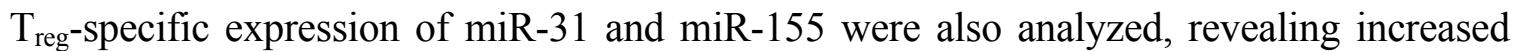
miR-31 levels 2 and 7 days post 0.5\% TDI exposure (Figure 4.7 A) and increased miR-155 levels 7 days post 4\% TDI exposure (Figure 4.7 B). Since miR-31 was identified to increase in expression earlier than miR-210 in the dLN and $T_{\text {regs }}$, miR-210 expression was evaluated in dLN cells treated with 31 and 155 mimics. However no changes in expression were observed. Similarly, expression of miR-31 and -155 was analyzed in cells treated with -210 mimic but no significant changes in expression were observed (data not shown). 
A

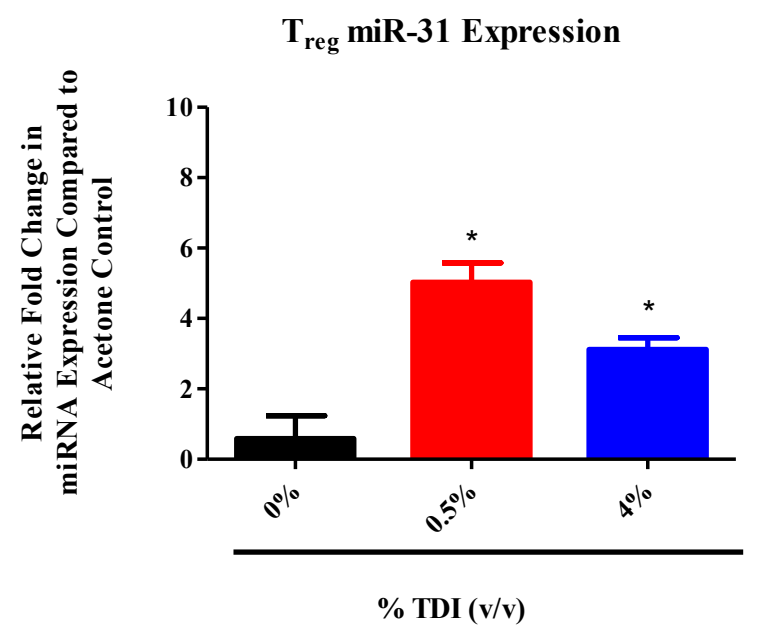

B

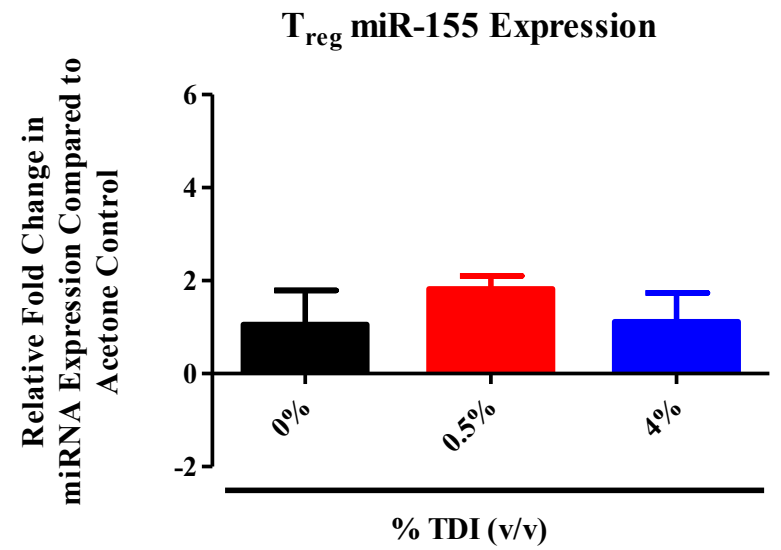

7 Days

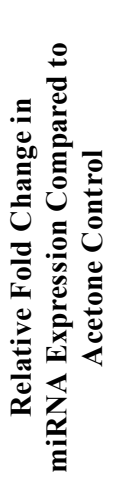

$\mathbf{T}_{\text {reg }}$ miR-31 Expression

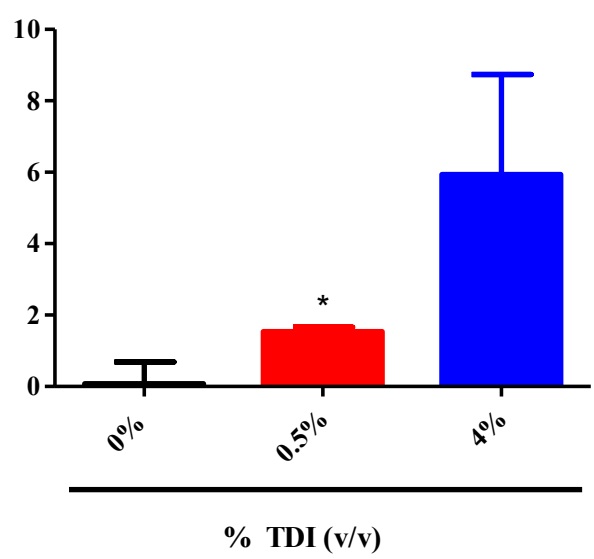

$T_{\text {reg }}$ miR-155 Expression

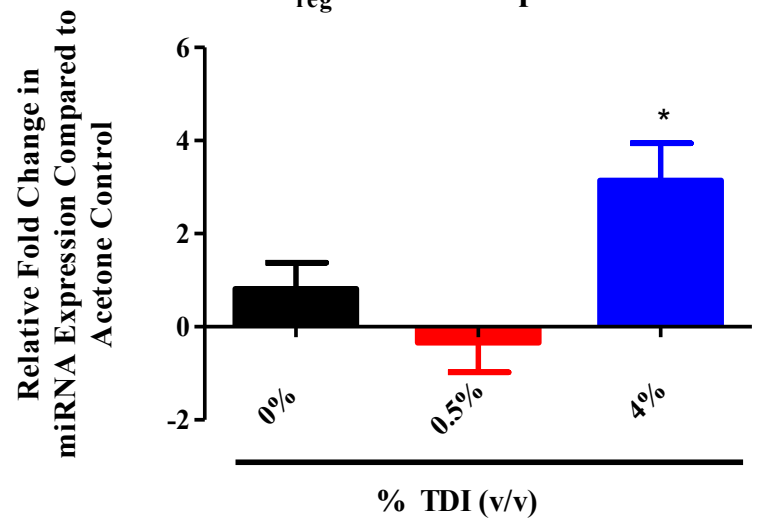

Figure 4.7 Mature miR-31 and -155 expression increases in $T_{\text {regs }}$ during TDI sensitization

RT-PCR analysis of miR-31 (A) and -155 (B) expression in the dLN $\mathrm{T}_{\text {reg }}$ subset at 2 and 7 days post TDI exposure. $\mathrm{T}_{\text {regs }}$ were isolated as $\mathrm{CD} 4^{+} \mathrm{CD} 25^{+}$cells and cellular purity was assessed via flow cytometric staining for $\mathrm{CD}^{+} \mathrm{CD}^{+}{ }^{+} \mathrm{Foxp}^{+}$events $\left(2\right.$ days: $\% \mathrm{~T}_{\text {regs }}$ of all $\mathrm{CD} 4^{+}$events, mean, $\mathrm{n}=4-5$ per group: Acetone: $83.8 \% \pm 1.6,0.5 \%$ TDI: $67.1 \% \pm 4.2$, and $4 \%$ TDI: $72.3 \% \pm 1.9 ; 7$ days: $\% \mathrm{~T}_{\text {regs }}$ of all $\mathrm{CD}^{+}$events, one representative sample: Acetone: $91 \%, 0.5 \%$ TDI: $88.4 \%$, and 4\% TDI: 
86.7\%). Bars represent mean relative fold change $( \pm \mathrm{SE})$ of $4-5$ mice per group. $P$ values are represented by $*(P<0.05)$.

\subsection{DISCUSSION}

The occupational use of sensitizing chemicals such as TDI remains a significant public health concern. There are no validated hazard identification strategies for respiratory sensitizers like TDI and the complete immunologic mechanisms of sensitization have not been elucidated for these agents, hindering development of appropriate preventative assays. This justifies research pertaining to the identification of novel cellular subsets and epigenetic regulatory mechanisms such as miRNAs that may be involved in the respiratory chemical sensitization process. Following the identification of several upregulated dLN miRNAs during TDI sensitization, these molecules were investigated during this response, specifically in relation to $T_{\text {reg }}$ development and functionality. To our knowledge, this is the first work that functionally investigates miRNAs in a model of Th2-mediated chemical sensitization.

miRNAs are powerful regulatory molecules which have been implicated in a number of immunologic states and conditions, including allergic disease (25-27). Specifically, miR-155 has demonstrated a critical role in the development of antibody responses and germinal center function (28), miR-326 has been shown to regulate Th17 differentiation, exhibiting critical involvement in multiple sclerosis pathogenesis (29), and in vivo miR-126 inhibition reduces a house dust miteinduced asthmatic phenotype, demonstrating the importance of this miRNA in the regulation of $\mathrm{Th} 2$ responses and allergic asthma (25). Vennegaard, et al. described upregulation of several miRNAs, including miR-21, in skin biopsies from patients with allergic responses to diphenylcyclopropenone and in a murine model of dinitrofluorobenzene (DNFB) allergic contact dermatitis (18). 
Additionally, previous work from our groups identified upregulation of several miRNAs, including miR-31, -155 , and -210 , in a murine model of epicutaneous TDI sensitization (1). These ubiquitous signaling molecules are well-established mediators of many of signaling pathways in a number of cell types; however, their role in chemical sensitization is not well understood. For the work described in this manuscript, miR-210 was selected for additional investigation since it has been predicted and demonstrated to target $\mathrm{T}_{\text {reg }}$-related genes. In addition, its role in chemical sensitization and $\mathrm{T}_{\text {reg }}$ regulation has not yet been described.

The expression of miR-210 was quantified in a variety of tissues and cellular subsets in a murine model of TDI sensitization. Consistent with previous findings (1), increased expression of miR-210 in the dLN was also demonstrated in the present study during TDI sensitization (Figure 4.1 A). In addition, increased expression of miR-210 was also identified in $\mathrm{T}_{\text {regs }}$ during TDI sensitization (Figure $4.4 \mathrm{~A}$ ). Since miRNA can be transported to cells via mechanisms such as exosomal transport, experiments to determine if cells are actively producing miR-210 following TDI exposure were conducted. The expression of pri-miRNA indicates gene level expression, presumably within the cell type tested. Pri-miR-210 was detected in the dLN and $\mathrm{CD}^{+}$subsets 4 days post TDI exposure (Figure 4.1 B), indicating that miR-210 is being expressed in this tissue by $\mathrm{CD}^{+} \mathrm{T}$ cells. Interestingly, although they were detectable, pri-miR-210 levels significantly decreased in $\mathrm{CD}^{+} \mathrm{T}$ cells 4 days post $4 \%$ TDI exposure compared to equivalent cells in acetone-exposed mice, potentially indicating that the majority of mature miR-210 in the $\mathrm{dLN}$ is being produced by another cell type, is being transported from another tissue, or is being transcriptionally downregulated at this point, the peak of mature miR-210 levels in the dLN. While pri-miR-210 levels in $T_{\text {regs }}$ were not investigated in the current study, previous studies have demonstrated miR-210 expression following the polarization of naïve $\mathrm{T}$ cells into $\mathrm{T}_{\text {regs }}(30)$. 
Since $\mathrm{T}_{\text {regs }}$ have been implicated as regulators of TDI sensitization (22) and miR-210 expression has been shown to increase in $\mathrm{T}_{\text {regs }}$ following TDI sensitization (Figure $4.4 \mathrm{~A}$ ), an ex vivo target analysis system was designed in order to directly examine the effects of miR-210 on $T_{\text {reg- }}$ related genes. Selected genes included foxp 3 , the master transcription factor of the $\mathrm{T}_{\text {reg }}$ subset and runx3, a transcription factor that signals upstream of foxp 3 by binding to this gene's promoter (31) and identified as a potential direct target of miR-210. Additionally, $c d 25$ and ctla4 were investigated as important $\mathrm{T}_{\text {reg }}$-related genes as they are involved in IL-2 signaling and proliferation along with direct suppressive functions, respectively. This setup revealed a potential role for miR-210 in the

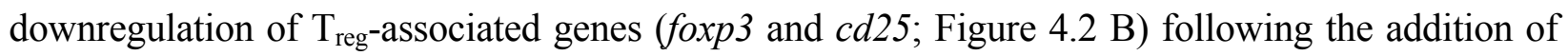
miR-210 mimic. In addition foxp 3 and runx $3 \mathrm{dLN}$ expression decreased in the $\mathrm{dLN}$ at various time points following TDI exposure (Figure $4.3 \mathrm{~A}$ and $\mathrm{B}$ ) which is consistent with our previously reported findings (22). The earlier decrease in runx3 expression observed at 4 days post $4 \%$ TDI exposure may be reflective of the upstream signaling activity of this transcription factor in relation to foxp 3 (Figure $4.3 \mathrm{~B}$ ). While the findings for the ex vivo assay did not reach statistical significance, further

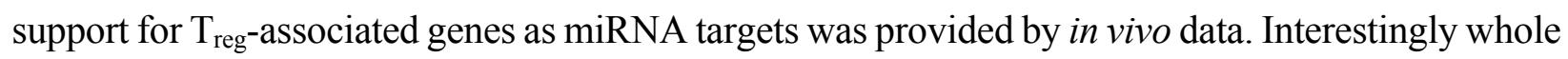
dLN expression of $c t l a 4$ and $c d 25$ increased at 1,2, and 4 days post 4\% TDI exposure (Figure $4.3 \mathrm{C}$ and $\mathrm{D}$ ) which is likely a reflection of the activation of both $\mathrm{T}_{\text {regs }}$ and conventional $\mathrm{T}$ cells as elevated protein expression of these molecules is observed in $\mathrm{T}_{\text {regs }}$ at these time points (22) and would likely be increased in conventional $\mathrm{T}$ cells involved in TDI sensitization as well. In $\mathrm{T}_{\text {regs }}$, decreases in foxp $3, c d 25$ and $c t l a 4$ were observed at 2 and 7 days with runx 3 only being decreased at the earlier time point post TDI exposure (Figure $4.4 \mathrm{~B}$ ). These early changes in $\mathrm{T}_{\text {reg }}$ factors provide further support that additional factors might be involved in $\mathrm{T}_{\text {reg }}$ regulation since peak increases in miR-210 occur later than 2 days; accordingly, miR-31 was shown be increased at this time point. In contrast 
to the transcript, the expression kinetics of Runx3 increased following TDI exposure (Figure 4.4 C). This expression pattern was similar to other $\mathrm{T}_{\text {reg }}$ proteins such as CD25 and Foxp3 (which are represented by the general $\mathrm{T}_{\text {reg }}$ population) and $\mathrm{T}_{\text {reg-specific }}$ CTLA4 expression which have previously been investigated during TDI sensitization (22). The kinetics of $\mathrm{T}_{\text {regs }}$ bearing these molecules tended to peak at 4 days post TDI exposure with a relative decrease in both cellular frequency and number at 7 days post TDI exposure (22). In relation to miR-210 expression kinetics, this data may suggest that miR-210 has a regulatory role on the $\mathrm{T}_{\text {reg }}$ subset, as its expression wanes in concert with the general $\mathrm{T}_{\text {reg }}$ population as well as CTLA4 ${ }^{+}$and Runx $3^{+} \mathrm{T}_{\text {regs. }}$. Additionally, miR210 is a putative runx 3 target, suggesting a potential direct effect on this gene (1). Collectively, this data is suggestive of $\mathrm{T}_{\text {reg }}$ regulation with visible effects on the expression of proteins beginning at day 7 post TDI exposure. miR-210 expression remains elevated in the dLN throughout 9 days post 0.5 and $4 \%$ TDI exposure (Figure $4.1 \mathrm{~A}$ ) and in $\mathrm{T}_{\text {regs }}$ at 7 days post 0.5 and $4 \%$ TDI exposure (Figure $4.4 \mathrm{~A})$.

Due to the potential link between miR-210 and $\mathrm{T}_{\text {reg-related gene expression, the functional }}$ capabilities of $\mathrm{T}_{\text {regs }}$ (acetone and TDI -derived) were examined in the presence and absence of miR210 mimic. Interestingly, it appeared that miR-210 levels were lower in wells containing $\mathrm{T}_{\text {regs }}$ from TDI-treated mice and miR-210 mimic compared to wells with acetone-derived $\mathrm{T}_{\text {regs }}$ and miR-210 mimic (Figure $4.5 \mathrm{~A}$ ). The increased suppressive capability of TDI $\mathrm{T}_{\text {regs }}$ with miR-210 mimic (Figure 4.5 B) may be a reflection of reduced miR-210 levels, as we hypothesize that miR-210 is inhibiting $\mathrm{T}_{\text {reg }}$ differentiation and/or function. This finding suggested that other regulatory factors including other miRNAs might be involved in the regulation of $\mathrm{T}_{\text {reg }}$ function. Complex interactions and interplay have often been reported for other miRNAs (32), therefore this concept was evaluated in the current study. Typically direct miRNA-miRNA interactions are mediated by reverse 
complementary binding, resulting in the formation of duplexes (32). Additionally, indirect miRNAmiRNA interaction may occur via target gene interaction; e.g. if a miRNA targets a gene that induces a different miRNA, this miRNA is being regulated by its own species.

miRNA-31 and-155 were further investigated for the potential to regulate the expression of miR-210 as they were identified to increase at early time points in TDI sensitization in the dLN (Figure 4.6 A (miR-31) and B (miR-155)) and Tregs (Figure 4.7 A (miR-31)). Similarly to miR210, miR-31 and - 155 were shown to potentially downregulate foxp 3 expression in this assay (Figure 4.6 E and F). Although limitations in the assay sensitivities did not reflect significant changes, this may be reflective of a direct effect on foxp 3 or an indirect effect on this gene via other signaling pathways such as miR-210. These alterations are in accordance with recent findings pertaining to miRNA-mRNA interactions. miR-31 may indirectly target foxp3, leading to suppressed $\mathrm{iT}_{\text {reg }}$ development (20), accounting for the potential decreases in this gene evidenced following miR-31 mimic transfection. Also miR-31 increases earlier when more persistent decreases in foxp 3 were observed. Additionally, miR-155 expression appears to be controlled by foxp 3 in $\mathrm{T}_{\text {regs }}$ via binding to the intron within the DNA sequence encoding Bic, the precursor transcript of miR-155; accordingly, $\mathrm{T}_{\text {reg }}$ miR-155 levels have been shown to be highly responsive to foxp 3 levels (33). This regulation may be interrupted by abnormally high levels of miR-155 in the mimic transfection system, resulting in decreased foxp3 expression in these conditions via signaling feedback. This data suggests that miR-31 and -155 may be influencing the expression of miR-210 and/or $\mathrm{T}_{\text {regs, }}$ possibly acting as early signaling mediators in the TDI sensitization response.

The lack of significance associated with the ex vivo experiments conducted in this work could be a reflection of experimental variability associated with similar assays and temporal discrepancies associated with signaling events. The ex vivo system displays several limitations, explaining the 
utilization of the in vivo TDI sensitization model in the target investigation as well. The $\mathrm{T}_{\text {reg-related }}$ gene alterations that were observed as a consequence of miRNA mimic transfections in this system may indicate direct and/or indirect targeting by the miRNA. We propose that for the majority of miRNA-mRNA interactions investigated in our model, regulation is indirect, as few, if any, putative binding sites were identified for many of the potential targets and the corresponding miRNA. For example, miR-210 is predicted to target the 3' UTR of runx3 (1) and although we did not observe significant alterations in runx3 expression following miR-210 mimic transfection in our ex vivo system, the in vivo expression kinetics of runx 3 suggest potential regulation. The ubiquitous nature of miRNAs and their involvement in various signaling processes accounts for their functional significance but can also cloud investigations into their mechanistic functions.

It is important to note that the increases in miRNA expression were not dependent on the irritant response, as dLN miR-210 levels significantly increased (Figure 4.1 A) following the nonirritating (22) $0.5 \%$ TDI exposure. As 4\% TDI exposure causes significant dermal irritation (22), ear miR-210 expression was analyzed at both non-irritant (0.5\%) and irritant (1, 2, and 4\%) TDI concentrations, revealing significant increases in dLN and ear expression at both non-irritant and irritant does (A 4.1 A). In addition other miRNAs including miR-22, -31, and -301a were also shown to increase significantly in expression regardless of the irritant status of the TDI dose (data not shown). This data prompts insight into the concept of the "two-signal" sensitization hypothesis which states that antigen delivery alone is insufficient for effective immunological priming but rather a second, innate signal is necessary to ensure the development of sensitization $(34,35)$. As noted in previous studies, the irritant response appears to be a prerequisite for strong sensitization responses in the case of dermal TDI sensitization (22). Regardless, the expression of multiple miRNAs in the dLN appears to be due to the sensitization response alone and not significantly influenced by the 
irritant component of this response, which may be revealing as to their supposed functional roles in the sensitization response and may suggest potential utility as biomarkers of sensitization.

These studies reveal a potential role for miR-210 in a murine model of dermal TDI sensitization. Additionally, miR-31 and miR-155 were investigated for their regulatory potential in this response. The investigation of novel mediators of chemical-induced allergic disease is important for the overall understanding of the mechanisms involved in these responses. Therefore, this data may result in enhanced understanding of the mechanisms involved in chemical sensitization and could potentially aid in the development of hazard identification strategies for respiratory chemical sensitizers. In conclusion, we have demonstrated that miR-210 may negatively influence the differentiation and/or function of $\mathrm{T}_{\text {regs }}$ via direct targeting of runx3 and/or indirect actions on other

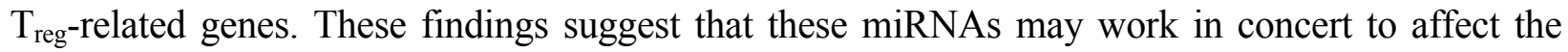
differentiation and function of $\mathrm{T}_{\text {regs }}$ as well as the expression and function of miR-210. 


\subsection{REFERENCES}

1. Anderson, S. E., K. Beezhold, E. Lukomska, J. Richardson, C. Long, K. Anderson, J. Franko, B. J. Meade, and D. H. Beezhold. 2013. Expression kinetics of miRNA involved in dermal toluene 2,4-diisocyanate sensitization. Journal of immunotoxicology.

2. Johnson, V. J., B. Yucesoy, J. S. Reynolds, K. Fluharty, W. Wang, D. Richardson, and M. I. Luster. 2007. Inhalation of toluene diisocyanate vapor induces allergic rhinitis in mice. Journal of immunology (Baltimore, Md. : 1950) 179: 1864-1871.

3. Agency, U. S. E. P. 2011. Toluene Diisocyanate (TDI) And Related Compounds Action Plan

[RIN 2070-ZA14].

4. Mapp, C. E. 2001. Agents, Old and New, Causing Occupational Asthma. Occupational and Environmental Medicine 58: 354-354.

5. Kim, S. H., G. S. Choi, Y. M. Ye, I. Jou, H. S. Park, and S. M. Park. 2010. Toluene diisocyanate (TDI) regulates haem oxygenase-1/ferritin expression: implications for toluene diisocyanate-induced asthma. Clinical and experimental immunology 160: 489497.

6. NTP. 2011. Report on Carcinogens. 12 ed. P. H. S. U.S. Department of Health and Human Services, National Toxicology Program, ed, Research Triangle Park, NC. 499.

7. Bello, D., C. A. Herrick, T. J. Smith, S. R. Woskie, R. P. Streicher, M. R. Cullen, Y. Liu, and C. A. Redlich. 2007. Skin exposure to isocyanates: reasons for concern. Environmental health perspectives 115: 328-335.

8. Anderson, S. E., and B. J. Meade. 2014. Potential Health Effects Associated with Dermal Exposure to Occupational Chemicals. Environmental Health Insights: 51-62.

9. Vandebriel, R. J., W. H. De Jong, S. W. Spiekstra, M. Van Dijk, A. Fluitman, J. Garssen, and H. Van Loveren. 2000. Assessment of preferential T-helper 1 or T-helper 2 induction by low molecular weight compounds using the local lymph node assay in conjunction with RT-PCR and ELISA for interferon-gamma and interleukin-4. Toxicology and applied pharmacology 162: 77-85.

10. Karol, M. H., E. J. Hauth, C. M. Riley, and Magreni. 1981. Dermal contact with toluene diisocyanate (TDI) produces respiratory tract hypersensitivity in guinea pigs. Toxicology and applied pharmacology 58: 221-230.

11. Anderson, S. E., P. D. Siegel, and B. J. Meade. 2011. The LLNA: A Brief Review of Recent Advances and Limitations. Journal of allergy 2011: 424203.

12. Kopriva, S. E., V. L. Chiasson, B. M. Mitchell, and P. Chatterjee. 2013. TLR3-Induced Placental miR-210 Down-Regulates the STAT6/Interleukin-4 Pathway. PLoS ONE 8: e67760.

13. Mycko, M. P., M. Cichalewska, A. Machlanska, H. Cwiklinska, M. Mariasiewicz, and K. W. Selmaj. 2012. MicroRNA-301a regulation of a T-helper 17 immune response controls autoimmune demyelination. Proceedings of the National Academy of Sciences of the United States of America 109: E1248-1257.

14. Qi, J., Y. Qiao, P. Wang, S. Li, W. Zhao, and C. Gao. 2012. microRNA-210 negatively regulates LPS-induced production of proinflammatory cytokines by targeting NF- $\kappa \mathrm{B} 1$ in murine macrophages. FEBS letters 586: 1201-1207. 
15. Taganov, K. D., M. P. Boldin, and D. Baltimore. 2007. MicroRNAs and Immunity: Tiny Players in a Big Field. Immunity 26: 133-137.

16. Baltimore, D., M. P. Boldin, R. M. O'Connell, D. S. Rao, and K. D. Taganov. 2008. MicroRNAs: new regulators of immune cell development and function. Nature immunology 9: 839-845.

17. Xiao, C., and K. Rajewsky. 2009. MicroRNA Control in the Immune System: Basic Principles. Cell 136: 26-36.

18. Vennegaard, M. T., C. M. Bonefeld, P. H. Hagedorn, N. Bangsgaard, M. B. Lovendorf, N. Odum, A. Woetmann, C. Geisler, and L. Skov. 2012. Allergic contact dermatitis induces upregulation of identical microRNAs in humans and mice. Contact Dermatitis.

19. Lodish, H. F., B. Zhou, G. Liu, and C. Z. Chen. 2008. Micromanagement of the immune system by microRNAs. Nature Rev. Immunol. 8: 120-130.

20. Zhang, L., F. Ke, Z. Liu, J. Bai, J. Liu, S. Yan, Z. Xu, F. Lou, H. Wang, H. Zhu, Y. Sun, W. Cai, Y. Gao, Q. Li, X.-Z. Yu, Y. Qian, Z. Hua, J. Deng, Q.-J. Li, and H. Wang. 2015. MicroRNA-31 negatively regulates peripherally derived regulatory T-cell generation by repressing retinoic acid-inducible protein 3. Nat Commun 6.

21. Christensen, A. D., S. Skov, P. H. Kvist, and C. Haase. 2015. Depletion of regulatory T cells in a hapten-induced inflammation model results in prolonged and increased inflammation driven by T cells. Clinical and experimental immunology 179: 485-499.

22. Long, C. M., N. B. Marshall, E. Lukomska, M. L. Kashon, B. J. Meade, H. Shane, and S. E. Anderson. 2016. A Role for Regulatory T Cells in a Murine Model of Epicutaneous Toluene Diisocyanate Sensitization. Toxicological sciences : an official journal of the Society of Toxicology.

23. Anderson, S. E., C. Umbright, R. Sellamuthu, K. Fluharty, M. Kashon, J. Franko, L. G. Jackson, V. J. Johnson, and P. Joseph. 2010. Irritancy and allergic responses induced by topical application of ortho-phthalaldehyde. Toxicological sciences : an official journal of the Society of Toxicology 115: 435-443.

24. Franko, J., L. G. Jackson, A. Hubbs, M. Kashon, B. J. Meade, and S. E. Anderson. 2012. Evaluation of furfuryl alcohol sensitization potential following dermal and pulmonary exposure: enhancement of airway responsiveness. Toxicological sciences : an official journal of the Society of Toxicology 125: 105-115.

25. Mattes, J., A. Collison, M. Plank, S. Phipps, and P. S. Foster. 2009. Antagonism of microRNA-126 suppresses the effector function of TH2 cells and the development of allergic airways disease. Proceedings of the National Academy of Sciences of the United States of America 106: 18704-18709.

26. Lu, T. X., and M. E. Rothenberg. 2013. Diagnostic, functional, and therapeutic roles of microRNA in allergic diseases. The Journal of allergy and clinical immunology 132: 313; quiz 14.

27. Zech, A., C. K. Ayata, F. Pankratz, A. Meyer, K. Baudiss, S. Cicko, G. G. Yegutkin, S. Grundmann, and M. Idzko. 2015. MicroRNA-155 modulates P2R signaling and Th2 priming of dendritic cells during allergic airway inflammation in mice. Allergy 70: 11211129.

28. Thai, T. H. 2007. Regulation of the germinal center response by microRNA-155. Science 316: 604-608. 
29. Du, C., C. Liu, J. Kang, G. Zhao, Z. Ye, S. Huang, Z. Li, Z. Wu, and G. Pei. 2009. MicroRNA miR-326 regulates TH-17 differentiation and is associated with the pathogenesis of multiple sclerosis. Nature immunology 10: 1252-1259.

30. Wang, H., H. Flach, M. Onizawa, L. Wei, M. T. McManus, and A. Weiss. 2014. Negative regulation of Hifla expression and TH17 differentiation by the hypoxiaregulated microRNA miR-210. Nature immunology 15: 393-401.

31. Bruno, L., L. Mazzarella, M. Hoogenkamp, A. Hertweck, B. S. Cobb, S. Sauer, S. Hadjur, M. Leleu, Y. Naoe, J. C. Telfer, C. Bonifer, I. Taniuchi, A. G. Fisher, and M. Merkenschlager. 2009. Runx proteins regulate Foxp3 expression. J Exp Med 206: 23292337.

32. Guo, L., Y. Zhao, S. Yang, H. Zhang, and F. Chen. 2014. Integrative Analysis of miRNA-mRNA and miRNA-miRNA Interactions. BioMed Research International 2014: 8.

33. Lu, L.-F., T.-H. Thai, D. P. Calado, A. Chaudhry, M. Kubo, K. Tanaka, G. B. Loeb, H. Lee, A. Yoshimura, K. Rajewsky, and A. Y. Rudensky. Foxp3-Dependent MicroRNA155 Confers Competitive Fitness to Regulatory T Cells by Targeting SOCS1 Protein. Immunity 30: 80-91.

34. Kimber, I., D. A. Basketter, J. P. McFadden, and R. J. Dearman. 2011. Characterization of skin sensitizing chemicals: a lesson learnt from nickel allergy. Journal of immunotoxicology 8: 1-2.

35. McFadden, J. P., and D. A. Basketter. 2000. Contact allergy, irritancy and 'danger'. Contact Dermatitis 42: 123-127. 


\section{CHAPTER 5}

General Discussion 


\subsection{Introduction}

Recent increases in the global burden of allergic disease have prompted study into the underlying immunologic mechanisms of these conditions. Encompassing a wide variety of conditions, the umbrella of allergic disease may include asthma, contact dermatitis, eczema, folliculitis, hypersensitivity pneumonitis, rhinitis, and urticaria. Although many factors may contribute to the development of allergic disease, including atopy, environmental exposures, epigenetics, genetics, and stress, occupational exposures are a major cause of allergic disease. It is evident that exposure to a variety of substances via multiple routes of exposure can lead to allergic disease, illustrating the significant breadth of occupational allergic disease.

While protein and metal allergens are important causative agents of allergic disease, this work focuses on TDI, an organic LMW chemical agent of allergic disease. In general, LMW chemical allergens are diverse and encompass a wide variety of chemical structures and are utilized in a number of industries worldwide (Table 1.1). While it may be easy to imagine significant chemical exposure as a factory worker in a chemical plant, these exposures may occur in virtually any industry. Many disinfectants utilized in the healthcare and cosmetology industries are known to cause asthma and contact dermatitis (e.g. eugenol, glutaraldehyde, ortho-phthalaldehyde (OPA), quaternary ammonium compounds) or may augment existing allergies (e.g. triclosan). Many of these chemicals are found in consumer products such as antimicrobial coatings and cleaning products, further illustrating the ubiquity of these products and potential for exposure.

As eloquently summarized by TV Rajan, the term "allergy" was initially utilized to identify both immune responses that were protective and deleterious to the host; this concept was also initially applied to the term "hypersensitivity" which was used to indicate the [typically] protective response that took place upon re-exposure to an infectious agent (1). The more recent view of 
"hypersensitivity" as a host-deleterious response with an allergic component is illustrated in the Gell and Coomb's hypersensitivity classification (Table 1.1). In this context, the Gell and Coomb's classification is largely accurate, yet non-inclusive for a wide variety of reactions, particularly those caused by chemicals, metals, and drugs. In line with the origins of the term "hypersensitivity", the four types of reactions classified by Gell and Coombs may be attributed to overarching mechanisms originating from those utilized by the immune system during pathogen defense (1). This view, proposed by TV Rajan, is based on the idea that immune reactions likely arose for host-protective reasons rather than solely to cause harm to the host, as seems to be the case when allergy is viewed from a separate origin from pathogen defense strategies (1). This understanding may aid in the interpretation of each reaction and appropriate revisions that could possibly be made to the classification, in light of the dramatically altered landscape of immunological knowledge. Essentially, the inappropriate activation and/or execution of these "protective" mechanisms may result in host-deleterious conditions. Type I hypersensitivity is characterized by IgE and mast cell activation; this reaction may have initially developed as a parasite-defense mechanism, indicated by similar IgE-mediated mechanisms and expulsive strategies manifested in symptoms such as vasodilation and mucin production (1). Type II hypersensitivity is characterized by complement activation (due to antibody-antigen recognition) and neutrophil invasion and these mechanisms are involved in extracellular pathogen clearance (1); antibody opsonization is a classic mechanism of pathogen clearance as is complement activation and neutrophil recruitment. The main effector mechanisms of type III hypersensitivity reactions are the formation of antibody-antigen complexes, deposition of these complexes in tissue, and complement and neutrophil recruitment (1); these mechanisms are proposed to be based on viral clearance strategies. Type IV hypersensitivity is characterized by delayed $\mathrm{CD}^{+}{ }^{+} \mathrm{Th} 1$ and $\mathrm{CD} 8^{+}$cytotoxic $\mathrm{T}$-cell action, leading to host cellular 
destruction and conditions such as contact dermatitis and diabetes mellitus (1). This reaction is thought to be an inappropriate manifestation of both viral and intracellular bacterial host clearance strategies, which commonly involve the same effector cellular subsets. A strong epidemiological link has been noted between respiratory virus infection and asthma risk, suggesting that these conditions may share common risk factors and mechanisms (2). The inverse is also true; atopy has also been associated with increased severity of respiratory viral infections and wheezing (2). These associations emphasize both the common underlying mechanism of each condition as well as the potential common evolutionary origins of each disease state.

While viewing hypersensitivity reactions in light of their proposed evolutionary origins is helpful for the understanding of the mechanisms involved, there remains uncertainty regarding the validity of Gell and Coomb's classification in the context of new immunological insights into both allergic disease and pathogen defense. For many conditions, the current parameters of Gell and Coombs do not provide an accurate classification. These conditions include hypersensitivity pneumonitis and certain instances of chemical-induced asthma (3). The pathogenesis of hypersensitivity pneumonitis is similar to "traditional" atopic asthma (which is typically considered a Type I hypersensitivity reaction) in many ways, yet several key differences exist. Neutrophilia, alveolitis, Th1 involvement, and eventual fibrosis are all important components of hypersensitivity pneumonitis reactions that may not be present in conventional asthmatic responses (4). The acute phase of hypersensitivity pneumonitis can be summarized as an inflammatory process characterized by non-atopic neutrophilic inflammation caused by small organic particles, generally, nonspecific airway hyperreactivity and mucus production are not observed during this reaction as is typically they case with atopic asthma (4). The chronic symptoms associated with hypersensitivity pneumonitis are interstitial pneumonitis, lymphatic bronchiolitis (primarily $\mathrm{CD} 8^{+} \mathrm{T}$ cells), and 
granulomas along with fibrosis of the alveoli and bronchioles (4). These pathological features differ from those associated with atopic asthma, clearly delineating these two conditions. Hypersensitivity pneumonitis has been considered both a Type III and IV hypersensitivity reaction due to the formation of IgG-antigen complexes and the involvement of $\mathrm{CD}^{+}{ }^{+}$and Th1 cells, respectively $(4,5)$. It is important to note that, while hypersensitivity pneumonitis exhibits features of multiples classifications of hypersensitivity, leading to potential misunderstanding of the underlying mechanisms of disease. This condition may warrant its own subtype of hypersensitivity, due to its shared, yet unique characteristics. In either case, it is important to note that this condition transcends the Gell and Coomb's classification by encompassing multiple reactions at once.

Many cases of chemical-induced asthma cannot be accurately classified utilizing the Gell and Coomb's system. Specifically, diisocyanate-induced asthma exhibits immunologic and clinical features that are not accurately summarized by any of the four types of hypersensitivity reactions individually. While diisocyanate-induced asthma shares several commonalities with type I hypersensitivity reactions including eosinophilia, Th2-involvment, and clinical features of asthma, many other distinguishing characteristics do not fit within this classification. Neutrophil involvement, a Th1 component, IgG involvement, and the contested role of $\operatorname{IgE}$ are all components of diisocyanate-induced asthma that contribute to hypersensitivity classification uncertainty. Diisocyanate-induced asthma also shares similar features with hypersensitivity pneumonitis such as neutrophilia, Th1, $\mathrm{CD} 8^{+} \mathrm{T}$ cell, and $\operatorname{IgG}$ involvement, yet clinical symptoms are significantly divergent. LMW chemical-induced asthma seems to be related to both atopic asthma and hypersensitivity pneumonitis while remaining a unique entity. It may be classified as a mixed type I and IV response; however, this does not account for the condition as a whole. Additionally, as sensitization events precipitate elicitation and allergic symptoms, it is important to keep the 
mechanisms of sensitization in perspective when setting classification guidelines for allergic reactions. With the investigation of additional mediators of allergic disease such as novel $\mathrm{T}$ cell subsets, this predicament will likely be amplified. This work identified the potential involvement of $\mathrm{T}_{\text {regs }}$ and Th17 cells in TDI sensitization, and although the functional roles of these cells need to be investigated further, particularly in the elicitation phase, these subsets are not addressed in the current classification.

When evaluating Gell and Coomb's classification in the context of modern immunologic knowledge, it is important to consider all significant aspects of each hypersensitivity reaction without getting "bogged down". All hypersensitivity reactions are unique in some way; therefore, emphasis of less functionally-relevant mechanisms may result in an overly complicated classification system, defeating the entire purpose of the system. Gell and Coomb's classification has withstood the test of time remarkably well, considering the massive influx of data and knowledge gained regarding hypersensitivity reactions. With this in mind, I propose a reevaluation of the current classification system, potentially resulting in further sub-classification of current types of hypersensitivity along with novel types of hypersensitivity reactions. The current sub classification of Type IV reactions is a poignant example of the potential diversity of reactions that fall in the same classification. Divided based on the cytokine milieu and effector cells present, four Type IV subclasses have been described (6) and these descriptive groupings aid in the understanding of each unique reaction. Following a basic survey of each of the four types of hypersensitivity reactions, the possible subcategorization of each type could be useful. In light of the known role of relatively new mediators such as Th17 cells, this reevaluation would serve as an update to the current system, potentially aiding student and clinicians in the understanding of these conditions. This also brings to light the necessity of further investigation into the mechanisms of allergic disease. Additional understanding 
of the underlying mechanisms of hypersensitivity reactions may result in the re-classification of certain poorly understood conditions or the formation of novel types of hypersensitivity. Overall, the Gell and Coomb's classification system remains valid for a number of conditions but others remain un-classifiable with the current system. This should be taken into consideration by researchers and clinicians alike, as further investigation into the immune effectors of hypersensitivity reactions is needed and the current system should be interpreted with care.

LMW chemical allergens are an occupationally relevant class of compounds that are responsible for a variety of allergic diseases, perhaps the most notable being asthma and contact dermatitis. LMW chemical allergens are generally characterized as dermal (Th1) or respiratory (Th2) sensitizers, depending on the type of disease they elicit. While this classification is technically valid for some sensitizers, it is confusing in many cases. Certain LMW chemical sensitizers like TDI may elicit asthma following respiratory and/or dermal sensitization, yet this chemical is known as a respiratory sensitizer. This is a misnomer because although TDI exposure primarily causes respiratory disease, sensitization may occur by the dermal route. TDI may be more accurately classified as a systemic sensitizer and a respiratory allergen. Furthermore, respiratory sensitizers are generally associated with a Th2-dominant response with contact sensitizers being linked to Th1dominant mechanisms. TDI induces a mixed Th1/Th2 response in both animal models and humans, further emphasizing the ambiguous nature of the current nomenclature. Nevertheless, there are no validated hazard identification strategies for LMW chemicals that are capable of causing respiratory allergic disease. This suggests that further research is necessary to elucidate the mechanisms of LMW chemical-induced sensitization and elicitation in both animal models and humans.

With recent expansions of immunology knowledge, specifically relating to novel mediators of allergic disease, the study of chemical-induced allergy has many new, exciting potential areas of 
study. Some novel mediators include ILCs, miRNAs, and additional Th subsets. Currently, the general understanding of the mechanisms of chemical sensitization are sometimes defined by the Gell and Coombs classification; typically, dermal sensitizers are considered Type IV inducers and respiratory sensitizers are considered Type I inducers. This may be appropriate for certain sensitizers; however, many LMW chemicals induce responses that do not fit within these categories. TDI is an example of this conundrum, as previously described. This work identifies several novel immunoregulatory elements as being potentially involved in TDI sensitization. The suppressive role of $\mathrm{T}_{\text {regs }}$ is demonstrated both ex vivo and in vivo, the increased presence of Th17 cells is documented, and a potential immunomodulatory role for miR-210 is identified in this work. This data reveals the involvement of several $\mathrm{T}$ cell subsets along with epigenetic mechanisms that have been understudied in the context of chemical sensitization and allergy. Additionally, our lab has investigated the phenotype of ILCs during TDI sensitization, revealing increased activation of dermal ILC2s at 1-9 days post single TDI exposure (data not shown). While the role of these cells remains to be elucidated during the elicitation phase of allergy, the identification of these mediators during the sensitization response provides valuable mechanistic insight into the key events that take place prior to the establishment of the allergic threshold. Many additional innate and adaptive immune modulators need to be studied in models of chemical allergy including T cell subsets (e.g. Th9, Th22, and $\mathrm{T}_{\mathrm{FH}}$ cells), ILCs, and epigenetic factors. Pertinent investigations will result in the expansion of current knowledge regarding immune mechanisms responsible for chemical allergy and may ultimately aid in the development of preventative and therapeutic strategies to combat disease caused by these agents.

With the increasing immunologic perspective into the mechanisms of chemical sensitization, T cell analysis paired with the LLNA seems to be a promising direction of future study for the 
development of hazard ID strategies to differentiate respiratory and contact sensitizers. Because the Gell and Coomb's classification does not take into account the mixed responses that are observed during both types of sensitization, it is important to define common effector mechanisms and biomarkers of sensitization in order to utilize methods like T cell phenotyping and cytokine profiling along with the LLNA. Although much remains to be investigated regarding these responses, the growing body of experimental data is adding to our knowledge of the mechanisms underlying chemical sensitization and this can only enhance efforts to develop predictive assays for chemical sensitizers.

\subsection{TDI Sensitization}

TDI sensitization may occur via the skin or respiratory tract and is due to the coordinated action of innate and adaptive immunological cells and mediators (7), some of which have, presumably, not yet been identified nor investigated. TDI sensitization may be viewed as a systemic event, illustrated by the ability of dermal sensitization to lead to asthma following a single respiratory exposure post sensitization. According to the most recent compilation of experimental data, the TDI sensitization response is initiated by penetration of TDI through the stratum corneum and other dermal structures (e.g. hair follicles and sebaceous glands) followed by the haptenation of selfproteins with TDI molecules. This event emphasizes the reactivity of the isocyanate groups on TDI molecules and serves as the mechanism responsible for the formation of a TDI-protein complex that can be recognized by APCs, initiating the adaptive immune response. The unique formation of hapten complexes may be a critical determinant of the downstream immunological mechanisms involved in LMW chemical allergy; however, further investigation is needed regarding this subject. APC activation and mobilization are important events modulated primarily by local cytokine and 
chemokine expression induced by danger signals and skin irritation. In mice, three primary dendritic cell types are purported to be involved in chemical sensitization, including Langerhans cells $\left(\right.$ Langerin ${ }^{+} \mathrm{CD}_{103^{+}}$), and two additional subsets of dermal dendritic cells (Langerin ${ }^{-} \mathrm{CD} 103^{-}$and Langerin ${ }^{+} \mathrm{CD} 103^{-}$). Following APC-antigen uptake and lymphatic migration, APCs are thought to present fragments of the TDI-protein conjugates to T cells via MHC-mediated antigen presentation, although this mechanism has not been fully confirmed in models of TDI sensitization. This action results in the proliferation of $\mathrm{T}$ cells into a number of effector subsets including $\mathrm{CD} 4^{+} \mathrm{Th} 1$, Th2, Th17, $\mathrm{T}_{\text {reg, }}$ and cytotoxic $\mathrm{T}$ cells. Data from our model of dermal TDI sensitization shows increased Th1, Th2, Th17, and $\mathrm{T}_{\text {reg }}$ cell numbers in the dLN following exposure (Figures 3.2, 3.4 and A3.4). A mixed Th1/Th2 response (based on T cells and associated cytokines) is observed in both animal models and humans exposed to diisocyanates like TDI (8). Additionally, the presence and importance of $\mathrm{CD} 8^{+} \mathrm{T}$ cells has been established in murine models of TDI sensitization (9). These activated $\mathrm{T}$ cells can migrate through the lymphatics, blood, and local tissues; orchestrating an adaptive immune response specific to the TDI-protein antigen. Activated T cells and the allergic microenvironment may serve as mediators of B cell activation. Although the role of IgE is contested in a portion of TDI asthma, IgG is thought to play a role in the development and pathogenesis of this condition (10). Both Th1 and Th2 cells are important mediators of antibody class switching due to cytokine production. Another T cell subset intimately involved in germinal center B cell maturation is the $\mathrm{T}_{\mathrm{FH}}$ cell which remains uninvestigated in chemical allergy but may be heavily involved in the pathogenesis of this process. Collectively, these processes allow the immune system to develop an "arsenal" of TDI-specific cells; subsequent exposures may further augment this process and will eventually lead to the elicitation phase, which is typically represented by asthma. The immunologic progression of TDI sensitization is illustrated in Figure 5.1. The involvement of several components 
of the response have not been fully proven such as $\mathrm{T}_{\mathrm{FH}}$ cells and ILCs; however, existing data from models of other types of allergy indicate that these cell types may play an important role in the TDI sensitization response.

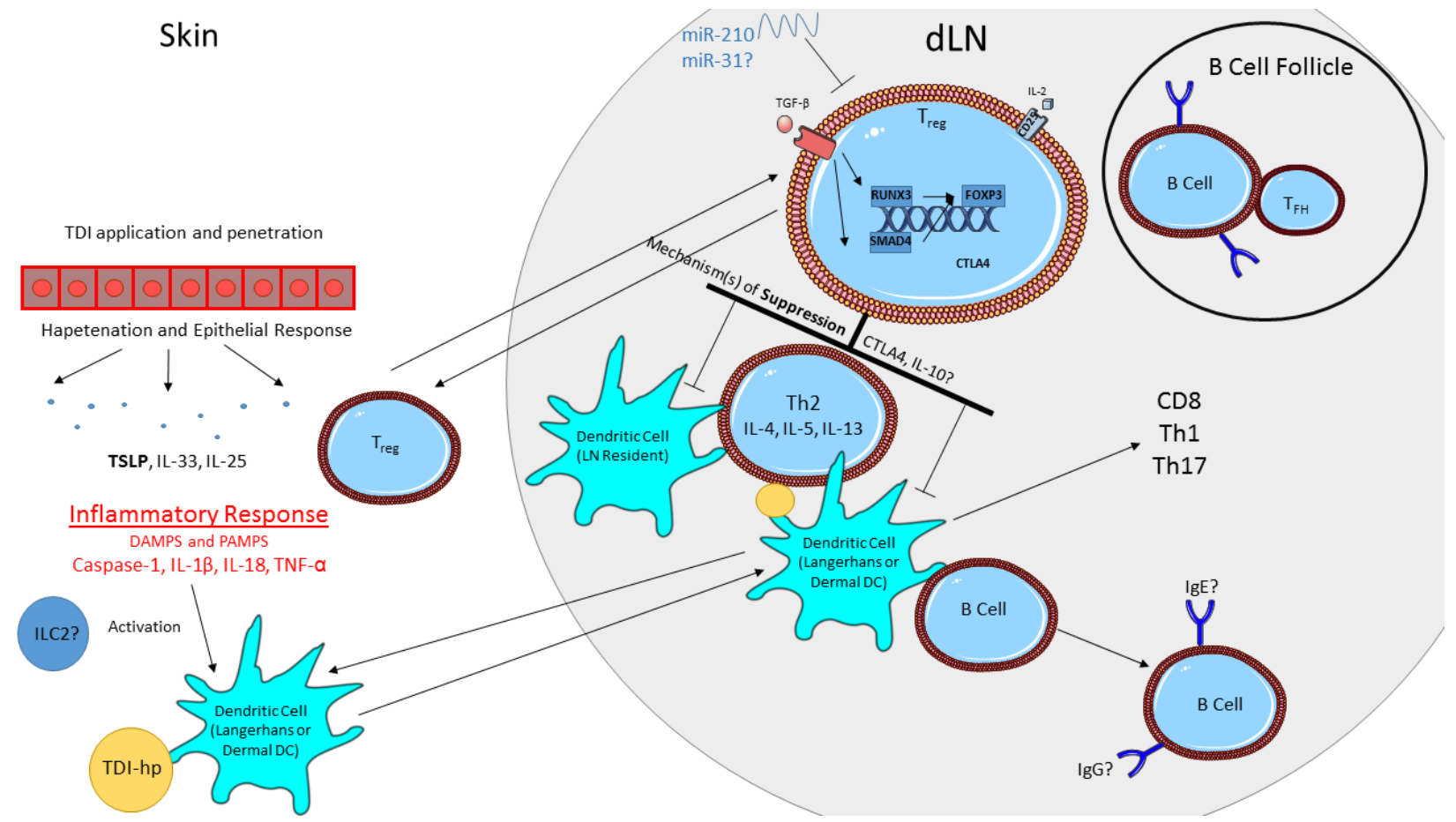

Figure 5.1 Overview of the Immune Mechanisms of TDI Sensitization

Upon initiation of the elicitation phase, allergic symptoms begin to appear. This response is thought to involve the TDI-protein complex and immune cell recognition (APCs, B cells, and T cells), potentially causing crosslinking of the TDI-protein antigen with antibody, leading to mast cell degranulation, the production of additional antigen-specific allergic antibody, the proliferation of antigen-specific T cells, and the involvement of memory T cells. These processes likely contribute to the manifestation of diverse symptoms observed in human TDI asthmatics such as airway inflammation, bronchial thickening, epithelial alterations, hyperreactivity, lymphocyte, neutrophil, and eosinophil infiltration and excessive mucus secretion (11-13). Following sensitization and a latency period which may last for months to years following initial TDI exposure, asthmatic 
symptoms usually begin to appear. Chest tightness, cough, shortness of breath, and wheezing are frequently described anywhere from $<1$ to 4 hours following TDI exposure (13).

Unfortunately, TDI sensitization is a difficult response to fully characterize due to the difficulty of performing appropriate human studies and variation observed between human and mouse models. Accordingly, the clinical pathogenesis of TDI-induced asthma is not fully understood, beyond observational data collected from patients with this condition. The contested role of IgE in TDI sensitization and asthma is a poignant example of the lack of understanding of basic mechanisms involved in these conditions. The consistent appearance of $\operatorname{IgE}$ in murine models of TDI allergy is contrasted by the inconsistent appearance of this antibody (both total and specific) in human patients. The fact that $\operatorname{IgE}$ is associated with other chemical allergens and the pathogenesis of allergic asthma caused by these agents further complicates this question. When present, TDIspecific IgE serves as a predictive tool but this antibody is not detected in many TDI asthmatics who also frequently exhibit normal total $\operatorname{IgE}$ levels (14). It is possible that IgE-independent mechanisms of sensitization and asthma such as those mediated by Th1, Th17, and IgG are integral in the pathogenesis of TDI allergy. Regarding the IgE conundrum along with general mechanisms of disease, it is evident that additional understanding of the immunologic mechanisms of sensitization and elicitation will better enable the development of appropriate hazard identification strategies and therapeutic targets relevant to TDI sensitization and asthma.

\subsection{The role of $\mathbf{T}_{\text {regs }}$ in TDI sensitization}

Among the numerous regulatory strategies employed by the immune system, $\mathrm{T}_{\text {regs }}$ are one of the most functionally significant. These cells act as both general and specific immunoregulators; they are instrumental in the maintenance of tolerance and in the dampening of immune responses. 
The rocky history of $\mathrm{T}_{\text {regs }}$ began in the 1970s when Gershon and Kondo identified suppressor $\mathrm{T}$ cells which were capable of dampening immune responses (15). In the 1980s, the study of suppressor T cells was shaken by scrutiny based on observations that the MHC gene did not encode the I-J region which was purported to be associated with the function of these cells (15). This observation, paired with difficulties in the identification of reliable markers for suppressor $\mathrm{T}$ cells and uncertainty regarding specific mechanisms of suppression resulted in the decline of suppressor T cell study (15). The study of $\mathrm{nT}_{\text {regs }}$ that arise naturally in the thymus, rather than experimentally-induced cells (15) aided in the "rebirth" of the suppressor $\mathrm{T}$ cell, now known as the $\mathrm{T}_{\text {reg. }}$. The identification of Foxp3 as the "master transcription factor" responsible for the differentiation and function of $\mathrm{T}_{\text {regs }}$ was prompted by the investigation of the genetic mechanisms responsible for the symptoms seen in patients with immunodysregulation polyendocrinopathy enteropathy X-linked syndrome (IPEX) and in scurfy mice which are mediated by loss-of-function mutations in foxp $3(16,17)$.

$\mathrm{T}_{\text {regs }}$ can be derived from the thymus $\left(\mathrm{nT}_{\text {reg }}\right)$ or induced in the periphery ( $\left.\mathrm{iT}_{\text {regg }}\right)$ (18), acquiring suppressive capabilities that are mediated through a diverse repertoire of mechanisms. $\mathrm{T}_{\text {regs }}$ aid in the mediation of self-reactive or overzealous immunity utilizing a variety of mechanisms. $\mathrm{T}_{\text {regs }}$ have a known role in a plethora of diseases and conditions mediated by the immune system including allergy, asthma, autoimmune disorders, cancer, and infections (19). Regarding allergic disease, impaired $\mathrm{nT}_{\text {reg }}$ inhibition of allergen-specific $\mathrm{Th} 2$ responses during hay fever responses, decreased levels of $\mathrm{T}_{\text {regs }}$ in patients with allergic disease compared to healthy individuals, and a protective role for $T_{\text {regs }}$ in grass, milk, and nickel allergy have been demonstrated (19), emphasizing the functional importance of these cells in the control of allergic responses. Additionally, depletion of $\mathrm{T}_{\text {regs }}$ in a model of OVA atopic dermatitis lead to augmented lung responses (characterized by increased pathology, inflammation, IL-4, eosinophil, and $\mathrm{CD} 4^{+} \mathrm{T}$ cell levels) following intranasal 
OVA challenge in a murine model (20). The corresponding study found that $\mathrm{T}_{\text {regs }}$ are important in the regulation of both skin inflammation and allergen-specific immune responses, both of which are involved in TDI sensitization as well. Several studies have explored the potential action of IL-10 secretion by $\mathrm{T}_{\text {regs }}$ in a nickel allergy model and the presence of $\mathrm{T}_{\text {regs }}$ in murine models of urushiol 3pentadecylcatechol and TNCB sensitization (7). Generally, $\mathrm{T}_{\text {regs }}$ are able to regulate immune response and their numbers and/or function appear to be impaired in various disease states.

Chapter 3 described several experiments demonstrating the role of $\mathrm{T}_{\text {regs }}$ in TDI sensitization. This subset expands in the dLN (Figure 3.2) and ears (Figure 5.4), was phenotypically diverse, and likely contained a number of functionally significant subsets. The expansion of the general $\mathrm{T}_{\text {reg }}$ population in the dLN (Figure 3.2) was significant in number following both 0.5 and $4 \%$ TDI exposure; however, increases in frequency were only observed for the 4\%-exposed mice (Figure 3.2; significant at days 4-9). This may be indicative of $\mathrm{T}_{\text {reg }}$ migration and proliferation in response to the strongest sensitizing concentration and may also be influenced by the irritant nature of this dose, as cytokine and chemokine signaling would be augmented in response to both of these factors. This hypothesis is based on studies demonstrating IL-4 and IL-13-dependent ${ }_{\mathrm{i}} \mathrm{T}_{\text {reg }}$ differentiation (21), which is likely occurring in response to the Th2 component of TDI sensitization.

Thymic $\mathrm{nT}_{\text {regs }}$ are typically $\mathrm{CD} 25^{\text {hi }} \mathrm{CD} 62 \mathrm{~L}^{+} \mathrm{CCR} 7^{+}$and migrate to secondary lymphoid tissues such as lymph nodes following the completion of their development (22). Upon egress, a subset of these $\mathrm{T}_{\text {reg }}$ emigrants acquire high CD44 expression; this confers non-lymphoid tissue access to these cells (22). These CD44 ${ }^{\text {hi }} \mathrm{T}_{\text {regs }}$ may be attributed to recognition of self-antigens in secondary lymphoid tissues (22). Their phenotypic divergence represents the innate diversity in the $\mathrm{T}_{\text {reg }}$ repertoire. It may also shed light upon their functional potential. High CD44 expression allows $\mathrm{T}_{\text {regs }}$ 
to proliferate more quickly than their counterparts and their presence in non-lymphoid environments may allow them to incorporate diverse suppressive strategies.

Peripherally-induced $\mathrm{iT}_{\text {regs }}$ typically exhibit a more diverse phenotypic profile due to their origin. $i \mathrm{~T}_{\text {regs }}$ may be generated during an active immune response that is skewed towards a certain Th phenotype or that involves diverse antigen presenting cells, influencing $T_{\text {reg }}$ development. $i T_{\text {regs }}$ are thought to be less stable than $\mathrm{nT}_{\text {regs }}$, further emphasizing their apparent plasticity and responsespecific nature. Both $\mathrm{nT}_{\text {regs }}$ and $\mathrm{iT}_{\text {regs }}$ were found in the dLN of mice during TDI sensitization, with the frequency of $\mathrm{nT}_{\text {regs }}$ actually decreasing at 7 and 9 days post 0.5 and $4 \%$ TDI exposure (Figure 3.2a). This may be a reflection of the reduced trafficking of these cells to the lymphatics at later time points post exposure or may simply be that these cells are "overshadowed" by the expanding $i \mathrm{~T}_{\text {reg }}$ population, as the number of $\mathrm{nT}_{\text {regs }}$ is still significantly increased compared to the acetone control at these time points. The presence and expansion of both $\mathrm{nT}_{\text {regs }}$ and $\mathrm{iT}_{\text {regs }}$ is reflective of the systemic nature of TDI sensitization as well as the migratory and proliferative potential of $\mathrm{T}_{\text {regs }}$ in response to an antigenic challenge.

Recent data suggests the development of specialized $\mathrm{T}_{\text {reg }}$ phenotypes which allow these cells to respond to individual Th subsets $(18,22)$. In order to migrate to areas of Th action, $\mathrm{T}_{\text {regs }}$ have been shown to express transcription factors such as tbet (Th1), interferon regulatory factor-4 (Th17, Th2, and $\mathrm{T}_{\mathrm{FH}}$ ), stat3 (Th17), and gata3 (Th2) while retaining immunosuppressive functions such as the secretion of IL-10 (18). Steady-state $T_{\text {regs }}$ have also been shown to dynamically express tbet and gata3 in order to maintain homeostasis (23). This phenotypic diversity and plasticity is an important concept relevant to all types of $\mathrm{T}$ cells. A phenotypically varied $\mathrm{T}_{\text {reg }}$ population was observed in both tissues during TDI sensitization and this would be expected in terms of Th-specific transcription factor expression due to the assortment of Th subtypes involved in TDI sensitization. The additional 
phenotyping of $\mathrm{T}_{\text {regs }}$ involved in TDI sensitization (in both the dLN and ears) may reveal diverse transcription factor expression; therefore, influencing $\mathrm{T}_{\text {reg- }}$-Th dynamics and the suppressive capacity of these cells in relation to the diverse Th response involved in TDI sensitization.

\subsection{1. $\mathbf{T}_{\text {regs }}$ Suppressive Strategies}

Investigations into the suppressive mechanisms of $\mathrm{T}_{\text {reg function during TDI sensitization are }}$ warranted based on the data in Chapter 3. These mechanisms generally raise the $\mathrm{T}$ cell activation threshold and/or inhibit dendritic cell function, preventing the priming of self-reactive $\mathrm{T}$ cells and aberrant immune responses. Cells that may be directly impacted by the suppressive actions of $\mathrm{T}_{\text {regs }}$ include B cells, $\mathrm{CD}^{+}$and $\mathrm{CD} 8^{+} \mathrm{T}$ cells, NK cells, and NKT cells (24). Not only can $\mathrm{T}_{\text {regs }}$ suppress the activation and expansion of naïve $\mathrm{T}$ cells but they can inhibit previously activated $\mathrm{T}$ cells (including memory and effector $\mathrm{T}$ cells) (25). $\mathrm{T}_{\text {regs }}$ may utilize a variety of mechanisms including secretion of immunosuppressive cytokines (IL-10, IL-35, and TGF- $\beta$ ), CTLA4 expression (via CD80/86 downregulation on dendritic cells), indolamine 2,3-dioxygenase (IDO) expression, IL-2 consumption, and perforin-dependent cytolysis of dendritic cells (Summarized in Figure 5.2). IL10 secretion and CTLA- 4 expression have been proven as imperative for $\mathrm{T}_{\text {reg }}$ function in $\mathrm{T}_{\text {reg-specific }}$ selective depletion models exposing spontaneous colitis and augmented immune responses (IL-10 depletion) and systemic multi-organ autoimmunity paired with dysregulated $\mathrm{T}$ cell activation profiles (CTLA-4 depletion) (22). Cell-to-cell suppression has also been documented between $\mathrm{T}_{\text {regs }}$ and dendritic cells; in some cases this may be dependent on LFA-1 dependent formation of $\mathrm{T}_{\text {reg- }}$ immature dendritic cell aggregates leading to LFA-1 and CTLA4-mediated downregulation of CD80/86 on dendritic cells (26). The type(s) of suppressive mechanism employed by $\mathrm{T}_{\text {regs }}$ may depend on many factors, including the site, type, and intensity of a reaction. The relationship 
between $T_{\text {reg }}$ function and localization remains complex and merits further investigation in a variety of environments, including during TDI sensitization.

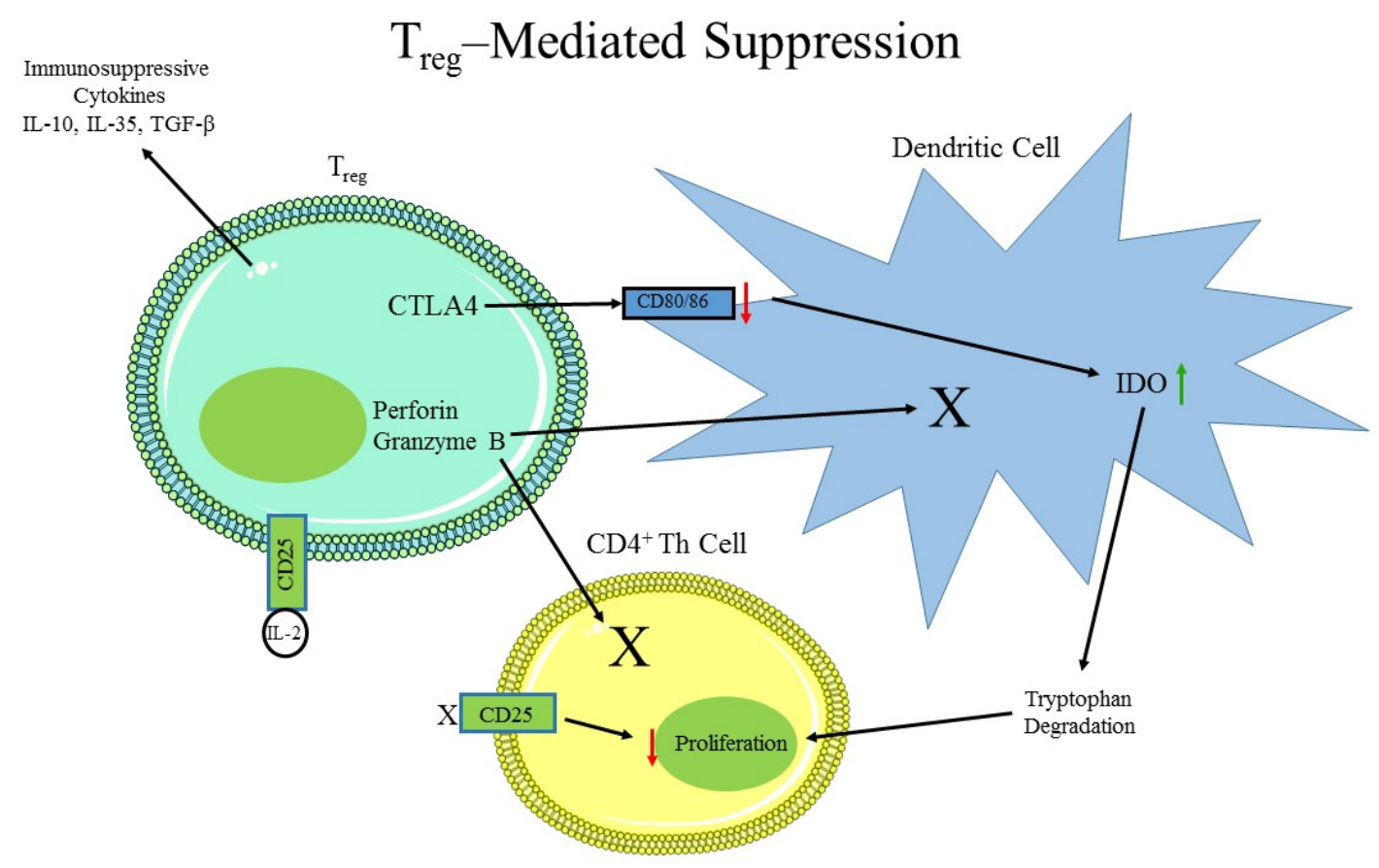

Figure 5.2 Mechanisms of $T_{\text {reg }}$ Suppression

$\mathrm{T}_{\text {reg }}$ phenotyping data implied that $\mathrm{T}_{\text {regs }}$ may employ a number of functional strategies to suppress the TDI sensitization response, including CTLA4 expression. The increased expression of CTLA4 was evident following 0.5 and 4\% TDI exposure at all time points analyzed (Figure 3.2a A and $\mathrm{B})$. This data suggests that CTLA4 expression may be utilized by $\mathrm{T}_{\text {regs }}$ in order to dampen TDI sensitization responses in a cell-to-cell manner, which should be investigated further.

The expression of CD103, ICOS, and chemokine receptors are also linked to effector functions of $T_{\text {regs }}$, as described in Chapter 3. The expression of both ICOS and CD103 increased among $\mathrm{T}_{\text {regs }}$ in the skin (Figure 5.4 F and G) and dLN (Table 3.2) during TDI sensitization. More specifically, $\mathrm{T}_{\text {regs }}$ co-expressing both ICOS and CD103 were identified in the skin and dLN during TDI sensitization (Figure 5.3 A and B). This subset was previously identified as a lymph node- 
specific differentiation stage of $\mathrm{T}_{\text {regs }}(27)$. ICOS expression is likely connected to $\mathrm{T}_{\text {reg }}$ - migratory dendritic cell interactions (27) and is associated with activated $\mathrm{T}_{\mathrm{regs}}$ and suppressive activity. As expected based on their lymph node specificity, the increase in frequency of $\operatorname{ICOS}^{+} \mathrm{CD}_{103^{+}} \mathrm{T}_{\text {regs }}$ was more pronounced in the dLN than in the ears (Figure 5.3 A and B). Interestingly, $\mathrm{ICOS}^{+} \mathrm{CD}_{103}{ }^{+}$ $\mathrm{T}_{\text {regs }}$ also slightly increased in the ear during TDI sensitization, possibly indicative of a migrating population of cells capable of suppression.

A
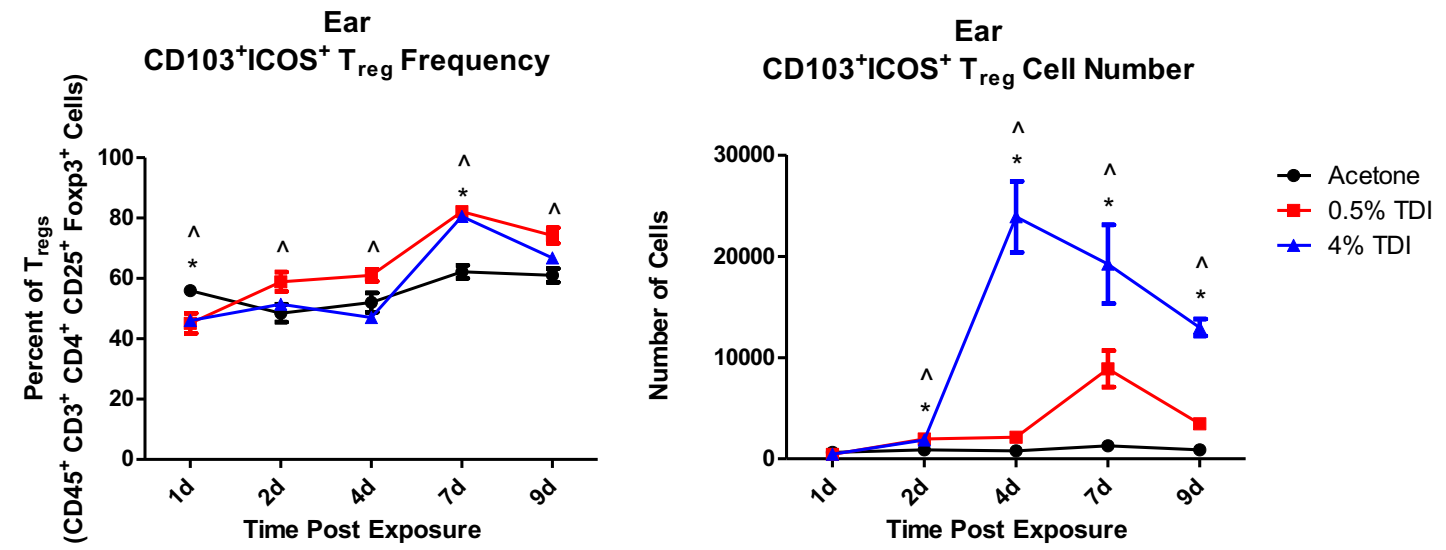

B
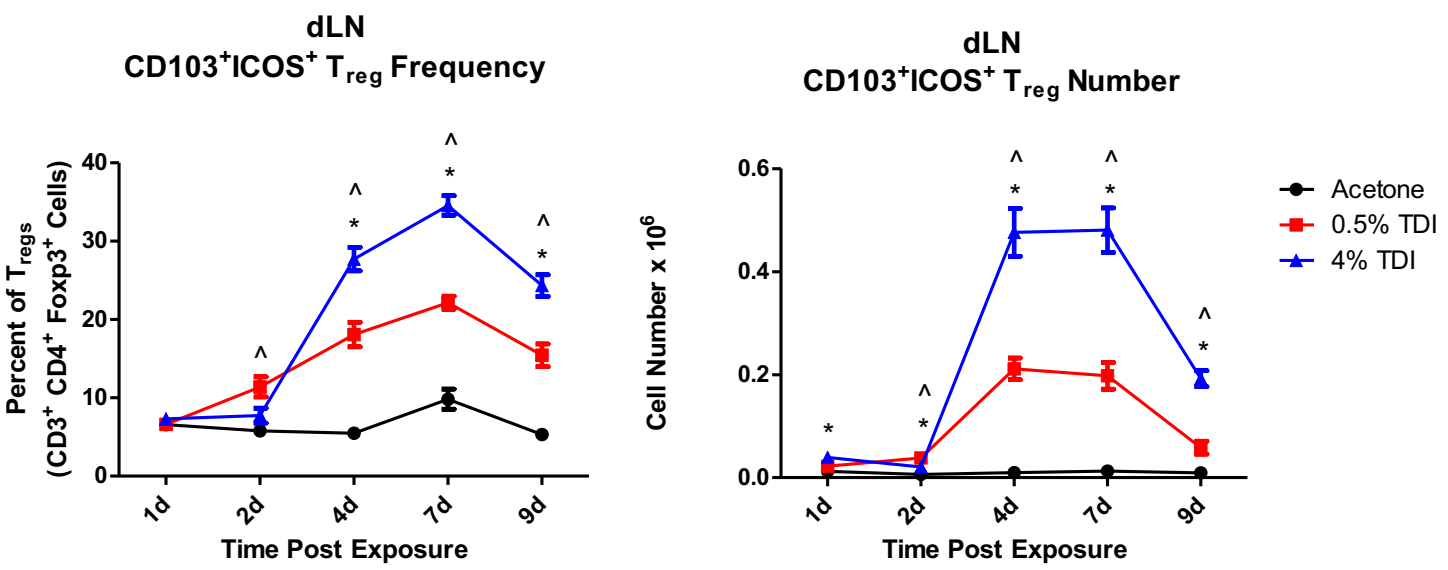

Figure 5.3 $\mathrm{ICOS}^{+} \mathrm{CD}_{103^{+}} T_{\text {reg }}$ Population in the Ear and dLN during TDI sensitization

$\mathrm{ICOS}^{+} \mathrm{CD}_{103}{ }^{+} \mathrm{T}_{\text {regs }}$ were identified in the ear (A) and dLN (B) of mice exposed to $0,0.5$, or $4 \%$ TDI at various points post exposure via flow cytometry. Bars represent mean relative fold change $( \pm \mathrm{SE})$ 
of 5 mice per group. $P$ values are represented by $\wedge(0.5 \%$ TDI $)$ and $*(4 \%$ TDI $)(P<0.05)$. Dermal treatment groups are indicated by the following symbols: circle- acetone, square- $0.5 \%$ TDI, and triangle- $4 \%$ TDI.

\subsubsection{Skin $T_{\text {regs }}$ and Dendritic Cells}

The epithelium is a barrier to allergens like TDI; specifically, the skin and its related structures, specifically, play an important role in the development of TDI sensitization. The skin has been implicated in the development of both dermal and respiratory sensitization (via dermal exposure) in a variety of models of allergic disease, encompassing both protein allergens such as OVA (28) and chemical allergens such as TDI (29). Occupational practices may compromise epithelial surfaces, further contributing to the development of allergic disease. The innate immune system houses many cells and surveillance systems in the skin and related tissues, presumably as a "first line defense" against pathogens. These cells include keratinocytes, T cells, dendritic cells, macrophages, monocytes, granulocytes, and innate lymphoid cells (30). Innate factors may also contribute to the development of allergic disease by precipitating, augmenting, and/or initiating the adaptive immune response that is characteristic of disorders like TDI allergy.

Skin $\mathrm{T}_{\text {regs }}$ were phenotyped (Gating strategy is shown in Appendix 5.1) during TDI sensitization in an effort to profile these cells and gauge their involvement in this response. $\mathrm{T}_{\text {regs }}$ increase in the skin in both frequency and number following 0.5 and 4\% TDI exposure (Figure 5.4 D). These cells may be skin resident $T_{\text {regs }}$ or they may be trafficked in from other tissues such as the dLN. $T_{\text {regs }}$ are capable of expressing an abundance of chemoattractant and surface adhesion receptors, allowing them to be present in nearly all tissues in the body (22). Clearly, the presence of inflammation enhances $\mathrm{T}_{\text {reg }}$ recruitment and the specific signaling pathways involved are dictated by 
the inflammatory environment present in the impacted tissue. During experimental autoimmune encephalomyelitis (EAE), Th17-mediated inflammation promotes epithelial expression of the chemokine CCL20, which is recognized by CCR6, leading to increased CCR6 expression on $\mathrm{T}_{\text {regs }}$ and recruitment to epithelial tissue (22). Alpha E integrin, or CD103, is expressed by a high frequency of skin $\mathrm{T}_{\text {regs }}$ (Figure $5.4 \mathrm{~F}$ ) due to its importance in the migration and retention of these cells in the skin (22). Conversely, CCR7 is involved in $\mathrm{T}_{\text {reg }}$ migration to dLN and overall $\mathrm{T}_{\text {reg }}$ function as loss of this receptor results in loss of the ability of $\mathrm{T}_{\text {regs }}$ to migrate to the $\mathrm{dLN}$ and function in a murine model of colitis $(22,31)$. $\mathrm{T}_{\text {reg }}$ migration is highly coordinated by a number of signaling molecules and remains a highly temporal and site-specific process. Compartmentalization and proper localization have been shown to be imperative for $T_{\text {reg }}$ function, with each unique subset working in concert in a "division of labor" to maintain tolerance and regulate immune responses (32). In light of this, therapeutic targeting of $\mathrm{T}_{\text {reg }}$ migration is not fully feasible and such efforts will require additional understanding into this process and the mechanisms involved.

During TDI sensitization ear $\mathrm{T}_{\text {regs }}$ expand in frequency at 2 and 4 (4\%) and 4 and $7(0.5 \%)$ days post exposure (Figure 5.4 D). They also expand in number during days 2-9 following exposure to both concentrations of TDI (Figure 5.4 D). This expansion exhibited similar kinetics to the dLN $\mathrm{T}_{\text {regs }}$ during this response, with an apparent peak in $\mathrm{T}_{\text {reg }}$ expression 4 days post TDI exposure. This congruency between tissues was intriguing and may reveal the systemic nature of sensitization and $\mathrm{T}_{\text {reg }}$ trafficking. As previously mentioned, CCR7 expression is involved with $\mathrm{T}_{\text {reg }}$ lymph node homing and the expression of this receptor was analyzed on $\mathrm{T}_{\text {regs }}$ during TDI sensitization (Figure 5.4 E). $\mathrm{T}_{\text {reg }}$ CCR7 expression was decreased in frequency during 4\% TDI sensitization (2-7 days post exposure) but due to the general expansion of $\mathrm{T}_{\text {regs }} \mathrm{CCR} 7^{+}$cells increased in number during 0.5 and 4\% TDI sensitization. dLN-derived $\mathrm{T}_{\text {regs }}$ may be losing expression of their lymph node 
migratory markers in order to move to the ear, the site of chemical application and of a significant inflammatory response in the $4 \%$ TDI-exposed mice. This hypothesis is supported by decreased expression of CD103, an epithelial $\mathrm{T}_{\text {reg }}$ marker, in skin $\mathrm{T}_{\text {regs }}$ during $0.5 \%$ (4 days post exposure) and 4\% (1-9 days post exposure) TDI sensitization (Figure 5.4 F). ICOS ${ }^{+} \mathrm{T}_{\text {regs }}$ significantly increased in frequency and number during $0.5 \%$ and $4 \%$ TDI sensitization (Figure $5.4 \mathrm{G}$; 0.5\%: $1-9$ days post exposure and 4\%: 2-9 days post exposure). This population accounted for more than $70 \%$ of skin $\mathrm{T}_{\text {regs }}$ in acetone-treated control mice and nearly $100 \%$ of skin $\mathrm{T}_{\text {regs }}$ in TDI-exposed mice, revealing the dermal $\mathrm{T}_{\text {reg }}$ population is probably capable of being functionally active and is at a high activation status as ICOS is a costimulatory molecule important to $T_{\text {reg }}$ function (33). These data reveal an expansion of dermal $\mathrm{T}_{\text {regs }}$ at the site of TDI application during sensitization that is potentially functionally active and phenotypically diverse.

In line with the general migratory capabilities of lympocytes (34), the $\mathrm{T}_{\text {regs }}$ identified in both the ear and dLN during TDI sensitization are potentially migratory, allowing for the regulation of the systemic sensitization response that develops in response to TDI. Comparison of the dLN and skin $\mathrm{T}_{\text {reg }}$ subsets lends important insight into the potential migration and action of $\mathrm{T}_{\text {regs }}$ during TDI sensitization. While the general kinetics of $\mathrm{T}_{\text {reg }}$ frequency appeared to be similar between dLN (Figure 3.2 B) and skin (Figure 5.4 D) $\mathrm{T}_{\text {regs, }}$, the overall percentages are very different for each tissue. Approximately $5-10 \%$ of $\mathrm{CD}^{+} \mathrm{T}$ cells in the $\mathrm{dLN}$ are $\mathrm{T}_{\text {regs }}$ and approximately $10-30 \%$ of $\mathrm{CD}^{+} \mathrm{T}$ cells in the ear are $\mathrm{T}_{\text {regs. }}$ This may be a reflection of the greater percentage of naïve and/or effector $\mathrm{T}$ cells in the lymph node as a secondary lymphoid organ. $\mathrm{T}_{\text {reg }}$ numbers varied greatly between the dLN (Figure $3.2 \mathrm{C}$ ) and skin (Figure 5.4 D), revealing up to approximately 1.6 million $\mathrm{T}_{\text {regs }}$ in the $\mathrm{dLN}$ and 50,000 $\mathrm{T}_{\text {regs }}$ in the skin of TDI-treated mice. This is likely a reflection of the status of the lymph node as a secondary lymphoid organ and a major site of lymphocyte retention. The decreased 
expression of CCR7 following 4\% TDI exposure in the ear $\mathrm{T}_{\text {regs }}$ (Figure $5.4 \mathrm{E}$ ) indicated that $\mathrm{dLN}$ $\mathrm{T}_{\text {regs }}$ were migrating to the ears. This was supported by increased dLNCCR $6{ }^{+} \mathrm{T}_{\text {reg }}$ frequency during 0.5\% (2-9 days post exposure) and 4\% (4-9 days post exposure) TDI sensitization (Table 3.2). CCR6 is a lymphocyte chemotactic factor that causes $\mathrm{T}$ cell migration to inflammatory tissues (35) and its upregulation on dLN $T_{\text {regs }}$ during TDI sensitization suggests that $T_{\text {regs }}$ are moving from the dLN to the ear during TDI sensitization. CD103 was expressed on approximately $80 \%$ of acetone-treated $\mathrm{T}_{\text {regs }}$ in the ear (Figure $5.4 \mathrm{~F}$ ) compared with approximately $20 \%$ of their counterparts in the skin (Table 3.2). This is in accordance with CD103's skin homing role in $\mathrm{T}_{\text {regs }}$ described above. CD103 ${ }^{+}$ $\mathrm{T}_{\text {regs }}$ increased in frequency in dLN $\mathrm{T}_{\text {regs }}$ during $0.5 \%$ (2-9 days post exposure) and 4\% (4-9 days post exposure) TDI sensitization (Table 3.2), while the frequency of this subset decreases in the ear following $0.5 \%$ (4 days post exposure) and 4\% (1-9 days post exposure) TDI exposure (Figure 5.4 F). This increase in $\mathrm{CD}_{103^{+}} \mathrm{T}_{\text {reg }}$ frequency in the $\mathrm{dLN}$ may indicate $\mathrm{T}_{\text {reg }}$ migration to the skin as observed with CCR6 expression. Decreases in $\mathrm{CD}_{103^{+}} \mathrm{T}_{\text {reg }}$ frequency in the skin may be attributable to lymph node migration from the ear, particularly at later time points such as 4 days post exposure, where this population seems to be the most well represented during $4 \%$ TDI sensitization. Lastly, the $\operatorname{ICOS}^{+} T_{\text {reg }}$ subsets increased in both the dLN (Table 3.2; 2-9 days post exposure) and ear (Figure $5.4 \mathrm{G} ; 0.5 \%$ : $1-9$ days post exposure and 4\%: 2-9 days post exposure), suggesting an activated state in these $T_{\text {regs. }}$ Overall, it appeared that more ear $T_{\text {regs }}$ expressed ICOS (in both the basal and TDItreated states) than dLN $T_{\text {regs }}$ in terms of frequency. All ear $\mathrm{T}_{\text {reg }}$ subsets increased in number during TDI sensitization (Figure 5.4 E-G) with similar kinetics, indicating that regardless of percentage alterations, increased $\mathrm{T}_{\text {regs }}$ expressing each marker analyzed expanded in the skin due to the overall increase in $\mathrm{T}_{\text {reg }}$ numbers. 
A

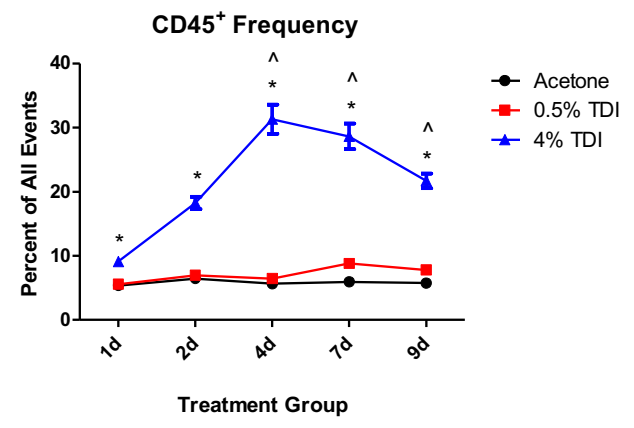

B

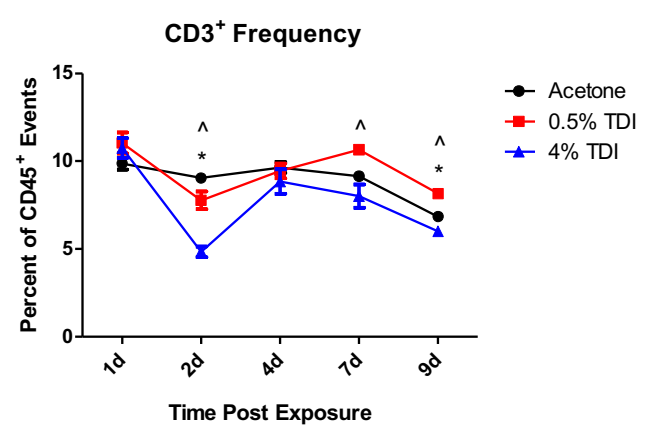

C

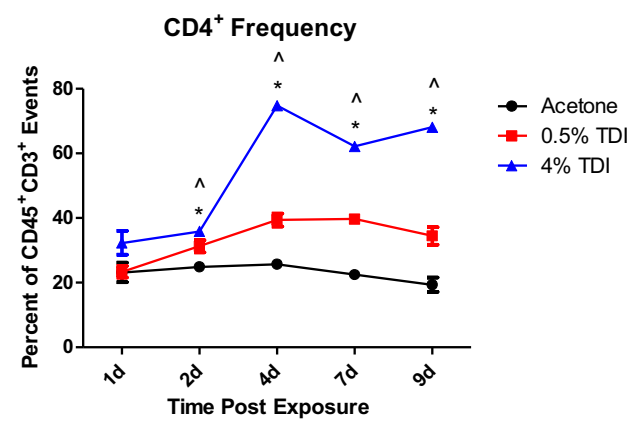

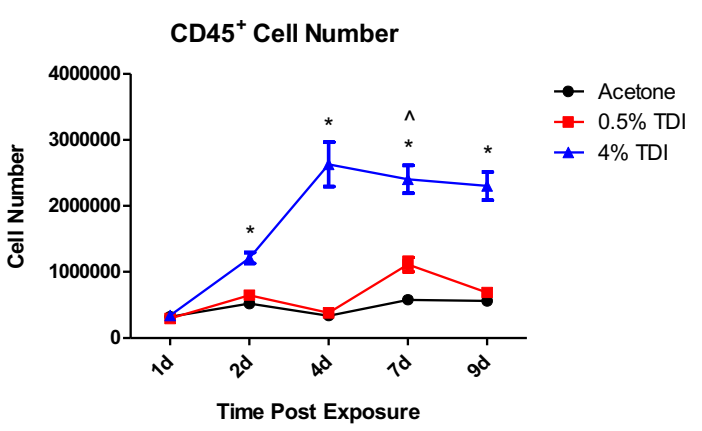
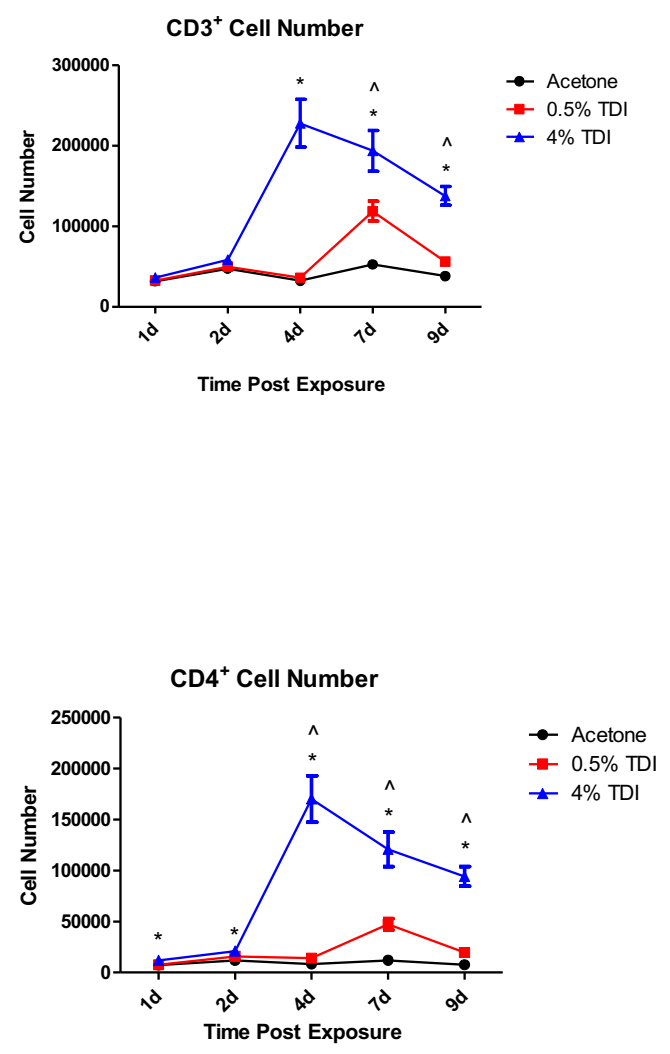
D

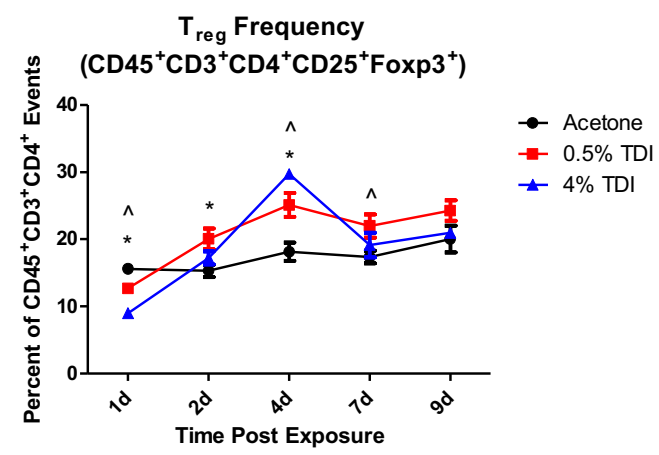

E

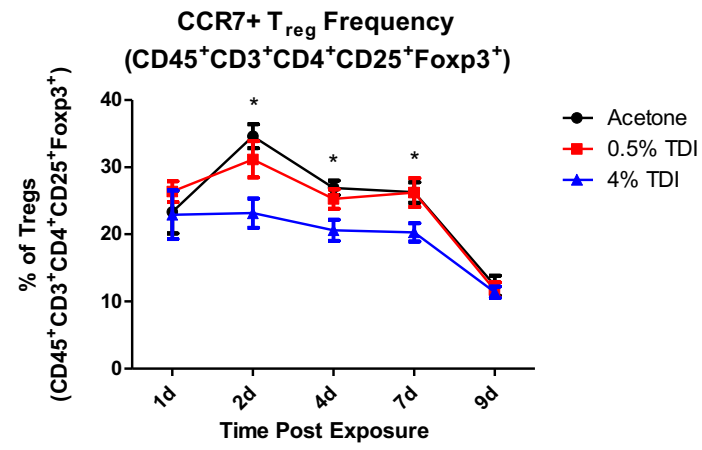

F

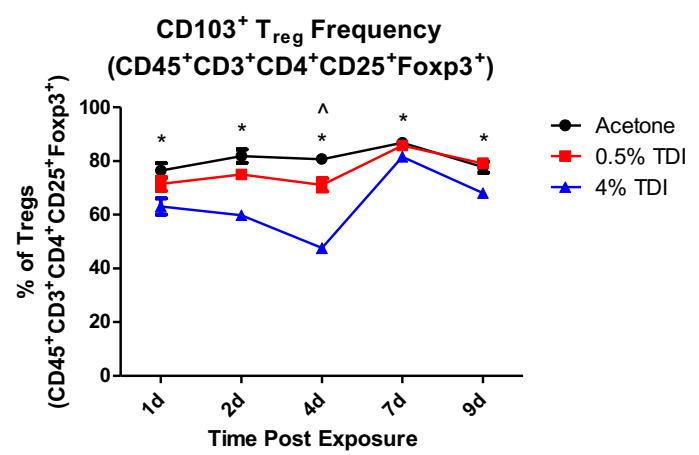

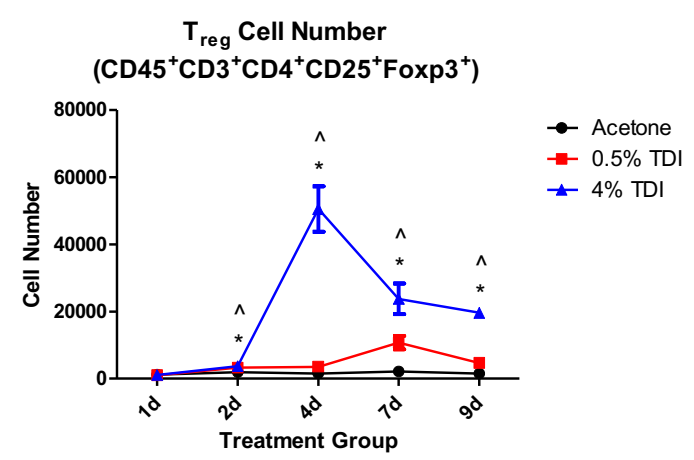
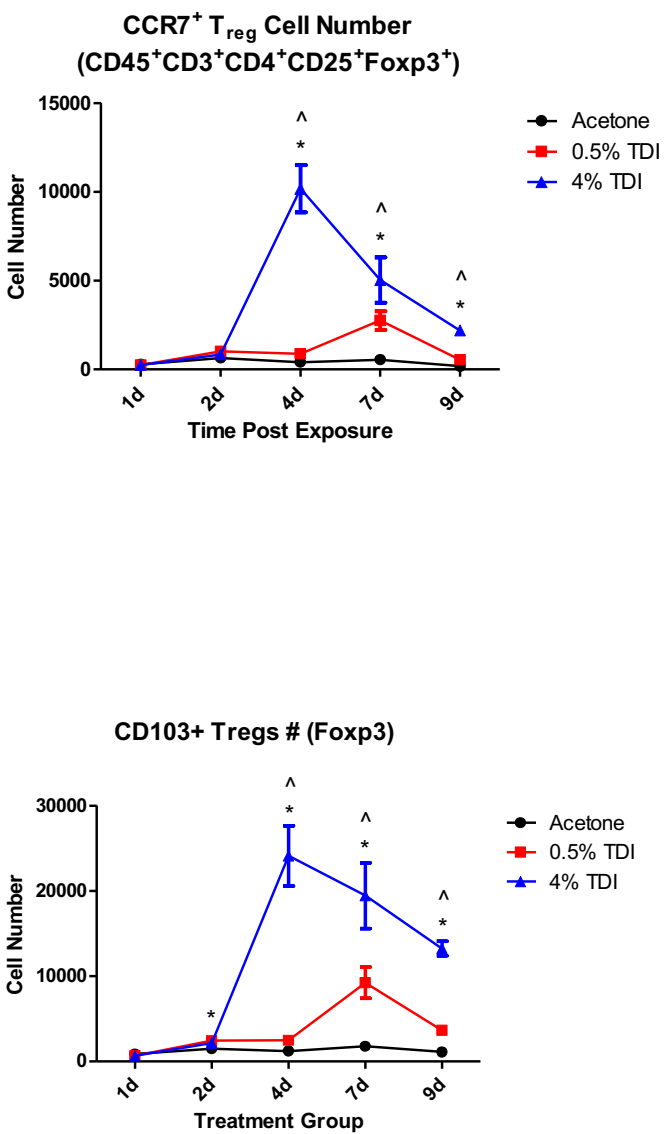

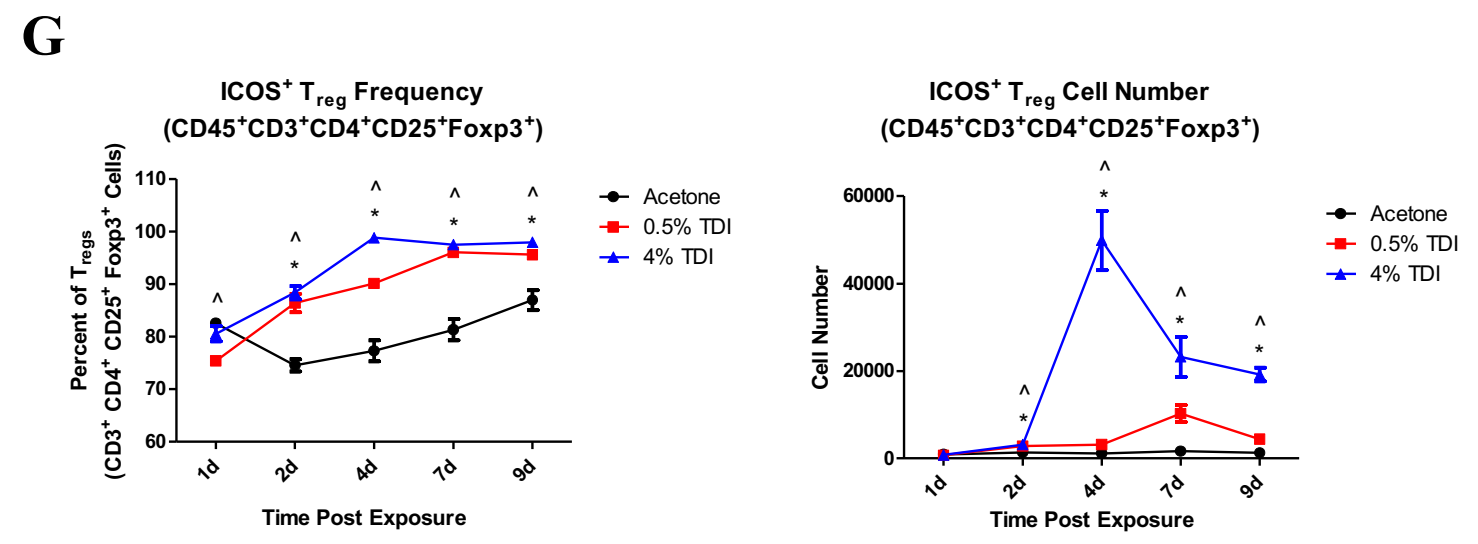

Figure 5.4 Ear $T_{\text {reg }}$ Phenotyping

Flow cytometric analysis of dermal $\mathrm{T}_{\text {regs }}$ following dermal TDI sensitization. $\mathrm{T}_{\text {regs }}$ were first gated on their expression of CD45 (A), CD3 (B), and CD4 (C) then were further identified by CD25 and Foxp3 expression ( $\left.\mathrm{T}_{\text {regs }}\right)$ at indicated time points. $T_{\text {reg }}$ frequency and number $(D)$ were determined based on flow cytometry analysis and extrapolation of this data with total ear cellularity. $\mathrm{T}_{\text {regs }}$ were also analyzed for CCR7 (E), CD103 (F), and ICOS (G) expression. Graph symbols represent mean $( \pm \mathrm{SE})$ of 5 mice per group. $P$ values are represented by ${ }^{\wedge}(0.5 \% \mathrm{TDI})$ and $*(4 \% \mathrm{TDI})(P<0.05)$. Dermal treatment groups are indicated by the following symbols: circle- acetone, square- $0.5 \% \mathrm{TDI}$, and blue triangle- $4 \%$ TDI.

The $\mathrm{T}_{\text {reg }}$ phenotyping carried out in a murine model of TDI sensitization did not specifically characterize effector memory $T_{\text {regs. }}$. This is primarily due to the fact that this model utilizes a single exposure and may not induce high numbers of effector memory $\mathrm{T}_{\text {regs }}$ by the assayed time points; however, this subset is likely important in the elicitation phase of allergic disease and upon repeated allergen exposures. While several of the migratory-related receptors may be expressed on these cells, complete phenotyping of effector memory $\mathrm{T}_{\text {regs }}$ would require the identification of CD127 (IL7R), CD44, CD27, and CCR6 expression in mice (36). Skin-residing memory $\mathrm{T}_{\text {regs }}$ appear to express 
lower levels of CD25 and higher levels of CD127 compared to $\mathrm{T}_{\text {regs }}$ in the dLN and IL-2 ${ }^{-/}$and IL7Ra-blocking antibody studies indicate that murine skin memory $\mathrm{T}_{\text {regs }}$ require IL-7 but not IL-2 for their survival in this tissue (36). The IL-7 requirement was not evidenced with respect to human memory $\mathrm{T}_{\text {regs }}$ in the skin (37). Murine and human $\mathrm{T}_{\text {regs }}$ in the skin localize to hair follicles, in close proximity to the follicular epithelium while conventional $\mathrm{T}$ cells did not appear to preferentially localize to the hair follicle (37). Interestingly, in our epicutaneous murine TDI sensitization model, TDI-hapten complexes localize to several sites in the skin, including the hair follicles; these TDIhapten complexes were shown to co-localize with $\mathrm{CD}_{11}{ }^{+}$, Langerin $^{+}$, and $\mathrm{CD}_{103^{+}}$cells in the hair follicles, presumably demonstrating APC-hapten interaction (38). The presence of $\mathrm{T}_{\text {regs }}$ at sites like the hair follicles may be a protective mechanism due to the accessibility of these structures by allergens. In order to compare the antigen-specificity of human skin memory $\mathrm{T}_{\text {regs }}$ and memory $\mathrm{T}$ cells deep sequencing of the TCR $\beta$ chain was performed in each of these subsets and this analysis revealed that these two cell types likely recognize dissimilar antigens (37). Another unique attribute of human skin memory $\mathrm{T}_{\text {regs }}$ is that they are largely nonmotile, compared to memory conventional $\mathrm{T}$ cells which tend to express CCR7, a lymphatic homing marker (37). In a murine model of DNFB contact allergy, memory effector $\mathrm{T}_{\text {regs }}$ were found to be capable of circulating from the blood and skin, returning to the skin upon antigen exposure (39). This data suggests that memory effector $\mathrm{T}_{\text {regs }}$ are likely present in both the skin and in the circulation in our model of TDI sensitization, migrating throughout the body but able to respond to TDI exposure both locally and distally.

$\mathrm{dLN}$ and ear $\mathrm{T}_{\text {reg }}$ comparisons reveal potential insights into the function of these cells. Presumably, each tissue holds a diverse array of $\mathrm{T}_{\text {regs }}$ whose origins and functions are as unique as their home. Dendritic cell interactions play an important role in the differentiation and stimulation of $\mathrm{T}_{\text {regs }}$, providing direct interactions and influencing the local cytokine and chemokine milieu. The 
dendritic cell populations of the lymph nodes and skin are innately diverse yet contain many shared populations due to the normal migration of immune cells between barrier surfaces and dLNs. Typically, the murine lymph node dendritic cell population is made up of several main subsets including $\mathrm{CD}^{+} \mathrm{CD} 8^{-} \mathrm{DCE}-205^{-}, \mathrm{CD}^{-} \mathrm{CD} 8^{-} \mathrm{DCE}-205^{-}$, and $\mathrm{CD} 4^{-} \mathrm{CD} 8^{+} \mathrm{DCE}-205^{+}$dendritic cells along with skin-derived dendritic cells which may originate as dermal dendritic cells or Langerhans cells (40). Langerhans cells are the only dendritic cell subset present in the epidermis at a basal level and the dermis contains several dermal dendritic cell subtypes (41). Homeostatic migration of skinderived dendritic cells is considered normal even in the absence of an active immune response (40). Additionally, skin $\mathrm{T}_{\text {regs }}$ may actively migrate to the lymph nodes and back, participating the maintenance of tolerance and in the regulation of immune responses such as TDI sensitization. The ability of immune cells to access the lymphatic network from barrier sites such as the skin is imperative in normal functioning of the immune system and is also a major contributor to the development of systemic sensitization. Dendritic cells are often regarded as the "bridge" between innate and adaptive immunity due to their antigen presentation abilities. Although they are involved in the activation of reactive Th cells, dendritic cells play a crucial role in $\mathrm{T}_{\text {reg }}$ induction. IL-10, IL27 , and TGF- $\beta$ production and IOCSL signaling by dendritic cells promotes Tr1 differentiation and thymic dendritic cells produce thymic stromal lymphopoetin (TSLP) to promote $n T_{\text {reg }}$ differentiation, generally from self-reactive $\mathrm{T}$ cells (42). $\mathrm{iT}_{\text {reg }}$ differentiation can be influenced dendritic cell-derived IDO and tryptophan depletion metabolites 3-hydroxyanthranilate and kynurenine, dendritic cell TGF- $\beta$, retinoic acid, and RANKL signaling (42).

The role of dendritic cells in relation to $\mathrm{T}_{\text {regs }}$ has been investigated in a murine model of DNTB contact hypersensitivity (41). This work utilized a weak hapten model in an effort to understand the mechanisms driving tolerance to weak haptens (e.g. DNTB) vs. strong haptens (e.g. 
DNFB). DNTB cannot activate the inflammasome nor can it induce contact hypersensitivity following a single exposure in mice yet it generates similar self-peptide complexes upon skin contact as those associated with DNFB which behaves as a strong allergen (41). As a weak hapten, DNTB appears to promote tolerance to DNFB sensitization and this effect is thought to be mediated by $\mathrm{T}_{\text {reg }}$ induction (41). Additionally, Langerhans cells are able to cause anergy and deletion of DNTBreactive $\mathrm{CD}^{+} \mathrm{T}$ cells and promote the expansion of $\mathrm{ICOS}^{+} \mathrm{T}_{\text {regs }}$ in order to suppress allergic contact dermatitis (41). In this model of DNFB allergy, Langerhans cells and dermal dendritic cells were able to present the hapten-protein complex within 24 hours of dermal exposure, emphasizing the quick response time of these cells and their important role in the allergic response (41). The importance of Langerhans cells in the maintenance of tolerance in this "weak hapten" model is relevant to "strong haptens" like TDI; although different dendritic cell populations may be mediating this effect (possibly monocyte-derived skin dendritic cells and/or $\mathrm{CD} 207^{+}$dermal dendritic cells) (41), it is likely a part of the immune response involved in TDI allergy. Based on the importance of both MHC I and II in the induction of dendritic cell-initiated tolerance in the DNTB model (41), in the case of TDI sensitization, it is likely that this mechanism of dendritic cell tolerance establishment is skewed, resulting in the massive expansion of antigen-reactive $\mathrm{T}$ cells. The difference between tolerance established following "weak hapten" exposure and the allergic disease established following "strong hapten" exposure may be attributed to variant outcomes following dendritic cell antigen presentation in the lymph node.

In our TDI sensitization model, tolerance may not be established due to skin irritation causing danger signal induction and antigen presentation by dendritic cells resulting in activation of antigenreactive $\mathrm{T}$ cells. Although $\mathrm{T}_{\text {regs }}$ do expand and some antigen-reactive $\mathrm{T}$ cells may be deleted, these events do not appear to be strong enough to overcome the sensitization response that has begun. The 
local cytokine environment is a very important factor involved in the maintenance of tolerance or the induction of an allergic response. IL-35 has been shown to impact tolerance by promoting antiinflammatory pathways; this cytokine acts as a regulatory signaling molecule in a murine model of OVA-induced allergic airway inflammation (43). IL-35 exerts these effects by a number of mechanisms, including the suppression of inflammatory dendritic cells at the site of inflammation as well as the dLNs (43). Another anti-inflammatory cytokine, IL-10, is known to downregulate pro-inflammatory cytokine (IL-1 $\beta$ and IL-6) production if produced early in the innate immune response (44). IL-10 may be produced by $\mathrm{T}_{\text {regs, }}$ macrophages, dendritic cells, neutrophils, and keratinocytes (20) and may play a role in regulating the TDI sensitization response as early as the initiation of dendritic cell function. A study by Cumberbatch, et al. revealed dichotomous immune responses in the skin of mice exposed to contact (DNCB) and respiratory (TMA) allergens. Langerhans cell migration to the dLN was delayed in response to TMA compared to DNCB which was attributed to differential epidermal cytokine profiles, in particular altered IL-10 expression leading to reduced IL-1 $\beta$ levels (45). This data reveals the importance of the cytokine environment in the development of allergic disease, as well as the potential importance of IL-10 in the development of Th2 sensitization. The increased inflammatory response observed in our murine TDI sensitization model (Figure 3.1) may influence the phenotype and functional capabilities of skin dendritic cells, leading to the development of an adaptive response which we know as sensitization. Clearly the local cytokine and chemokine environment can guide the dendritic cell response, which is also a crucial component of the induction of allergic disease. Further investigation into dendritic cell and $\mathrm{T}_{\text {reg }}$ activity during TDI sensitization may reveal valuable information regarding the mechanisms involved in the orchestration of sensitization and the balance between allergic disease and tolerance, as dendritic cells appear to be key players. 


\subsubsection{Therapeutic Potential of $T_{\text {regs }}$}

The therapeutic potential of $\mathrm{T}_{\text {regs }}$ is an exciting prospect, yet in many cases this concept remains in its infancy in functional terms. General challenges regarding the development of $\mathrm{T}_{\text {reg- }}{ }^{-}$ based therapeutics include $\mathrm{T}_{\text {reg }}$ isolation and identification issues, plasticity, high cost, and unintended, "off-target" effects on pathogen clearance or tumor immunity (46). Regardless, several Phase I clinical trials have been completed utilizing $\mathrm{T}_{\text {regs }}$ therapeutically in the context of graft versus host disease and type 1 diabetes (46). These studies revealed generally safe responses to supplemental $\mathrm{T}_{\text {reg }}$ therapy with immunosuppression being a major side effect (46). Several Phase I and II clinical trials are currently recruiting and will investigate the use of $\mathrm{T}_{\text {reg }}$ therapy in kidney and liver transplant, Crohn's disease, and multiple sclerosis (46). Although a Phase I trial for the use of autologous polyclonal $\mathrm{T}_{\text {regs }}$ in steroid-resistant asthma is purported to be initiated soon, this has not begun (46). The subcutaneous and intradermal administration of insulin-like growth factor-1 helped to alleviate inflammation (ear swelling) in a murine model of DNFB contact hypersensitivity (47), demonstrating that $\mathrm{T}_{\text {reg }}$ expansion is helpful in the control of allergic responses in the skin. It seems that much remains to be learned about these cells before they may be used in the effective treatment of allergic disease. In terms of TDI allergy, the role of $\mathrm{T}_{\text {regs }}$ in TDI elicitation is currently unknown and should be elucidated to fully characterize the importance of these cells in a complete model of TDI allergy, encompassing both sensitization and elicitation. This would allow for a clear understanding of the temporal significance of $\mathrm{T}_{\text {regs }}$ during all phases of this response, which may have strong implications in regards to clinical uses of these cells.

In models of OVA-induced allergy, $\mathrm{T}_{\text {regs }}$ were shown to have a protective role in the sensitization but not the elicitation phase of this response $(48,49)$. The suppressive role of $\mathrm{T}_{\text {regs }}$ has also been investigated and confirmed in a model of DNFB-induced sensitization and contact 
hypersensitivity (50). If $\mathrm{T}_{\text {regs }}$ play a role in TDI sensitization but not in elicitation, these cells may not have an immediately apparent therapeutic or preventative role. Because sensitization is typically not accompanied by any clinical symptoms or "outward" signs, the interventional significance of $\mathrm{T}_{\text {regs }}$ at this time in the development of the response may be difficult to discern. In line with the thoughts of Baru, et al. (49) the apparent lack of $\mathrm{T}_{\text {reg }}$ importance during OVA-induced elicitation does not automatically discredit the idea that $\mathrm{T}_{\text {regs }}$ may be able to help lessen allergic inflammation and pathology if administered exogenously or induced at this phase of the response. Exogenous $\mathrm{T}_{\text {reg }}$ administration has been shown to ameliorate tissue damage, remodeling, and pathology in murine models of LPS-induced acute lung injury (51) and OVA-induced allergic airway inflammation (52, 53). Also, adoptive transfer of preactivated OVA-specific $T_{\text {regs }}$ into OVA-sensitized mice resulted in a blunted Th2 response in the lung in response to OVA challenge (54). Importantly, $\mathrm{T}_{\text {reg }}$ supplementation following the establishment of allergic symptoms did not reverse airway hyperreactivity, regardless of the decreased airway inflammation and eosinophilia observed following treatment (52). This data indicate that $\mathrm{T}_{\text {regs }}$ exhibit therapeutic potential in the regulation of allergic disease, even if administered once symptoms appear. Clearly, further investigation into the mechanisms and temporal influence of $\mathrm{T}_{\text {regs }}$ during TDI sensitization and elicitation is necessary in order to fully realize the potential utility of these cells. Ideally, therapeutic strategies involving $T_{\text {regs }}$ such as vitamin D treatment leading to dexamethasone-induced IL-10 responsiveness $\left(T_{\text {reg }}\right.$ mediated) in glucocortacoid-resistant asthmatics (55) may be effective for TDI asthmatics.

\subsection{The role of miRNAs in TDI sensitization}

Just as $\mathrm{T}_{\text {regs }}$ are important in the regulatory milieu of the immune system, miRNAs have exhibited powerful regulatory functions in a number of disease states and conditions. It has been 
estimated that approximately $30-92 \%$ of human genes are regulated by miRNAs (56). The ability of multiple miRNAs to regulate multiple genes and simultaneously impact target protein translation demonstrates the ubiquitous regulatory power of these tiny structures. These small RNA molecules originate from mRNA that is typically transcribed by RNA polymerase II or III, producing primary miRNA transcripts (56). miRNAs can originate from the activation of independent promoters as polycistronic transcripts from the introns of protein-coding genes (57). Primary RNA transcripts are then processed into pre-miRNA stem loops which contain approximately 60 nucleotides; this is mediated by the RNase III enzyme Drosha and DGCR8 (56). The pre-miRNA stem loops are transported out of the nucleus into the cytoplasm by Exportin-5 and are processed into mature miRNA molecules by the cytoplasmic Rnase III ribonuclease Dicer (56). This mature miRNA molecule can then form a complex with RNA-induced silencing complex (RISC) machinery and impact the translation of target gene by sequence-specific targeting of mRNA, typically within the 3' UTR where their binding is the most efficient $(57,58)$. RISC-miRNAs bind through complementarity that may be partial (at least 6-8 nucleotides) or perfect, leading to repression of the target gene's translation or mRNA degradation via initiation of deadenylation (57). Mature miRNAs can be released from their cells of origin via exosomes, which are cell-membrane derived vesicles, by cellular degradation, or by complexing with proteins such as high-density lipoprotein and Argonaute (57). These extracellular miRNAs may be taken up by recipient cells bearing scavenger receptors (HDL-bound miRNAs) or passively (57).

miRNAs have integral functions in the development of the immune system, as conditional Dicer depletion in hematopoietic stem cells leads to dysfunction in the hematopoietic compartment and this setup in T or B cells causes lymphopenia and reduced functional capacity of these cells (58). The role of these regulatory elements is beginning to be explored in the context of allergic disease. 
Several miRNAs have been shown to be differentially expressed in the airways of asthmatic patients and in the lymphocytes of mice in models of allergic asthma (57). miR-155 appears to be a major player in the development of Th2-mediated allergic disease as miR-155 deficient mice exhibit reduced eosinophilic inflammation and reduced Th2 cell numbers in a murine model of OVAinduced asthma (57). The upregulation of this miRNA during TDI sensitization (Figure 4.7 B) suggests that this miRNA may be involved in the development of TDI sensitization, which contains strong Th2 components. The inhibition of several miRNAs (including miR-106a, $-126,-145$, and $221)$ in murine models of allergic asthma has resulted in the reduction of pathogenic symptoms (57, 59), suggesting important roles for additional miRNAs in the development of allergic asthma. Alternatively, miR-24 and -27 suppress Th2 differentiation via IL-4 downregulation in T cells, acting as negative regulators of OVA-induced allergic disease (60). miR-21 is thought to target IL-12p35, leading to augmented Th2 responses in both murine and human models (57). miR-155 has also been found to be overexpressed in skin samples from patients with atopic dermatitis and from skin challenged with diphenylcyclopropenone (57). Additional miRNAs have been shown to be differentially expressed in models of allergic skin disease, including atopic dermatitis and allergic contact dermatitis (57). There is likely a complex network of miRNAs involved in the regulation of allergic disease, both augmenting and decreasing the response.

\subsubsection{Overview of Selected miRNAs and their Relationship with $\mathbf{T}_{\text {regs }}$}

Although miR-210 was the focus of the miRNA-based studies included in this work, miR31 and -155 were also investigated for their potential to induce miR-210 expression and to influence $\mathrm{T}_{\text {reg }}$ differentiation and function. Interestingly, miR-21, -155, and -301a made up a signature expression profile in stimulated splenic $\mathrm{CD}^{+} \mathrm{T}$ cells (both nonspecific and $\mathrm{MOG}_{35-55}$ peptidespecific) derived from a murine EAE model (61). These three miRNAs were also increased in the 
dLN of mice dermally sensitized to TDI (62). Due to obvious differences in treatment and exposures in each of the models, the temporal kinetics of each miRNA were variable; however, for each response, these miRNAs were significantly elevated at time points encompassing immunologically significant events. Collectively, this data emphasizes the importance of multiple miRNAs in immunologic processes and the conserved nature of these miRNAs in similar cell types and responses.

Thymic $\mathrm{T}_{\text {reg }}$ development is affected by miRNAs as conditional Dicer1 allele deletion at the double negative/double positive transition results in a significant decrease in $\mathrm{Foxp}^{+} \mathrm{nT}_{\text {reg }}$ frequency in the LN, spleen, and thymus (63). The authors also investigated $\mathrm{iT}_{\text {regs }}$ in the context of Dicer depletion and upon stimulation and dicer-deficient, TGF- $\beta$ stimulated $\mathrm{CD} 4^{+} \mathrm{CD} 25^{-} \mathrm{T}$ cells produced less $\mathrm{T}_{\text {regs }}(13.5 \%)$ than Dicer-competent $\mathrm{T}$ cells $(48.5 \%)$. In a recent work by Liston, et al. $\mathrm{T}_{\text {reg- }}{ }^{-}$ specific miRNA depletion via Dicer caused a lethal autoimmune condition analogous to that observed in foxp3-deficient mice (64). These data show the importance of miRNAs in the development of $T_{\text {regs. }}$. Murine $n T_{\text {regs }}$ and $T_{\text {cons }}$ exhibit distinct miRNA expression profiles; $\mathrm{nT}_{\text {regs }}$ exhibited increased expression of miR-21, $-22,-27 \mathrm{~b}$, and -155 (among others) compared to $\mathrm{T}_{\text {cons }}$ (63). The human cord blood-derived $\mathrm{nT}_{\text {reg }}$ miRNA signature is similar with increased miR-21 and decreased miR-31 (65). The same study revealed that in human cord blood-derived non- $\mathrm{T}_{\text {regs }}$ miR21 induces foxp3 expression while in $\mathrm{nT}_{\text {regs }}$ miR-31 targets foxp3, antagonizing $\mathrm{T}_{\text {reg }}$ development. The impact of miRNAs on $T_{\text {reg }}$ development is clearly significant, and may occur through positive or negative regulation. In light of their potential roles in $\mathrm{T}_{\text {reg }}$ differentiation and/or function, miR$210,-31$, and -155 will be discussed in the context of current knowledge from the literature as well as experimental data presented in this work. 


$$
\underline{\text { miRNA } 210}
$$

miR-210 is upregulated in breast cancer, pancreatic tumors, and head and neck cancer (66). Functionally, this miRNA is known to be cytoprotective, increase angiogenesis, and inhibit apoptosis in hypoxic conditions, precluding its moniker, the "master hypoxamir" (66). miR-210 has also been associated with breast cancer tumor proliferation (67), identified as a potential human serum biomarker for pancreatic cancer (68), and has been suggested as a therapy for the treatment of ischemic heart disease (69). The relationship between miR-210 and $\mathrm{T}_{\text {regs }}$ is not well studied; however, most of the investigations into this concept have been carried out in humans. In a study involving patients with psoriasis vulgaris, miR-210 levels were increased in peripheral blood mononuclear cells (PBMCs) from patients with psoriasis (66). Foxp3 was identified as a miR-210 target and this interaction was correlated with downregulated IL-10 and TGF- $\beta$ secretion by $\mathrm{T}_{\text {regs. }}$ This study suggested that miR-210 negatively regulates foxp3, leading to immune dysfunction. In $\mathrm{T}_{\text {regs }}$ isolated from healthy adult donor blood miR-210 was found to potentially target the 3' UTR of foxp3 and ctla4 (70). Additionally, foxp3 has been predicted to target runx3 (62), a transcription factor that acts upstream of foxp3 and is imperative for $\mathrm{iT}_{\text {reg }}$ activation $(71,72)$. Our investigations

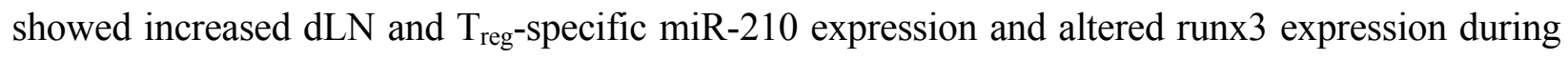
TDI sensitization. Collectively, this data suggests that miR-210 may be targeting $\mathrm{T}_{\text {regs }}$ during TDI sensitization.

miR-210 may be induced by HIF-1 $\alpha$ and may also target this gene (73). Due to the hypoxic conditions in lymphoid tissues such as the lymph nodes and inflammatory sites such as TDI-exposed skin, it is logical to assume HIF-1 $\alpha$ is inducing the expression of miR-210 during TDI sensitization. HIF-1 $\alpha$ expression increases in allergic murine and human airways (74). HIF-1 $\alpha$ protein levels in ear lysates appear to increase during TDI sensitization (Figure 5.5 A), suggesting that this signaling 
factor is increasing miR-210 expression in the ear. dLN levels of HIF-1 $\alpha$ should be investigated as primary miR-210 expression was noted in this tissue, indicating that miR-210 was being produced locally. Interestingly, the increased expression of miR-210 at non-irritant TDI concentrations in both the dLN (Figure 4.1) and ear (A4.1) suggests an alternative induction pathway for this miRNA.

In hypoxic conditions, HIF-1 $\alpha$ can induce foxp3 expression by binding to the hypoxia response elements found within the foxp3 promotor (75). Dissimilarly, an earlier study reported the negative effect of HIF-1 $\alpha$ on $\mathrm{T}_{\text {reg }}$ development via targeting foxp3 for proteasomal degradation (76). This was elegantly refuted by studies utilizing foxp3-GFP transcriptional reporter mice which showed that the frequency of foxp3 mRNA-expressing cells $\left(\mathrm{GFP}^{+}\right)$was tightly correlated with the frequency of foxp3 protein-expressing cells in normoxic and hypoxic conditions (75). HIF-1 $\alpha$ has also been reported to affect Th17 cells by inducing transcription of roryt, promoting the differentiation of this subtype (73), emphasizing the global and diverse effects of this signaling molecule on T cells. If HIF- $1 \alpha$ is inducing the expression of miR-210 during TDI sensitization, it is possible that this is a regulatory mechanism to prevent the over proliferation of $\mathrm{T}_{\text {regs }}$ (and maybe Th17 cells as well) in hypoxic conditions, assuming miR-210's purported action on $\mathrm{T}_{\text {regs }}$ is valid. miR-210 has been investigated in the context of hifl $\alpha$ expression and $\mathrm{T}$ cell differentiation both at steady state conditions and in a model of experimental colitis (73). These studies revealed increased miR-210 levels in activated T cells and that HIF-1 $\alpha$ is both a target and important inducer of miR-210 (73). Additionally, miR-210 suppressed Th17 differentiation in specific oxygenation conditions and was able to reduce the severity of colitis, presumably due to targeting hifla (73). Although this data does not directly address $\mathrm{T}_{\text {regs }}$ in relation to miR-210, the authors show increased miR-210 levels in this subset following in vitro polarization of naïve $\mathrm{T}$ cells (73). Clearly regulatory elements like HIF-1 $\alpha$ and miR-210 are tightly regulated both temporally and in terms of the specific 
immune response. While miR-210 may be suppressing Th17 differentiation during TDI sensitization this remains to be investigated. Overall, this data exposes the dynamic nature of miRNAs and their targets which may be variable among unique immune responses.

\section{A}

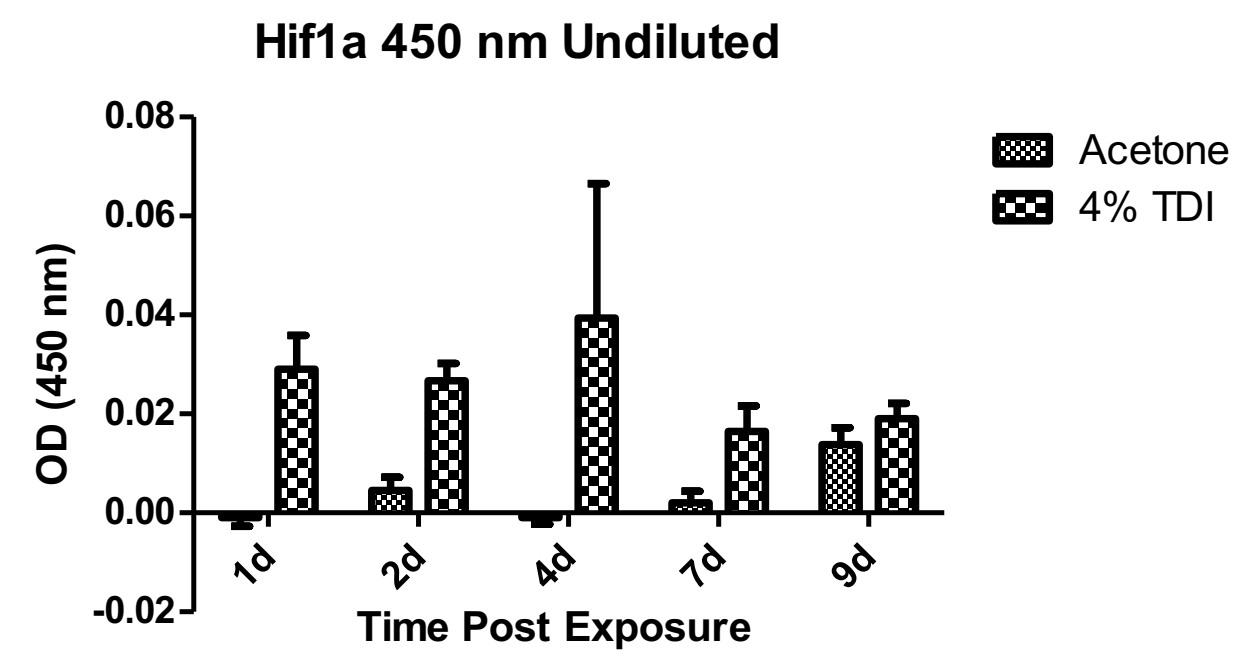

Figure 5.5 HIF-1 $\alpha$ Protein Levels in Ear Lysates During TDI Sensitization

HIF-1 $\alpha$ levels were quantified in lysates from ear cells collected at various time points during TDI sensitization utilizing a DNA-binding ELISA (A). Bars represent mean ( \pm SE) of 4 mice per group. $P$ values are represented by $*(P<0.05)$.

dLN and CD4 expression of primary miR-210 during TDI sensitization (Figure 4.1 B) indicates that this tissue and cell type are capable of producing miR-210 at the transcriptional level. Additionally, mature miR-210 levels are detected (and increase) in $\mathrm{T}_{\text {regs }}$ following ex vivo $\mathrm{T}_{\text {reg }}$ polarization (73). This data suggests that miR-210 is expressed by $\mathrm{CD} 4^{+} \mathrm{T}$ cells in the dLN during TDI sensitization. Interestingly, although they were detectable, primary miR-210 levels significantly decreased in the $\mathrm{CD}^{+}$subset compared to the equivalent cells in acetone-exposed mice 4 days post 
4\% TDI exposure (Figure $4.1 \mathrm{~B}$ ). This data may suggest that $\mathrm{CD}^{+} \mathrm{T}$ cells are not the primary producers of miR-210 in the $\mathrm{dLN}$, as mature miR-210 levels significantly increase at this time point in the dLN (Figure 4.1 A). Because 4 days post TDI exposure appears to be the peak of mature miR210 expression, decreasing primary miR-210 levels at this time may indicate the beginning of transcriptional downregulation of miR-210, which could be reflected by relative decreases in mature miR-210 expression at later time points (Figure 4.1 A). Another possibility is that miR-210 could be shuttled into the dLN via exosomes or other trafficking machinery which would result in increased mature miR-210 but not necessarily increased primary miR-210 levels. Regardless of the method or site of induction, it is clear that mature miR-210 is likely responsible for a regulatory functions during TDI sensitization as illustrated in Figure 5.6. 


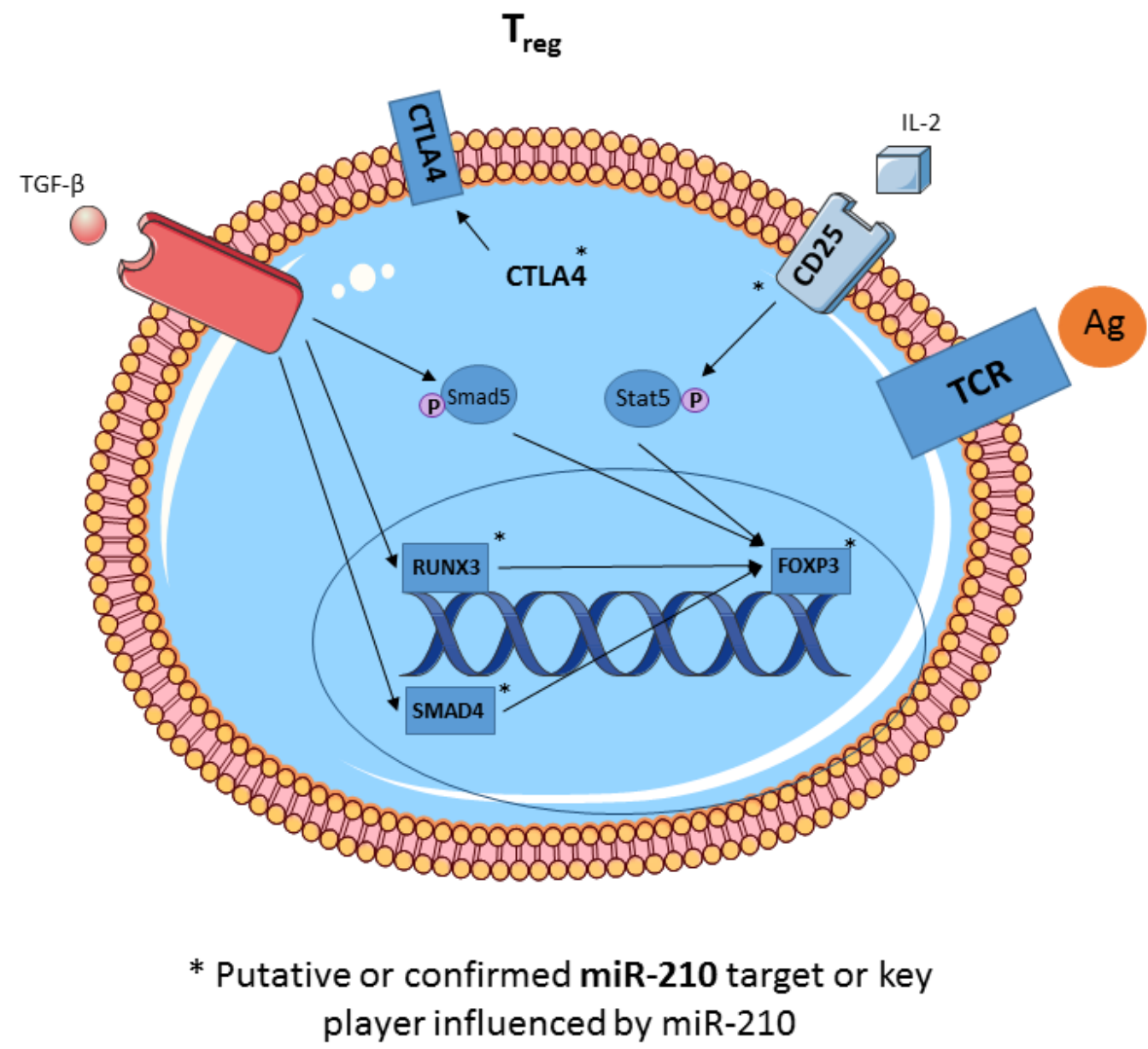

Figure 5.6 Potential sites of miR-210 action in $\mathrm{T}_{\text {reg }}$ Biology

*Indicates putative or confirmed targets of miR-210. This may be occuring through direct or indirect means.

\section{miRNA 31}

Due to the reported miR-31 binding site on foxp3 mRNA, this miRNA has been investigated for its potential role in the development and/or function of $\mathrm{T}_{\text {regs. }}$. In a murine model of EAE, increased miR-31 expression was observed in pathogenic $\mathrm{CD} 4^{+} \mathrm{T}$ cells along with stimulated $\mathrm{CD} 4^{+} \mathrm{T}$ cells from naïve mice, implicating TCR signaling as an inducer of this miRNA (77). In an effort to examine miR-31 expression in EAE-relevant $\mathrm{T}$ cell lineages, naïve $\mathrm{T}$ cells were polarized to Th1, 
Th17, and $\mathrm{T}_{\text {reg }}$ subsets in vitro and each population's miR-31 expression was measured. miR-31 levels increased in Th1 and Th17 cells but decreased in $\mathrm{T}_{\text {regs }}$ when compared to naïve $\mathrm{T}$ cells; the authors also discovered that foxp 3 was significantly recruited to the putative miR-31 promoter (via chromatin immunoprecipitation assay), suggesting that foxp3 may bind to the miR-31 promoter and downregulate its expression when $\mathrm{T}_{\text {regs }}$ are present and/or expanding. Gprc5a, or retinoic acidinducible protein 3, was identified as a target of miR-31, its knockdown leading to $i T_{\text {reg }}$ downregulation and increased EAE severity. These data suggest that miR-31 is a negative regulator of $\mathrm{iT}_{\text {reg }}$ generation via downregulation of Gprc5a expression.

\section{$\underline{\text { miRNA } 155}$}

miR-155 is a very well-investigated molecule that was one of the initial miRNAs functionally identified in T cells and associated with TCR stimulation and inflammation $(61,78)$. miR-155 can be induced by a number of innate immune signaling elements, including LPS, Poly (I:C), interferons, TNF- $\alpha$, CpG, and PMA (78). Autoimmune symptoms have been observed in miR-155-deficient mice and this has been attributed to a Th2 imbalance (61). miR-155 deficient mice exhibit dysfunctional Th1 and Th17 differentiation and are highly resistant to EAE $(57,79)$. The proinflammatory and pro-allergic role of miR-155 has been linked to its action in macrophages, where it targets IL-13RA, SOCS1, and SHIP1; upon reduction of miR-155 levels, macrophages assume a M2 phenotype, suggesting that miR-155 promotes the inflammatory M1 phenotype (57). miR-155 has also been linked to dendritic cell Th2 priming, as miR-155-deficient dendritic cells exhibit limited Th2 priming function in vitro and failed to induce airway inflammation following intratracheal transfer in a murine model of ovalbumin-induced allergic airway disease (80). These effects were shown to be mediated by miR-155 targeting of ATP-induced dendritic cell migration and activation (80). miR-155 has also been implicated as a player in IgG class switching, germinal 
center B cell expansion, EAE pathogenesis, and dendritic cell function $(56,61)$, emphasizing the global importance and complexity of this miRNA. MiR-155 expression increases in response to various inflammatory stimuli, potentially explaining its early increases in response to irritant concentrations of TDI (Figure 4.6 B). These increases are typically attributed to TLR activation or inflammatory signaling mediated by cytokines such as tumor necrosis factors, interferons, and NF$\kappa \mathrm{B}(58)$.

The intron encoding miR-155 (precursor mRNA, Bic) can be bound by Foxp3 $(81,82)$,

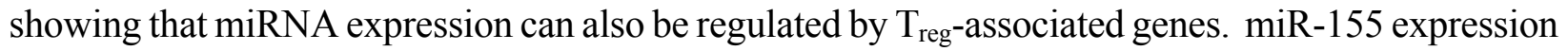
was found to increase in $T_{\text {regs }}$ and this was dependent on sustained foxp3 expression (81). The authors also found that miR-155 had a positive effect on the numbers of $\mathrm{T}_{\text {regs }}$ and the proliferative potential of these cells; these effects were attributed to attenuated IL-2 signaling primarily due to elevated SOCS1 protein expression in miR-155-deficient $T_{\text {regs }}$ as miR-155 was verified as a target of socs1 (83). miR-155 was shown to target socs 1, a negative regulator of IL-2R/STAT5 signaling, enhancing foxp3 expression (84). This study demonstrated the critical role of miR-155 in $\mathrm{T}_{\text {reg }}$ homeostasis in competitive IL-2 scenarios (but not in lymphopenic situations where IL-2 is dispensable) along with the crucial activity of foxp3 in the maintenance of miR-155 expression. Additionally, miR-155 deficient mice exhibit reduced thymic and peripheral $\mathrm{T}_{\text {reg }}$ numbers (84). Generally, it seems that miR-155 affects the proliferation and differentiation of $\mathrm{T}_{\text {regs }}$ but not the suppressive capability nor specific markers expressed by these cells, although miR-155 was shown to be a direct target of ctla4, which would affect $\mathrm{T}_{\text {reg }}$ function (84). miR-155 can also suppress cMaf, leading to impaired IL-4 and Th2 responses and enhanced Foxp3 and $\mathrm{T}_{\text {reg }}$ responses (84). Overall, miR-155 positively regulates tbet, foxp3, and ror $\gamma$ t while it negatively regulates gata3, further influencing $\mathrm{T}$ cell lineage specificity (83). 
miR-31, -155 , and -210 are all valid experimental focuses in future studies evaluating TDI sensitization. Their unique expression and functions hold much potential in terms of elucidating the underlying mechanisms of allergic disease as well as the identification of biomarkers for these conditions. Before confirming the functional roles of these miRNAs, the functional availability of these structures should be confirmed, either by Luciferase binding assays to evaluate the ability of these miRNAs to bind targets or by Argonaute immunoprecipitation assays which identify mature miRNAs, the RISC, and their target mRNA in active complex. Because the specific targets of these miRNAs have not been fully elucidated, these target-based mechanisms may not be feasible; however, it is important to consider miRNA degradation by nucleases (85) and natural circular RNA (86) in this context. Generally mature miRNAs are stable and degradation should not interfere with functional roles.

\subsubsection{Therapeutic Potential of miRNAs}

The quantifiable expression of miRNAs in a variety of tissues and fluids in the body suggest their potential utility as biomarkers of disease. Perhaps the most promising site of miRNA expression regarding the use of these molecules as biomarkers is the blood. miRNAs can be expressed in additional bodily fluids such as lavage fluids, saliva, and urine; however, blood miRNAs have been proposed as suitable biomarkers for cancer, inflammatory disease, and tissue injury (57). The blood miRNA profile of patients with chronic obstructive pulmonary disease, allergic rhinitis, and the BAL fluid miRNA profiles of patients with mild asymptomatic asthma have been shown to be unique and may have potential use as biomarkers of allergic disease $(57,87)$. When mice were dermally exposed to archetypal Th1 (DNCB and $\alpha-\mathrm{HCA}$ ) or Th2 (TDI and OPA) sensitizers dLN miR-210 expression was increased in response to the Th2 sensitizers but was 
decreased in response to the Thl sensitizers (data not shown). This suggests the potential utilization of miRNA expression as a tool to determine if a chemical is a dermal or respiratory sensitizer. Furthermore, miR-210 expression was investigated in a variety of tissues during TDI sensitization and expression was significantly increased in the ear at various time points post $4 \%$ TDI exposure (A $4.1 \mathrm{~A}$ ). miR-210 expression in the ear was significantly increased 4 days post $0.5,2$, and $4 \%$ TDI exposure; however, expression following the strong irritant dose of $4 \%$ was much higher in relation to the less irritating doses, indicating that miR-210 expression in the ear is more dependent on dLN expression of miR-210 at the same doses (data not shown). miR-210 expression was also examined at day 4 post $4 \%$ TDI exposure in the blood (A $4.1 \mathrm{~B}$ ). Blood miR-210 levels were not altered at this time point in response to TDI sensitization; this warrants further investigation at multiple time points post exposure in the study of miR-210 as a biomarker.

MicroRNA-based therapies are in their infancy, with several currently undergoing Phase I and II clinical trials. Regardless, these therapies exhibit great potential due to the ubiquitous functional power of miRNAs. miRNA-based therapies can involve the inhibition or overexpression of individual or multiple miRNAs. Miravirsen, the first miRNA-based therapeutic to undergo clinical trials, is a miR-122 inhibitor which inhibits Hepatitis $\mathrm{C}$ replication, acting as a potent antiviral agent in nonhuman primate studies (57). Although no miRNA-based therapeutics are currently in clinical trials to combat allergic disease, intranasal inhalation of various miRNA inhibitors has been shown to reduce allergic airway inflammation in murine models (57), providing experimental evidence that miRNA-based therapies for allergic disease is a viable concept. 


\subsection{Other Conclusions}

\subsubsection{Irritancy and the Development of Allergic Disease}

$\mathrm{Ni}^{2+}$ allergy is an example of the importance of innate signaling pathways in the development of allergy. $\mathrm{Ni}^{2+}$ is typically a false negative in the LLNA although it is an extremely common cause of allergic contact dermatitis in humans (88). The explanation for this phenomenon are speciesspecific variations in TLR4 histidine residues (positions 456 and 458 on human TLR4 but not on mouse TLR4) that allow $\mathrm{Ni}^{2+}$ to activate this receptor, if present (88). This response illustrates the necessity of the innate "danger signaling" in the initiation and sustainability of an adaptive allergic response. Local trauma, endotoxin, and additional adjuvants may serve as danger signals to allow for the initiation of adaptive responses that may have been suppressed in the absence of these signals; essentially, these events control the fine balance between tolerance and immunity. It is assumed that many chemical allergens are capable of inducing irritation or inflammation, supporting the initiation of an adaptive response and sensitization (88-90). As noted in section 5.1 regarding hypersensitivity classifications, innate mechanisms precluding allergy are remarkably similar to pathogen clearance responses. These signals may originate from epidermal cells which may produce inflammatory cytokines such as IL-1 $\beta$ and IL-6 when activated (44). This is summarized in the "two signal" hypothesis which states that antigen delivery alone is insufficient for effective immunological priming but rather a second, innate signal is necessary to ensure the development of sensitization $(88,90)$. This concept is illustrated in the studies outlined in Chapter 3. The contrasting biological effects of 0.5 and $4 \%$ TDI are evident, with increased dermal inflammation, dLN cellularity, and augmented sensitization noted for the $4 \%$ dose (Figures 3.1-3.4). A key difference between the low and high dose utilized in these studies is the presence of strong (4\%) and minimal $(0.5 \%)$ dermal 
irritation. As noted in Chapter 3, the irritant response appears to be a prerequisite for strong sensitization responses in the case of dermal TDI sensitization. This observation has been noted in models of contact dermatitis as well, Bonneville, et al. noted the conditioning role that acute skin irritation appeared to play in a murine model of DNFB contact dermatitis (44). Protein allergens typically require the exogenous administration of adjuvants or additional innate signaling to cause irritation (91), illustrating the unique ability of many LMW chemicals to serve as their own "second step" in the journey to allergenicity.

The mechanisms of innate responses involved in dermal sensitization have been investigated in a variety of models of contact hypersensitivity. The dual absence of TLR2 and 4 in a murine model of contact hypersensitivity prevented TNCB, oxazolone, and fluorescein isothiocyanate sensitization from occurring, revealing the importance of these two pattern recognition receptors in the development of contact hypersensitivity (92). This study also revealed that mice lacking both IL-12Rß2 and TLR2 or 4 were also resistant to contact hypersensitivity; this was not demonstrated in mice lacking only one of the following components (92). These results indicate that allergic sensitization may depend on several innate factors, including: an IL-12-dependent mechanism mediated in concert with TLRs and an IL-12-independent mechanism that involves TLR2 and 4 (92). IL-12 likely plays a role in dendritic cell and Th1 activation and function, further contributing to the pathogenesis of allergic disease. Interestingly, TNCB sensitization and contact hypersensitivity was sustained in germ free mice (92), suggesting a role for skin-derived TLR ligands in the innate response to chemical allergens.

While significantly augmented miR-210 expression was observed in the dLN ( 0.5 and $4 \%$ TDI) and ear (4\% TDI) at various time points post chemical exposure, $4 \%$ TDI is a dermallyirritating concentration (93), indicating that miR-210 expression may be somewhat dependent on 
this response. To investigate this, a range of TDI concentrations were selected to encompass both non-irritant ( $0.5 \%)$ and irritant $(1,2$, and $4 \%)$ doses based on ear swelling and inflammatory cytokine mRNA levels in the ear, as reported by Long, et al. (93). dLN and ear miR-210 expression was quantified 4 days post 0.5 and $4 \%$ TDI exposure. dLN miR-210 levels were significantly upregulated at all TDI concentrations, regardless of irritant status (Figure 4.2A), indicating that dLN miR-210 expression is not dependent on dermal irritation. Ear miR-210 levels appeared to be more affected by the irritant status of the TDI concentration, revealing significantly increased miR-210 levels following $0.5,2$, and $4 \%$ TDI exposure yet the magnitude of miR-210 fold change is much higher in 4\%-treated ears (Appendix $4.1 \mathrm{~B}$ ). While irritation is considered by many to be an important component of sensitization, this is not unexpected; however, the increased expression of miR-210 in the $0.5 \%$-treated ears further suggests a role for miR-210 in the sensitization response and not solely the irritant response. The expression of additional miRNAs that were previously shown to be upregulated during TDI sensitization (62) was investigated at non-irritant and irritant TDI levels and dLN miR-22 and -31 siginficantly increased at various time points post $0.5,1,2$, and 4\% TDI exposure (data not shown). An additional study was completed in order to further confirm the sensitization-related expression of miR-210. Dermal application of a known irritant, nonanoic acid (NA), which lacks sensitization capabilities, was carried out followed by confirmation of dermal irritation and no significant changes in dLN miR-210, -22, nor -31 expression following NA exposure and the development of an irritant response in the absence of sensitization (data not shown). Altogether, this data suggests that several miRNAs are significantly increased due to the TDI sensitization response as a whole and not singularly due to the irritant component of this response. 


\subsubsection{Of Mouse and Man: Important Considerations}

Clearly, murine and human immunology share many conserved features, emphasizing the utility and popularity of experimental murine models. Mouse research has been a staple in many landmark immunologic discoveries of the past century. Mice, in particular, are very useful for the study of human diseases because of the highly conserved gene repertoire between the two species. While these models are extremely useful and can mimic the human disease state in many instances, they are not a perfect reflection of the human condition. Regarding immunology in particular, many key differences in the two organisms should be noted. Murine blood contains a high percentage of lymphocytes (75-90\% of all cells) while human blood is mostly composed of neutrophils (50-70\% of all cells) (94). This may be significant in systemic responses such as TDI sensitization, as a determinant of cellular responsiveness. Several innate immune structures are altered in mice and humans, including TLR expression, defensing production, and inducible nitric oxide synthase production by macrophages (94). In terms of adaptive immunity, humans express several FcRs that mice do not, there is variation in antibody isotype structure between the two species, several chemokines and receptors have been identified in one species but not the other (e.g. CXCR1, CCL6, and MCP-4), and T-helper skewing may not be as "clear cut" in humans as it is in mice (94). T cell activation is characterized by several key steps, one being inward calcium flux which is thought to be mediated by the outward flow of potassium via the $\mathrm{Kv} 1.3 \mathrm{~K}^{+}$channel; murine $\mathrm{T}$ cells do not express this channel, calling into question the mechanism of calcium flux sustainability by murine $\mathrm{T}$ cells (94). In addition to the basic mechanistic differences in murine and human models, many differences exist in the manifestation of disease in models of illness such as delayed type hypersensitivity, where the cellular components of the response are divergent (humans- neutrophils initially followed by $\mathrm{T}$ cells and macrophages and mice- more neutrophil rich throughout the 
response) and where mice typically require higher antigen concentrations for the elicitation of the allergic response than humans (94). In terms of TDI-induced asthma, the choice of mouse strain determines the asthma phenotype (e.g. severity and cellular involvement) (95), demonstrating intraspecies variability. As previously noted, several important species-to-species disparities remain in the study of TDI-allergic disease, including the role of IgE (Ref Chapter 2). Additionally, $\mathrm{T}_{\text {regs }}$ vary considerably in rodents and humans; CD103 is robustly expressed on naïve and activated murine $\mathrm{T}_{\text {regs }}$ (Ref Chapter 3 ) yet this molecule is essentially nonexistent on human $\mathrm{T}_{\text {regs (96). This is }}$ an important consideration in regards to extrapolation of data from studies utilizing CD103 as a $\mathrm{T}_{\text {reg }}$ marker in mice.

It is very important to consider species-specific differences when utilizing animal models in both basic and preclinical research. One of the most haunting examples of failure to take into account these differences is the 2006 TGN1412 (CD28 superagonist) clinical trial which resulted in life threatening cytokine storms in six healthy young male volunteers. This agent, which was intended to stimulate the production of $\mathrm{T}_{\text {regs }}(97)$ and Th cells (98) underwent preclinical evaluation in rodents and nonhuman primates, showing no significant adverse effects. The unprecedented, nearly fatal cytokine storm (primarily IFN- $\gamma$, IL-2, and TNF) in Phase I human volunteers has been determined to be due to $\mathrm{CD}^{+}$effector memory $\mathrm{T}$ cells $\left(\mathrm{T}_{\mathrm{EM}}\right)$ which are produced by exposure to infectious agents, which is not experienced by laboratory animals housed in pathogen-free conditions, resulting in a disadvantageous $\mathrm{T}_{\text {reg }}: \mathrm{T}_{\mathrm{EM}}$ balance not seen in rodents utilized in preclinical studies (97). Nonhuman primates, which are virtually genetically analogous to humans, were also utilized in preclinical studies and cynomolgus macaques were administered TGN1412 at doses up to 500 times higher than the dose given to the human volunteers in the absence of negative effects (97). One important caveat that was overlooked is that macaque $\mathrm{CD}^{+} \mathrm{T}$ cells lose $\mathrm{CD} 28$ expression during 
$\mathrm{T}_{\mathrm{EM}}$ differentiation, while human $\mathrm{T}_{\mathrm{EM}}$ cells retain $\mathrm{CD} 28$ expression (97), possibly accounting for the massive $\mathrm{T}_{\mathrm{EM}}$ activation and cytokine release following TGN1412 administration. Additionally, the human CD28 extracellular domain varies by four amino acids from the macaque molecule, one of the substitutions occurring in the C'D binding loop which is the site of TGN1412 binding (98). This tragic event emphasizes the sometimes subtle yet critical species-specific differences between humans and model organisms that should be fully investigated and always considered both in basic and preclinical research. Additionally, retrospective studies with humanized mice revealed concerning effects of TGN1412 administration on the immune system of these mice, including rapid peripheral lymphopenia, which was also evidenced in the human volunteers during the clinical trial (98). This emphasizes the utility of humanized animal models, particularly in immunologic studies.

The divergent immune systems of humans and mice can be explained by natural selection; each unique mechanism was likely adopted as a selective advantage for each species based on their environment, lifespan, size, and specific pathogens encountered. These differences are inevitable and do not invalidate the use or validity of murine models in immunology research. Rather, the careful consideration of species-specific differences and the resultant thoughtful extrapolation of this data to human disease is required for these studies to reach their maximum impact on human health.

\subsubsection{Summary}

Overall, much progress has been made in the understanding of TDI sensitization and allergic disease; however, there is still a pressing need for hazard identification strategies for respiratory sensitizers like TDI. The involvement of novel mediators of sensitization like $\mathrm{T}_{\text {regs }}$ and miRNAs has implications on this burden. Not only is the data presented in this work relevant for TDI 
sensitization, but presumably it is relevant to many chemical sensitizers. We have identified a functional role for $\mathrm{T}_{\text {regs }}$ in a murine model of epicutaneous TDI sensitization. This role appears to be significant in the dampening of allergic responses; however, the overall sensitization response is not abrogated due to the expansion of these cells. Although $\mathrm{T}_{\text {regs }}$ may be suppressive in the TDI sensitization response, the proliferation of allergic cells and their secretion of cytokines may be overwhelming to the $T_{\text {regs }}$ that are present during the response. This concept has been applied to autoimmune responses in murine models of atherosclerosis, rheumatoid arthritis, and primary biliary cirrhosis where peak inflammatory conditions and peak $T_{\text {reg }}$ levels occur at the same time, suggesting that the suppressive capabilities of these cells are overtaken by the strong autoimmune response that originally resulted in their induction (99). This is not to say that the $T_{\text {regs }}$ aren't having a regulatory effect at all in conditions such as TDI sensitization and autoimmune disorders; however, their presence is not enough to diminish symptoms completely and stop the response "in its tracks".

The hypothesized action of miR-210 and other miRNAs such as miR-31 as $\mathrm{T}_{\text {reg }}$ antagonists suggest more intricate regulatory mechanisms at play than are currently understood in chemical sensitization. While $\mathrm{T}_{\text {regs }}$ expand and are functionally active during TDI sensitization, these cells are likely being regulated by a number of factors including miRNAs, as reported in this work. miRNAs display great promise as biomarkers of disease in a number of conditions and these molecules could potentially be investigated as sensitization biomarkers in chemical sensitization or utilized to distinguish contact and respiratory sensitizers. Additional miRNAs were upregulated in the dLN during TDI sensitization, including miR-21, $-22,-126$, and $-301 \mathrm{a}$ (62). While these miRNAs were not investigated in this work, they may also play important regulatory roles in the TDI sensitization response. Further research characterizing the miRNome during TDI sensitization and elicitation would lend insight into the potential roles of the miRNAs thought to be involved. 
Altogether, this work represents insight into the regulatory mechanisms involved in the complex TDI sensitization immune response. Both $T_{\text {regs }}$ and miRNAs are significant in their regulatory functions and their newfound roles in TDI sensitization are illustrated in figure 5.1. These insights may aid in the further exploration of immunoregulatory mechanisms and novel effectors of chemical sensitization. Ultimately, this work may promote the development of novel hazard identification strategies that are designed in regard to the complex regulatory mechanisms that are a major component the chemical sensitization immune response. 


\subsection{REFERENCES}

1. Rajan, T. V. 2003. The Gell-Coombs classification of hypersensitivity reactions: a reinterpretation. Trends in immunology 24: 376-379.

2. Holtzman, M. J. Asthma as a chronic disease of the innate and adaptive immune systems responding to viruses and allergens. The Journal of Clinical Investigation 122: 27412748.

3. Descotes, J., and G. Choquet-Kastylevsky. 2001. Gell and Coombs's classification: is it still valid? Toxicology 158: 43-49.

4. Bogaert, P., K. G. Tournoy, T. Naessens, and J. Grooten. 2009. Where Asthma and Hypersensitivity Pneumonitis Meet and Differ : Noneosinophilic Severe Asthma. The American Journal of Pathology 174: 3-13.

5. Mohr, L. C. 2004. Hypersensitivity pneumonitis. Current opinion in pulmonary medicine 10: 401-411.

6. Czarnobilska, E., K. Obtulowicz, and K. Wsolek. 2007. [Type IV of hypersensitivity and its subtypes]. Przeglad lekarski 64: 506-508.

7. Kimber, I., M. A. Travis, S. F. Martin, and R. J. Dearman. 2012. Immunoregulation of skin sensitization and regulatory T cells. Contact Dermatitis 67: 179-183.

8. Johnson, V. J., B. Yucesoy, J. S. Reynolds, K. Fluharty, W. Wang, D. Richardson, and M. I. Luster. 2007. Inhalation of toluene diisocyanate vapor induces allergic rhinitis in mice. Journal of immunology (Baltimore, Md. : 1950) 179: 1864-1871.

9. Matheson, J. M., V. J. Johnson, and M. I. Luster. 2005. Immune Mediators in a Murine Model for Occupational Asthma: Studies with Toluene Diisocyanate. Toxicological Sciences 84: 99-109.

10. Park, H. S., H. Y. Kim, D. H. Nahm, J. W. Son, and Y. Y. Kim. 1999. Specific IgG, but not specific IgE, antibodies to toluene diisocyanate-human serum albumin conjugate are associated with toluene diisocyanate bronchoprovocation test results. The Journal of allergy and clinical immunology 104: 847-851.

11. Fisseler-Eckhoff, A., H. Bartsch, R. Zinsky, and J. Schirren. 2011. Environmental Isocyanate-Induced Asthma: Morphologic and Pathogenetic Aspects of an Increasing Occupational Disease. International Journal of Environmental Research and Public Health 8: 3672-3687.

12. Finotto, S., L. M. Fabbri, V. Rado, C. E. Mapp, and P. Maestrelli. 1991. Increase in numbers of CD8 positive lymphocytes and eosinophils in peripheral blood of subjects with late asthmatic reactions induced by toluene diisocyanate. British journal of industrial medicine 48: 116-121.

13. Redlich, C. A., and M. H. Karol. 2002. Diisocyanate asthma: clinical aspects and immunopathogenesis. International immunopharmacology 2: 213-224.

14. Liu, Q., and A. V. Wisnewski. 2003. Recent developments in diisocyanate asthma. Annals of Allergy, Asthma \& Immunology 90: 35-41.

15. Sakaguchi, S. 2011. Regulatory T cells: history and perspective. Methods in molecular biology (Clifton, N.J.) 707: 3-17.

16. Rudensky, A. Y. 2011. Regulatory T cells and Foxp3. Immunol Rev 241: 260-268.

17. Lin, W., N. Truong, W. J. Grossman, D. Haribhai, C. B. Williams, J. Wang, M. G. Martín, and T. A. Chatila. 2005. Allergic dysregulation and hyperimmunoglobulinemia E in Foxp3 mutant mice. Journal of Allergy and Clinical Immunology 116: 1106-1115. 
18. Caton, A. J., and K. A. Weissler. 2014. Regulatory cells in health and disease. Immunological reviews 259: 5-10.

19. Taams, L. S., D. B. Palmer, A. N. Akbar, D. S. Robinson, Z. Brown, and C. M. Hawrylowicz. 2006. Regulatory T cells in human disease and their potential for therapeutic manipulation. Immunology 118: 1-9.

20. Fyhrquist, N., S. Lehtimaki, K. Lahl, T. Savinko, A. M. Lappetelainen, T. Sparwasser, H. Wolff, A. Lauerma, and H. Alenius. 2012. Foxp3+ cells control Th2 responses in a murine model of atopic dermatitis. The Journal of investigative dermatology 132: 16721680 .

21. Skapenko, A., J. R. Kalden, P. E. Lipsky, and H. Schulze-Koops. 2005. The IL-4 receptor alpha-chain-binding cytokines, IL-4 and IL-13, induce forkhead box P3-expressing CD25+CD4+ regulatory T cells from CD25-CD4+ precursors. Journal of immunology (Baltimore, Md. : 1950) 175: 6107-6116.

22. Campbell, D. J., and M. A. Koch. 2011. Phenotypic and functional specialization of FOXP3(+) regulatory T cells. Nature Reviews. Immunology 11: 119-130.

23. Yu, F., S. Sharma, J. Edwards, L. Feigenbaum, and J. Zhu. 2015. Dynamic expression of transcription factors T-bet and GATA-3 by regulatory T cells maintains immunotolerance. Nature immunology 16: 197-206.

24. Schmidt, M., and M. Goebeler. 2015. Immunology of metal allergies. Journal der Deutschen Dermatologischen Gesellschaft $=$ Journal of the German Society of Dermatology : JDDG 13: 653-660.

25. Schmidt, A., N. Oberle, and P. H. Krammer. 2012. Molecular mechanisms of tregmediated T cell suppression. Frontiers in immunology 3: 51.

26. Onishi, Y., Z. Fehervari, T. Yamaguchi, and S. Sakaguchi. 2008. Foxp3+ natural regulatory $\mathrm{T}$ cells preferentially form aggregates on dendritic cells in vitro and actively inhibit their maturation. Proceedings of the National Academy of Sciences of the United States of America 105: 10113-10118.

27. Barthlott, T., A. J. T. Bosch, C. Berkemeier, R. Nogales-Cadenas, L. T. Jeker, M. P. Keller, A. Pascual-Montano, and G. A. Holländer. 2015. A subpopulation of CD103posICOSpos Treg cells occurs at high frequency in lymphopenic mice and represents a lymph node specific differentiation stage. European journal of immunology 45: 1760-1771.

28. Herrick, C. A., L. Xu, A. N. McKenzie, R. E. Tigelaar, and K. Bottomly. 2003. IL-13 is necessary, not simply sufficient, for epicutaneously induced Th2 responses to soluble protein antigen. Journal of immunology (Baltimore, Md. : 1950) 170: 2488-2495.

29. Bello, D., C. A. Herrick, T. J. Smith, S. R. Woskie, R. P. Streicher, M. R. Cullen, Y. Liu, and C. A. Redlich. 2007. Skin exposure to isocyanates: reasons for concern. Environmental health perspectives 115: 328-335.

30. Ono, S., and K. Kabashima. 2015. Novel insights into the role of immune cells in skin and inducible skin-associated lymphoid tissue (iSALT). Allergo journal international 24: 170-179.

31. Schneider, M. A., J. G. Meingassner, M. Lipp, H. D. Moore, and A. Rot. 2007. CCR7 is required for the in vivo function of CD4+ CD25+ regulatory T cells. J Exp Med 204: 735-745.

32. Huehn, J., and A. Hamann. 2005. Homing to suppress: address codes for Treg migration. Trends in immunology 26: 632-636. 
33. Burmeister Y, e. a. 2007. ICOS Controls the Pool Size of Effector-Memory and Regulatory T Cells. Journal of Immunology: 8.

34. Lehmann, C., A. Wilkening, D. Leiber, A. Markus, N. Krug, R. Pabst, and T. Tschernig. 2001. Lymphocytes in the bronchoalveolar space reenter the lung tissue by means of the alveolar epithelium, migrate to regional lymph nodes, and subsequently rejoin the systemic immune system. The Anatomical record 264: 229-236.

35. Yamazaki, T., X. O. Yang, Y. Chung, A. Fukunaga, R. Nurieva, B. Pappu, N. MartinOrozco, H. S. Kang, L. Ma, A. D. Panopoulos, S. Craig, S. S. Watowich, A. M. Jetten, Q. Tian, and C. Dong. 2008. CCR6 Regulates the Migration of Inflammatory and Regulatory T Cells. Journal of immunology (Baltimore, Md. : 1950) 181: 8391-8401.

36. Gratz, I. K., H. A. Truong, S. H. Yang, M. M. Maurano, K. Lee, A. K. Abbas, and M. D. Rosenblum. 2013. Cutting Edge: memory regulatory t cells require IL-7 and not IL-2 for their maintenance in peripheral tissues. Journal of immunology (Baltimore, Md. : 1950) 190: 4483-4487.

37. Sanchez Rodriguez, R., M. L. Pauli, I. M. Neuhaus, S. S. Yu, S. T. Arron, H. W. Harris, S. H.-Y. Yang, B. A. Anthony, F. M. Sverdrup, E. Krow-Lucal, T. C. MacKenzie, D. S. Johnson, E. H. Meyer, xF, A. hr, A. Hsu, J. Koo, W. Liao, R. Gupta, M. G. Debbaneh, D. Butler, M. Huynh, E. C. Levin, A. Leon, W. Y. Hoffman, M. H. McGrath, M. D. Alvarado, C. H. Ludwig, H.-A. Truong, M. M. Maurano, I. K. Gratz, A. K. Abbas, and M. D. Rosenblum. Memory regulatory T cells reside in human skin. The Journal of Clinical Investigation 124: 1027-1036.

38. Nayak, A. P., J. M. Hettick, P. D. Siegel, S. E. Anderson, C. M. Long, B. J. Green, and D. H. Beezhold. 2014. Toluene diisocyanate (TDI) disposition and co-localization of immune cells in hair follicles. Toxicological sciences : an official journal of the Society of Toxicology 140: 327-337.

39. Tomura, M., T. Honda, H. Tanizaki, A. Otsuka, G. Egawa, Y. Tokura, H. Waldmann, S. Hori, J. G. Cyster, T. Watanabe, Y. Miyachi, O. Kanagawa, and K. Kabashima. 2010. Activated regulatory $\mathrm{T}$ cells are the major $\mathrm{T}$ cell type emigrating from the skin during a cutaneous immune response in mice. The Journal of Clinical Investigation 120: 883-893.

40. Henri, S., D. Vremec, A. Kamath, J. Waithman, S. Williams, C. Benoist, K. Burnham, S. Saeland, E. Handman, and K. Shortman. 2001. The dendritic cell populations of mouse lymph nodes. Journal of immunology (Baltimore, Md. : 1950) 167: 741-748.

41. Gomez de Agüero, M., M. Vocanson, F. Hacini-Rachinel, M. Taillardet, T. Sparwasser, A. Kissenpfennig, B. Malissen, D. Kaiserlian, and B. Dubois. 2012. Langerhans cells protect from allergic contact dermatitis in mice by tolerizing CD8(+) T cells and activating Foxp3(+) regulatory T cells. The Journal of Clinical Investigation 122: 17001711.

42. Kushwah, R., and J. Hu. 2011. Role of dendritic cells in the induction of regulatory T cells. Cell \& bioscience 1: 20.

43. Dong, J., C. K. Wong, Z. Cai, D. Jiao, M. Chu, and C. W. Lam. 2015. Amelioration of allergic airway inflammation in mice by regulatory IL-35 through dampening inflammatory dendritic cells. Allergy 70: 921-932.

44. Bonneville, M., C. Chavagnac, M. Vocanson, A. Rozieres, J. Benetiere, I. Pernet, A. Denis, J. F. Nicolas, and A. Hennino. 2007. Skin contact irritation conditions the development and severity of allergic contact dermatitis. The Journal of investigative dermatology 127: 1430-1435. 
45. Cumberbatch, M., K. Clelland, R. J. Dearman, and I. Kimber. 2005. Impact of cutaneous IL-10 on resident epidermal Langerhans' cells and the development of polarized immune responses. Journal of immunology (Baltimore, Md. : 1950) 175: 43-50.

46. Trzonkowski, P., R. Bacchetta, M. Battaglia, D. Berglund, H. R. Bohnenkamp, A. ten Brinke, A. Bushell, N. Cools, E. K. Geissler, S. Gregori, S. Marieke van Ham, C. Hilkens, J. A. Hutchinson, G. Lombardi, J. A. Madrigal, N. Marek-Trzonkowska, E. M. Martinez-Caceres, M. G. Roncarolo, S. Sanchez-Ramon, A. Saudemont, and B. Sawitzki. 2015. Hurdles in therapy with regulatory T cells. Science translational medicine 7: $304 \mathrm{ps} 318$.

47. Johannesson, B., S. Sattler, E. Semenova, S. Pastore, T. M. Kennedy-Lydon, R. D. Sampson, M. D. Schneider, N. Rosenthal, and D. Bilbao. 2014. Insulin-like growth factor-1 induces regulatory $\mathrm{T}$ cell-mediated suppression of allergic contact dermatitis in mice. Disease Models \& Mechanisms 7: 977-985.

48. Baru, A. M., A. Hartl, K. Lahl, J. K. Krishnaswamy, H. Fehrenbach, A. O. Yildirim, H. Garn, H. Renz, G. M. Behrens, and T. Sparwasser. 2010. Selective depletion of Foxp3+ Treg during sensitization phase aggravates experimental allergic airway inflammation. European journal of immunology 40: 2259-2266.

49. Baru, A. M., V. Ganesh, J. K. Krishnaswamy, C. Hesse, C. Untucht, S. Glage, G. Behrens, C. T. Mayer, F. Puttur, and T. Sparwasser. 2012. Absence of Foxp $3<$ sup $>+</$ sup $>$ Regulatory T Cells during Allergen Provocation Does Not Exacerbate Murine Allergic Airway Inflammation. PLoS ONE 7: e47102.

50. Christensen, A. D., S. Skov, P. H. Kvist, and C. Haase. 2015. Depletion of regulatory T cells in a hapten-induced inflammation model results in prolonged and increased inflammation driven by T cells. Clinical and experimental immunology 179: 485-499.

51. D'Alessio, F. R., K. Tsushima, N. R. Aggarwal, E. E. West, M. H. Willett, M. F. Britos, M. R. Pipeling, R. G. Brower, R. M. Tuder, J. F. McDyer, and L. S. King. 2009. $\mathrm{CD} 4+\mathrm{CD} 25+$ Foxp3+ Tregs resolve experimental lung injury in mice and are present in humans with acute lung injury. J Clin Invest 119: 2898-2913.

52. Kearley, J., D. S. Robinson, and C. M. Lloyd. 2008. CD4+CD25+ regulatory T cells reverse established allergic airway inflammation and prevent airway remodeling. The Journal of allergy and clinical immunology 122: 617-624.e616.

53. Xu, W., Q. Lan, M. Chen, H. Chen, N. Zhu, X. Zhou, J. Wang, H. Fan, C. S. Yan, J. L. Kuang, D. Warburton, D. Togbe, B. Ryffel, S. G. Zheng, and W. Shi. 2012. Adoptive transfer of induced-Treg cells effectively attenuates murine airway allergic inflammation. PLoS One 7: e40314.

54. Saito, K., M. Torii, N. Ma, T. Tsuchiya, L. Wang, T. Hori, D. Nagakubo, N. Nitta, S. Kanegasaki, K. Hieshima, O. Yoshie, E. C. Gabazza, N. Katayama, H. Shiku, K. Kuribayashi, and T. Kato. 2008. Differential regulatory function of resting and preactivated allergen-specific CD4+ CD25+ regulatory T cells in Th2-type airway inflammation. Journal of immunology (Baltimore, Md. : 1950) 181: 6889-6897.

55. Xystrakis, E., S. Kusumakar, S. Boswell, E. Peek, Z. Urry, xEb, D. F. Richards, T. Adikibi, C. Pridgeon, M. Dallman, T.-K. Loke, D. S. Robinson, F. J. Barrat, x, A. Garra, P. Lavender, T. H. Lee, C. Corrigan, and C. M. Hawrylowicz. Reversing the defective induction of IL-10-secreting regulatory T cells in glucocorticoid-resistant asthma patients. The Journal of Clinical Investigation 116: 146-155. 
56. Lodish, H. F., B. Zhou, G. Liu, and C. Z. Chen. 2008. Micromanagement of the immune system by microRNAs. Nature Rev. Immunol. 8: 120-130.

57. Rebane, A., and C. A. Akdis. 2014. MicroRNAs in allergy and asthma. Current allergy and asthma reports 14: 424.

58. Baltimore, D., M. P. Boldin, R. M. O'Connell, D. S. Rao, and K. D. Taganov. 2008. MicroRNAs: new regulators of immune cell development and function. Nature immunology 9: 839-845.

59. Mattes, J., A. Collison, M. Plank, S. Phipps, and P. S. Foster. 2009. Antagonism of microRNA-126 suppresses the effector function of TH2 cells and the development of allergic airways disease. Proceedings of the National Academy of Sciences of the United States of America 106: 18704-18709.

60. Pua, Heather H., David F. Steiner, S. Patel, Jeanmarie R. Gonzalez, Jorge F. OrtizCarpena, R. Kageyama, N.-T. Chiou, A. Gallman, D. de Kouchkovsky, Lukas T. Jeker, Michael T. McManus, David J. Erle, and K. M. Ansel. MicroRNAs 24 and 27 Suppress Allergic Inflammation and Target a Network of Regulators of T Helper 2 Cell-Associated Cytokine Production. Immunity 44: 821-832.

61. Mycko, M. P., M. Cichalewska, A. Machlanska, H. Cwiklinska, M. Mariasiewicz, and K. W. Selmaj. 2012. MicroRNA-301a regulation of a T-helper 17 immune response controls autoimmune demyelination. Proceedings of the National Academy of Sciences of the United States of America 109: E1248-1257.

62. Anderson, S. E., K. Beezhold, E. Lukomska, J. Richardson, C. Long, K. Anderson, J. Franko, B. J. Meade, and D. H. Beezhold. 2013. Expression kinetics of miRNA involved in dermal toluene 2,4-diisocyanate sensitization. Journal of immunotoxicology.

63. Cobb, B. S. 2006. A role for Dicer in immune regulation. J. Exp. Med. 203: 2519-2527.

64. Liston, A., L. F. Lu, D. O'Carroll, A. Tarakhovsky, and A. Y. Rudensky. 2008. Dicerdependent microRNA pathway safeguards regulatory T cell function. J. Exp. Med. 205: 1993-2004.

65. Rouas, R., H. Fayyad-Kazan, N. El Zein, P. Lewalle, F. Rothe, A. Simion, H. Akl, M. Mourtada, M. El Rifai, A. Burny, P. Romero, P. Martiat, and B. Badran. 2009. Human natural Treg microRNA signature: role of microRNA-31 and microRNA-21 in FOXP3 expression. European journal of immunology 39: 1608-1618.

66. Zhao, M., L. T. Wang, G. P. Liang, P. Zhang, X. J. Deng, Q. Tang, H. Y. Zhai, C. C. Chang, Y. W. Su, and Q. J. Lu. 2014. Up-regulation of microRNA-210 induces immune dysfunction via targeting FOXP3 in CD4(+) T cells of psoriasis vulgaris. Clinical immunology (Orlando, Fla.) 150: 22-30.

67. Rothé, F., M. Ignatiadis, C. Chaboteaux, B. Haibe-Kains, N. Kheddoumi, S. Majjaj, B. Badran, H. Fayyad-Kazan, C. Desmedt, A. L. Harris, M. Piccart, and C. Sotiriou. 2011. Global MicroRNA Expression Profiling Identifies MiR-210 Associated with Tumor Proliferation, Invasion and Poor Clinical Outcome in Breast Cancer. PLoS ONE 6: e20980.

68. Ho, A. S., X. Huang, H. Cao, C. Christman-Skieller, K. Bennewith, Q. T. Le, and A. C. Koong. 2010. Circulating miR-210 as a Novel Hypoxia Marker in Pancreatic Cancer. Translational oncology 3: 109-113.

69. Hu, S., M. Huang, Z. Li, F. Jia, Z. Ghosh, M. A. Lijkwan, P. Fasanaro, N. Sun, X. Wang, F. Martelli, R. C. Robbins, and J. C. Wu. 2010. MicroRNA-210 as a novel therapy for treatment of ischemic heart disease. Circulation 122: S124-131. 
70. Fayyad-Kazan, H., R. Rouas, M. Fayyad-Kazan, R. Badran, N. El Zein, P. Lewalle, M. Najar, E. Hamade, F. Jebbawi, M. Merimi, P. Romero, A. Burny, B. Badran, and P. Martiat. 2012. MicroRNA profile of circulating CD4-positive regulatory T cells in human adults and impact of differentially expressed microRNAs on expression of two genes essential to their function. The Journal of biological chemistry 287: 9910-9922.

71. Sugai, M., K. Aoki, M. Osato, Y. Nambu, K. Ito, M. M. Taketo, and A. Shimizu. 2011. Runx3 is required for full activation of regulatory $\mathrm{T}$ cells to prevent colitis-associated tumor formation. Journal of immunology (Baltimore, Md. : 1950) 186: 6515-6520.

72. Klunker, S., M. M. Chong, P. Y. Mantel, O. Palomares, C. Bassin, M. Ziegler, B. Ruckert, F. Meiler, M. Akdis, D. R. Littman, and C. A. Akdis. 2009. Transcription factors RUNX1 and RUNX3 in the induction and suppressive function of Foxp3+ inducible regulatory T cells. $J$ Exp Med 206: 2701-2715.

73. Wang, H., H. Flach, M. Onizawa, L. Wei, M. T. McManus, and A. Weiss. 2014. Negative regulation of Hifla expression and TH17 differentiation by the hypoxiaregulated microRNA miR-210. Nature immunology 15: 393-401.

74. Rangasamy, T., G. L. Semenza, and S. N. Georas. 2011. What is hypoxia-inducible factor-1 doing in the allergic lung? Allergy 66: 815-817.

75. Clambey, E. T., E. N. McNamee, J. A. Westrich, L. E. Glover, E. L. Campbell, P. Jedlicka, E. F. de Zoeten, J. C. Cambier, K. R. Stenmark, S. P. Colgan, and H. K. Eltzschig. 2012. Hypoxia-inducible factor-1 alpha-dependent induction of FoxP3 drives regulatory T-cell abundance and function during inflammatory hypoxia of the mucosa. Proceedings of the National Academy of Sciences of the United States of America 109: E2784-2793.

76. Dang, E. V., J. Barbi, H. Y. Yang, D. Jinasena, H. Yu, Y. Zheng, Z. Bordman, J. Fu, Y. Kim, H. R. Yen, W. Luo, K. Zeller, L. Shimoda, S. L. Topalian, G. L. Semenza, C. V. Dang, D. M. Pardoll, and F. Pan. 2011. Control of T(H)17/T(reg) balance by hypoxiainducible factor 1. Cell 146: 772-784.

77. Zhang, L., F. Ke, Z. Liu, J. Bai, J. Liu, S. Yan, Z. Xu, F. Lou, H. Wang, H. Zhu, Y. Sun, W. Cai, Y. Gao, Q. Li, X.-Z. Yu, Y. Qian, Z. Hua, J. Deng, Q.-J. Li, and H. Wang. 2015. MicroRNA-31 negatively regulates peripherally derived regulatory T-cell generation by repressing retinoic acid-inducible protein 3. Nat Commun 6.

78. Sheedy, F. J., and L. A. O'Neill. 2008. Adding fuel to fire: microRNAs as a new class of mediators of inflammation. Annals of the rheumatic diseases 67 Suppl 3: iii50-55.

79. O'Connell, R. M., D. Kahn, W. S. J. Gibson, J. L. Round, R. L. Scholz, A. A. Chaudhuri, M. E. Kahn, D. S. Rao, and D. Baltimore. 2010. MicroRNA-155 Promotes Autoimmune Inflammation by Enhancing Inflammatory T Cell Development. Immunity 33: 607-619.

80. Zech, A., C. K. Ayata, F. Pankratz, A. Meyer, K. Baudiss, S. Cicko, G. G. Yegutkin, S. Grundmann, and M. Idzko. 2015. MicroRNA-155 modulates P2R signaling and Th2 priming of dendritic cells during allergic airway inflammation in mice. Allergy 70: 11211129.

81. Lu, L.-F., T.-H. Thai, D. P. Calado, A. Chaudhry, M. Kubo, K. Tanaka, G. B. Loeb, H. Lee, A. Yoshimura, K. Rajewsky, and A. Y. Rudensky. Foxp3-Dependent MicroRNA155 Confers Competitive Fitness to Regulatory T Cells by Targeting SOCS1 Protein. Immunity 30: 80-91.

82. Sadlon, T. J., B. G. Wilkinson, S. Pederson, C. Y. Brown, S. Bresatz, T. Gargett, E. L. Melville, K. Peng, R. J. D'Andrea, G. G. Glonek, G. J. Goodall, H. Zola, M. F. Shannon, 
and S. C. Barry. 2010. Genome-wide identification of human FOXP3 target genes in natural regulatory T cells. Journal of immunology (Baltimore, Md. : 1950) 185: 10711081.

83. Yao, R., Y. L. Ma, W. Liang, H. H. Li, Z. J. Ma, X. Yu, and Y. H. Liao. 2012. MicroRNA-155 modulates Treg and Th17 cells differentiation and Th17 cell function by targeting SOCS1. PLoS One 7: e46082.

84. Melnik, B. C., S. M. John, and G. Schmitz. 2014. Milk: an exosomal microRNA transmitter promoting thymic regulatory $\mathrm{T}$ cell maturation preventing the development of atopy? Journal of translational medicine 12: 43.

85. Zhang, Z., Y.-W. Qin, G. Brewer, and Q. Jing. 2012. MicroRNA degradation and turnover: regulating the regulators. Wiley interdisciplinary reviews. RNA 3: 593-600.

86. Hansen, T. B., T. I. Jensen, B. H. Clausen, J. B. Bramsen, B. Finsen, C. K. Damgaard, and J. Kjems. 2013. Natural RNA circles function as efficient microRNA sponges. Nature 495: 384-388.

87. Panganiban, R. P., Y. Wang, J. Howrylak, V. M. Chinchilli, T. J. Craig, A. August, and F. T. Ishmael. 2016. Circulating microRNAs as biomarkers in patients with allergic rhinitis and asthma. The Journal of allergy and clinical immunology 137: 1423-1432.

88. Kimber, I., D. A. Basketter, J. P. McFadden, and R. J. Dearman. 2011. Characterization of skin sensitizing chemicals: a lesson learnt from nickel allergy. Journal of immunotoxicology 8: 1-2.

89. Freudenberg, M. A., P. R. Esser, T. Jakob, C. Galanos, and S. F. Martin. 2009. Innate and adaptive immune responses in contact dermatitis: analogy with infections. Giornale italiano di dermatologia e venereologia : organo ufficiale, Societa italiana di dermatologia e sifilografia 144: 173-185.

90. McFadden, J. P., and D. A. Basketter. 2000. Contact allergy, irritancy and 'danger'. Contact Dermatitis 42: 123-127.

91. Martin, S. F., P. R. Esser, F. C. Weber, T. Jakob, M. A. Freudenberg, M. Schmidt, and M. Goebeler. 2011. Mechanisms of chemical-induced innate immunity in allergic contact dermatitis. Allergy 66: 1152-1163.

92. Martin, S. F., J. C. Dudda, E. Bachtanian, A. Lembo, S. Liller, C. Durr, M. M. Heimesaat, S. Bereswill, G. Fejer, R. Vassileva, T. Jakob, N. Freudenberg, C. C. Termeer, C. Johner, C. Galanos, and M. A. Freudenberg. 2008. Toll-like receptor and IL12 signaling control susceptibility to contact hypersensitivity. J Exp Med 205: 21512162.

93. Long, C. M., N. B. Marshall, E. Lukomska, M. L. Kashon, B. J. Meade, H. Shane, and S. E. Anderson. 2016. A Role for Regulatory T Cells in a Murine Model of Epicutaneous Toluene Diisocyanate Sensitization. Toxicological sciences : an official journal of the Society of Toxicology.

94. Mestas, J., and C. C. W. Hughes. 2004. Of Mice and Not Men: Differences between Mouse and Human Immunology. The Journal of Immunology 172: 2731-2738.

95. De Vooght, V., J. A. Vanoirbeek, K. Luyts, S. Haenen, B. Nemery, and P. H. Hoet. 2010. Choice of mouse strain influences the outcome in a mouse model of chemical-induced asthma. PLoS One 5: e12581.

96. Rotzschke, O., G. Borsellino, L. Battistini, K. Falk, and M. Kleinewietfeld. 2009. In vivo-activated CD103+ Foxp3+ Tregs: of men and mice. Blood 113: 2119-2120; author reply 2120 . 
97. Hunig, T. 2012. The storm has cleared: lessons from the CD28 superagonist TGN1412 trial. Nat Rev Immunol 12: 317-318.

98. St. Clair, E. W. 2008. The calm after the cytokine storm: lessons from the TGN1412 trial. The Journal of Clinical Investigation 118: 1344-1347.

99. Garetto, S., A. E. Trovato, A. Lleo, F. Sala, E. Martini, A. G. Betz, G. D. Norata, P. Invernizzi, and M. Kallikourdis. 2015. Peak inflammation in atherosclerosis, primary biliary cirrhosis and autoimmune arthritis is counter-intuitively associated with regulatory T cell enrichment. Immunobiology 220: 1025-1029. 
APPENDIX 
A

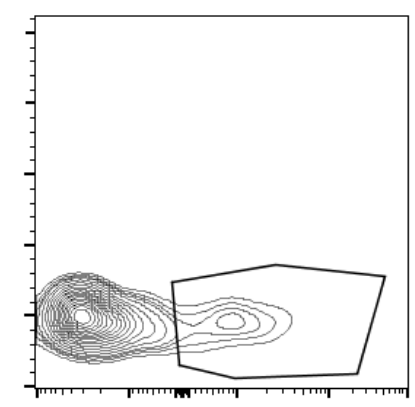

CTLA4

C

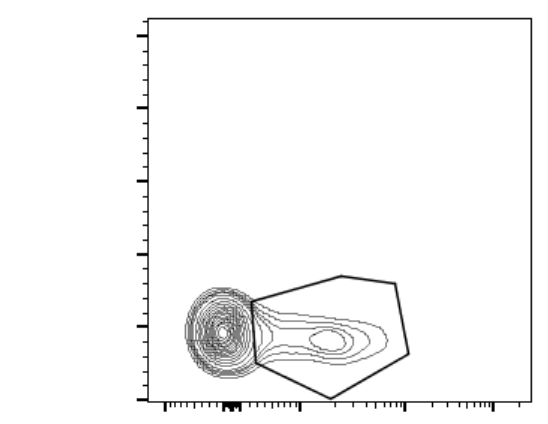

CCR6
B

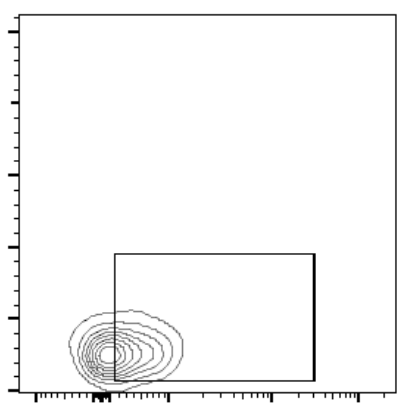

FMO Control

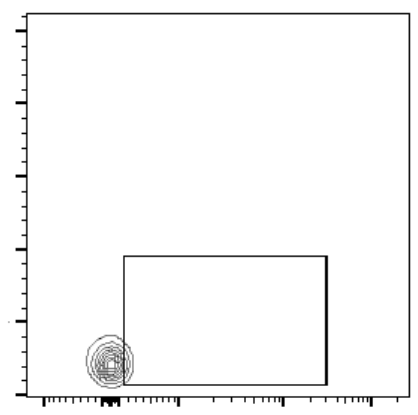

\section{Neuropilin-1}
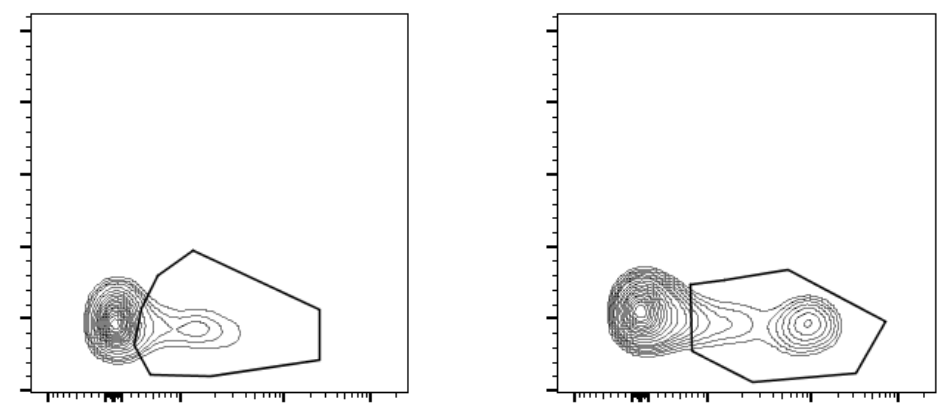

\section{A 3.1 $T_{\text {reg }}$ Phenotyping Gating Strategy}

$\mathrm{T}_{\text {reg }}$ gating strategy for dLN flow cytometric analysis of CTLA4 (A), Neuropilin-1 (B), and CCR6, CD103, and ICOS (C) expression. Examples are shown for populations positive for each marker and a FMO control is shown for Neuropilin-1 staining in part B 
A

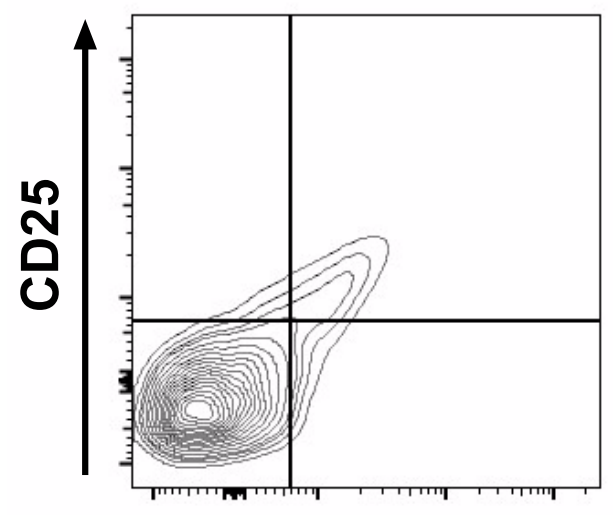

Depleted

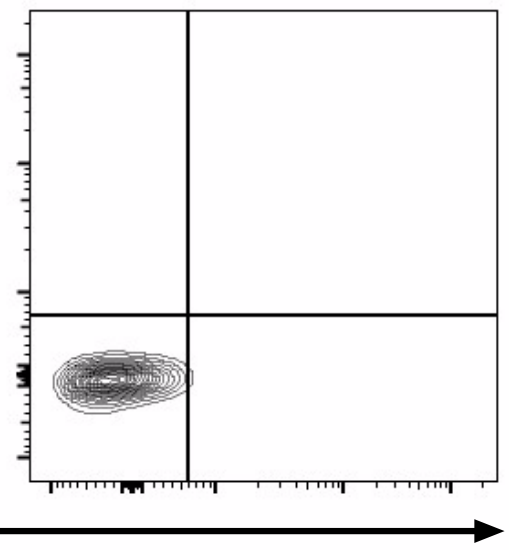

\section{Foxp3}

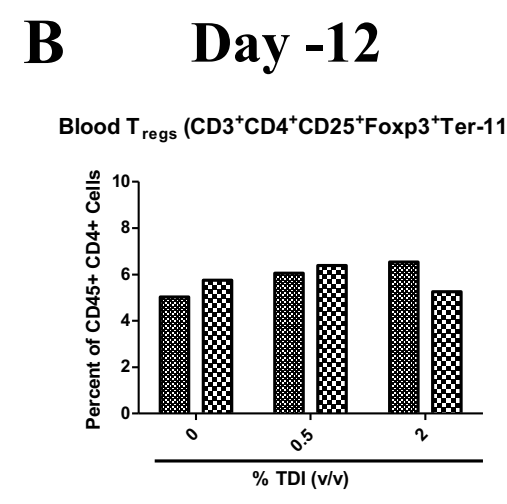

Day -2

Day 7

Blood $\mathrm{T}_{\text {regs }}\left(\mathrm{CD}^{+}{ }^{+} \mathrm{CD} 4^{+} \mathrm{CD}^{+} 5^{+} \mathrm{Foxp}^{+}{ }^{+} \mathrm{Ter}-1199^{-}\right)$Blood $\mathrm{T}_{\text {regs }}\left(\mathrm{CD}^{+}{ }^{+} \mathrm{CD} 4^{+} \mathrm{CD} 25^{+} \mathrm{Foxp}^{+}{ }^{+} \mathrm{Ter}-1^{-19}\right)$
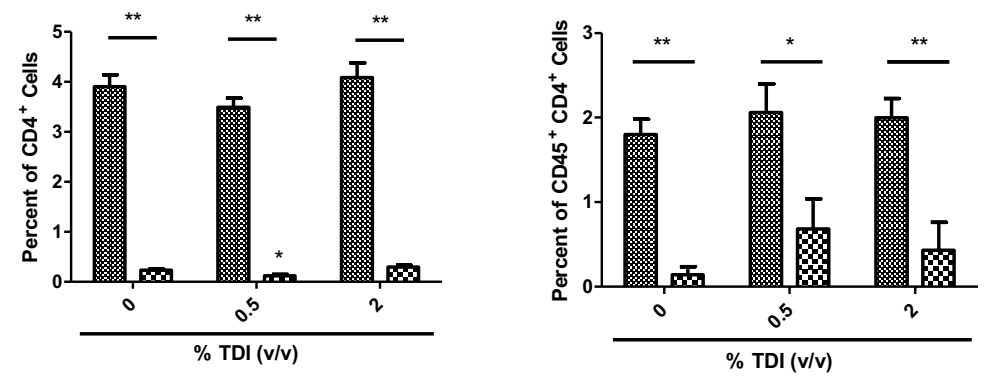

C

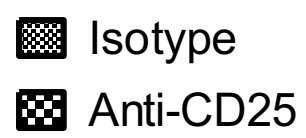

\section{Day 7}
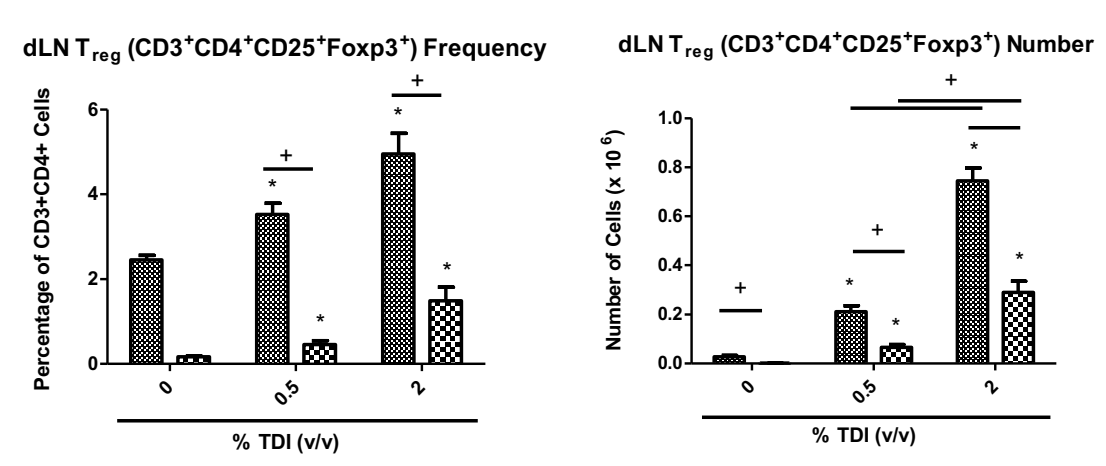

\section{A 3.2 $T_{\text {reg }}$ Depletion Study Model Confirmation}

(A) Blood $\mathrm{T}_{\text {reg }}$ gating strategy for flow cytometric analysis. Examples are shown for baseline (left panel) and depleted (right panel) samples. (B) Blood $\mathrm{T}_{\text {reg }}$ flow cytometric analysis is shown for 
baseline (left panel), day -2 (center panel), and day 7 (right panel) samples and is presented as percent of $\mathrm{CD} 5^{+} \mathrm{CD}^{+}$or $\mathrm{CD}^{+}$cells. (C) dLN Treg flow cytometric analysis is shown for day 7 as percentage of $\mathrm{CD} 45^{+} \mathrm{CD} 4^{+}$cells (left panel) and number of cells (right panel) based on extrapolation of this data with total dLN cellularity. Bars represent mean $( \pm \mathrm{SE})$ of 5 mice per group. Statistical significance was determined by Student $t$-test and is indicated as follows: $p$ value $<0.05$ and $\left.{ }^{* *}\right) p$ value $<0.01$. $P$ values are represented by asterisks (comparison of acetone to TDI-exposed group from the same antibody treatment regimen) or horizontal bars with asterisks above (comparison of identical chemical treatment between antibody and isotype-treated groups). 
A
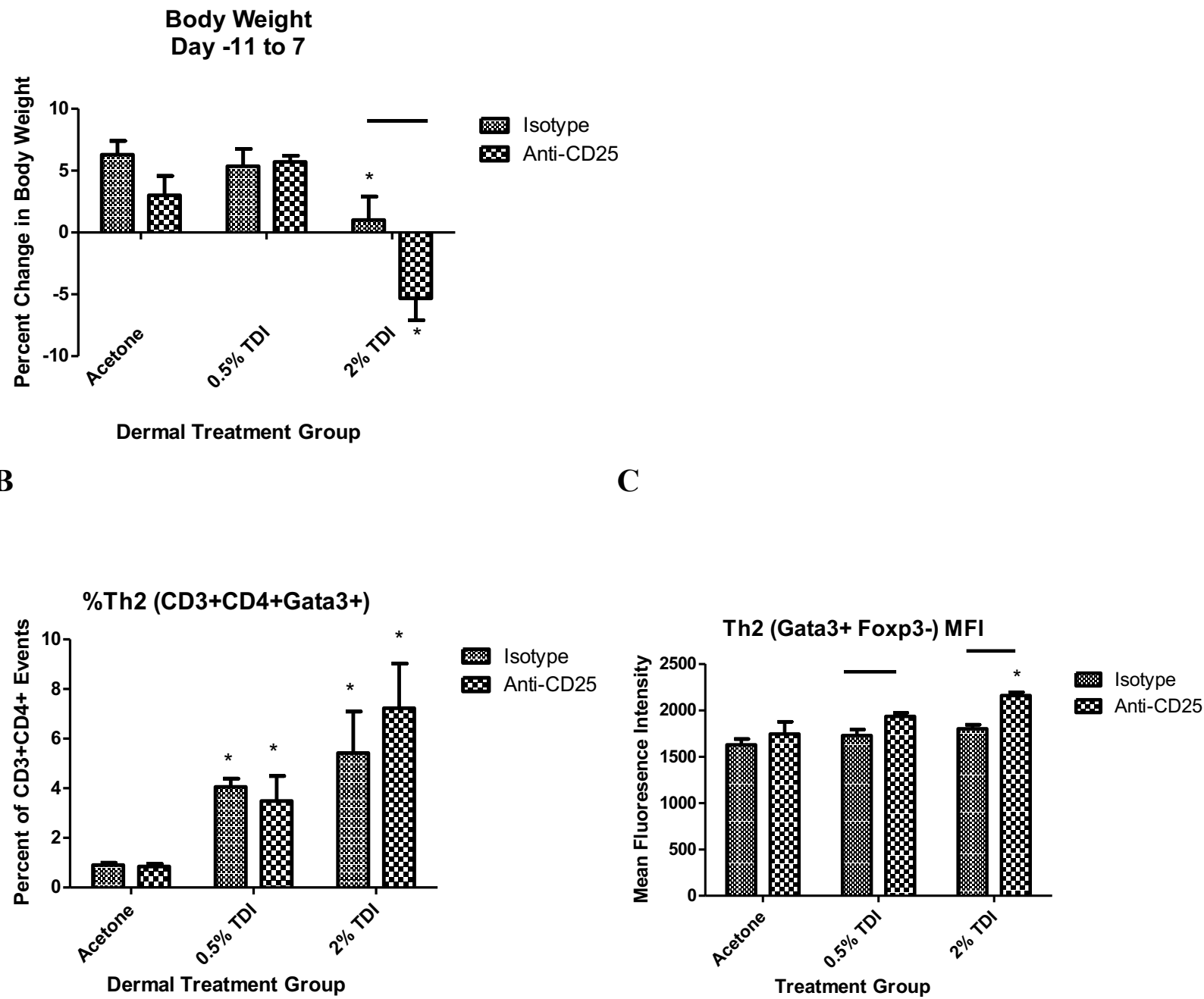

\section{A 3.3 $T_{\text {reg }}$ Depletion Study Supplemental Data}

Percent change in total body weight (tracked per individual mouse, presented as SEM) as determined from day -11 to 7 (A). dLN T cell phenotyping was performed 7 days following dermal TDI exposure as in Figure 3.4. Th2 $\left(\mathrm{CD}^{+} \mathrm{CD}^{+} \mathrm{Gata}^{+}\right)$frequency (B) and Th2 $\left(\mathrm{CD}^{+} \mathrm{CD}^{+} \mathrm{Gata}^{+} \mathrm{Foxp}^{-}\right) \mathrm{MFI}(\mathrm{C})$ were determined based on flow cytometric analysis (frequency and MFI) and extrapolation of this data with total dLN cellularity. Bars represent mean $( \pm \mathrm{SE})$ of 5 mice per group. Statistical significance was determined by Student $t$-test and is indicated as follows: $p$ value $<0.05$ and $\left({ }^{*}\right) p$ value $<0.01$. $P$ values are represented by asterisks (comparison of acetone 
to TDI-exposed group from the same antibody treatment regimen) or horizontal bars $(\mathrm{p}<0.05$; comparison of identical chemical treatment between antibody and isotype-treated groups). 


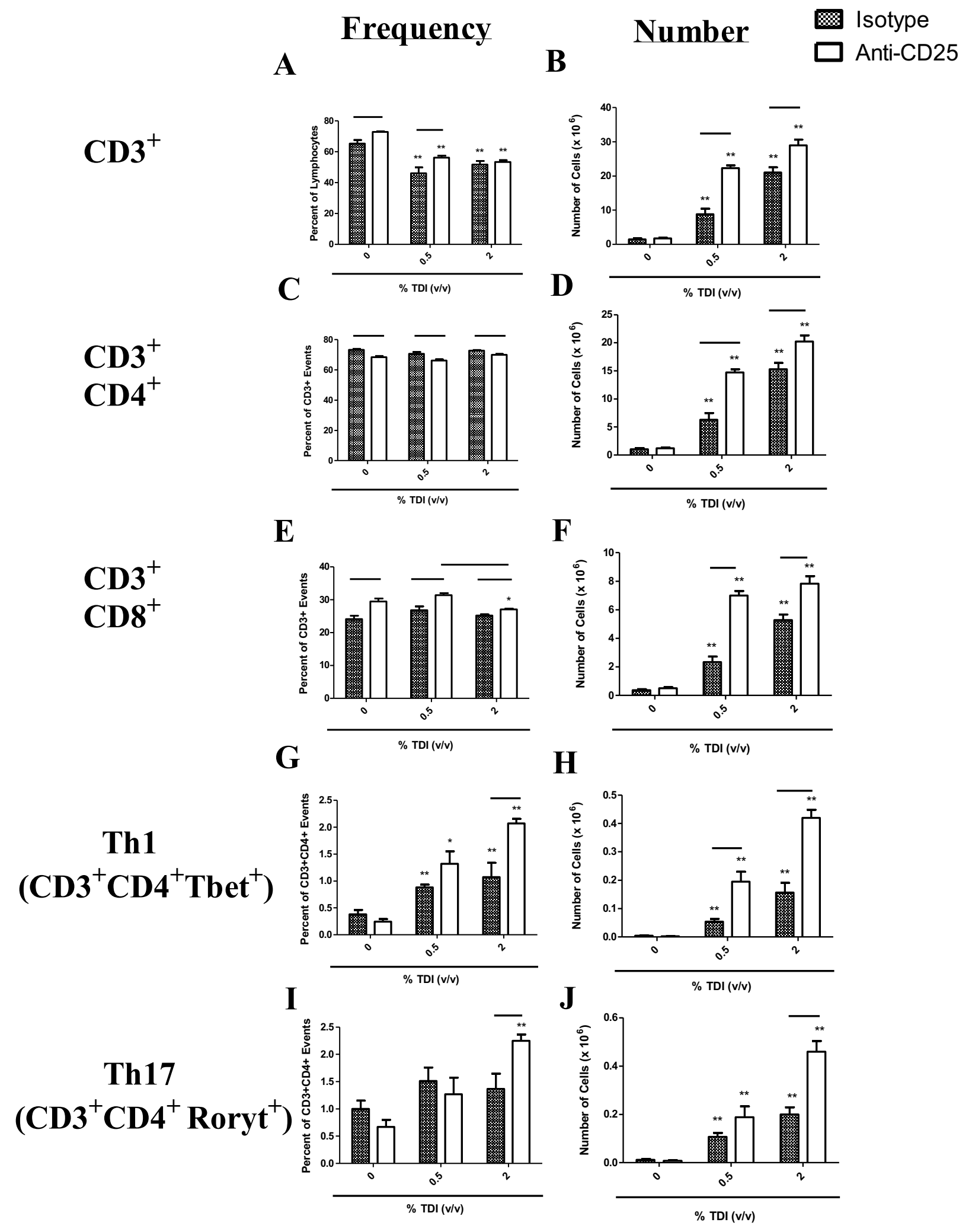

A 3.4 $T_{\text {reg }}$ Depletion Study General T Cell Endpoints 
dLN T cell phenotyping was performed 7 days following dermal TDI exposure. $\mathrm{CD}^{+}$frequency (A) and number (B), $\mathrm{CD}^{+} \mathrm{CD}^{+}$frequency (C) and number (D), $\mathrm{CD} 3{ }^{+} \mathrm{CD} 8^{+}$frequency (E) and number $(\mathrm{F})$, Th1 $\left(\mathrm{CD}^{+} \mathrm{CD}^{+}{ }^{+} \mathrm{Tbet}^{+}\right)$frequency $(\mathrm{G})$ and number $(\mathrm{H})$, and Th17 $\left(\mathrm{CD}^{+} \mathrm{CD}^{+} \mathrm{Ror}^{+} \mathrm{t}^{+}\right)$ frequency (I) and number ( $\mathrm{J})$ were determined based on flow cytometric analysis and extrapolation of this data with total dLN cellularity. Bars represent mean $( \pm \mathrm{SE})$ of 5 mice per group. Statistical significance was determined by Student $t$-test and is indicated as follows: $p$ value $<0.05$ and (**) $p$ value $<0.01$. $P$ values are represented by asterisks (comparison of acetone to TDI-exposed group from the same antibody treatment regimen) or horizontal bars $(\mathrm{p}<0.05$; comparison of identical chemical treatment between antibody and isotype-treated groups). 
A

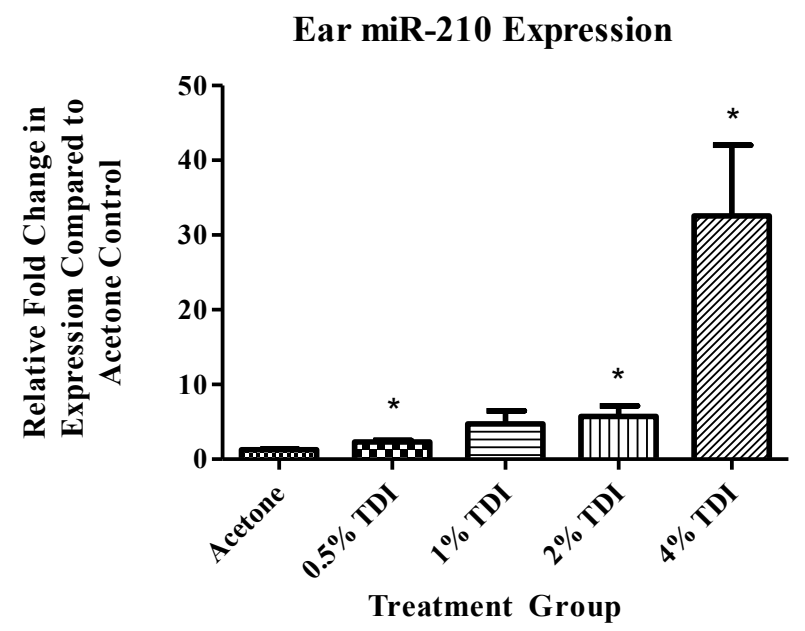

B

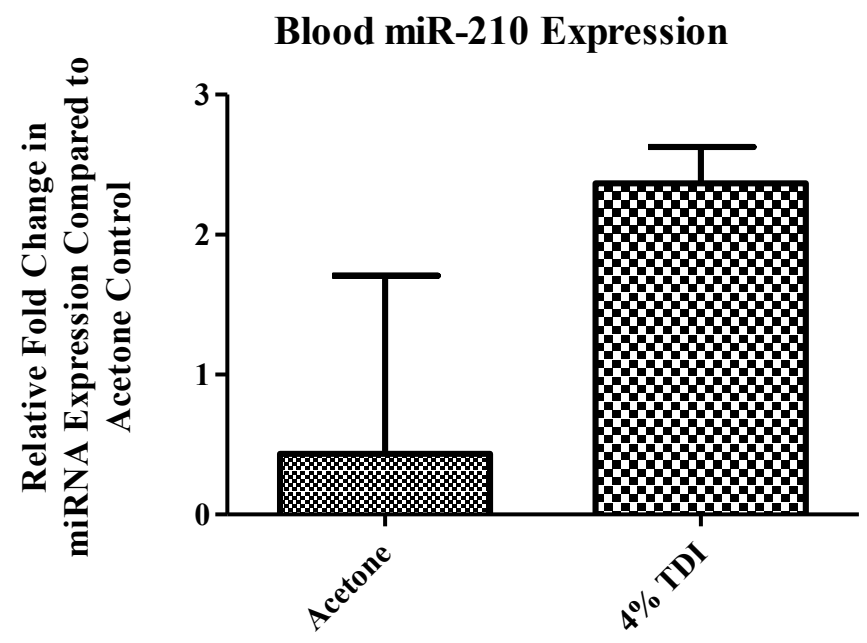

A 4.1 miR-210 Expression in a Variety of Tissues During 4\% TDI Sensitization

RT-PCR analysis of miR-210 expression in the ears (A) and blood (B) 4 days post TDI exposure. Bars represent mean relative fold change $( \pm \mathrm{SE})$ of 4-5 mice per group. $P$ values are represented by asterisks $(P<0.05)$. 
A

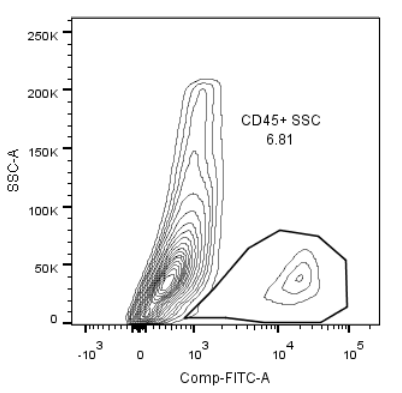

\section{CD45}

B

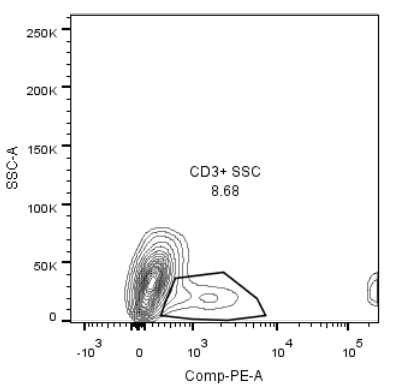

CD3

C

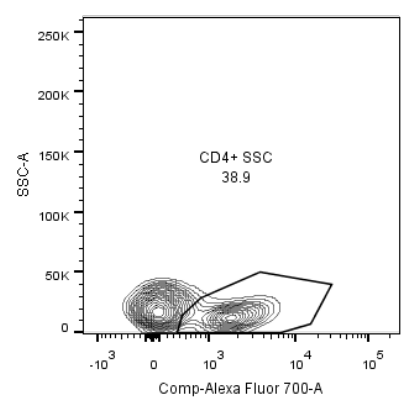

CD4

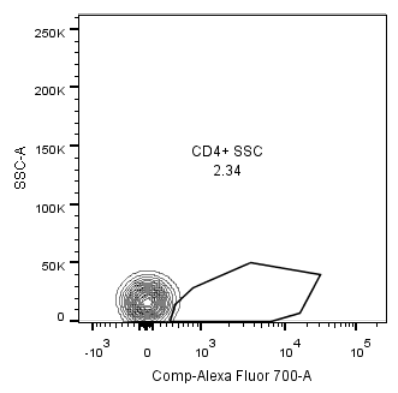

FMO Control
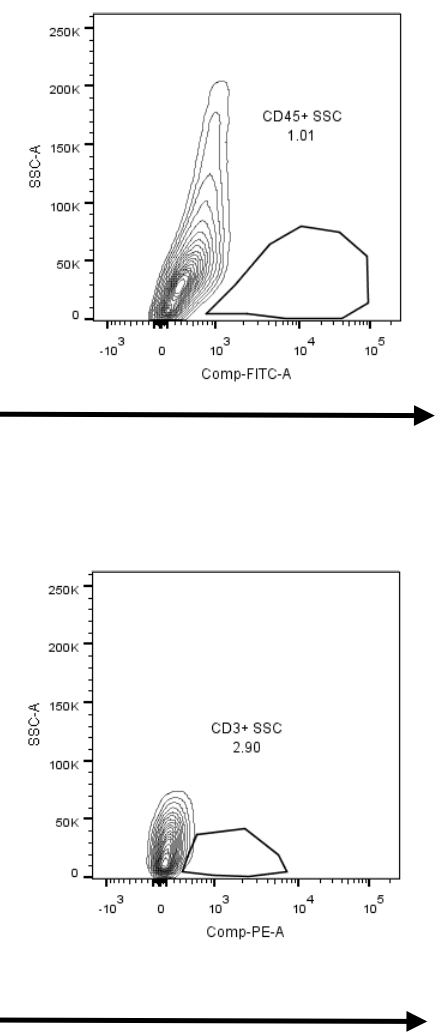

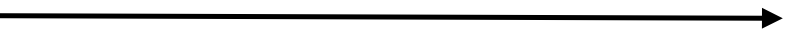

D 

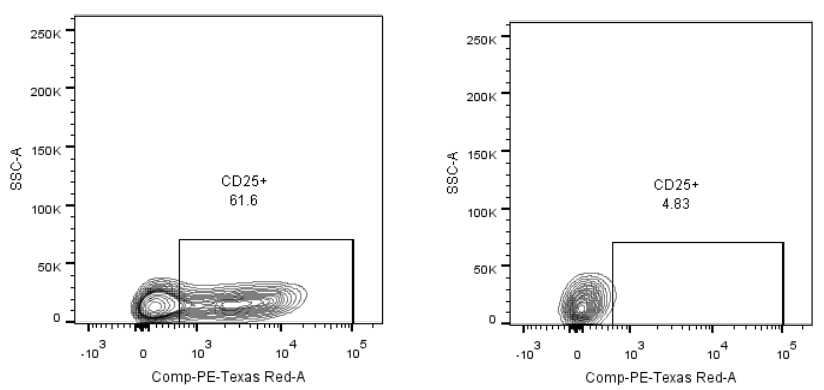

CD25

E
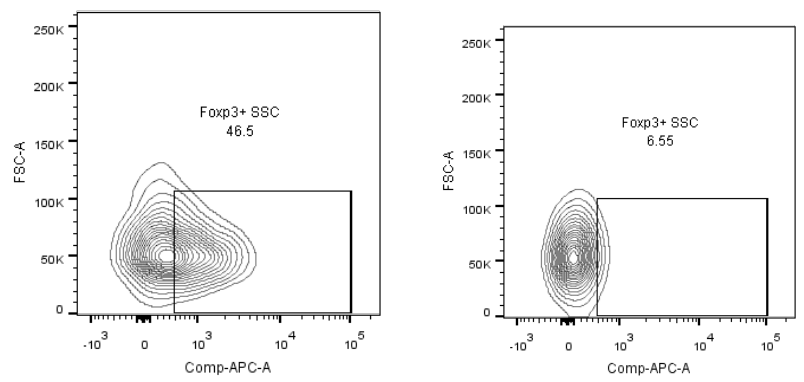

Foxp3

F
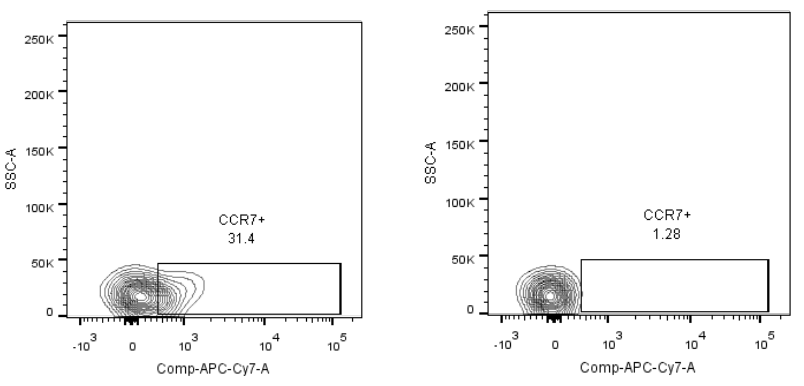

CCR7

G
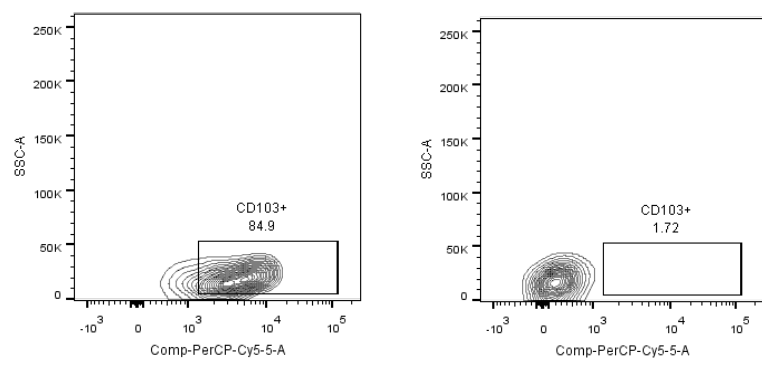

CD103 
$\mathbf{H}$
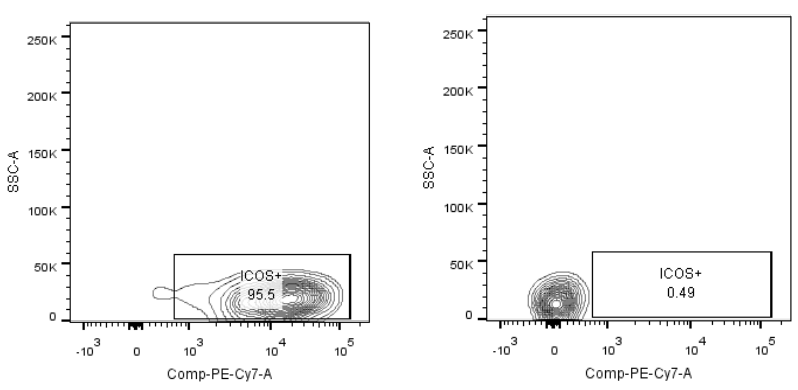

ICOS

Figure A 5.1 Ear $T_{\text {reg }}$ Phenotyping Gating Strategy

$\mathrm{T}_{\text {reg }}$ gating strategy for dLN flow cytometric analysis of CD45 (A), CD3 (B), CD4 (C), CD25 (D), Foxp3 (E), CCR7 (F), CD103 (G), and ICOS (H) expression. Examples are shown for populations positive for each marker and a fluorescence minus one (FMO) control is shown for each marker. 


\section{OXFORD UNIVERSITY PRESS LICENSE \\ TERMS AND CONDITIONS}

Jul 05, 2016

This Agreement between Carrie M Long ("You") and Oxford University Press ("Oxford University Press") consists of your license details and the terms and conditions provided by Oxford University Press and Copyright Clearance Center.

License Number

License date

Licensed content publisher

Licensed content publication

Licensed content title

Licensed content author

Licensed content date

Type of Use

Institution name

Title of your work

Publisher of your work

Expected publication date

Permissions cost

Value added tax

Total

Requestor Location

Billing Type

Billing Address
3864840619115

May 09, 2016

Oxford University Press

Toxicological Sciences

A Role for Regulatory T Cells in a Murine Model of Epicutaneous Toluene Diisocyanate Sensitization:

Carrie Mae Long, Nikki B Marshall, Ewa Lukomska, Michael L Kashon, B. Jean Meade, Hillary Shane, Stacey E Anderson

$04 / 21 / 2016$

Thesis/Dissertation

Novel Immunoregulatory Elements in a Murine Model of Epicutaneous Chemical Sensitization

$\mathrm{n} / \mathrm{a}$

Jul 2016

0.00 USD

0.00 USD

0.00 USD

Carrie M Long

2312 Suncrest Village

MORGANTOWN, WV 26505

United States

Attn: Carrie M Long

Invoice

Carrie M Long

2312 Suncrest Village

MORGANTOWN, WV 26505

United States

Attn: Carrie M Long 
Terms and Conditions

\section{STANDARD TERMS AND CONDITIONS FOR REPRODUCTION OF MATERIAL FROM AN OXFORD UNIVERSITY PRESS JOURNAL}

1. Use of the material is restricted to the type of use specified in your order details.

2. This permission covers the use of the material in the English language in the following territory: world. If you have requested additional permission to translate this material, the terms and conditions of this reuse will be set out in clause 12 .

3. This permission is limited to the particular use authorized in (1) above and does not allow you to sanction its use elsewhere in any other format other than specified above, nor does it apply to quotations, images, artistic works etc that have been reproduced from other sources which may be part of the material to be used.

4. No alteration, omission or addition is made to the material without our written consent. Permission must be re-cleared with Oxford University Press if/when you decide to reprint.

5. The following credit line appears wherever the material is used: author, title, journal, year, volume, issue number, pagination, by permission of Oxford University Press or the sponsoring society if the journal is a society journal. Where a journal is being published on behalf of a learned society, the details of that society must be included in the credit line.

6. For the reproduction of a full article from an Oxford University Press journal for whatever purpose, the corresponding author of the material concerned should be informed of the proposed use. Contact details for the corresponding authors of all Oxford University Press journal contact can be found alongside either the abstract or full text of the article concerned, accessible from www.oxfordjournals.org Should there be a problem clearing these rights, please contact journals.permissions@oup.com

7. If the credit line or acknowledgement in our publication indicates that any of the figures, images or photos was reproduced, drawn or modified from an earlier source it will be necessary for you to clear this permission with the original publisher as well. If this permission has not been obtained, please note that this material cannot be included in your publication/photocopies. 8. While you may exercise the rights licensed immediately upon issuance of the license at the end of the licensing process for the transaction, provided that you have disclosed complete and accurate details of your proposed use, no license is finally effective unless and until full payment is received from you (either by Oxford University Press or by Copyright Clearance Center (CCC)) as provided in CCC's Billing and Payment terms and conditions. If full payment is not received on a timely basis, then any license preliminarily granted shall be deemed automatically revoked and shall be void as if never granted. Further, in the event that you breach any of these terms and conditions or any of CCC's Billing and Payment terms and conditions, the license is automatically revoked and shall be void as if never granted. Use of materials as described in a revoked license, as well as any use of the materials beyond the scope of an unrevoked license, may constitute copyright infringement and Oxford University Press reserves the right to take any and all action to protect its copyright in the materials.

9. This license is personal to you and may not be sublicensed, assigned or transferred by you to any other person without Oxford University Press's written permission. 
10. Oxford University Press reserves all rights not specifically granted in the combination of (i) the license details provided by you and accepted in the course of this licensing transaction, (ii) these terms and conditions and (iii) CCC's Billing and Payment terms and conditions.

11. You hereby indemnify and agree to hold harmless Oxford University Press and CCC, and their respective officers, directors, employs and agents, from and against any and all claims arising out of your use of the licensed material other than as specifically authorized pursuant to this license.

12. Other Terms and Conditions:

v1.4

Questions? customercare@copyright.com or +1-855-239-3415 (toll free in the US) or +1978-646-2777. 


\section{CARRIE MAE LONG}

Home: 2312 Suncrest Village

Morgantown, WV 26505

Tel: (828) 421-0303

E-mail: clong14@mix.wvu.edu
Work: 1095 Willowdale Road Morgantown, WV 26505

(304) 285-6106 Opt: 9

\section{EDUCATION}

Ph.D., Immunology and Microbial Pathogenesis

2011-2016 (est.)

West Virginia University (WVU), Morgantown, WV

Committee: Drs. Stacey Anderson (advisor), John Barnett, BJ Meade, Rosana Schafer (chair), and Paul Siegel

B.S., Biology

2007-2011

Gardner-Webb University (GWU), Boiling Springs, NC

Summa Cum Laude with Honors

Honors Thesis: The Epidemiology of Emerging Viral Diseases

Minor: Spanish

\section{PROFESSIONAL EXPERIENCE}

Graduate Teaching Assistant

Spring 2014/2016

West Virginia University Medical Microbiology 323 Laboratory Planned class lectures and instructed students in microbiological lab techniques including: microscopy, bacterial staining, growing microorganisms, disinfectants and antiseptics, antibiotic resistance, microbial metabolic reactions, differential/selective media, serology, polymerase chain reaction, restriction enzyme digest, Western blotting, and Southern blotting. Evaluated student performance by grading lab reports, quizzes, and practical exams.

Regular Fellow /PhD Candidate

2012-Present

Centers for Disease Control and Prevention (CDC), National Institute of Occupational Safety and Health (NIOSH), Health Effects Laboratory Division, Allergy and Clinical Immunology Branch 
I perform my graduate research in the Immunotoxcology and Hazard Identification Lab at NIOSH. I design and perform research in order to elucidate the role of microRNAs and regulatory T cells in a murine model of chemical sensitization induced by toluene 2,4-diisocyanate. I also contribute to projects which include immunotoxicological profiling of occupationally relevant chemicals, the role of innate lymphoid cells in chemical-induced allergy, and effects of triclosan, an antimicrobial chemical, in allergy and viral infection.

Peer Tutor for GWU Learning Assistance Program

$2008-2010$

Subjects tutored: Organic Chemistry and Calculus I

\section{SERVICE}

Postdoctoral Representative (Pending Graduation) 2016-present Dermal Toxicology Specialty Section (DTSS): Society of Toxicology (SOT)

WVU Subcommittee for Graduate Faculty Mentor Award

SOT Annual Meeting High School Program Volunteer Scavenger Hunt Guide

Graduate Student Representative DTSS: SOT

Graduate Student Leadership Committee Member Programming Subcommittee Member

Volunteer, WVU Medicine Neonatal Intensive Care Unit and Pediatrics

Total service hours: 157

SOT Continuing Education Volunteer

WVU Health Sciences Center Graduate Student Association

Summer Camp Counselor

Camp Boggy Creek

GWU Student Government Association

Executive Treasurer

Sophomore Class Senator 2016-present

2016

2015-2016

2015-2016

2014-2016

2014-present

2013-present

2010

$2008-2011$ 


\section{HONORS}

Best Poster, Graduate Student Year 5

2016

WVU Van Liere Convocation

Charles River Graduate Student Travel Award

2016

DTSS: SOT

Featured Graduate Student: Portraits of Excellence

2016

WVU Graduate Life and Education

CDC-Charles Shepard Award Nominee

2015 and 2016

Laboratory Science

Nayak, et al. 2014 and Marshall, et al. 2015

Best Overall Methodology

Allegheny-Erie SOT Regional Chapter Annual Meeting

Selected Oral Presentation

Allegheny-Erie SOT Regional Chapter Annual Meeting

2015

Three Minute Thesis Finalist

2015

WVU Office of Graduate Life and Education

Battelle Research Award

DTSS: SOT

2015

Best Presentation by a Graduate Student, First Place

SOT Immunotoxicology Specialty Section

2015

Annual Meeting Graduate Student Travel Award

2015

Allegheny-Erie SOT Regional Chapter

SOT Graduate Student Travel Award

2014

WVU Graduate Student Travel Award

2014

Selected Oral Presentation

2014 and 2016

WVU Van Liere Convocation, Basic Science

AAAS/Science Program for Excellence Nominee

2013

WVU Varsity Track and Field Letter winner

WVU Academic-Athletic Honor Roll

2011-2012

Big East Conference All-Academic Team 
Graduated from GWU with a 4.0 GPA

Senior Scholastic Award 2011

1-3 Year Academic Award Recipient 2008-2010

Big South Conference-NCAA Woman of the Year Nominee 2011

George A. Christenberry Award for Academic/Athletic Excellence Awarded by the Big South Conference 2011

Big South Conference Scholar Athlete of the Year 2010-2011 Indoor and Outdoor Track and Field

Presidential Scholar and Dean's List 2007-2011

Varsity Track and Field Letterwinner 2007-2011

Team Captain ('10-'11)

Atlantic Sun and Big South Conference 2008-2011

Women's Indoor and Outdoor Track and Field All-Academic and AllConference Team

NCAA Division 1 Academic All-American 2008

United States Track and Field and Cross Country Association

\section{SELECTED PEER-REVIEWED PUBLICATIONS}

Long CM, Marshall, NB, Lukomska, E, Nayak A, Meade B, Anderson S. Potential Inhibitory Influence of miRNA 210 on Regulatory T Cells During Epicutaneous Chemical Sensitization. [In Preparation]

Long, CM, Marshall, NB, Lukomska E, Kashon M, Meade B, Shane H, Anderson S. A Role for Regulatory $\mathrm{T}$ Cells in a Murine Model of Epicutaneous TDI Sensitization. Tox Sci. doi: 10.1093/toxsci/kfw074

Anderson S, Shane H, Long C, Lukomska E, Meade B, Marshall N. Evaluation of the Irritancy and Hypersensitivity Potential following Topical Application of Didecyldimethylammonium chloride. J Immunot. [Accepted]

Marocco A, Meade BJ, Long CM, Lukomska E, Marshall, NB, Anderson SE [2015]. Immunotoxicity and Allergic Potential Induced by Topical Application of N-Butylbenzenesulfonamide in a Murine Model. J Toxicol. Environ. Health Part A: Current Issues. PMID: 26291892

Marshall NB, Lukomska E, Long CM, Kashon ML, Sharpnack DD, Nayak AP, Anderson KL, Meade BJ, Anderson SE [2015]. The antimicrobial chemical triclosan induces thymic stromal lymphopoietin in skin promoting Th2 allergic responses. Tox Sci. PMID: 26048654 
Anderson SE, Meade BJ, Long CM, Lukomska E, Marshall NB [2015]. Investigations of Immunotoxicity and Allergic Potential Induced by Topical Application of Triclosan in Mice. J Immunot. 25812624

Nayak, AP, Hettick, J, Siegel, PD, Anderson, SE, Long, CM, Green, B, Beezhold, D. [2014]. Toluene diisocyanate (TDI) disposition and co-localization of immune cells in hair follicles. Tox Sci, PMID: 24798378

Anderson SE, Beezhold K, Lukomska E, Richardson J, Long CM, Anderson KL, Franko J, Meade BJ, Beezhold D [2013]. Expression Kinetics of miRNAs involved in Chemical Sensitization. J Immunot, PMID: 24063594

Brock KL, Anderson SE, Lukomska E, Long CM, Anderson KL, Marshall NB, Meade BJ [2013]. Immune Stimulation Following Dermal Exposure to Unsintered Indium Tin Oxide. J Immunot, PMID: 24164313

\section{PRESENTATIONS}

Shane HL, Marshall NB, Lukomska E, Long CM, Anderson SE. Evaluation of dermal immune responses following didecyldimethylammonium chlorideinduced hypersensitivity. Allegheny-Erie Society of Toxicology Annual Meeting, Morgantown, WV. 2016

Marshall N, Lukomska E, Long C, Anderson S. Dermal exposure to the antimicrobial triclosan affects the gut microbiome and augments Th2 allergic responses mediated through toll-like receptor 4. Journal of Immunology. American Association of Immunologists Annual Meeting, Seattle, WA. Poster. 2016

Anderson S, Shane H, Long C, Lukomska E, Meade B, Marshall N. Irritancy and Allergic Responses Induced by Topical Application of Didecyldimethylammonium Chloride. Toxcologist. Society of Toxicology Annual Meeting, New Orleans, LA. Poster. 2016

Long, CM, Marshall NB, Lukomska E, Kashon M, Shane H, Siegel PD, Meade B, Anderson S. The Immunomodulatory Potential of Regulatory T Cells in a Murine Model of Epicutaneous Chemical Sensitization. Toxcologist. Society of Toxicology Annual Meeting, New Orleans, LA. Poster. 2016

Long, CM, Marshall NB, Lukomska E, Kashon M, Anderson S. The Immunomodulatory Potential of Regulatory T Cells in a Murine Model of Epicutaneous Chemical Sensitization. Van Liere Convocation, Morgantown, WV. Oral Presentation and Poster. 2016 
Long CM, Marshall NB, Lukomska E, Nayak A, Siegel P, Meade B, Anderson S. Immunoregulatory potential of microRNA 210 in a murine model of chemical sensitization. AESOT Annual Meeting, Morgantown, WV. Oral Presentation. 2015

Marshall NB, Lukomska E, Long CM, Anderson SE. Elucidating the mechanisms of augmented allergic responses with dermal triclosan exposure. AESOT Annual Meeting, Morgantown, WV. Oral Presentation. 2015

Anderson SE, Franko J, Lukomska E, Meade BJ, Long CM, Marshall NB. The Influence of Innate Immune Signaling and the Microbiome on Adaptive Immune Responses following Exposure to the Antimicrobial Triclosan. Keystone Symposia on Molecular and Cellular Biology, "Innate Immunity and Determinants of Microbial Pathogenesis", Olympic Valley, CA. Poster. 2015

Marshall NB, Lukomska E, Long CM, Nayak AP, Meade BJ, Anderson SE. Dermal exposure to the antimicrobial chemical triclosan augments allergic responses by inducing expression of thymic stromal lymphopoietin. Toxicologist. 144(1):143-144 \#671. Society of Toxicology 2015 Annual Meeting, San Diego, CA. Poster. 2015

Long CM, Marshall NB, Lukomska E, Nayak AP, Siegel PD, Meade BJ, Anderson SE. Increased Expression and Immunoregulatory Potential of MicroRNA 210 in a Murine Model of TDI Sensistization. Toxicologist. 144(1):144145 \#676. Society of Toxicology 2015 Annual Meeting, San Diego, CA. Poster. 2015

Nayak, AP, Green, B, Croston, T, Lemons, AR, Marshall, NB, Goldsmith, WT, Kashon, ML, Law, BF, Wagner, LM, Long, CM, Germolec, DM, Beezhold, D. Characterization of antigen presenting cells in a murine subchronic fungal exposure model. J Allergy Clin Immuno. American Academy of Allergy, Asthma, and Immunology 2015 Annual Meeting. Houston, TX. Poster. 2015

Green, B, Nayak, AP, Croston, T, Lemons AR, Marshall NB, Goldsmith WT, Kashon ML, Law BF, Wagner, LM, Long, CM, Germolec DM, Beezhold, D. Fungal viability is essential in modulating of adaptive immune resposnses in mice. J Allergy Clin Immuno. American Academy of Allergy, Asthma, and Immunology 2015 Annual Meeting, Houston, TX. Poster. 2015

Long, CM, Marshall, NB, Siegel, PD, Meade, BJ, Lukomska, E, Anderson, KL, Beezhold, D, and Anderson, SE. Exploring the role of miRNA-210 and regulatory $\mathrm{T}$ cells during TDI sensitization. Journal of Immunology. 
American Association of Immunologists Annual Meeting. Pittsburgh, PA. Poster. 2014

Marshall, NB, Long, CM, Anderson, KL, Lukomska, E, Anderson, SE. Dermal exposure to the commonly used antimicrobial chemical triclosan promotes allergic responses in skin and lung. Journal of Immunology. American Association of Immunologists Annual Meeting. Pittsburgh, PA. Poster. 2014

Hettick, J, Nayak, AP, Long, CM, Anderson, SE, Siegel, PD. [2014]. Identification of toluene diisocyanate-conjugated murine protein targets following dermal exposures. Baltimore, MD. Poster. 2014

Long, CM, Marshall, NB, Siegel, PD, Meade, BJ, Lukomska, E, Anderson, KL, Beezhold, D, Anderson, SE. An immunologic role of mirR-210 in a murine model of dermal toluene 2,4-diisocyanate sensitization. Toxicologist. Society of Toxicology Annual Meeting. Phoenix, AZ. Poster. 2014

Anderson, SE, Marshall, NB, Long, CM, Anderson, KL, Lukomska, E, and Meade, BJ. Dermal exposure to triclosan induces changes in expression of innate and adaptive immune genes in a mouse model. Toxicologist. Society of Toxicology Annual Meeting. Phoenix, AZ. Poster. 2014

Marshall, NB, Anderson, SE, Anderson, KL, Long, CM, Lukomska, E, and Meade, BJ. Early immunomodulatory effects of dermal triclosan exposure in mice. Toxicologist. Society of Toxicology Annual Meeting. Phoenix, AZ. Poster. 2014

Long, CM, Marshall, NB, Siegel, PD, Meade, BJ, Lukomska, E, Anderson, KL, Beezhold, DH, and Anderson, SE. Exploring the Role of miRNA 210 and Regulatory T Cells in a Murine Model of Toluene 2,4-diisocyanate Sensitization. Van Liere Research Convocation, Morgantown, WV. Oral Presentation. 2014

Long, CM, Beezhold K, Lukomska E, Anderson KL, Meade BJ, Beezhold D, Anderson SE. Expression Kinetics of miRNA Involved in Dermal Toluene 2,4diisocyanate Sensitization. Allegheny-Erie Society of Toxicology Annual Meeting. Morgantown, WV. Poster. 2013

Anderson, SE, Beezhold, K, Lukomska, E, Richardson, J, Long, CM, Anderson, K, Franko, J, Meade, BJ, and Beezhold, DH. Differential Expression Kinetics of miRNA involved in Allergic Chemical Sensitization following Dermal exposure in a Murine Model. Toxicologist. Society of Toxicology Annual Meeting. San Antonio, TX. Poster. 2013 
Long, CM, Franko, J, Kashon, ML, Anderson, KL, Hubbs, AF, Lukomska, E, Meade, BJ, and Anderson, SE. Exposure to Triclosan Augments the Allergic Response to Ovalbumin in a Mouse Model of Asthma. Toxicologist. Society of Toxicology Annual Meeting. San Antonio, TX. Poster. 2013

Meade, BJ, Lukomska, E, Brock, K, Long, CM, Anderson, K, and Anderson, SE. Potential for Immune Sensitization following Dermal Exposure to Indium Tin Oxide. Toxicologist. Society of Toxicology Annual Meeting. San Antonio, TX. Poster. 2013

Long, CM, Anderson, SE, Beezhold, K, Lukomska, E, Anderson, KL, Meade, BJ, and Beezhold, D. Expression Kinetics of miRNAs involved in Chemical Sensitization. Van Liere Research Convocation. West Virginia University, Morgantown, WV. Poster. 2013

Long, CM. Darwinian Aspects of the Evolution of Methicillin-Resistant Staphylococcus aureus. Darwin's Legacy Conference. University of North Carolina-Wilmington. Wilmington, NC. Poster. 2009

\section{PROFESSIONAL MEMBERSHIPS}

American Association of Immunologists

2014-present

American Association for the Advancement of Science

2014-present

Society of Toxicology

2012-present

Dermal Toxicology, Immunotoxicology, Women in Toxicology

Allegheny-Erie Society of Toxicology

2012-present

Beta Beta Beta National Biological Honors Society

2010

Sigma Zeta National Science and Mathematics Honor Society

2010

Alpha Chi National Honor Society

2009

\section{RELEVANT SKILLS AND EXPERIENCE}

- Animal Models

Small rodent exposure (dermal exposure, pulmonary aspiration, nasal instillation) and necropsy, Blood and tissue collection (mouse and rat), Bronchoalveolar lavage (mouse and rat), Intravenous tail vein and 
intraperitoneal injection (mouse), Peritoneal lavage (mouse), Tail bleeding (mouse)

- Cellular and Molecular Biology

Bacterial Culture, Bacterial Staining, Mammalian Cell Culture, Cellometer, Coulter Counter, Cytometric Bead Array, Cytospin, ELISA, Ex vivo cellular stimulation, Local Lymph Node Assay, Magnetic Cell Separation, miRNA Detection (mature and primary), miRNA mimic and inhibitor transfection, Gene and miRNA expression microarray, Nanodrop, Sheep Red Blood Cell Plaque-forming Cell Assay, Real Time PCR (SYBR green and TaqMan), Regulatory T Cell Suppression Assay, Reverse Transcription, RNA/DNA isolation, Serum Chemistry/Hematology (IDEXX ProCyte and Catalyst), Thymidine-Uptake Lymphocyte Proliferation Assay, Tissue homogenization and lysis, Western Blot

- Computing

Adobe Photoshop, Applied Biosystems 7500 PCR Software, Cmap, Endnote, FACSDiva, FlowJo, GraphPad Prism, Microsoft Office, Softmax Pro

- Flow Cytometry

Cell Surface Staining, CFSE proliferation assay, Intracellular Staining, LSR II, Multicolor cellular phenotyping, viability dyes 